\begin{tabular}{|c|l|}
\hline Title & The Photoelectrochemical Production of Hydrogen \\
\hline Author(s) & Uosaki, Kohei \\
\hline Issue Date & 1976-10 \\
\hline Doc URL & http://hdl.handle.net/2115/42803 \\
\hline Type & article \\
\hline Note & A Thesis Presented for the Degree of Doctor of Philosophy in The Flinders University of South A ustralia \\
\hline File Information & uosaki_thesis.pdf \\
\hline
\end{tabular}

Instructions for use 
THE PHOTOELECTROCHEMICAL PRODUCTION OF HYDROGEN

\author{
A Thesis \\ Presented for the Degree \\ of \\ Doctor of Philosophy
}

in

The Flinders University of South Australia

by

Kohei Uosaki, B.Eng., M.Eng. (Osaka)

School of Physical Sciences

October, 1976 
CHAPTER ONE INTRODUCTION

1.1 HISTORICAL 1

1.2 THE OUTLINE OF THIS PROSPECT
7 BIBLIOGRAPHY OF CHAPTER ONE

CHAPTER TWO THEORETICAL TREATMENT OF PHOTOELECTROCHEMICAL KINETICS AT METAL ELECTRODES

$\begin{array}{lll}2.1 & \text { INTRODUCTION } & 13\end{array}$

2.2 PHOTOCURRENT EXPRESSION 14

2.2.1 Photon Absorption Step 14

2.2.2 Excitation Process 14

2.2.3 Number of Excited E1ectrons 15 Arriving at the Surface

2.2.4 Electrochemical Process 19

2.3 COMPUTATION OF THE PHOTOCURRENT 23

2.3.1 Quantum Efficiency-Potential 23 Relation at Several Photon Energies

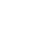


CHAPTER THREE THE THEORY OF HYDROGEN PRODUCTION

IN A PHOTOELECTROCHEMICAL CELL

3.1 INTRODUCTION

3.2 PHOTOEFFECT ON ELECTRODE REACTIONS AT

A SEMICONDUCTOR SOLUTION INTERFACE

3.2.1 The Photoeffect on a Cathodic

Current at a p-Type SemiconductorSolution Interface

3.2.1.1 The enthalpy change for electron transfer from semiconductor to $\mathrm{H}_{3} \mathrm{O}$

3.2.1.2 Photon absorption step

3.2.1.3 The creation of excited

3.2.1.4 Potential profile in a p-type semiconductor

3.2.1.5 Number of excited electrons arriving at the surface

3.2.1.6 Electron transfer process

3.2.2 The Photoeffect on the Anodic Current at n-Type Semiconductors

3.2.2.1 The estimation of the standard 48 enthalpy change for electron transfer from the donor to a hole in the valence band

3.2.2.2 The creation of holes

3.2.2.3 The potential energy profiles in $n$-type semiconductor

3.2.2.4 The number of holes arriving at the surface

3.2.2.5 Electron transfer process

3.3 THE COMPUTATION OF THE QUANTUM EFFICIENCY currents at p-Type Semiconductor Electrodes

3.3.1.1 Effect of potential

3.3.1.2 Effect of the energy of the photon 
Contents (3)

3.3.1.3 The effect of life time $\quad 57$

3.3.1.4 The effect of the electron 57 affinity of the semiconductor

3.3.1.5 The energy gap effect 59

3.3.1.6 The effect of electron $\quad 59$ mobility

3.3.2 Predicted Results for n-Type Semi- $\quad 59$ conductors

3.3.2.1 Effect of potential 59

3.3.2.2 The effect of the electron 62 affinity of the semiconductor

3.3.2.3 The effect of the energy gap 62

3.3.2.4 Comparison with the experi- 62 mental results of $n$-type semiconductors

3.3.2.5 Surface states involved in the $\mathrm{TiO}_{2}$ mechanisms

3.4 WHOLE CELL SYSTEM

3.4.1 The Relation between the Potential of an Electrode and a Cell

66

3.4.2 The Calculated Hydrogen Production Rate from Solar Energy Using $\mathrm{TiO}_{2}$ Photo-driven Ce11s

3.5 OPTIMUM PROPERTIES OF ELECTRODES 71

$\begin{array}{ll}3.5 .1 & \text { Electron Affinity }\end{array}$

$\begin{array}{lll}3.5 .2 & \text { Energy Gap } & 71\end{array}$

3.5.3 Electron Mobility and Life Time 71

3.5.4 Flat Band Potential 71

$\begin{array}{lll}3.5 .5 & \text { Surface States } & 71\end{array}$

$\begin{array}{lll}\text { APPENDIX } 3.1 & 74\end{array}$

$\begin{array}{lll}\text { APPENDIX } 3.2 & 77\end{array}$

$\begin{array}{ll}\text { BIBLIOGRAPHY OF CHAPTER THREE } & 79\end{array}$ 


\section{Contents (4)}

CHAPTER FOUR EXPERIMENTAL

4.1 PHOTOELECTROCHEMICAL SYSTEM AND MEASUREMENTS

4.1.1 Electrochemical Cel1 82

4.1.2 Electrode Holder $\quad 82$

4.1.3 Electrochemical Apparatus 82

4.1.4 Optical Apparatus 86

$\begin{array}{lll}4.1 .5 & \text { Experimental Set Up } & 87\end{array}$

$\begin{array}{lll}4.1 .6 & \text { Transient Measurement } & 87\end{array}$

4.2 IMPEDANCE MEASUREMENTS $\quad 89$

4.2.1 Impedance Measurement Cell $\quad 89$

4.2.2 Principle of Measurement 89

4.3 PREPARATION AND PRETREATMENT OF 94 SEMICONDUCTORS

4.3.1 n-Type Semiconductors 94

4.3.1.1 Titanium Dioxide $\left(\mathrm{TiO}_{2}\right) \quad 94$

4.3.1.1.1 $\mathrm{TiO}_{2}$ single crystals 94

4.3.1.1.2 Titanium anodic 94 oxide film

4.3.1.1.3 Titanium oxide film 95 by high temperature oxidation

4.3.1.1.4 Titanium oxide film 95 by chemical vapor deposition (CVD)

4.3.1.2 Metal Titanate 96

4.3.1.2.1 Cobalt titanate 96 polycrystal

4.3.1.2.2 Iron titanate 96 polycrystal

4.3.2 p-Type Semiconductors 98

4.3.2.1 Zinc Telluride (ZnTe) 98

4.3.2.2 Cadmium Telluride (CdTe) 98 
Contents

(5)

4.3.2.3 Ga11ium Arsenide (GaAs) 99

4.3.2.4 Indium Phosphide (InP) $\quad 100$

4.3.2.5 Gallium Phosphide (GaP) $\quad 100$

4.3.2.6 Silicon Carbide (SiC) $\quad 100$

4.3.2.7 Silicon (Si) 101

4.3.2.8 Summary of p-type semiconduc- 101 tors

BIBLIOGRAPHY OF CHAPTER FOUR

105

CHAPTER FIVE EXPERIMENTAL RESULTS

5.1 PHOTOEFFECTS ON ANODIC REACTION AT n-TYPE 106 SEMICONDUCTORS

5.1.1 Titanium Dioxide $\left(\mathrm{TiO}_{2}\right) \quad 106$

5.1.1.1 $\mathrm{TiO}_{2}$ single crystals $\quad 106$

5.1.1.1.1 Current-potential 106 relation in solutions of various pH's

5.1.1.1.2 Photocurrent 108

(quantum efficiency) -photon energy relations at several potentials

5.1.1.1.3 Stability $\quad 108$

5.1.1.2 Titanium anodic oxide film 108

5.1.1.3 Titanium oxide film by high 111 temperature oxidation

5.1.2 Cadmium Single Crystal Coated with $\quad 116$ $\mathrm{TiO}_{2} \mathrm{Film}$

5.1.3 Metal Titanate 119

5.1.3.1 Cobalt titanate $\left(\mathrm{CoTiO}_{3}\right) \quad 119$

5.1.3.2 Iron titanate $\left(\mathrm{Fe}_{2} \mathrm{TiO}_{5}\right) \quad 123$ 
Contents (6)

5.2 PHOTOEFFECTS ON CATHODIC REACTION AT p-TYPE 127 SEMICONDUCTORS

5.2.1 Zinc Telluride ( $\mathrm{nTTe}$ )

5.2.1.1 The current-potential relation 127

5.2.1.2 Photocurrent (quantum effic- 127 iency)-wavelength relation at several potentials

5.2.1.3 The flat band potential

5.2.1.4 Transient measurement

5.2.1.5 Stability

5.2.2 Cadmium Telluride (CdTe)

5.2.2.1 The current-potential

5.2.2.2 Photocurrent (quantum efficiency)-wavelength relation at several potentials

5.2.2.3 The flat band potential

5.2.2.4 Transient measurement

5.2.2.5 Stability

5.2.3 Gallium Arsenide (GaAs)

5.2.3.1 The current-potential relation

5.2.3.2 Photocurrent (quantum efficiency)-wavelength relation at several potentials

5.2.3.3 The flat band potential

5.2.3.4 Transient measurement

5.2.3.5 Stability

5.2.4 Indium Phosphide (InP)

5.2.4.1 The current-potential

5.2.4.2 Photocurrent (quantum efficiency)-wavelength relation at several potentials 
Contents (7)

5.2.4.3 The flat band potential ... 155

5.2.4.4 Transient Measurement $\quad 160$

5.2.4.5 Stability 160

5.2.5 Gallium Phosphide (GaP) 160

5.2.5.1 The current-potential 160 relation

5.2.5.2 Photocurrent (quantum effic- 165 iency)-wavelength relation at several potentials

5.2.5.3 The flat band potential 165

5.2.5.4 Transient measurement $\quad 165$

5.2.5.5 Stability $\quad 165$

5.2.6 Silicon Carbide (SiC) 165

5.2.6.1 The current-potential 165

5.2.6.2 Photocurrent (quantum effic- 173 iency)-wavelength relation at several potentials

5.2.6.3 The flat band potential 173

5.2.6.4 Transient measurement $\quad 177$

5.2.6.5 Stability $\quad 177$

$\begin{array}{lll}5.2 .7 & \text { Silicon (Si) } & 177\end{array}$

5.2.7.1 The current-potential $\quad 177$ relation

5.2.7.2 Photocurrent (quantum effic- 177 iency)-wavelength relation at several potentials

5.2.7.3 The flat band potential 177

5.2.7.4 Transient measurement $\quad 183$

5.2.7.5 Stability 183

BIBLIOGRAPHY OF CHAPTER FIVE 186 
6.2 COMPARISON OF EXPERIMENTAL RESULTS WITH THOSE OF PREVIOUS WORKS

\subsubsection{Titanium Dioxide Single Crystal}

6.2.2 Titanium Oxide Film

6.2.3 Prevention of Anodic Dissolution

6.2.4 Metal Titanate

6.2.6 Cadmium T'elluride

6.2.7 Gallium Arsenide

6.2.8 Indium Phosphide

6.2.9 Gallium Phosphide

6.2.10 Silicon Carbide

6.3 PHENOMENOLOGICAL GENERALIZATIONS ARISING FROM THE RESULTS

6.3.1 Current-Potential Relations

6.3.2 Quantum Efficiency-Wavelength

\subsubsection{F1at Band Potential}

\subsubsection{Transient Behaviour}

6.3.5 $\mathrm{TiO}_{2}$ Film

6.4 ANALYSIS OF THE PHOTOCURRENT-POTENTIAL RELATION

6.4.2 Comparison Between Experimental

6.4.3 Qualitative Analysis of the Discrepancies Between the Experimental Results and the Calculated Results 
Contents (9)

6.4.5 Alternative Mechanisms 201

6.4.6 Modification of the Potential 205 Barrier

6.4.6.1 Effect of proton transfer 205

6.4.6.2 Effect of dielectric constant 205

6.4.6.3 Direction of Coulomb force 207

6.4.6.4 Image interaction and di- 207 electric constant of water

6.4.6.5 Field effect 208

6.4.6.6 Modified barrier construction 208

6.4.7 Effect of a Potential Drop in the 210

Electric Double Layer at the Flat

Band Potential on the Quantum Efficiency-Potential Relation (Theory)

6.4.7.1 Estimation of the potential drop in the electric double layer at the flat band potential

6.4.7.2 The energy level of an electron in the ground state of $\mathrm{H}_{3} \mathrm{O}^{f}$ ion

6.4.8 Calculation of Quantum Efficiency with New Barrier and New Energy Level

6.4.9 Potential Distribution

6.4.10 Modified Quantum Efficiency-Potential Relation

6.5 THE RELATION BETWEEN THE CRITICAL POTENTIAL

IN THE PHOTOELECTROCHEMICAL GENERATION OF HYDROGEN AND THE PROPERTIES OF THE SEMICONDUCTORS

6.6 pH DEPENDENCE OF THE FLAT BAND POTENTIAL

6.7 HYDROGEN EVOLUTION IN ALKALINE SOLUTION 233

6.7.1 The Energy Leve1 of $\mathrm{H}_{2} \mathrm{O} 233$

6.7.2 The Energy Level of $\mathrm{Na}^{+} \quad 234$

6.7.3 The Quantum Efficiency-Potential 235 Relation in Alkaline Solution 
Contents (10)

6.8 EFFECT OF POTENTIAL ON QUANTUM EFFICIENCYWAVELENGTH RELATION

6.8.1 Qualitative Analysis

6.8.2 Semi-Quantitative Analysis for Maxima in the Quantum EfficiencyPotential Relation

6.9 ANALYSIS OF TRANSIENT BEHAVIOUR

6.9.1 The Origin of the Transient Behaviour

6.9.2 Cathodic Current Other than Hydrogen Evolution

6.9.3 Time Dependence of the Cathodic Current

6.9.4 Comparison with the Experimental Results

6.10 THE EFFECT OF THE FILM THICKNESS (TiO) ON QUANTUM EFFICIENCY-WAVELENGTH RELATION

6.11 THE PREVENTION OF ANODIC DISSOLUTION OF CdS BY COATING WITH $\mathrm{TiO}_{2}$ FILM

6.12 FUTURE RESEARCH

6.12.1 Estimation of the Potential Drop in the Double Layer

6.12.2 Surface Recombination

6.12.3 Surface States

6.12.4 Carrier Density

6.12.5 Transient Measurement

6.12.6 Coating

6.13 FUTURE PROSFECT OF THIS FIELD

6.14 SUMMARY OF CHAPTER SIX 


\section{SUMMARY}

The photoeffects on the oxygen and hydrogen evolution reactions at $\mathrm{n}$ - and p-type semiconductors, respectively, have been studied theoretically and experimentally in connection with the direct production of hydrogen from solar energy.

The experimental techniques involved in this work include:

1. Photocurrent measurements under the illumination of a $150 \mathrm{~W}$ or a $900 \mathrm{~W}$ Xe lamp, using potential sweep methods.

2. Photocurrent measurements under illumination by monochromatic light using a Jarrel1-Ash grating monochrometer and a Xe lamp.

3. Impedance measurements, using the direct method.

4. Transient photocurrent measurements following light illumination and light interruption.

5. Chemical vapor deposition to make $\mathrm{TiO}_{2}$ films on other semiconductors.

6. Sintering method for metal titanates synthesis.

The following novel experimental matter has been resolved:

1. The quantum efficiency of photoelectrochemical reactions involving hydrogen or oxygen evolution at several potentials and wavelengths involving $\mathrm{TiO}_{2}, \mathrm{Fe}_{2} \mathrm{TiO}_{5}$, $\mathrm{ZnTe}, \mathrm{CdTe}, \mathrm{GaAs}, \mathrm{InP}, \mathrm{GaP}, \mathrm{SiC}$ and $\mathrm{Si}$ in alkaline and acid solution.

2. The flat band potentials of $\mathrm{ZnTe}, \mathrm{CdTe}$ and $\mathrm{SiC}$ in alkaline and acid solution and of InP in alkaline solution at various frequencies.

3. The break down of the photoelectrodes, i.e., $\mathrm{TiO}_{2}, \mathrm{Fe}_{2} \mathrm{TiO}_{5}, \mathrm{ZnTe}$, 
CdTe, GaAs, InP, GaAs, SiC and $\mathrm{Si}$ in alkaline solution and acid solution, as a function of time.

4. The transient behaviour of photocurrents.

5. The prevention of the anodic dissolution of CdS by the use of thin film coating transparent to light.

6. The finding of $\mathrm{Fe}_{2} \mathrm{TiO}_{5}$ as a stable photoanode and of $\mathrm{CdTe}$ as a stable photocathode.

The theory of photoelectrochemical system has been developed originally in the following way.

Gurney's quantum mechanical theory of charge transfer reaction was modified to account for the photoelectrochemical charge transfer reaction. The number of electrons arriving at the electrode surface per unit time per unit area at certain energy level was calculated by considering the properties of the semiconductor. The energy levels of an acceptor and a donor states in the OHP were estimated. The potential drop was at first considered to occur totally within the semiconductor.

Following this model, photocurrents were calculated and compared with the experimental results. Considerable discrepancies existed between calculated and experimental results.

Energy losses of excited electrons within the semiconductor and the potential drop in the electric double layer were then taken into account. Also, the potential barrier for emitted electrons was modified by considering the image interaction of the emitting electron with the semiconductor electrode.

The photocurrents calculated by this modified theory agreed fairly well with the experimental results. 
(iii)

By applying this theory, the critical potential, at which the quantum efficiency becomes significant, has been related to the flat band potential and the energy gap. 


\section{DECLARATION}

I certify that this thesis does not incorporate without acknowledgment any material previously submitted for a degree or diploma in any University; and that to the best of my knowledge and belief it does not contain any material previously published or written by another person except where due reference is made in the text.

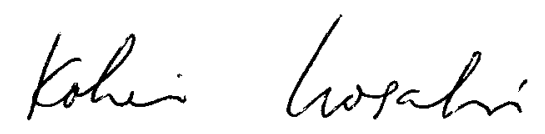

KOHEI UOSAKI 


\section{ACKNOWLEDGMENT}

I should like to thank Prof. J.0'M. Bockris for his invaluable comments, discussions and suggestions and his constant encouragement during the period of this research project.

My thanks are also due to Dr. E.F. McCoy and Dr. B.G. Baker for their helpful suggestions and their kind permission to use their equipment.

I am grateful to the people who kindly donated the semiconductor single crystals for this research project, namely, Mr. H. Kimura of Mitsubishi Electric Co. Ltd. (ZnTe and CdTe), Dr. O. Mizuno of Nippori Electric Co. Ltd. (GaAs and InP), Dr. K. Akita of Fujitsu Lab. Ltd. (GaP), Prof. von Münch of Technische Universität, Hannover (SiC) and Toyo Silicon Co. Ltd. (Si).

Thanks are also due to Dr. D.B. Matthews for many helpful discussions; to Dr. A. Fujishima of Tokyo University for providing valuable information and suggestions; to $\mathrm{Dr}$. K. Ohashi of Osaka City University for his help and discussions in the final stages of this work; to my colleagues at Flinders University; Dr. M. Mohri, Dr. M.A. Habib, Mr. S.U.M. Khan and Mr. S.P.S. Badwal, for the many fruitful discussions; to Prof. N. Tokura, Prof. H. Tamura and Dr. Y. Kondo of Osaka University for their encouragement throughout the period of this research project; and to my colleagues at Mitsubishi Petrochemical Co. Ltd., from which I was on leave, for much useful information and constant encouragement.

The technical staff of the engineering workshop, especially Mr. R. Parrott and Mr. J. Gostlow of the glass blowing section, are acknowledged for their effort in the construction and maintenance of the apparatus used in this work. 
I am also thankful to my wife, Emiko, who not only has encouraged and helped me in many ways throughout this period, but who also drew most of the figures for this thesis; without her efforts it would not have been possible to complete this research by now. I would like to take this opportunity to thank my parents who gave me constant support and kind encouragement throughout my whole educational period.

I must also thank Mrs. D.C. Hampton for typing this manuscript in a most expert and efficient manner.

Throughout the period of this project I was supported by a Flinders University Research Scholarship, for which I am most grateful, 
CHAPTER ONE

INTRODUCTION 


\section{CHAPTER ONE}

INTRODUCTION

\subsection{HISTORICAL}

Recently, strong attention has been paid to photoelectrochemistry in respect to solar-hydrogen production.

The first observation of a photo effect on electrochemical reaction was in 1839 when Becqerel found an electric current flowed if one of the electrodes which were immersed in dilute acid was illuminated by light [1]. This effect is known as the Becqerel effect.

Although many researches followed this observation, the results before about 1950, most of which were reviewed by Copeland et al. ir. 1942 [2], were complicated and not reliable because of poor experimertal technique. Several theories to attempt to explain these experimental results appeared $[3,4]$, but lack of available experimental data made a match between theory and experiment difficult to find.

Apart from the contribution of Hillson and Rideal [5] who established an experimental relation between $\log$ (quantum efficiency) and the photon energy in hydrogen and oxygen evolution reactions, researches on the photoeffect on metal electrodes had to wait until the $1960^{\prime} \mathrm{s}$ for reliable work.

M. Heyrovský examined the photoeffect on cathodic and anodic reactions and found a logarithmic relation between the photocurrent and electrode potential $[6,7]$. He interpreted these photoeffects in terms of the absorption of photons by charge-transfer complexes on tis electrode surface, a model qualitatively similar to that of Hillsor. and Ricieal. 
Barker et al. introduced solvated electron mechanisms and showed that such mechanisms could explain the experimental fact that (Photocurrent) ${ }^{\frac{1}{2}}$ was proportional to the electrode potential [8] . Later Brodsky et a1, proposed that this was not a square law but a $5 / 2$ law for the electrode potential which is proportional to the photocurrent theoretically [9].

This theory of the 5/2 law was supported by Matthews et a1. from a different approach [10] .

Delahay et a1. [11], de Levie et al. [12] and Pleskov et al. [13] were among those who carried out intensive studies on photoeffects on metal electrodes.

Because of the existence of the energy gap between the conduction and valence bands, and of two kinds of carrier, i.e., electron and hole, electrochemical reactions at semiconductors are different from those at metal electrodes, especially under illumination.

Germanium was the first semiconductor used as an electrode by Brattain and Garrett in 1955 [14] .

Since then, many researches on semiconductor electrodes were carried out and progress of early stage was reviewed by M. Green in 1959 [15] .

Gerischer et a1. [16], and also Pleskov et al. [17] and Memining et a1. [18], were the leading groups in the field of photoeffects on electrochemical reactions on semiconductor electrodes, during the $1960^{\prime} \mathrm{s}$. Many reviews and books on the semiconductor electrochemistry are available $[19,20]$.

Some of the semiconductors on which photoeffects were studied are listed in Table 1.1 with the values of energy gap. 
3.

TABLE 1.1 LIST OF SEMICONDUCTORS INVESTIGATED PHOTOELECTROCHEMICALLY

\begin{tabular}{|c|c|c|c|}
\hline Semiconductor & Type & Energy $\mathrm{GaP}, \mathrm{eV}$ & References \\
\hline $\mathrm{Ge}$ & $\mathrm{n}, \mathrm{p}$ & 0.66 & 14 \\
\hline $\mathrm{Si}$ & $\mathrm{n}, \mathrm{p}$ & 1.1 & $21 \sim 26$ \\
\hline GaAs & $n, p$ & $1.35 \sim 1.43$ & $16,17,27 \sim 29$ \\
\hline${ }^{*}[\mathrm{CdTe}$ & $n, p$ & $1.44 \sim 1.5$ & $30]$ \\
\hline CdSe & $\mathrm{n}$ & 1.74 & 31,32 \\
\hline$\overline{\mathrm{CuO}}$ & & 1.95 & 307 \\
\hline $\mathrm{CdO}$ & & 2.2 & 30 \\
\hline $\mathrm{Cu}_{2} \mathrm{O}$ & $\mathrm{p}$ & 2.2 & $31,33,34$ \\
\hline $\mathrm{Fe}_{2} \mathrm{O}_{3}$ & $\mathrm{n}$ & 2.2 & 35 \\
\hline${ }_{2}{ }^{0} 5$ & $\mathrm{n}$ & 2.23 & 36,37 \\
\hline $\mathrm{ZnTe}$ & $\mathrm{p}$ & 2.26 & 31,38 \\
\hline $\mathrm{GaP}$ & $\mathrm{n}, \mathrm{p}$ & $2.25 \sim 2.35$ & 18,39 \\
\hline $\mathrm{CdS}$ & $\mathrm{n}$ & 2.4 & $31,40 \backsim 42$ \\
\hline $\mathrm{ZnSe}$ & $\mathrm{n}$ & 2.6 & 43 \\
\hline$w_{3}$ & $\mathrm{n}$ & 2.7 & 44 \\
\hline$\alpha-S i C$ & $\mathrm{n}, \mathrm{p}$ & $2.75 \sim 3.1$ & 45 \\
\hline $\mathrm{TiO}_{2}$ & $\mathrm{n}$ & 3.0 & $46 \sim 49$ \\
\hline $\mathrm{ZnO}$ & $\mathrm{n}$ & 3.2 & $50 \sim 53$ \\
\hline $\mathrm{SrTiO}_{3}$ & $\mathrm{n}$ & 3.2 & 54,55 \\
\hline $\mathrm{KTaO}_{3}$ & $\mathrm{n}$ & 3.5 & 56 \\
\hline $\mathrm{SnO}_{2}$ & $\mathbf{n}$ & 3.7 & 57,58 \\
\hline [ NiO & $\mathrm{p}$ & 4.0 & $59,60]$ \\
\hline $\mathrm{Ta}_{2} \mathrm{O}_{5}$ & $\mathrm{n}$ & 4.6 & 61 \\
\hline
\end{tabular}

* Semiconductors shown in brackets were examined ir dark only. 
4 .

Although studies of photoeffects on metal and semiconductor electrodes were carried out very actively, little attention was given to the relation between such researches and solar-energy conversion until Fujishima and Honda drew attention to the possibility of direct hydrogen production by a photodriven electrochemical cell without any applied potential. They proposed the cell, $\mathrm{TiO}_{2} /$ electrolyte solution/Pt. The $\mathrm{TiO}_{2}$ electrode was irradiated and hydrogen evolved on Pt [48].

Many groups have started on research on the direct production of hydrogen by photodriven electrochemical cell, triggered by the Fujishima and Honda publication, although later it became clear that the cathodic reaction originally observed on the $\mathrm{Pt}$ electrode in the ce11, $\mathrm{TiO}_{2} /$ electrolyte solution/Pt was not the hydrogen evolution reaction but oxygen reduction reaction, unless a $\mathrm{pH}$ gradient existed between the anodic and the cathodic compartments [62]. Fujishima and Honda showed later that the more basic the $\mathrm{TiO}_{2}$ (anodic) compartment and the more acidic the Pt (cathodic) compartment, the higher the photocurrent [63] .

One of the big advantages of this method compared with photovoltaic method is that there is no need for a single crystal which is a very critical factor in photovoltaic case. Fujishima et al. and other workers examined the possibilities of the use of $\mathrm{TiO}_{2}$ polycrystal made by several methods, i.e., anodic oxide film $[64,65]$, thermal oxidation $[62,65]$ and chemical vapor deposition [64], and Fujishima et al. showed that the efficiencies of $\mathrm{TiO}_{2}$ films made by suitable high temperature oxidation were the same as those of single crystal [65].

However, there are two great difficulties in respect to the use of this method as a cheap hydrogen production device. 
5.

One is that, although the quantum efficiency of the photoelectrochemical oxygen evolution on $\mathrm{TiO}_{2}$ is quite high [66], the relatively high energy gap of $\mathrm{TiO}_{2}$, i.e., $3 \mathrm{eV}$, makes it impossible to utilize a large portion of solar energy. The maximum may be $3 \%$ efficiency and Fujishima et a1. reported $0.4 \%$ efficiency for the average in field tests [65]. In this respect, one must find a semiconductor of lower energy gap with high stability. Recently, $\mathrm{WO}_{3}[44]$ and $\mathrm{Fe}_{2} \mathrm{O}_{3}$ [35], which have lower energy gaps, $2.7 \mathrm{eV}$ and $2.2 \mathrm{eV}$, respectively, were examined and reported.

The other difficulty is that as mentioned above a $\mathrm{pH}$ gradient is required to get the cell to work as a photo-driven cell. Mavroides et al. reported that by using $\mathrm{SrTiO}_{3}$ as a photoanode instead of $\mathrm{TiO}_{2}$ the cell, $\mathrm{SrTiO}_{3} /$ electrolyte solution/Pt, would work as a photo-driven cell without a $\mathrm{pH}$ gradient [54]. However the energy gap of $\mathrm{SrTiO}_{3}$, $3.2 \mathrm{eV}$, is higher than that of $\mathrm{TiO}_{2}$ and, therefore, it absorbs almost no solar energy.

Yoneyama et al. demonstrated this difficulty could be resolved by using a p-type semiconductor as a cathode and illuminating both electrodes [67], although GaP, which was used by Yoneyama et al., had a poor stability.

Nozik [68] and Wrighton et al. [69] studied the efficiencies of photo-assisted electrolysis of water in $\mathrm{TiO}_{2}$ /electrolyte solution/ Pt cell, in which $\mathrm{TiO}_{2}$ was illuminated and water was decomposed at relatively low applied potential, as low as $0.25 \mathrm{~V}$.

Partly because of the absence of a fundamental treatment and systematic quantitative experimental work, it is difficult to judge what kind of electrode characteristics are required to optimise the 
6.

effects concerned, particularly as these must work in a cell, e.g. the effects of the properties of two electrodes must be taken into account. 


\subsection{THE OUTLINE OF THIS PROJECT}

The major purpose of this project was to find the relations between properties of semiconductor and efficiencies as photoelectrodes, so that one can predict which semiconductor will be useful as a photoelectrode.

This project can be divided into two big parts, theoretical ard experimental.

Chapters Two and Three are the theoretical parts and Chapters Four, Five and Six are experimental parts.

Chapter Two treats some aspects of the photoeffect on the hydrogen evolution reaction at metal electrodes theoretically and the absolute values of photocurrents have been calculated in terms of the properties of metals for the first time.

Such treatments are modified and applied to the photoeffect on electrochemical reactions at semiconductor electrodes in Chapter Three. Optimum conditions for semiconductor properties are given, purely on a theoretical basis.

In Chapter Four, the experimental apparatus and techniques employed in this work are described. Those are the photoelectrochemical system, the impedance measurement and the preparation and pretreatments of the semiconductors.

Chapter Five describes the experimental results. The photoeffects on anodic reaction at $\mathrm{TiO}_{2}$ single crystal, $\mathrm{TiO}_{2}$ films and 
8.

metal titanates are reported. Also, the photoeffects on cathodic reaction at seven p-type semiconductors ( $\mathrm{ZnTe}$, CdTe, GaAs, InP, $\mathrm{GaP}, \mathrm{SiC}$ and $\mathrm{Si}$ ) are reported.

In Chapter Six, the experimental results, especially those of p-type semiconductors, are generalised and discussed. The theory given in Chapter three is applied to analyse the experimental results and modified. 


\section{BIBLIOGRAPHY OF CHAPTER ONE}

1. E. Becquere1, Compt. rend., 9, 561 (1839).

2. A.W. Copeland, O.D. Black and A.B. Garrett, Chem. Rev., $\underline{31}, 177$ (1942).

3. E. Adler, J. Chem. Phys., 8, 500 (1940).

4. J.0'M. Bockris, "Modern Aspects of Electrochemistry", Vo1. 1, Chapter 4, Eds., J.O'M. Bockris and B.E. Conway, Butterworths, London (1954) .

5. P.J. Hillson and E.K. Rideal, Proc. Roy. Soc. (London), A216, 458 (1953).

6. M. Heyrovský and R.G.W. Norrish, Nature, 200, 880 (1963).

7. M. Heyrovský, Proc. Roy. Soc. (London), A301, 411 (1967).

8. G.C. Barker, A.W. Gardner and D.C. Sammon, J. Electrochem. Soc., $113,1182(1966)$.

9. A.M. Brodsky and Yu. Ya. Gurevich, EZectrochim. Acta, 13, 1245 (1968).

10. D.B. Matthews and S.U.M. Khan, Aust. J. Chem., 28, 253 (1975).

11. P. Delahay and V.S. Srinivasan, J. Phys. Chem., 70,420 (1966).

12. R. de Levie and J.C. Kreuser, J. Electroanal. Chem., 21, 221 (1969) .

13. Yu. V. Pleskov and Z.A. Rotenberg, J. EZectroanal. Chem., 20, 1 (1969).

14. W.H. Brattain and C.G.B. Garrett, Bell System Tech. J., 34, 129 (1955).

15. M. Green, "Modern Aspects of Electrochemistry", Vo1. 2, Chapter 5, Ed., J.0'M. Bockris, Butterworths, London (1959) . 
10.

16. H. Gerischer and I. Mattes, Z. Phys. Chem. (N.F.), 49 , $112(1966)$

17. Yu. V. P1eskov and V.V. Eletsky, Electrochim. Acta, 12, 707 (1967)

18. R. Memming and G. Schwandt, Electrochim. Acta, 13, 1299 (1968)

19. V.A. Myamlin and Yu. V. Pleskov, "Electrochemistry of Semiconductors" (English Edition), P1enum Press, New York (1967).

20. H. Gerischer, "Physical Chemistry: An Advanced Treatise", Vo1. IX A, Chapter 5, Ed. H. Eyring, Academic Press, New York (1970).

21. E.A. Efimov, I.G. Erusalimchik and G.P. Sokolova, Russ. J. Phys. Chem., 36, 524 (1962).

22. S.0. Izidinov, T.I. Borisova and V.I. Veselovskii, Dokl. Acad. Nauk. SSSR, 145, 598 (1962).

23. S.0. Izidinov, T.I. Borisova and V.I. Veselovskii, Russ. J. Phys. Chem., 36, 659 (1962).

24. R. Memming and G. Schwandt, Surface Sci., 4, 109 (1966).

25. F.F. Red'ko and S.0. Izidinov, Elektrokhimizya; 2,1128 (1966).

26. F.F. Red'ko and S.0. Izidinov, EZektrokhimiya, 2, 1282 (1966).

27. H. Gerischer, Ber. Bunsenges. Phys. Chem., 69, 578 (1965).

28. H. Gerischer, J. Electrochem. Soc., 113, 1174 (1960).

29. A. Yamamoto and S. Yano, J. Electrochem. Soc., 122, 260 (1975).

30. H. Gerischer and W. Mindt, Electrochim. Acta, 13, 1329 (1968).

31. R. Williams, J. Chem, Phys., 32, 1505 (1960).

32. R.A.L. Vanden Berghe, W.P. Gomes and F. Cardon, Z. Phys. Chern. (N.F.), $\underline{92}, 91$ (1974) . 
33. H.R. Schöppel and H. Gerischer, Ber. Bunsenges. Phys. Chem., 75, 1237 (1971).

34. K. Hauffe and K. Reinhold, Ber. Bunsenges. Phys. Chem., 76, $616(1972)$

35. K.L. Hardee and A.J. Bard, J. EZectrochem. Soc., 123, 1024 (1976) .

36. W.P. Gomes, Surface Sci., 19, 172 (1970).

37. K. Taki, T. Kishi and T. Nagai, Denki Kagaku, 40, 216 (1972).

38. V.I. Sapritskii and N.G. Bardina, Elektrokhimiya, $\underline{8}, 655$ (1972).

39. K.H. Beckmann and K. Memming, J. EZectrochem. Soc., 116, 368 (1969) .

40. V.A. Tyagai, Fiz. I'ver. TeZa, 6, 1602 (1964).

41. H. Gerischer, J. Electroanal. Chem., 58, 263 (1975).

42. H. Gerischer, Ber. Bunsenges. Phys. Chem., 80, 327 (1976).

43. R. Williams, J. Electrochem. Soc., 114, 1173 (1967).

44. G. Hodes, D. Cahen and J. Manessen, Nature, 260, 312 (1976).

45. M. Gleria and R. Memming, J. Electroanal. Chem., 65, 163 (1975).

46. P.J. Boddy, J. Electrochem. Soc., 115, 199 (1968).

47. A. Fujishima, K. Honda and S. Kikuchi, Kogyo Kagaku Zasshi, 72, 108 (1919).

48. A. Fujishima and K. Honda, Nature, 238, 37 (1972).

49. D.M. Shub, A.A. Remnev and V.I. Veselovskii, Elektrokhimiya, 9, 676 (1973).

50. F. Lohman, Ber. Bunsenges. Phys. Chem., 70, 87 (1966).

51. S.R. Morrison and T. Freund, Electrochim. Acta, 13, 1343 (1968).

52. K.A.L. Vanden Berghe, F. Cardon and W.P. Gomes, Surface Sci., 39, 368 (1973).

53. J. Cunningham and S. Corkery, J. Phys. Chem., 79, 933 (1975).

54. J.G. Mavroides, J.A. Kafalas and D.F. Kolesar, App Z. Phys. Leat., $28,241(1976)$. 
55. T. Watanabe, A. Fujishima and K. Honda, BuzZ. Chem. Soc. Japan, $\underline{49}, 355$ (1976) .

56. P.J. Boddy, D. Kahng and Y.S. Chen, EZectrochim. Acta, 13, 1311 (1968).

57. F. Möllers and R. Memming, Ber. Bunsenges. Phys. Chem., 76, 469 (1972).

58. H. Kim and H.A. Latinen, J. EZectrochem. Soc., 122, 53 (1975).

59. T.0. Rouse and J.L. Weininger, J. ELectrochem. Soc., 113, 184 (1966).

60. D. Yohe, A. Riga, R. Greef and E. Yeager, Electrochim. Acta, $\underline{13}, 1351$ (1968).

61. G. Krüger, Electrochim. Acta, 13, 1389 (1968).

62. W. Gissler, P.L. Lensi and S. Pizzini, J. App Z. EZectrochem,, $\therefore, 9(1976)$.

63. A. Fujishima, K. Kohayakawa and K. Honda, BuzZ. Chem. Soc. Japan, 48, 1041 (1975).

64. K.L. Hardee and A.J. Bard, J. Electrochem. Soc., 122, 739 (1975).

65. A. Fujishima, K. Kohayakawa and K. Honda, J. Electrochem. Soc., 122,1487 (1975).

66. T. Ohnishi, Y. Nakato and H. Tsubomura, Ber. Bunsenges. Phys. Chem., 79, 523 (1975).

67. H. Yoneyama, H. Sakamoto and H. Tamura, Electrochim. Acta, 20, 341 (1975).

68. A.J. Nozik, Nature, 257, 383 (1975).

69. M.S. Wrighton, D.S. Ginley, P.T. Wolczanski, A.B. El1is, D.L. Morse and A. Linz, Proc. Nat. Acad. Sci. U.S.A., 72, 1518 (1975) . 
CHAPTER TWO

THEORETICAL TREATMENT OF PHOTOELECTROCHEMICAL KINETICS AT METAL ELECTRODES 


\section{CHAPTER TWO*}

THEORETICAL TREATMENT OF PHOTOELECTROCHEMICAL KINETICS

AT METAL ELECTRODES

\subsection{INTRODUCTION}

Recently, many reliable experimental results of photoelectrochemical reactions on metal electrodes became available along with the development of experimental techniques [1 5] and also a number of theories were proposed $[1,2,6 \sim 9]$.The theories which have appeared so far have tried to explain the relations between photocurrent and electrode potential or photon energy. However no theory has taken into account the optical properties of metals, e.g., absorption coefficient etc. and, therefore, no theory has been able to calculate the absolute values of the photocurrent.

It is very important to estimate the absolute values of the quantum efficiency (photocurrent) as a function of metal properties in order to evaluate the potential of metal electrodes as a photoelectrode for solar-hydrogen production. Here the photoeffect on hydrogen evolution reaction on metal electrodes is considered.

* This Chapter is a modified version of the paper accepted for publication in $J$. Fes. Inst. for Cat., Hokkaido Univ., 24, 1 (1976). 


\subsection{PHOTOCURRENT EXPRESSION}

The photoemission of an electron from the metal to acceptor states in the electrolyte across the potential barrier at the metal solution interface is taken to be the rate determining step (Eq. 2.1))

$$
M(e)+\mathrm{H}_{3} \mathrm{O}^{+} \rightarrow \mathrm{M}--\mathrm{H}--\mathrm{H}_{2} \mathrm{O}
$$

Let it be supposed that the metal is illuminated normal to the surface.

\subsubsection{Photon Absorption Step}

The number of photons absorbed by the metal between $x$ and $x+d x$ from the surface, $N_{p h}(h \nu, x) d x$, is given by:

$$
N_{p h}(h \nu, x) d x=I_{o}(1-R) \alpha_{p h} e^{-\alpha} p h^{x} d x
$$

where $I_{0}\left(\mathrm{~cm}^{-2} \cdot \mathrm{sec}^{-1}\right)$ is the total number of photons of incident light; $R$ is the reflectivity and $\alpha_{p h}\left(\mathrm{~cm}^{-1}\right)$ is the absorption coefficient of the metal for the photon of energy hv.

\subsubsection{Excitation Process}

Each absorbed photon excites an electron and the probability $P_{e x}(E, h) d E$ of excitation of an electron from the energy level between (E-hV) and ( $E-h V)+d E$ to the energy level between $E$ and $E+\mathrm{d}]$ is given by $[10]$;

$$
P_{e x}(E, h \nu) d E=k \rho(E)\{1-f(E)\} \rho(E-h \nu) f(E-h \nu) d E
$$

where $\rho(E)$ is the density of states at energy $E$ and $f(E)$ is the Fernij distribution function at encrgy E (Energy levels are taken as zero at the bottom of the conduction band); $k$ is a proportional constant. 
15.

Norma1izing $P_{\text {ex }}(E, h \nu) d E$ to unity, Eq. (2.3) becomes

$$
P_{e x}(E, h \nu) d E=\frac{\rho(E)\{1-f(E)\} \rho(E-h \nu) f(E-h \nu) d E}{\int_{h \nu}^{\infty} \rho(E)\{1-f(E)\} \rho(E-h \nu) f(E-h \nu) d E}
$$

Therefore the number of photo-excited electrons, the energy of which is between $E$ and $E+d E$ and which are excited between $x$ and $x+d x$, $N_{e}(E, h \nu, x) d E d x$, is given by:

$$
\begin{aligned}
N_{e}(E, h \nu, x) d E d x & =N_{p h}(h \nu, x) P_{e x}(E, h \nu) d E d x \\
& =(1-R) I_{o} \alpha_{p h} e^{-\alpha} \frac{p h}{\int_{h \nu}^{x} \rho(E)\{1-f(E)\} \rho(E-h \nu) f(E-h \nu) d E d x}
\end{aligned}
$$

\subsubsection{Number of Excited Electrons Arriving at the Surface}

By assuming the probability of having a number of electrons, the $x$ component of energy of which is $E_{x}$, is the same between $0 \leqslant E_{x} \leqslant E$, the number of electrons the energy of which is between $E$ and $E+d E$ and the $x$ component of the energy of which is between $E_{x}$ and $E_{x}+d E_{x}$, is given by:

$$
\frac{N_{e}(E, h \nu, x) d E d x}{E} d E_{x}
$$

This number represents the number of electrons, the $\mathrm{x}$ component of the velocity of which is $-\sqrt{2 \mathrm{E} / \mathrm{m}}$ and $\sqrt{2 \mathrm{E} / \mathrm{m}}$ and, therefore, number of electrons, the $x$ component of which is between $E_{x}$ and $E_{x}+d E_{x}$, and moving to the surface $\mathrm{N}_{\mathrm{e}}^{\prime}\left(\mathrm{E}, \mathrm{h} \nu, \mathrm{E}_{\mathrm{x}}, \mathrm{x}\right) \mathrm{dEdxdE} \mathrm{x}_{\mathrm{x}}$, is given by:

$$
\begin{aligned}
& N_{e}^{\prime}\left(E, h \nu, E_{x}, x\right) d E d x d E_{x}=\frac{N_{e}(E, h \nu, x) d E d x}{2 E} d E_{x} \\
& =I_{o}(1-R) \alpha_{p h} e^{-\alpha} p h^{x} \frac{1}{2 E} \frac{\rho(E)\{1-f(E)\} \rho(E-h \nu) f(E-h \nu) d E d x d E_{x}}{\int_{h \nu}^{\infty} \rho(E)\{1-f(E)\} \rho(E-h \nu) f(E-h \nu) d E}
\end{aligned}
$$


The probability of electrons from within the bulk of the metal arriving at the surface without suffering an inelastic electronphonon and the electron-electron scattering event is given by [11]

$$
\mathrm{P}_{\mathrm{SCAT}}=\exp \left(-\frac{\ell}{\mathrm{L}}\right)
$$

where $L$ is the electron-phonon or electron-electron scattering length and $\ell$ is the actual travelling distance of the electron between the excited position and the electrode surface (see Fig. 2.1) $\ell$ is the function of $x$ and the energy components $\dot{E}_{x}, E_{y}$ and $E_{z}$. Since,

$$
\ell \cos \theta \cos \Phi=\mathrm{x}
$$

and also

$$
\mathrm{v} \cos \theta \cos \Phi=\mathrm{v}_{\mathrm{x}}
$$

where $v$ is the total velocity of the electron and $v_{x}$ is the $x$ component of the velocity,

$\ell$ is given by

$$
\ell=x \frac{v}{v_{x}}
$$

$v$ and $v_{x}$ are given by:

$$
\begin{aligned}
& v=\sqrt{\frac{2 E}{m}} \\
& v_{x}=\sqrt{\frac{2 E x}{m}}
\end{aligned}
$$

and, therefore, Eq. (2.11) becomes,

$$
\ell=x \sqrt{\frac{E}{E_{x}}}
$$

Hence, the number of electrons arriving at the surface, the energy 


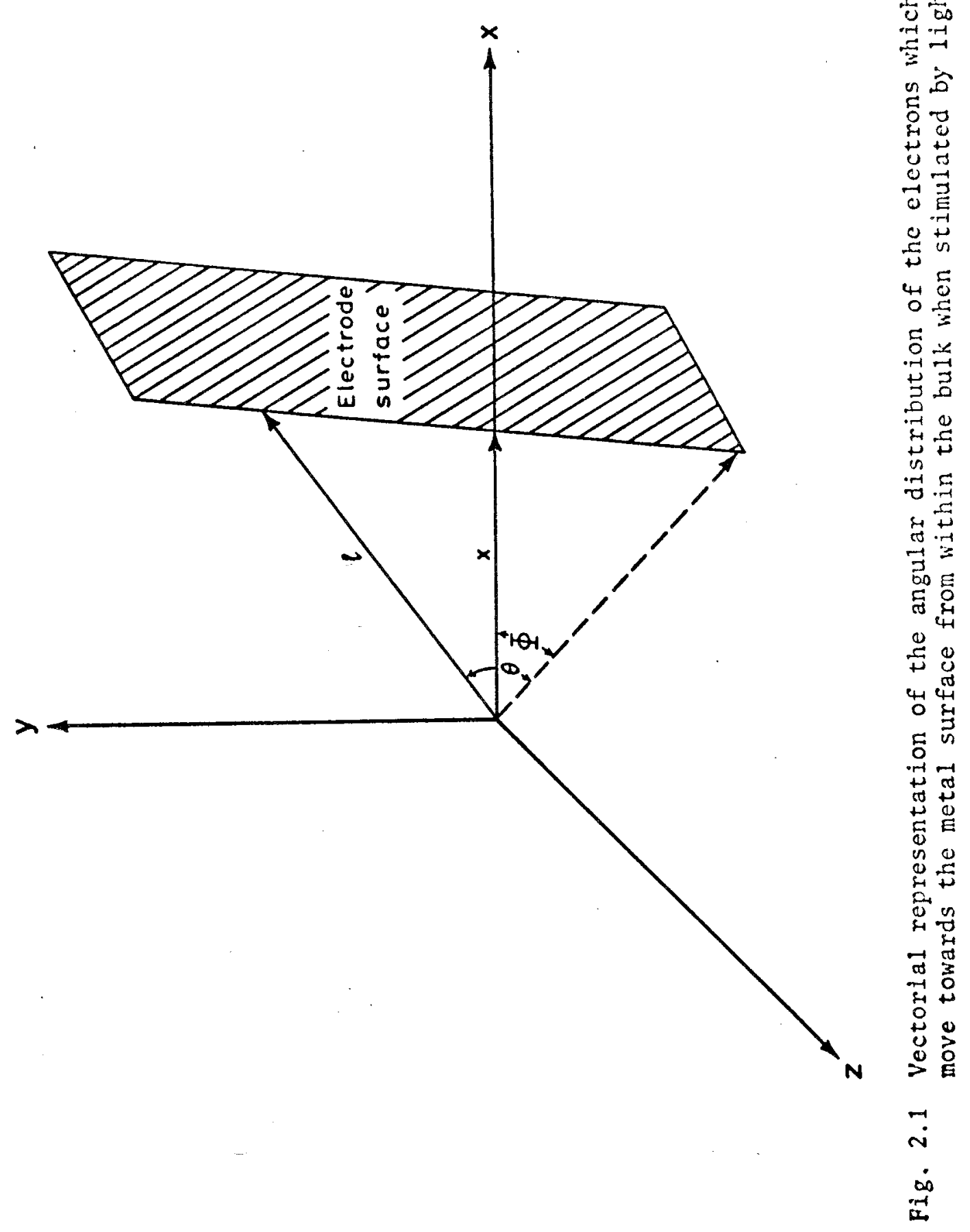


18.

of which is between $E$ and $E+d E$, the $x$ component of the energy of which is between $E_{x}$ and $E_{x}+d E_{x}$ and which are excited between $x$ and $x+d x$ from the surface, $N_{0}\left(E, h \nu, E_{x}, x\right) d E d x d E_{x}$, is given by:

$$
\begin{aligned}
& N_{0}\left(E, h \nu, E_{x}, x\right) d E d x d E_{x}=N_{e}^{\prime}\left(E, h \nu, E_{x}, x\right) \cdot P_{S C A T} d E d x d E E_{x} \\
& =I_{0}(1-R) \alpha_{p h} \exp \left\{-\left(\alpha_{p h}+\frac{1}{L} \sqrt{\frac{E}{E_{x}}}\right) x \frac{1}{2 E} \frac{\rho(E)\{1-f(E)\} \rho(E-h \nu) f(E-h \nu) d E d x d E x}{\int_{h \nu}^{\infty} \rho(E)\{1-f(E)\} \rho(E-h \nu) f(E-h \nu) d E}\right.
\end{aligned}
$$

By integrating with respect to $x$, the number of electrons arriving at the surface, the energy of which is between $E$ and $E+d E$ and the $x$ component of the energy of which is between $E_{x}$ and $E_{x}+d E_{x}$, $N_{0}^{\prime}\left(E, h \nu, E_{x}\right) d E d E_{x}$, is given by:

$$
\begin{aligned}
& N_{0}^{\prime}\left(E, h \nu, E_{x}\right) d E d E_{x}=\int_{0}^{\infty} N_{o}\left(E, h \nu, x, E_{x}\right) d E d E_{x} d x \\
& =I_{0}(1-R) \frac{\alpha_{p h}}{\alpha_{p h}+\frac{1}{L} \sqrt{\frac{E}{E_{x}}}} \cdot \frac{1}{2 E} \cdot \frac{\rho(E)\{1-f(E)\} \rho(E-h \nu) f(E-h \nu) d E d E_{x}}{\int_{h \nu}^{\infty} \rho(E)\{1-f(E)\} \rho(E-h \nu) f(E-h \nu) d E}
\end{aligned}
$$

Therefore, the total number of electrons arriving at the surface, the $x$ component of energy of which is between $E_{x}$ and $E_{x}+d_{x}$, $\mathrm{N}_{T}\left(\mathrm{E}_{\mathrm{X}}, \mathrm{h} \nu\right) \mathrm{dE}_{\mathrm{x}}$, is given by:

$$
\begin{aligned}
& N_{T}\left(E_{x}, h \nu\right) d E_{x}=\int_{E_{x}}^{\infty} N_{0}^{\prime}\left(E, h \nu, E_{x}\right) d E d E_{x} \\
& =I_{0}(1-R) \alpha_{p h} \int_{E_{x}}^{\infty} \frac{1}{\alpha_{p h}+\frac{1}{L} \sqrt{\frac{E}{E_{x}}}} \cdot \frac{1}{2 E} \cdot \frac{\rho(E)\{1-f(E)\} \rho(E-h \nu) f(E-h \nu) d E d E_{x}}{\int_{0}^{\infty} \rho(E)\{1-f(E)\} \rho(E-h \nu) f(E-h \nu) d E}
\end{aligned}
$$




\subsubsection{Electrochemical Process}

The photocurrent is proportional to the number of photoelectrons arriving at the surface, the probability of tunneling of these through the potential barrier at the interface and the probability of the presence of acceptor states and given by [12];

$$
i_{p}=e_{0} \frac{C_{A}}{C_{T}} \int_{h \nu}^{\infty} N_{T}\left(E_{x}, h \nu\right) W\left(E_{x}\right) G\left(E_{x}\right) d E_{x}
$$

where $C_{A}$ and $C_{T}$ are the total number of acceptors per unit area of the outer Helmholtz plane (OHP) and the total number of sites per unit area of OHP; $W\left(E_{x}\right)$ is the W.K.B. tunneling probability of electron across the potential barrier of height $U_{m}$ and width $l$, i.e.,

$$
W\left(E_{x}\right)=\exp \left\{-\frac{\pi^{2} \ell}{h}\left[2 m\left(U_{m}-E_{x}\right)\right]^{\frac{1}{2}}\right\}
$$

and $G\left(E_{x}\right)$ represents the population of vibrational-rotational states of acceptor in solution at different energies $E_{x}$, i.e.,

$$
G\left(E_{x}\right)=\exp \left\{-\beta\left(E_{0}-E_{x}\right) / k T\right\}
$$

where $\beta$ is the symmetry factor and $E_{0}$ is the energy level of electron in the ground state of an $\mathrm{H}_{3} \mathrm{O}^{+}$ion [13] .

Using Eq. (2.17) in Eq. (2.18) one gets

$$
i_{p}=e_{o} A_{C_{T}} \int_{h \nu E_{x}}^{\infty} \int_{p h+\frac{1}{L} \sqrt{\frac{E}{E_{x}}}}^{\infty} \frac{1}{\alpha_{h \nu}^{\infty}} \frac{\rho(E)\{1-f(E)\} \rho(E-h \nu) f(E-h \nu)}{\int_{h}^{\infty} \rho(E)\{1-f(E)\} \rho(E-h \nu) f(E-h \nu) d E} d E W\left(E_{x}\right) C\left(E_{x}\right) d E_{x}
$$

where

$$
A=I_{0}(1-R) \alpha_{p h}
$$


20.

The energy level of an electron in the ground state of $\mathrm{H}_{3} \mathrm{O}^{+}$ ion, $E_{o}$, the barrier height and the barrier width, $\ell$, have been estimated by Khan [12] as:

$$
\begin{aligned}
& E_{0}=-1.5+\Phi+E_{F}(\mathrm{eV}) \\
& U_{\max }=3.3+\Phi+E_{F}(\mathrm{eV}) \\
& \ell=2.2 \AA
\end{aligned}
$$

where $\Phi$ and $E_{F}$ are the work function and the Fermi energy of the metal.

The schematic energy diagram corresponding to these values for $\mathrm{Hg}$ is show in Fig. 2.2 [12].

Accordingly, for the practical evaluation of the photocurrent one can write the integral in Eq. (2.21) in three parts for the three region in the energy diagram, i.e.,

$$
\begin{aligned}
& i_{p}=e_{0} A \frac{C_{A}}{C_{T}} \iint_{h \nu}^{E} \int_{E_{x}}^{\infty} \frac{1}{\alpha_{p h}+\frac{1}{L} \sqrt{\frac{E}{E_{x}}}} \frac{1}{2 E} \frac{\rho(E)\{1-f(E)\} \rho(E-h \nu) f(E-h \nu)}{\int_{h \nu}^{\infty} \rho(E)\{1-f(E)\} \rho(E-h \nu) f(E-h \nu) d E}-1 E W\left(E_{\lambda}\right) G\left(E_{x}\right) d E_{x} \\
& +\int_{E_{0}}^{U_{m}} \int_{E_{x}^{\infty}}^{\alpha_{p h}+\frac{1}{L} \sqrt{\frac{E}{E_{x}}}} \frac{1}{2 E} \frac{\rho(E)\{1-f(E)\} \rho(E-h \nu) f(E-h \nu)}{\int_{h \nu}^{\infty} \rho(E)\{1-f(E)\} \rho(E-h \nu) f(E-h \nu) d E} d E_{i v}\left(E_{x}\right) d E_{x} \\
& \left.+\int_{U_{m}}^{\infty} \int_{E_{x}}^{\infty} \frac{1}{\alpha_{p h}+\frac{1}{L} \sqrt{\frac{E}{E_{x}}}} \frac{1}{2 E} \frac{\rho(E)\{1-f(E)\} \rho(E-h \nu) f(E-h \nu)}{\int_{h \nu}^{\infty} \rho(E)\{1-f(E)\} \rho(E-h \nu) f(E-h \nu) d E} d E d E\right\}
\end{aligned}
$$

The first integral of the Eq. (2.26) gives the contribution of photocurrent from the photoelectrons which tunnel through the barrier 


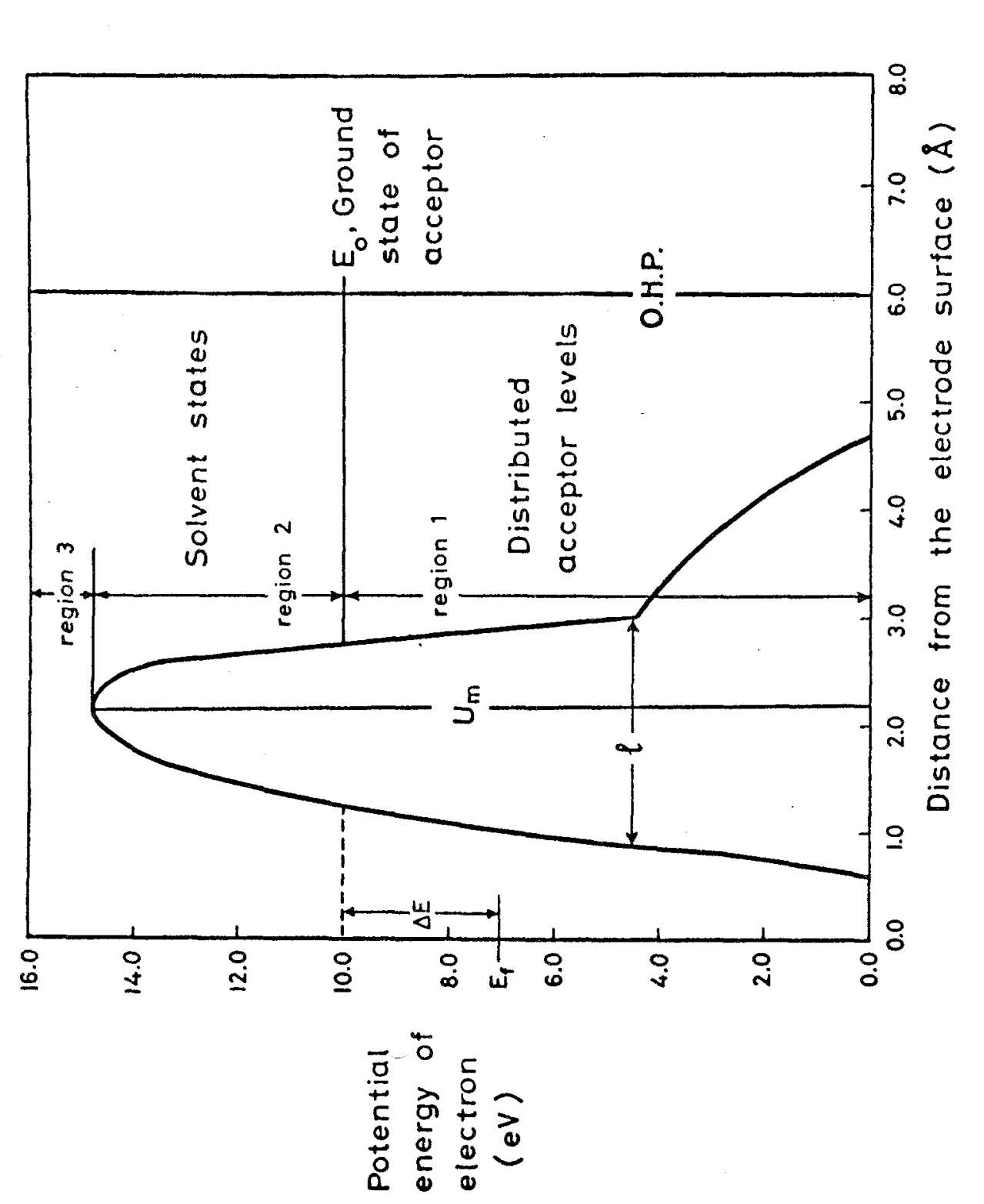

के

㲾兵

出

동

品

出怘

d)

क) 5

क⿺

4

$\stackrel{+4}{0}=$

$40 \div$

象

CO"I

$\& 40$

로용

$\underset{-1}{\infty}>\frac{1}{0}$

若

造 12

品

\&

44.

帠总苛

क्ष

of

नु

0 究苟

क्ष

4

焉

ड़

E

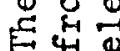

$\dddot{Y}$
$\sim$
$\dot{N}$
$\dot{1}$ 
22.

to the distributed acceptor states corresponding to the vibratiora? rotational energy of an acceptor, $\mathrm{H}_{3} \mathrm{O}^{+}$.

The second integral of the Eq. (2.26) gives the contribution of photocurrent from the photoelectrons which tumel through the barrich and \& to the solvent states. After emission into the solution these high energy electrons lose their kinetic energy by inelastic collision with the bulk water molecules and ultimately get accepted by the solvent molecules.

The third integral of Eq. (2.26) gives contribution to the photocurrent from the photoelectrons which can go over the barrier. 


\subsection{COMPUTATION OF THE PHOTOCURRENT}

\subsubsection{Quantum Efficiency-Potential Relation at Several}

Photon Energies

The photocurrent at the electrode potential $V$ with respect to the pzc can be calculated by replacing the value of $E_{F}$ by $\left(E_{F}-e_{0} V\right)$ in Eq. $(2.21)$ and $\mathrm{Eq} .(2.26)$.

The quantum efficiencies $\left(=i_{p} / I_{0}\right)$ for different incident light energies, hv, at the $\mathrm{Hg}$-solution interface were calculated as a function of electrode potential by numerical integration of Eq. (2.26) using the DEC-10 computer and are shown in Fig. 2.3. The values used in the calculation are listed in Table 2.1. The electron-phonon scattering length was taken as the mean free path, since electronelectron scattering length is usually longer than the electron-fhonon scattering length [14] .

The (quantum efficiency) ${ }^{0.4}$ against potential, $V$, has been plotted (Fig. 2.4) for different incident light energies hv. There is linearity for a potential change from the potential of zero charge (p.z.c.) for at least one decade.

The threshold energy, $h \nu_{0}$, for photoemission into the electrolyte was determined by plotting (quantum efficiency) ${ }^{0.4}$ against potentials, $V$ (Fig. 2.4), and extrapolating to (quantum efficiency) ${ }^{0.4}=0$. The extrapolated potential, corresponding to (quantum efficiency) ${ }^{0.4}=0$ is the threshold potential, $V_{0} \cdot$ The threshold photon energy $h \nu_{0}$ was obtained from the relation

$$
h v_{0}=h v-e_{0} v_{0}
$$

where $\mathrm{h} v$ is the incident photon energy. The results of the threshold energy from the plots of Fig. 2.4 are $2.60 \sim 2.83 \mathrm{eV}$ and in good agreement 


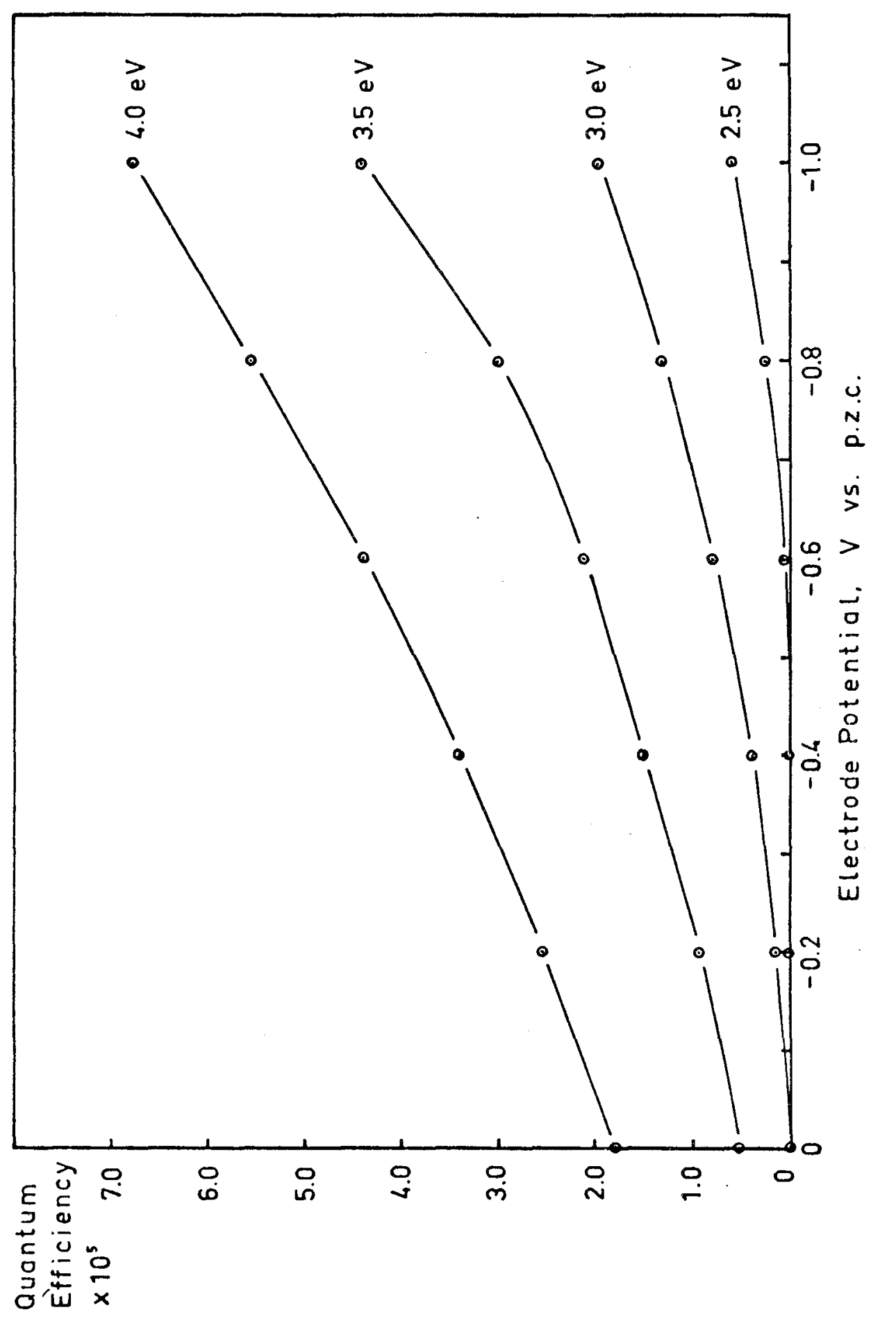

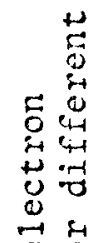
$\stackrel{0}{0}$ 告荠 당 出 D心 00 0. ․ 5 政 $\longrightarrow$

(1) के

on

- 5 .

.

足

出

๑ 5

통

可话否

号

出出

总总总

$m$
$\sim$
$\dot{n}$
$\dot{m}$ 
TABLE 2.1 PARAMETERS FOR QUANTUM EFFICIENCY CALCULATION

\begin{tabular}{|c|c|c|c|c|c|c|}
\hline Metal & $\begin{array}{l}\text { Fermi } \\
\text { Energy } \\
(\mathrm{eV})\end{array}$ & $\begin{array}{l}\text { Mean Free } \\
\text { Path }^{(\mathrm{a})} \\
\left(10^{-7} \mathrm{~cm}\right)\end{array}$ & $\begin{array}{l}\text { Work } \\
\text { Function (b) } \\
(\mathrm{eV})\end{array}$ & $\begin{array}{l}\text { Photon } \\
\text { Energy } \\
(\mathrm{eV})\end{array}$ & $\mid \begin{array}{l}\text { Reflection } \\
\text { Coefficient }\end{array}(c)$ & $\begin{array}{l}\text { Absorption } \\
\text { Coeffic- }(c) \\
\text { ient } \\
10^{6} \mathrm{~cm}^{-1}\end{array}$ \\
\hline $\mathrm{Hg}$ & 7.05 & 1.31 & 4.5 & $\begin{array}{l}2.0 \\
2.5 \\
3.0 \\
3.5 \\
4.0\end{array}$ & $\begin{array}{l}0.77 \\
0.75 \\
0.73 \\
0.71 \\
0.66\end{array}$ & $\begin{array}{l}0.94 \\
0.97 \\
1.0 \\
0.94 \\
0.89\end{array}$ \\
\hline $\mathrm{Cu}$ & 7.0 & 38.8 & 4.55 & $\begin{array}{l}2.0 \\
2.5 \\
3.0 \\
3.5 \\
4.0\end{array}$ & $\begin{array}{l}0.83 \\
0.55 \\
0.40 \\
0.31 \\
0.27\end{array}$ & $\begin{array}{l}0.67 \\
0.60 \\
0.56 \\
0.53 \\
0.56\end{array}$ \\
\hline $\mathrm{Ni}$ & 11.72 & 5.64 & 4.73 & $\begin{array}{l}2.0 \\
2.5 \\
3.0 \\
3.5 \\
4.0\end{array}$ & $\begin{array}{l}0.65 \\
0.60 \\
0.54 \\
0.47 \\
0.43\end{array}$ & $\begin{array}{l}0.73 \\
0.75 \\
0.76 \\
0.78 \\
0.79\end{array}$ \\
\hline $\mathrm{Fe}$ & 11.17 & 4.23 & 4.65 & $\begin{array}{l}2.0 \\
2.5 \\
3.0 \\
3.5 \\
4.0\end{array}$ & $\begin{array}{l}0.58 \\
0.56 \\
0.55 \\
0.51 \\
0.45\end{array}$ & $\begin{array}{l}0.69 \\
0.78 \\
0.85 \\
0.86 \\
0.81\end{array}$ \\
\hline Pt & 5.95 & 7.46 & 5.40 & $\begin{array}{l}2.0 \\
2.5 \\
3.0 \\
3.5 \\
4.0\end{array}$ & $\begin{array}{l}0.71 \\
0.67 \\
0.65 \\
0.51 \\
0.49\end{array}$ & $\begin{array}{l}0.93 \\
0.96 \\
0.97 \\
0.98 \\
0.97\end{array}$ \\
\hline $\mathrm{Al}$ & 11.63 & 14.5 & 4.19 & $\begin{array}{l}2.0 \\
2.5 \\
3.0 \\
3.5\end{array}$ & $\begin{array}{l}0.84 \\
0.70 \\
0.45 \\
0.31\end{array}$ & $\begin{array}{l}1.1 \\
0.76 \\
0.58 \\
0.53\end{array}$ \\
\hline
\end{tabular}
(a) Ref. 14
(b) Ref. 15
(c) Ref. 16 


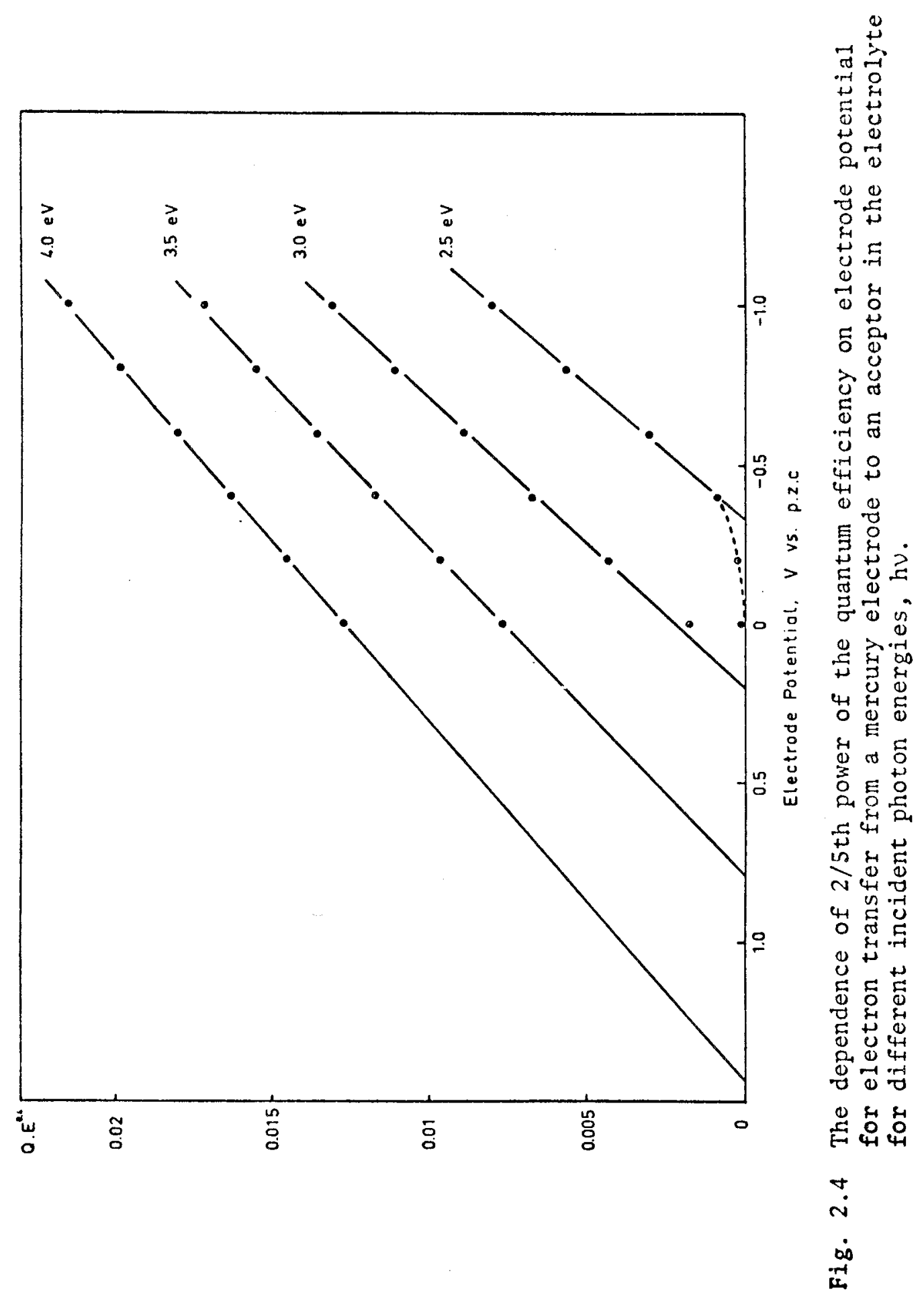


27.

with the experimental one $(3.15 \mathrm{eV})$. The linear behaviour of the

plot of $\left(I_{p}\right)^{2 / 5}$ against potential $V$, and agreement of the extrapolated threshold 1ight energy h $\nu_{0}$ with the experimental one [5], confirms the consistence of the model with experiment and with the $5 / 2$ law for the photocurrent.

\subsubsection{Effect of the Barrier Height}

Photocurrents were calculated using Eq. (2.26) for radiation energy hv $=3.5 \mathrm{eV}$ for arbitrary values of barrier heights from $3.5 \mathrm{eV}$ to $18 \mathrm{eV}$, and it was observed that, in such a range of the values of $U_{m}$, the theory gives rise to the $5 / 21$ aw, and the variation of the threshold energy in this wide range of the $U_{m}$ is negligible (Fig. 2.5).

\subsubsection{Quantum Efficiencies at Several Metal Electrodes}

The quantum efficiencies at several metal electrodes at $-1.0 \mathrm{~V}$ with respect to p.z.c. were calculated by using Eq. $(2.26)$ and the parameters given in Table 2.1 .

The results in Fig. 2.6 show relatively low quantum efficiencies for all metals calculated. A principal reason for this low quantum cificiency is that the photoexcited electrons in a metal seldom reach the surface because of the short mean free path. 
28.

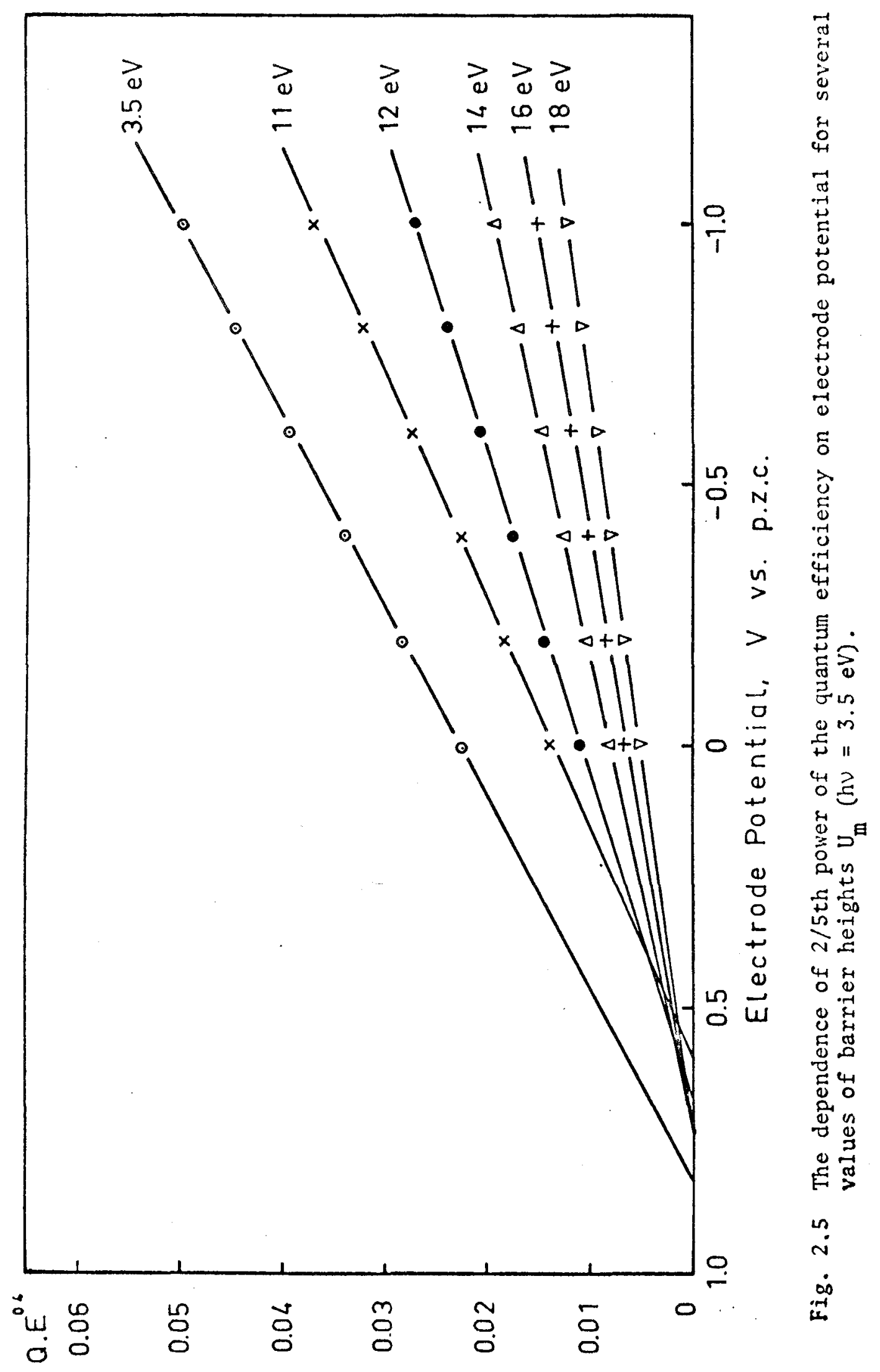


29.

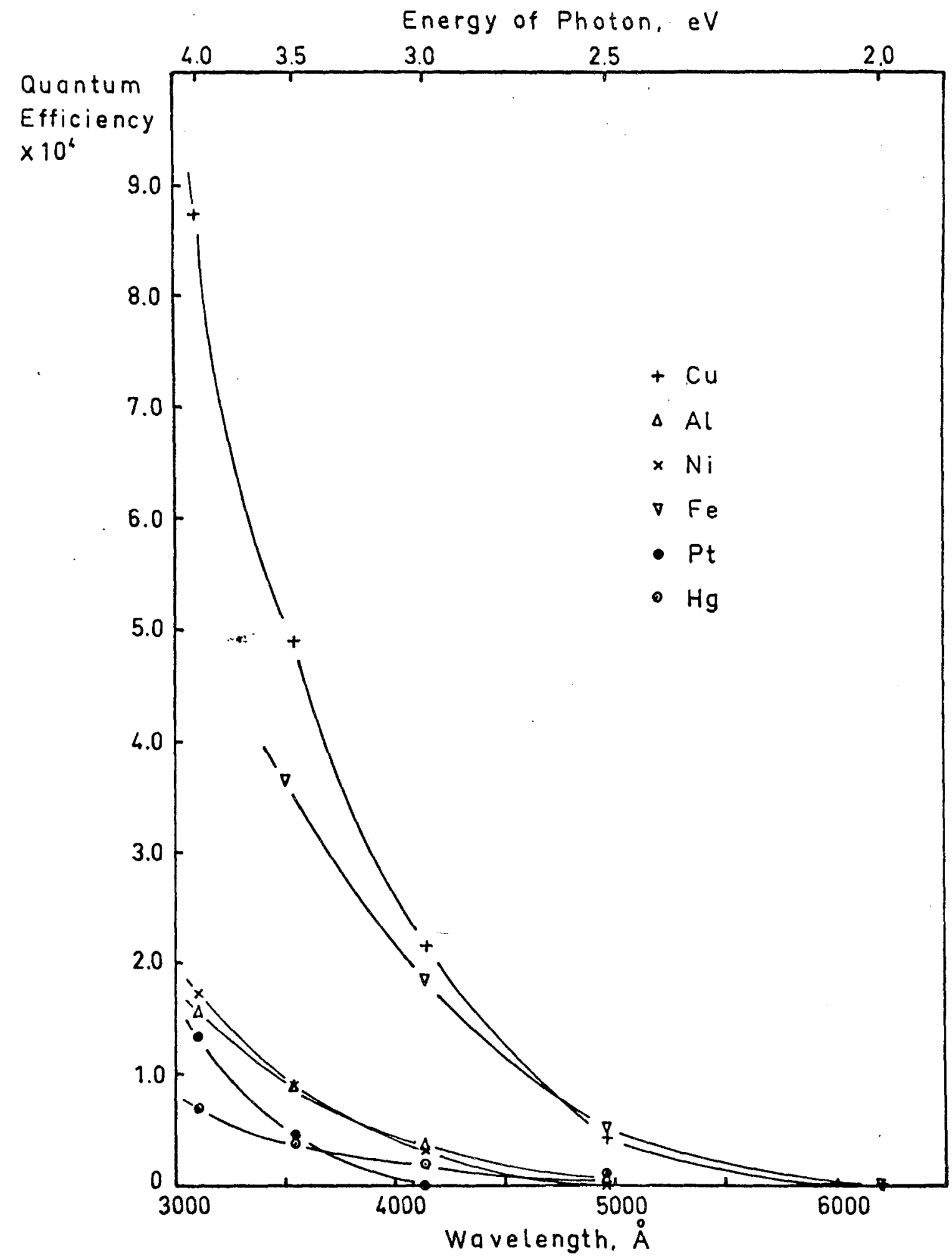

Pig. 2.6 The dependence of the quantum efficiency on wavelength of incident photon for several metals. 
30.

\subsection{CONCLUSION}

1. Photocurrent expressions which took into account the properties of the metal were derived for hydrogen evolution reaction at metal electrodes.

2. The equation was evaluated quantitatively and gave an absolute value of the quantum efficiency. It showed a linear relation between (quantum efficiency) ${ }^{0.4}$ and electrode potential which was also found experimentally. The threshold energy evaluated for $\mathrm{Hg}$ is in fair agreement with experiment. The ability of the equation to represent the $5 / 2 \mathrm{law}$ is insensitive to the change of barrier height.

3. The quantum efficiencies of all metals calculated in this work were relatively low and the reason for the low efficiencies is due to short mean free path. 


\section{BIBLIOGRAPHY OF CHAPTER TWO}

1. G.C. Barker, A.W. Gardner and D.C. Sammon, J. EZectrochem. Soc., 113,1183 (1966).

2. M. Heyrovský, Proc. Roy. Soc. (London), A301, 411 (1967).

3. R. de Levie and J.C. Kreuser, J. EZectroanaZ. Chem., 21, 221 (1969) .

4. Yu. V. Pleskov and R. Rotenberg, J. Electroanal. Chem., 20, 1 (1969).

5. L.I. Korshunov, Ya. M. Zolotovitskii and V.A. Benderskii, Russ. Chem. Rev., 40, 699 (1971).

6. H. Berg, H. Schweiss, E. Stutter and K. Weller, J. ElectroanaZ. Chem., 15, 415 (1967).

7. P. Delahay and V.S. Srinivasan, J. Phys. Chem., 70, 420 (1966) .

8. A.M. Brodsky and Yu. Ya. Gurevich, EZectrochim. Act $\alpha$, 13, 1245 (1968).

9. D.B. Matthews and S.U.M. Khan, Aust. J. Chem., 28, 253 (1975).

10. W.F. Krolikowski and W.E. Spicer, Phys. Rev., 185, 882 (1969).

11. J.I. Pankove, "Optical Processes in Semiconductors", Chap. 13, Prentice-Ha11, Inc., New Jersey (1971) .

12. S.U.M. Khan, Ph.D. Thesis, The Flinders University of South Australia (1976).

13. R.W. Gurney, Proc. Roy. Soc. (London), 134A, 137 (1932).

14. C. Kittel, "Introduction to Solid State Physics", 4th edition, John Wiley and Sons, Inc., New York (1971).

15. S. Trassatti, J. Electroanal. Chem., 33, 351 (1971).

16. NRC of USA, "International Critical Tables", Vol. III, McGraw Hill Book Co., New York (1929). 
CHAPTER THREE

THE THEORY OF HYDROGEN PRODUCTION IN A PHOTOELECTROCHEMICAL CELL 


\section{CHAPTER THREE*}

THE THEORY OF HYDROGEN PRODUCTION IN A

PHOTOELECTROCHEMICAL CELL

\subsection{INTRODUCTION}

As mentioned in chapter one, it is very important to know the relations between properties of semiconductors and photoelectrochemical efficiency. Theoretical analysis is essential for that understanding. Existing theories usually consider only the processes in semiconductors and neglect electrochemical processes [1] .

In this chapter, photoeffects on electrochemical reactions at semiconductor electrodes are considered theoretically in terms of the processes in semiconductors and electrochemical processes. The theoretical photocurrent expressions are derived.

* Submitted for publication to Int. J. Hydrogen Energy (1976). 


\subsection{THE PHOTOEFFECT ON ELECTRODE REACTIONS AT A SEMI- CONDUCTOR SOLUTION INTERFACE}

\subsubsection{The Photoeffect on a Cathodic Current at a p-Type Semiconductor-Solution Interface}

There are many holes in the valence band and few electrons in the conduction band of p-type semiconductors without illumination. Illumination with light, the energy of which is larger than the energy gap of the semiconductor, creates electrons in the conduction band and holes in the valence band. (See Fig. 3.1).

However, since there are many holes in the valence band without illumination and, usually, the number of holes created by light is small compared with the number of holes without light, the values of the anodic current via the valence band with and without illumination are nearly the same. On the other hand, there are almost zero electrons in the conduction band and therefore zero cathodic current via the conduction band without illumination. Consequently, a photoeffect would only be expected via the conduction band and would be cathodic.

We shall consider the hydrogen evolution reaction in acidic solutions. The following step is assumed to be rate determining step $[2,3]$ on the semiconductor concerned:

$$
\text { p-S.C (e) }+\mathrm{H}_{3} \mathrm{O}^{+} \rightarrow \text { p-S.C- }-\mathrm{H}--\mathrm{H}_{2} \mathrm{O}^{*}
$$

* The final state describes the state immediately after the electron transfer, i.e., before the various atoms and molecules relax into their ground vibration-rotation state. Confusion in comparison of this treatment with the treatments of redox systems should be avoided. Thus, in redox systems, there is an optical Born energy because the final state (e.g., $\mathrm{Fe}^{++}\left(\mathrm{H}_{2} \mathrm{O}_{6}\right)$ is the ferrous ion with the unrelaxed solvational environment of the ferric ion. Here, the final state is uncharged. Nevertheless, the present treatment implicitly involves a Born energy (that of $\mathrm{H}_{3} \mathrm{O}^{+}$) but the equilibrium static Born energy, not the optical one, is the relevant quantity. 
34.

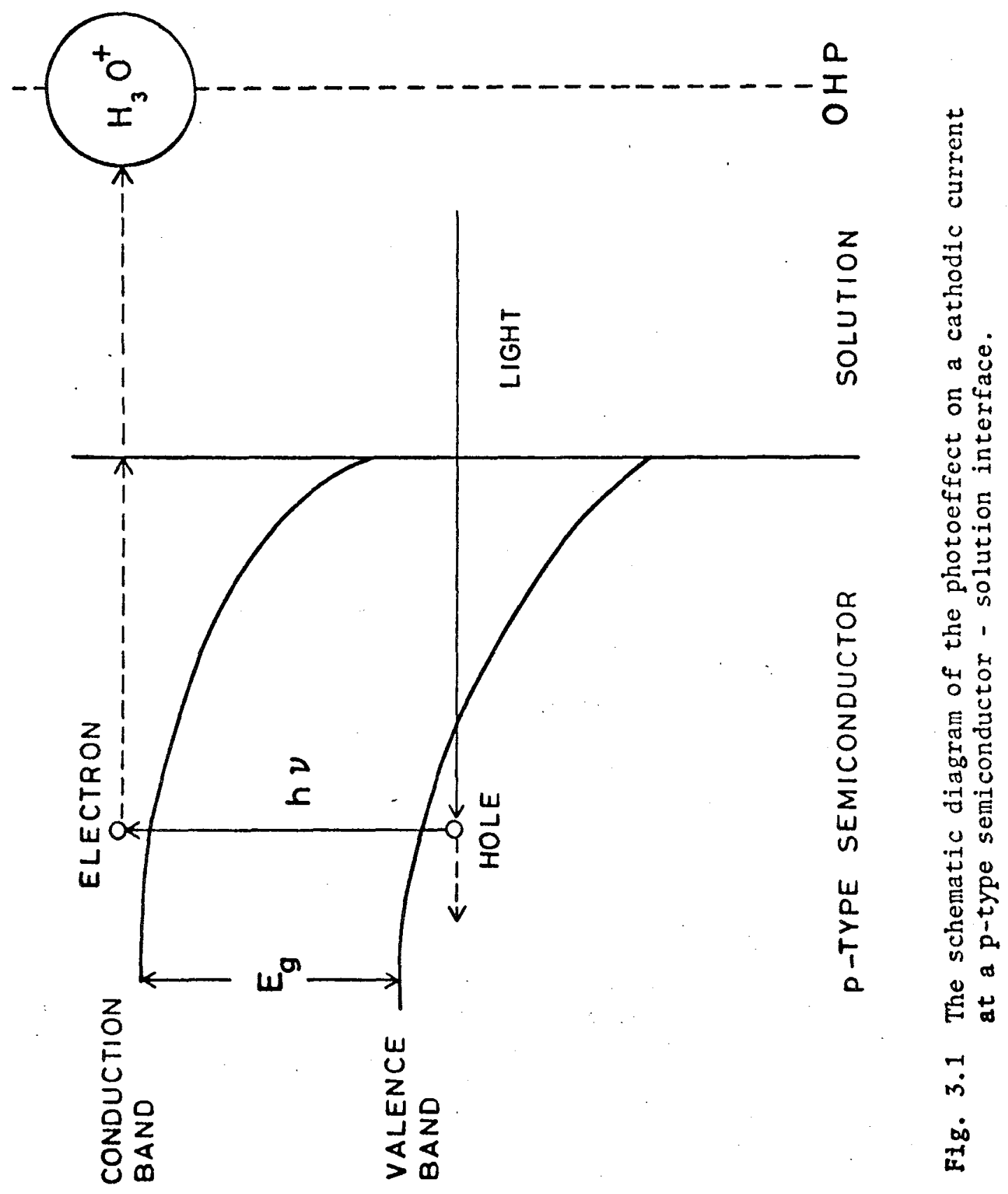


35.

The photocurrent corresponding to this reaction, $i_{p}$, is given by $[3,4]$ :

$$
i_{p}=e_{o} \frac{C_{A}}{C_{T}} \int_{0}^{\infty} N_{e}(E) G_{A}(E) W_{c}(E) d E
$$

where $N_{e}(E)$ is the number of electrons with energy $E$ which strike the semiconductor surface per unit time per unit area; $G_{A}(E)$ is the distribution of vibrational-rotational states of an acceptor, $\mathrm{H}_{3} \mathrm{O}^{+}$, at energy $E$ in the solution; $W_{c}(E)$ is the WKB tunneling probability of electrons through the potential barrier at energy $E ; C_{A}$ is the number of electron acceptors per unit area in the OHP; $\mathrm{C}_{\mathrm{T}}$ is the total number of sites per unit area in the OHP; $e_{0}$ is the electronic charge. Energy levels are taken as zero at the bottom of the conduction band.

\subsubsection{The enthalpy change for electron transfer from semiconductor to $\mathrm{H}_{3} \mathrm{O}^{7}$}

The standard enthalpy change $\Delta H(e)$ for the electron transfer reaction corresponding to Eq. (3.1) from the bottom of the conduction band of the semiconductor to the proton, when the proton-solvent system is in its ground state, can be obtained by using the following thermodynamic cycle:

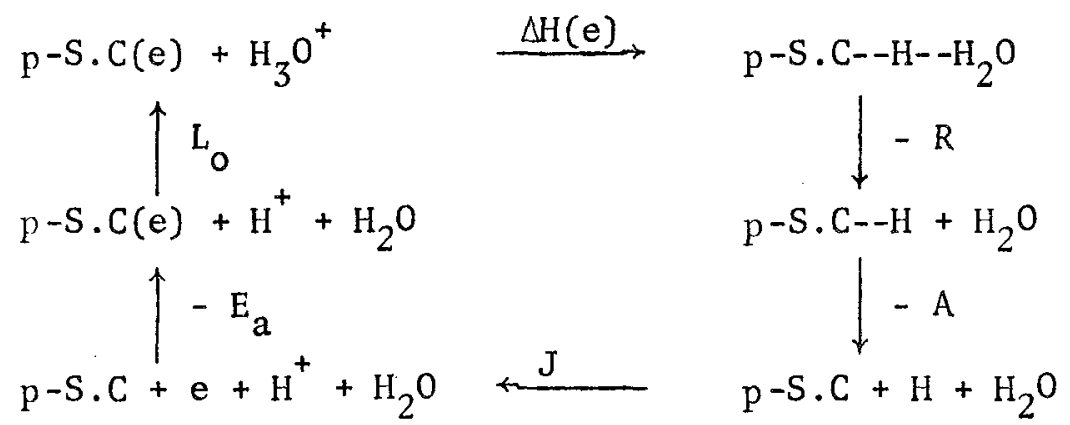

where $\mathrm{R}, \mathrm{A}, \mathrm{J}, \mathrm{E}_{\mathrm{a}}$ and $\mathrm{L}_{\mathrm{o}}$ represent the $\mathrm{H}-\mathrm{H}_{2} \mathrm{O}$ repulsive force, the heat of adsorption of a hydrogen atom on the semiconductor, the ionization potential of the hydrogen atom, the electron affinity of 
36.

the semiconductor and the hydration energy of proton, respectively. Therefore,

$$
\Delta H(e)=-L_{0}+E_{a}-J+A+R
$$

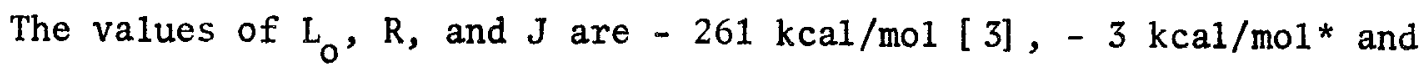
$313 \mathrm{kcal} / \mathrm{mol}[3]$, respectively. The value of $\mathrm{E}_{\mathrm{a}}$ is from $78 \mathrm{kcal} / \mathrm{mol}$ to $115 \mathrm{kcal} / \mathrm{mol}$ depending on the semiconductor [6]. The value of $\mathrm{A}$ is estimated as $-6 \mathrm{kcal} / \mathrm{mol} \sim-7 \mathrm{kcal} / \mathrm{mol}$ depending on the semiconductor (Appendix 3.1) ${ }^{\dagger}$. Therefore, the estimated value of $\Delta H(\mathrm{e})$ is from $16 \mathrm{kcal} / \mathrm{mol}$ to $54 \mathrm{kca} 1 / \mathrm{mol}$.

\subsubsection{Photon absorption step [4]}

Let it be supposed that the semiconductor is illuminated normal to the surface. The number of photons absorbed by the semiconductor between $x$ and $x+d x$ from the surface, $N_{p h}(x) d x$, is given by:

$$
N_{p h}(x) d x=I_{o}(1-R) \alpha_{p h} e^{-\alpha} p h x
$$

where $I_{0}$ is the total number of photons of incident light $\left(\mathrm{cm}^{-2} \mathrm{sec}^{-1}\right)$; $R$ is the reflectivity of the semiconductor; $\alpha_{p h}$ is the absorption coefficient of the semiconductor at the wavelength $\lambda\left(\mathrm{cm}^{-1}\right)$.

\subsubsection{The creation of excited electrons}

Each absorbed photon, the energy of which is greater than the energy gap of the semiconductor, makes an excited electron in the conduction band and a hole in the valence band (see Fig. 3.1). The

\footnotetext{
* The value for the $\mathrm{H}$ atom in ice [5].

The small variation arises from the presence of the electrode in solution, i.e., it results from the presence of adsorbed water molecules on the electrode.
} 
37.

number of excited electrons, the energy of which is between $E$ and $E+d E$ in the conduction band, between $x$ and $x+d x, N_{e}(E, x) d x d E$, is given by [4]:

$$
N_{e}(E, x) d x d E=N_{p h}(x) d x \frac{\rho(E, x)\{1-f(E)\} \rho(E-h \nu, x) f(E-h \nu) d E}{\int_{E}^{\infty} \rho(E, x)\{1-f(E)\} \rho(E-h \nu, x) f(E-h \nu) d E}
$$

i.e. from Eq. (3.4)

$$
=I_{0}(1-R) \alpha_{p h} e^{-\alpha} p h{ }^{x} \frac{S(E, x)\{1-f(E)\} S(E-h \nu, x) f(E-h \nu)}{\int_{E_{c}, x}^{\infty} S(E, x)\{1-f(E)\} S(E-h \nu, x) f(E-h \nu) d E}-d x d E
$$

where $E_{c, x}$ is the energy of the bottom of the conduction band at $x$ and $\rho(E, x)$ is the density of states at $E$ at $x$ and given by [7]

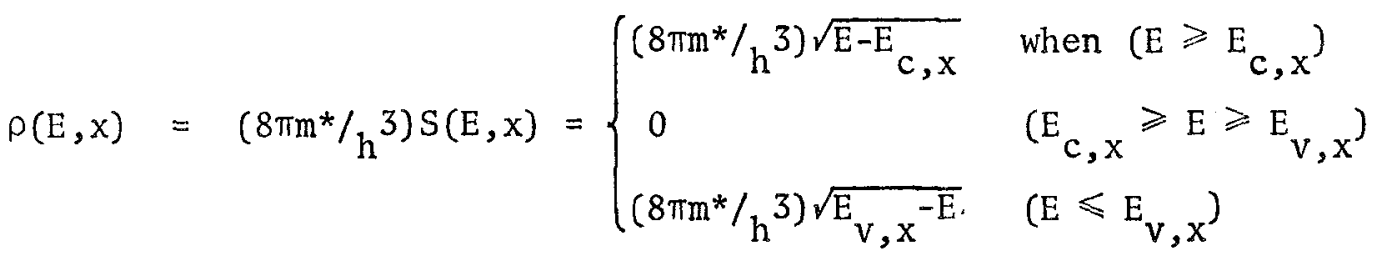

$f(E)$ is the Fermi distribution function; where $m^{*}$ is the effective mass of the electron in the semiconductor.

\subsubsection{Potential profile in a p-type semiconductor}

The excitation of electrons in the semiconductors has not only an energy but also a spatial aspect. The objective of the present work is to obtain the number of electrons excited by light which reach the electrode surface. The number of excited electrons which do this depends not only on the gradient of the chemical potential of the 
38.

excited electrons in conduction band but also on the field. This in turn depends on the potential gradient inside the semiconductor. Thus, it is important to know the potential gradient as a function of the distance from the electrode surface.

The potential-distance profile inside a semiconductor may be obtained by solving Poisson's equation (3.7).

$$
\frac{d^{2} v_{x}}{d x^{2}}=-\frac{4 \pi e_{0}}{\varepsilon}\left[p_{0} \exp \left\{-\frac{e_{0}\left(V_{x}-V_{B}\right)}{k T}\right\}-n_{0} \exp \left\{\frac{e_{0}\left(V_{x}-V_{B}\right)}{k T}\right\}+N_{D}-N_{A}\right]
$$

where $e_{0}$ is the electronic charge; $\varepsilon$ is the dielectric constant of the semiconductor; $\mathrm{p}_{\mathrm{O}}, \mathrm{n}_{\mathrm{O}}$ and $\mathrm{V}_{\mathrm{B}}$ are, respectively, the concentration of holes and electrons and the potential in the bulk of the semiconductor in the region beyond the space charge (when $x \rightarrow \infty$ ),$V_{x}$ is the potential at $x ; N_{D}$ and $N_{A}$ are the concentrations of donor levels and acceptor levels, respectively (all values are expressed by Gaussian system of units). The donors and the acceptors are assumed to be completely ionized and immobile.

Evaluation gives the following equation from Eq. (3.7) [8]

$$
\frac{d V_{x}}{d x}= \pm \sqrt{\frac{8 \pi k T}{\varepsilon}\left[-\left(N_{D}-N_{A}\right) y+p_{0}\left(e^{-y}-1\right)+n_{0}\left(e^{y}-1\right)\right]}
$$

where $y$ represents

$$
y=\frac{e_{0}\left(V_{x}-V_{B}\right)}{k T}
$$

The plus sign appears in front of the root when $y<0$ and the minus when $y>0$. Kingston and Neustäter calculated the electric field at the surface by using this equation [9]. Numerical solutions have been found for $\mathrm{V}$ as a function of $\mathrm{x}$. Typical results are shown in Fig. 3.2. The parameters used in the calculation are $\mathrm{N}_{\mathrm{A}}=\mathrm{p}_{\mathrm{O}}=10^{15}$ 


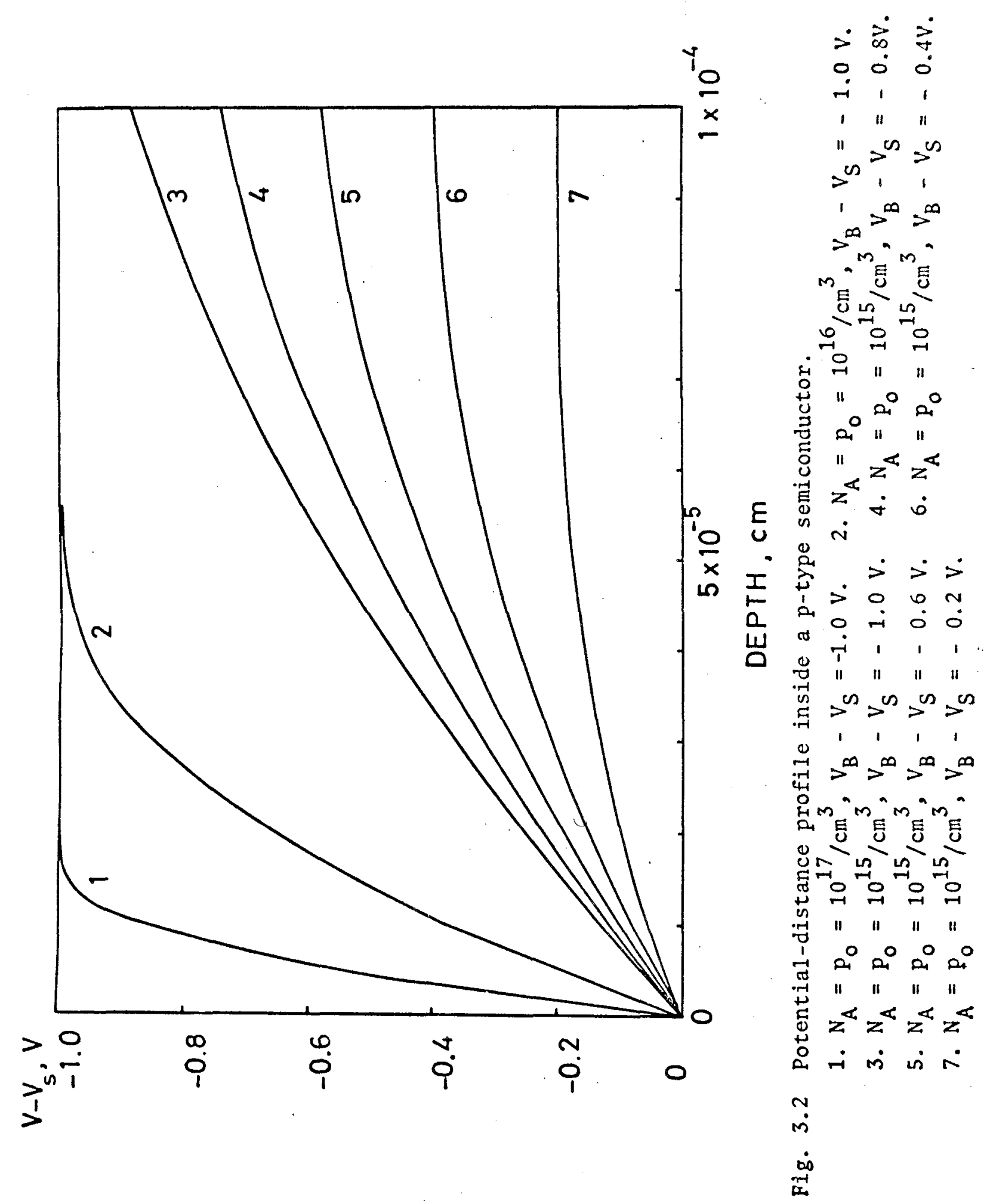


40.

$\sim 10^{17} / \mathrm{cm}^{3} ; \quad \mathrm{N}_{\mathrm{D}}=\mathrm{n}_{\mathrm{o}}=0 / \mathrm{cm}^{3} ; \quad \varepsilon=20.0$ and $\mathrm{V}_{\mathrm{B}}-\mathrm{V}_{\mathrm{S}}=0-1.0 \mathrm{~V}$, where $V_{B}$ and $V_{S}$ are the potential in the bulk and at the surface of semiconductor, respectively.

3.2.1.5 Number of excited electrons arriving at the surface

The number of photo-excited electrons, originally expressed for $x=x$ in $E q .(3.5)$, decreases to $N_{e, x=x-d x}(E, x) d x d E$ given by Eq. (3.10), after traveling $\mathrm{dx} . *$

$$
N_{e, x=x-d x}(E, x) d x d E=N_{e}(E, x) e^{-\frac{1}{L(x)} d x} d x d E
$$

where $L(x)$ is the mean free path of electrons at $x$ and is given by $[10]$

$$
L(x)=\frac{2 \ell_{D}^{2}}{\sqrt{\ell_{E}^{2}+4 \ell_{D}^{2}}-\ell_{E}}
$$

where $l_{D}$ is the diffusion length and $l_{E}$ is the drift length. The terms $\ell_{D}$ and $\ell_{E}$ are given by

$$
\begin{aligned}
& l_{D}=\sqrt{D \tau_{e}}=\sqrt{300 \mu_{e}} \overline{\tau_{e} k T / e_{o}} \\
& l_{E}=\tau_{e} \mu_{e} V^{\prime}(x)
\end{aligned}
$$

respectively, where $\mu_{\mathrm{e}}$ is the mobility of the electron in the semiconductor $\left(\mathrm{cm}^{2} / \mathrm{V} \cdot \mathrm{sec}\right), \tau_{e}$ is the life time of the electron and $V^{\prime}(x)$ is the potential drop at $x\left(=(\mathrm{dV} / \mathrm{dx})_{\mathrm{x}} ; \operatorname{Volt} / \mathrm{cm}\right) . \quad \mathrm{k}$ and $e_{0}$ are in $\mathrm{cgs}$ units.

* In the case of metal electrode (chapter two), the actual travel length of electron was considered as $x \sqrt{E / E_{x}}$. In this case, however, the actual travel length was assumed as $x$, because of the existence of a very strong field inside the semiconductor. Thus, it is assumed that the field accelerate all the electrons produced into the $x$ direction. 
41.

When $V^{\prime}(x)=0, L(x)$ becomes $l_{D}$ and when $V^{\prime}(x)$ is sufficiently high, $\ell_{E} \gg \ell_{D}$, and $L(x)$ becomes $\ell_{E}$ (Fig. 3.3). Here, $L$ changes after travelling $d x$ corresponding to a change of $V^{\prime}(x)$.

Similarly,

$$
\begin{aligned}
N_{e, x=x-2 d x}(E, x) d x d E & =N_{e, x=x-d x}(E, x) e^{-\frac{1}{L(x-d x)} d x} d x d E \\
& =N_{e}(E, x) e^{-\left(\frac{1}{L(x)}+\frac{1}{L(x-d x)}\right) d x} d x d E \\
N_{e, x=x-3 d x}(E, x) d x d E & =N_{e, x=x-2 d x}(E, x) e^{-\frac{1}{L(x-2 d x)} d x} d x d E \\
& =N_{e}(E, x) e^{-\left(\frac{1}{L(x)}+\frac{1}{L(x-d x)}+\frac{1}{L(x-2 d x)}\right) d x} d x d E
\end{aligned}
$$

and so on.

After $N$ steps $(N=x / d x)$,

$$
\begin{aligned}
N_{e, x=0}(E, x) d x d E & =N_{e, x=d x}(E, x) e^{-\frac{1}{L(d x)} d x} d x d E \\
& =N_{e}(e, x) \exp \left\{-\left(\frac{1}{L(x)}+\frac{1}{L(x-d x)}+\cdots+\frac{1}{L(d x)}\right) d x\right\} d x d E
\end{aligned}
$$

$\mathrm{N}_{\mathrm{e}, \mathrm{x}=0}(\mathrm{E}, \mathrm{x}) \mathrm{dxdE}$ gives the number of electrons arriving at the surface per unit area per unit time which were excited between $x$ and $x+d x$ and the energy of which is between $E$ and $E+d E$.

Therefore, the total number of electrons, $N_{e}(E) d E$, which has an energy between $E$ and $E+d E$ at the surface is given by

$$
N_{e}(E) d E=\int_{0}^{\infty} N_{e, x=0}(E, x) d x d E
$$


42.

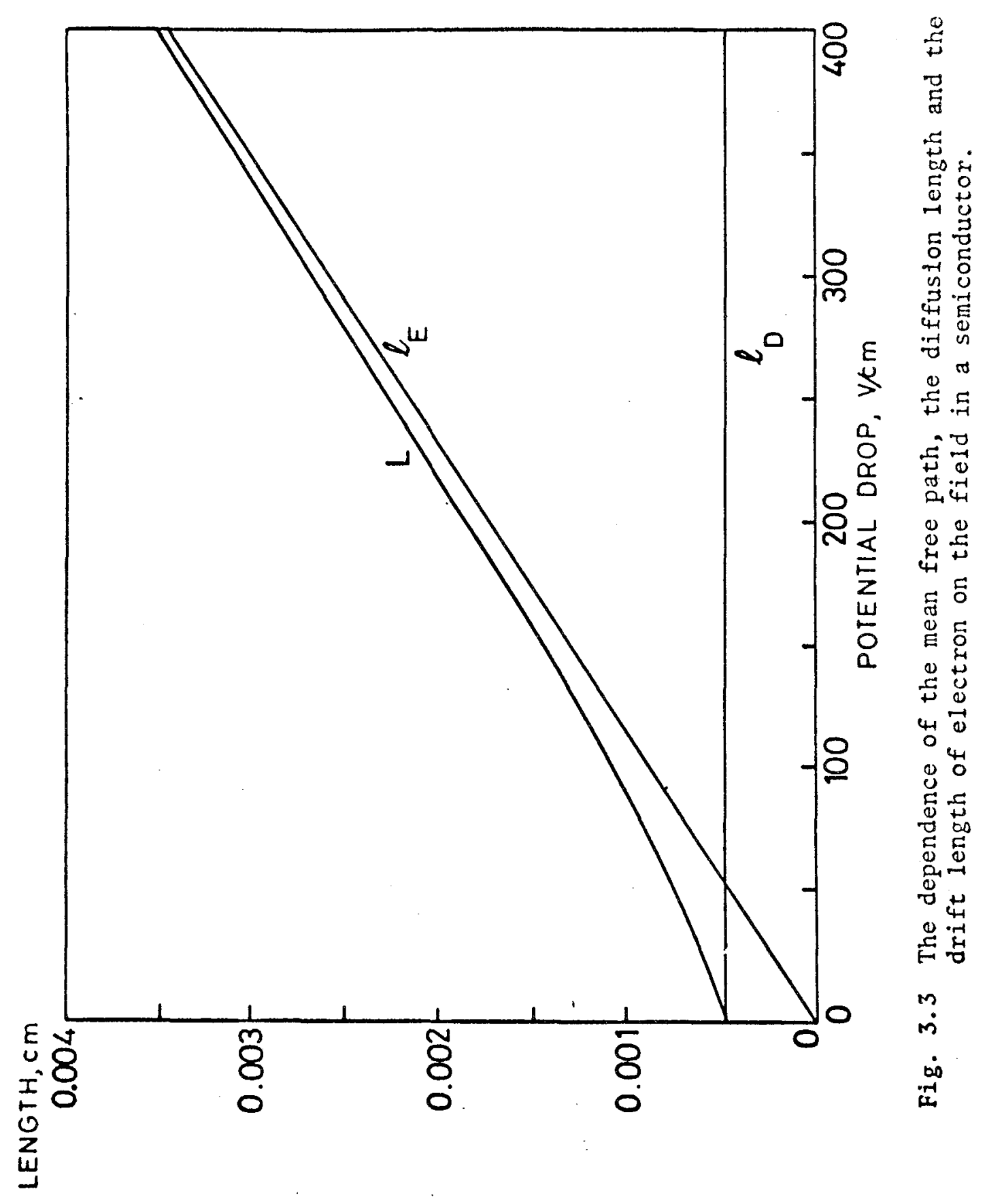




\subsubsection{Electron transfer process}

(a) Construction of the potential energy barrier

The potential energy barrier for electron transfer from the semiconductor to an acceptor in the OHP is constructed as follows:

(i) Interaction of an electron with the dipole potential of adsorbed water

The work required for the emitted electron to cross the adsorbed water layer is given as the negative value of the surface potential made by those waters, multiplied by the electronic charge. Since we assume (initially) that the concentration of surface state is less than $10^{14} /$ $\mathrm{cm}^{2}$, the surface charge on the electrode, even under cathodic polarization, is almost zero [11]. The surface potential due to adsorbed water dipoles at the potential of zero charge was calculated by Bockris and Habib [12] and is $0.03 \sim 0.04$ at $\mathrm{Hg}, \mathrm{Cd}$ and $\mathrm{Zn}$ electrodes. The width of the water barrier is the diameter of the water molecule, i.e., $2.76 \AA$.

\section{(ii) Interaction with ions in the OHP and their images}

When a photoexcited electron leaves the semiconductor surface, it interacts with all ions in the OHP and their electrical images in the semiconductor. The Coulombic force between this electron ( $x$ from electrode) and all ions in OHP and their images, $F(x)$, is given by

$$
\begin{aligned}
F(x)= & -\frac{e_{o}^{2}}{(d-x)^{2} \varepsilon_{o p}}+\frac{e_{o}^{2}}{(d+x)^{2} \varepsilon_{o p}} \frac{\varepsilon-\varepsilon_{o p}}{\varepsilon+\varepsilon_{o p}} \\
& -\frac{2 \pi e_{o}^{2}}{\varepsilon_{o p}} \sum_{n=1}^{\infty} n\left(\frac{1}{(d-x)^{2}+n^{2} R_{i}^{2}}-\frac{1}{(d+x)^{2}+n^{2} R_{i}^{2}} \frac{\varepsilon-\varepsilon_{o p}}{\varepsilon+\varepsilon_{o p}}\right)
\end{aligned}
$$

where $d$ is the distance between the semiconductor surface and OHP, 
44.

$\varepsilon_{\text {op }}$ is the optical dielectric constant of water, $n=1,2,3 \ldots$ and represents the succession of rings of ions around a given central ion, and $R_{i}$ is the distance between two ions in the OHP, depending on its coverage with ions and determined by $R_{i}=4 r_{i} /(\pi \theta)^{\frac{1}{2}}$, where $\theta$ is the coverage and $r_{i}$ is the radius of the ions.

The potential energy of an electron at $x$ due to this force, $U_{\text {ion }}(x)$, is given by:

$$
U_{\text {ion }}(x)=\int_{0}^{x} F(x) d x
$$

and this value is obtained by numerical integration.

\section{(iii) Optical Born energy of the electron}

In the region of water outside that of the layer attached to the electrode, it is difficult to calculate the electron interaction with the water upon a modelistic basis. It is possible to estimate the energy of an electron with respect to vacuum when it has entered this water layer by the use of the Born equation, with an optical dielectric constant:

$$
U_{o p t . B o r n}=-\frac{\dot{e}_{o}^{2}}{2 r_{c}}\left[1-\frac{1}{\varepsilon_{o p}}\right]
$$

The value of $r_{c}$ in this equation is taken from the S.C.F. calculations of Fueki et al. as $1 \AA$ [13]. On this basis, the value of $\mathrm{U}_{\mathrm{opt} . \text { Born }}$ is $-3.2 \mathrm{eV}$.

(iv) Calculation of the Barrier Maximum

According to these considerations, the potential energy of the electron with respect to the bottom of the conduction band is giver: by

$$
\mathrm{U}=\mathrm{E}_{\mathrm{a}}+\mathrm{U}_{\mathrm{H}_{2} \mathrm{O}}+\mathrm{U}_{\text {ion }}+\mathrm{U}_{\text {opt.Born }}
$$


45.

where $\mathrm{U}_{\mathrm{H}_{2} \mathrm{O}}$ is the interaction energy between an electron and an adsorbed water dipole layer. A potential energy profile based on these considerations is given as a function of distance in Fig. 3.4, assuming $\mathrm{d}$ is $6.5 \%[14]$ in Eq. (3.18). The dimensions of the barrier can also be seen in this figure. The maximum value of the barriex height, $U_{\max }$, depends on the electron affinity of the semiconductor, $\mathrm{E}_{\mathrm{a}}$, and is given (in $\mathrm{eV}$ ) by:

$$
\mathrm{U}_{\max }=\mathrm{E}_{\mathrm{a}}-0.2
$$

(b) The equation for the photocurrent

The equation for the current density may then be divided into three parts (see Fig. 3.4).

In section A of this figure, the photoelectrons pass through the barrier and are accepted by the $\mathrm{H}_{3} \mathrm{O}^{+}$ions in solution. The equation for this section, $i_{p, A}$ is given by:*

$$
\begin{aligned}
i_{p, A} & =e_{0} \frac{C_{A}}{C_{T}} \int_{0}^{\Delta H(e)} N_{e}(E) G_{A}(E) W_{c}(E) d E \\
& =e_{0} \frac{C_{A}}{C_{T}}\left\{\int_{0}^{\Delta H(e)} N_{e}(E) \exp \{-B(\Delta H(e)-E) / k T\} \exp \left\{-\frac{\pi^{2} l}{h} \sqrt{2 \operatorname{mi}\left(U_{\max }-E\right)}\right\} d E\right\}
\end{aligned}
$$

where $N_{e}(E)$ is given in Section 3.2.1.5, l is barrier width. In section $B$, the photo-electrons do not find acceptor state in $\mathrm{H}_{3} \mathrm{O}^{+}$ but in water. The current density for the B region is represented

* The justification for $\beta$ in Eq. (3.23) can be seen by studying the potential energy diagrams in Matthews and Bockris [3], which show the effect of the repulsive energy between, e.g., $\mathrm{H}$ and $\mathrm{H}_{2} \mathrm{O}$ in the neutralization of $\mathrm{H}_{3} \mathrm{O}^{+}$. 


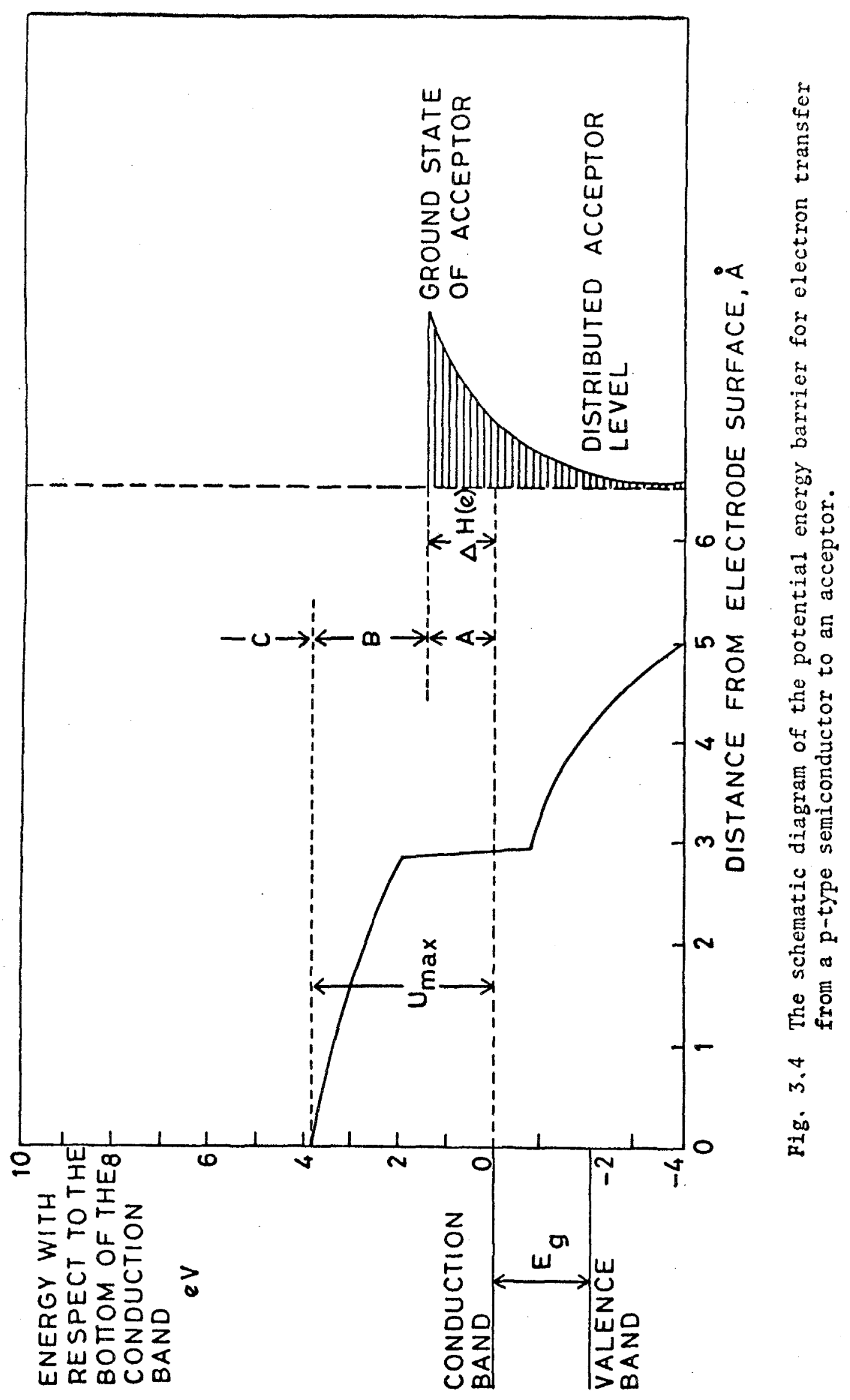


by:*

$i_{p, B}=e_{o} \frac{C_{A}}{C_{T}}\left\{\int_{\Delta H(e)}^{U_{\max }} N_{e}(E) W_{c}(E) d E\right\}=e_{o} \frac{C_{A}}{C_{T}} \iint_{\Delta H(e)}^{U_{\max }} N_{e}(E) \exp \left\{-\frac{\pi^{2} \ell \sqrt{2 m\left(U_{\max }-\mathrm{E}\right)}}{h}\right\} d E$

Finally, some photo-electrons may pass over the barrier and into the solvent water (section $\mathrm{C}$ ), and the current density from this contribution is given by:

$$
i_{p, C}=e_{0} \frac{C_{A}}{C_{T}}\left\{\int_{U_{\max }}^{\infty} N_{e}(E) d E\right\}
$$

In total, the photocurrent is given by

$$
i_{p}=i_{p, A}+i_{p, B}+i_{p, C}
$$

\subsubsection{The Photoeffect on the Anodic Current at n-Type Semiconductors}

There are many electrons in the conduction band and few holes in the valence band of an n-type semiconductor without illumination. Illumination, the energy of which is larger than the energy gap of the semiconductor, creates holes in the valence band and electrons in the conduction band.

However, since there are many electrons in the conduction band without illumination and, usually, the number of electrons created by light is small compared with the number of electrons without illumination, the value of the cathodic current via the conduction band with illumination and without illumination are almost the same. On the

* These electrons pass through the barrier to a state of equal total energy to that which they had in the semiconductor. They then lose their kinetic energy by inelastic collision with the solvent, and finally react with $\mathrm{H}_{3} \mathrm{O}^{+}$in the solution bulk. 
other hand, there is almost zero holes in the valence band and, hence, the anodic current via the valence band is zero without illumination. Consequently, a photoeffect on the anodic current via the valence band would be 1 arge.

The mechanism of anodic reactions is less well known than that of cathodic reactions. One complication is that there may be two reactions corresponding to the anodic current. One is the anodic dissolution of the semiconductor itself and another is the oxidation of a species, e.g., $\mathrm{OH}^{-}$, water, halogen ion, in the solution.

Let it be supposed that the anodic current corresponds to the oxidation of $\mathrm{OH}^{-}$and water and that the rate determining steps are:

$$
\begin{aligned}
& \text { n-S.C (hole) }+\mathrm{OH}_{\mathrm{aq}}^{-} \rightarrow \mathrm{n}-\mathrm{S} . \mathrm{C}--\mathrm{OH}--\mathrm{H}_{2} \mathrm{O} \\
& \mathrm{n}-\mathrm{S} . \mathrm{C}(\text { hole })+\mathrm{H}_{2} \mathrm{O} \rightarrow \mathrm{n}-\mathrm{S} \cdot \mathrm{C}--\mathrm{OH}--\mathrm{H}_{3} \mathrm{O}^{+}
\end{aligned}
$$

\subsubsection{The estimation of the standard enthalpy change for electron transfer from the donor to a hole in the valence band}

The standard enthalpy change, $\Delta H_{1}^{\prime}(e)$, for an electron transfer reaction corresponding to Eq. (3.27) from the electron level of the hydroxyl ion to the top of the valence band of the semiconductor, when the hydroxyl ion-solvent system is in its ground state, will be obtained using the following thermodynamic cycle:

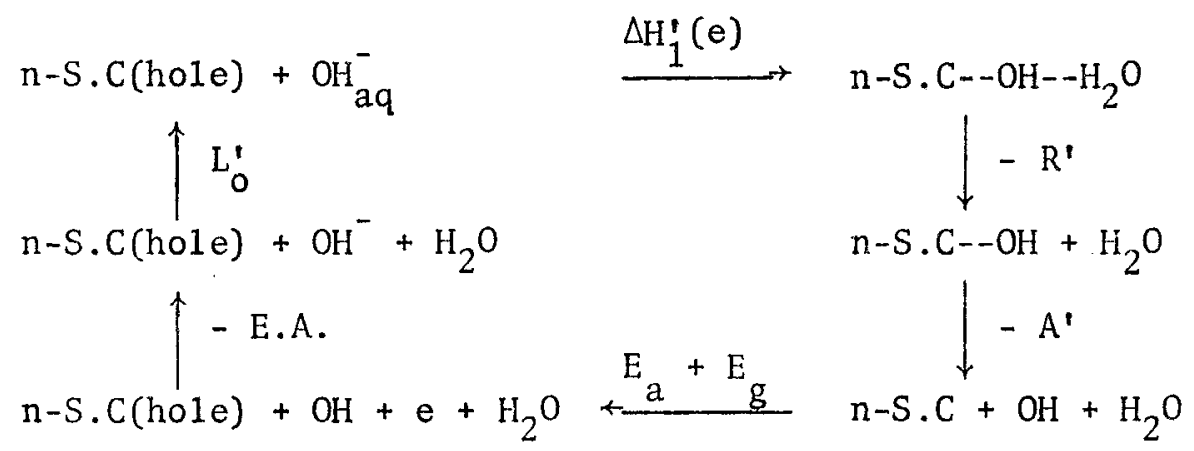


49.

where $A^{\prime}, R^{\prime}, E_{.} A ., E_{a}, L_{o}^{\prime}$ and $E_{g}$ represent the heat of adsorption of an $\mathrm{OH}$ group on the semiconductor, $\mathrm{OH}-\mathrm{H}_{2} \mathrm{O}$ repulsive force, the electron affinity of the $\mathrm{OH}$ group, the electron affinity of the semiconductor, the hydration energy of hydroxy1 ion, and the energy gap of the semiconductor, respectively.

Therefore,

$$
\Delta \mathrm{H}_{1}^{\prime}(\mathrm{e})=-\mathrm{L}_{\mathrm{o}}^{\prime}+\mathrm{E} \cdot \mathrm{A}-\mathrm{E}_{\mathrm{a}}-\mathrm{E}_{\mathrm{g}}+\mathrm{A}^{\prime}+\mathrm{R}^{\prime}
$$

The values of $R^{\prime}, L_{o}^{\prime}$ and E.A are $-3 \mathrm{kcal} / \mathrm{mol}^{*},-87 \mathrm{kcal} / \mathrm{mol}$ [15] and $42 \mathrm{kcal} / \mathrm{mol}$ [16], respectively. The value of $\mathrm{E}_{\mathrm{a}}$ is from $78 \mathrm{kcal} / \mathrm{mol}$ to $115 \mathrm{kcal} / \mathrm{mol}$ depending on the semiconductor [6]. Although the value of $\mathrm{E}_{\mathrm{g}}$ can vary over a wide range, a value from $23 \mathrm{kcal} / \mathrm{mol}$ to $69 \mathrm{kcal} / \mathrm{mol}$ is a reasonable range of choice for this purpose because too low an $\mathrm{E}_{\mathrm{g}}$ makes a short life time of created minority carriers and too large an $\mathrm{E}_{\mathrm{g}}$ makes no photon absorption in the solar spectrum range. The value of $A^{\prime}$ is taken as from $-3 \mathrm{kcal} / \mathrm{mol}$ to $-4 \mathrm{kcal} / \mathrm{mol}$. (See Appendix 3.2). Therefore, the estimated value of $\Delta \mathrm{H}_{1}^{\prime}(\mathrm{e})$ is from $-62 \mathrm{kcal} / \mathrm{mol}$ to $22 \mathrm{kcal} / \mathrm{mol}$. Similarly, the standard enthalpy change $\Delta \mathrm{H}_{2}^{\prime}(\mathrm{e})$ for an electron transfer reaction corresponding to Eq. (3.28) from the electron level of the water molecule to the top of the valence band of the semiconductor, when the $\mathrm{H}-\mathrm{OH}$ bond system is in its ground state will be obtained using the following thermodynamic cycle:

* See Section 3.2.1.1. 
50 .

$\mathrm{n}-\mathrm{S} . \mathrm{C}($ hole $)$
\[ -\mathrm{H}_{2} \mathrm{O} \text { aq } \]
$-\mathrm{E}_{\text {vap }}$

$\mathrm{n}-\mathrm{S} . \mathrm{C}($ hole $)+\mathrm{H}_{2} \mathrm{O}$ gas $+\mathrm{H}_{2} \mathrm{O}$ aq

$\uparrow-\mathrm{E}_{\text {Diss }}$

n-S.Chole $+\mathrm{H}+\mathrm{OH}+\mathrm{H}_{2} \mathrm{O}$ aq<smiles>[Tl]C1CCCC1</smiles>

$\mathrm{n}-\mathrm{S} \cdot \mathrm{C}($ hole $)+\mathrm{H}^{+}+\mathrm{OH}+\mathrm{e}+\mathrm{H}_{2} \mathrm{O}$ aq

$$
\Delta \mathrm{H}_{2}^{\prime}(\mathrm{e})
$$

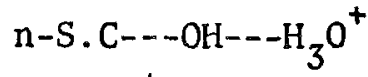

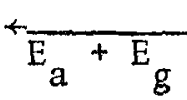

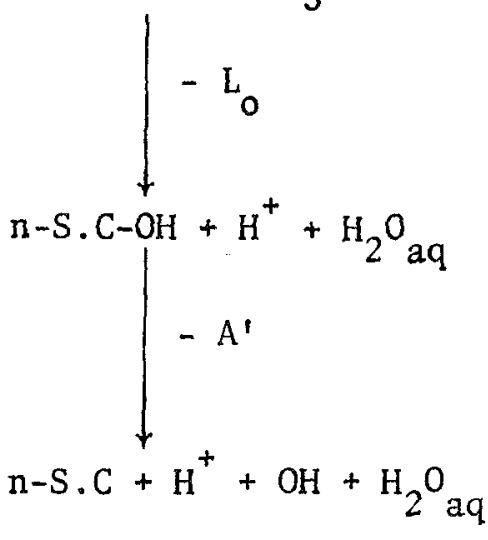

$\mathrm{n}-\mathrm{S} \cdot \mathrm{C}-\mathrm{OH}+\mathrm{H}^{+}+\mathrm{H}_{2} \mathrm{O}$ aq

$-A^{\prime}$

where $L_{0}, A^{\prime}, E_{a}, E_{g}, J, E_{D i s s}$ and $E_{v a p}$ represent hydration energy of proton, heat of adsorption of $\mathrm{OH}$ group on the semiconductor, the electron affinity of the semiconductor, the energy gap of the semiconductor, the ionization potential of hydrogen atom, the dissociation encrgy of water in gas phase and the heat of vaporization, respectively. Therefore,

$$
\Delta H_{2}^{\prime}(e)=L_{0}+A^{\prime}-E_{a}-E_{g}+J+E_{D i s s}+E_{v a p}
$$

The value of $\mathrm{L}_{\mathrm{o}}, \mathrm{J}, \mathrm{E}_{\mathrm{Diss}}$ and $\mathrm{E}_{\text {vap }}$ are $-261 \mathrm{kcal} / \mathrm{mol}[3] ; 313 \mathrm{kcal} / \mathrm{mol}$ [3], $119 \mathrm{kcal} / \mathrm{mol}$ [17] and $10.4 \mathrm{kcal} / \mathrm{mol}$ [18], respectively. The value of $\mathrm{E}_{\mathrm{a}}$ is from $78 \mathrm{kcal} / \mathrm{mol}$ to $115 \mathrm{kcal} / \mathrm{mol}$, depending on the semiconductor [6]. Although the value of $E_{g}$ can vary in wide ranges, the value from $23 \mathrm{kcal} / \mathrm{mol}$ to $69 \mathrm{kcal} / \mathrm{mol}$ is chosen because of the reason as mentioned above. Also, the value from $-3 \mathrm{kcal} / \mathrm{mol}$ to $-4 \mathrm{kcal} / \mathrm{mol}$ is taken for $A^{\prime}$ for reasons mentioned before. Therefore, the estimated value of $\Delta \mathrm{H}_{2}^{\prime}(\mathrm{e})$ is from $-7 \mathrm{kcal} / \mathrm{mol}$ to $83 \mathrm{kcal} / \mathrm{mol}$.

\section{2 .2 .2 The creation of holes}

Each photon, the energy of which is greater than the energy gap of the semiconductor, creates an electron in the conduction band and a hole in the valence band. The number of created holes, the energy of 
which is between $(E-h \nu)$ and $(E-h \nu)+d E$ in the valence band and at distances from the electrode surface between $x$ and $x+d x, N_{h}(E-h \nu, x) d x d E$, is equal to the number of created electrons the energy of which is between $E$ and $E+d E$ in the conduction band and at a distance between $x$ and $x+d x, N_{e}(E, x) d x d E$. Hence, using Eq. (3.5), $N_{h}(E, x) d x d E$ is given by

$$
N_{h}(E, x) d x d E=I_{0}(1-R) \alpha_{p h} e^{-\alpha} p h \frac{S(E+h \nu, x)\{1-f(E+h \nu)\} S(E, x) f(E)}{\int_{\infty}^{E} v, x(E(E+h \nu, x)\{1-f(E+h \nu)\} S(E, x) f(E) d E} d x d E
$$

where $\mathrm{E}_{\mathrm{v}, \mathrm{x}}$ is the energy of the top of the valence band at $\mathrm{x}$ from the e1ectrode surface.

\subsubsection{The potential energy profiles in n-type semiconductor}

Eq. (3.8) and (3.9) are applicable to an n-type semiconductor.

\subsubsection{The number of holes arriving at the surface}

The number of holes at the surface, the energy of which is between $E+d E$, is given in a similar way to that of electrons discussed in section 3.2.2.6, with the minor changes mentioned below. Thus,

$$
\begin{aligned}
& \ell_{D}=\sqrt{D \tau_{h}}=\sqrt{300 \mu_{h} \tau_{h} k T / e_{0}} \\
& l_{E}=-\tau_{h} \mu_{h} V^{\prime}(x)
\end{aligned}
$$

where $\mu_{h}$ is the mobility of the hole in the semiconductor and $\tau_{h}$ is the life time of the hole.

\subsubsection{Electron transfer process}

In anodic reactions at semiconductor/solution interfaces activated by light, electrons are transferred from a donor in solution to a hole in the valence band. Since $N_{D}(E)$ is an inverted Boltzman distribution 
52.

for donors [19], a photocurrent corresponding to a direct electron transfer from a donor to a hole is expected only when the energy of ground state of the donor is lower than the top of the valence band at the surface (see Fig. 3.5), i.e., $\Delta H^{\prime}<0$.

(a) Construction of the Potential Energy Barrier

The potential energy barrier for the electron from $\mathrm{OH}^{-}$is constructed by considering the optical Born energy, Coulombic interaction and interaction energy between electron and adsorbed water, analogously to p-type semiconductor case (see section 3.2.1.6).

The potential energy of the electron with respect to its value in the ground state of $\mathrm{OH}^{-}, \mathrm{U}^{\prime}$, is given by

$$
U^{\prime}=E \cdot A+U_{\text {opt } . B o r n}+U_{\text {ion }}^{\prime}+U_{\mathrm{H}_{2}} \mathrm{O}
$$

where

$$
\begin{aligned}
\mathrm{u}_{\text {ion }}^{\prime}= & \int_{0}^{\mathrm{x}}\left\{-\frac{\mathrm{e}_{\mathrm{o}}^{2}}{(2 \mathrm{~d}-\mathrm{x})^{2} \varepsilon_{\mathrm{op}}} \cdot \frac{\varepsilon-\varepsilon_{\mathrm{op}}}{\varepsilon+\varepsilon_{\mathrm{op}}}+\frac{\mathrm{e}_{\mathrm{o}}^{2}}{\mathrm{x}^{2} \varepsilon_{\mathrm{op}}}\right. \\
& \left.+\frac{2 \pi \mathrm{e}_{\mathrm{o}}^{2}}{\varepsilon_{\mathrm{op}}} \sum_{\mathrm{n}=1}^{\infty} \mathrm{n}\left(\frac{1}{(2 \mathrm{~d}-\mathrm{x})^{2}+\mathrm{n}^{2} \mathrm{R}_{i}^{2}} \cdot \frac{\varepsilon-\varepsilon_{\mathrm{op}}}{\varepsilon+\varepsilon_{\mathrm{op}}}-\frac{1}{\mathrm{x}^{2}+\mathrm{n}^{2} \mathrm{R}_{i}^{2}}\right)\right\} \mathrm{dx}
\end{aligned}
$$

Similarly, the potential energy of the electron from water with respect to its value in the ground state of water, U', is given by:

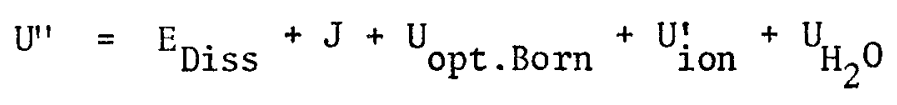

A potential energy profile based on these considerations is shown as a function of distance in Fig. 3.5 by assuming $d$ is $6.5 \AA$ in Eq. (3.35). Other parameters taken in this calculation are $\mathrm{E}_{\mathrm{g}}=1.5 \mathrm{eV}$ and $\mathrm{E}_{\mathrm{a}}=$ $3.5 \mathrm{eV}$. 
53.

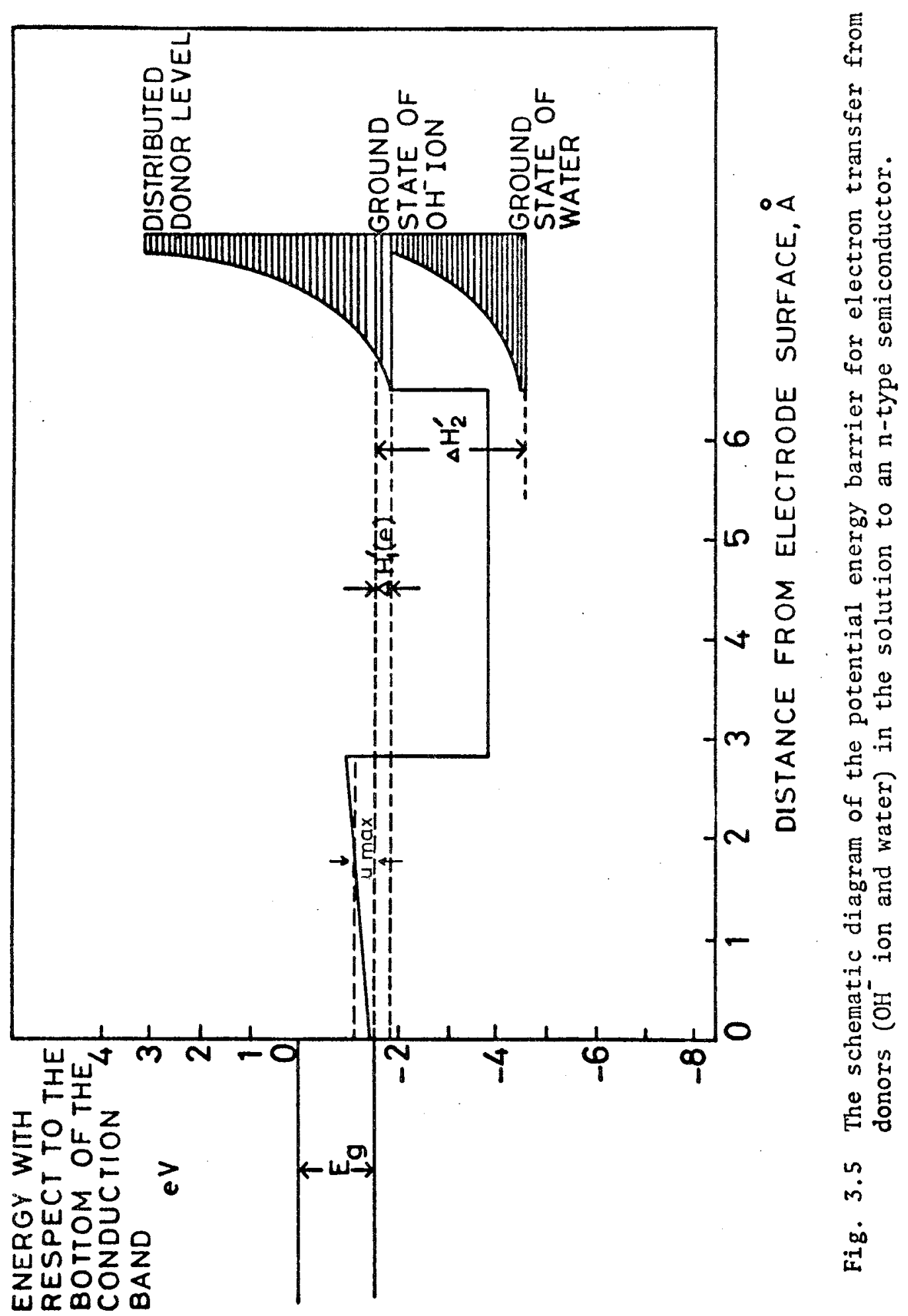


(b) The equation for the photocurrent

From Eq. (3.5), the photocurrent corresponding to an electron transfer from $\mathrm{OH}^{-}$is given in general by (cf. Fig. 3.5),

$$
i_{p, O H^{-}}=e_{0} \frac{C_{D}}{C_{T}} \int_{-\infty}^{-E} g
$$

where $N_{h}(E)$ is the number of holes with energy $E$ which strike the semiconductor surface per unit time per unit area; $G_{D}(E)$ is the distribution of vibrational-rotational states of donor at energy $E$ in the solution; $W_{A}(E)$ is the WKB tunneling probability of electrons through the potential barrier at energy $E ; C_{D}$ is the number of electron donors per unit area in the OHP.

$$
\text { Since }-\mathrm{E}_{\mathrm{g}}>-\mathrm{E}_{\mathrm{g}}-\Delta \mathrm{H}_{1}^{\prime}(\mathrm{e})>-\mathrm{E}_{\mathrm{g}}-\Delta \mathrm{H}_{2}^{\prime}(\mathrm{e}) \text {, photocurrent, } \mathrm{i}_{\mathrm{p}}^{\prime} \text {, }
$$

is given by:

$$
\begin{aligned}
& i_{p}^{\prime}=e_{0}\left[\frac{\bar{C}_{H_{2}} O}{C_{T}} \int_{-E}^{-E_{g}-\Delta H_{2}^{\prime}(e)} N_{h}(E) \exp \left\{\beta\left(-E_{g}-\Delta H_{2}^{\prime}(e)-E\right) / k T\right\}\right. \\
& \exp \left\{-\frac{\pi^{2} \ell}{h} \sqrt{2 m\left(-E_{g}-\Delta H_{2}^{\prime}(e)+U_{\max }^{\prime \prime}-E\right)}\right\} d E \\
& +\frac{\mathrm{C}_{\mathrm{OH}}=}{\mathrm{C}_{\mathrm{T}}} \int_{-\mathrm{E}_{\mathrm{g}}-\Delta \mathrm{H}_{1}^{\prime}(\mathrm{e})}^{-\mathrm{E}_{\mathrm{h}}} \mathrm{N}_{\mathrm{h}}(\mathrm{E}) \exp \left\{\beta\left(-\mathrm{E}_{\mathrm{g}}-\Delta \mathrm{H}_{1}^{\prime}(\mathrm{e})-\mathrm{E}\right) / \mathrm{kT}\right\} \\
& \left.\exp \left\{-\frac{\pi^{2} \ell}{h} \sqrt{2 m\left(-E_{g}-\Delta H_{1}^{\prime}(e)+U_{\max }^{1}-E\right)}\right\} d E\right]
\end{aligned}
$$

where $\mathrm{C}_{\mathrm{H}_{2} \mathrm{O}}$ and $\mathrm{C}_{\mathrm{OH}^{-}}$are the number of water molecules and $\mathrm{OH}^{-}$ions per unit area in the OHP, respectively; $U_{\max }^{\prime \prime}$ and $U_{\max }^{\prime}$ are the barrier maximum for the electrons from water and $\mathrm{OH}^{-}$ion, respectively. $\mathrm{N}_{\mathrm{h}}(\mathrm{E})$ is given in section 3.2 .2 .4 . 


\subsection{THE COMPUTATION OF THE QUANTUM EFFICIENCY FOR AN}

INDIVIDUAL ELECTRODE

The photocurrent is a function of the intensity of the incident light, as can be seen from Eq. (3.5) and quantum efficiencies* are given by Eq. (3.39). They have been computed using equations (3.26) for a $p$-type semiconductor and (3.38) for an n-type semiconductor. (The equations were programmed and a DEC-10 computer was used.)

The number of electrons transferred

The quantum efficiency $=\frac{\text { from or to a semiconductor }}{\text { The number of incident photons }}$

$$
=\frac{i_{p}}{e_{0} I_{0}}
$$

\subsubsection{Predicted Results for Cathodic Photocurrents at p-Type Semiconductor Electrodes}

\subsubsection{Effect of potential}

Since potential affects the potential energy profile in the scmiconductor and the position of the Fermi level, conduction band and valence band (see section 3.2.1.4), the energy distribution of excited electrons at the surface is changed by the electrode potential. Consequently, the quantum efficiency is changed by potential. In Fig. 3.6, the quantum efficiency calculated by Eq. (3.39) is shown as a function of potential. The parameters for computation are $\mathrm{h} \nu=3 \mathrm{eV}, \mathrm{R}=0.47[20], \alpha_{\mathrm{ph}}=4.4 \times 10^{5} \mathrm{~cm}^{-1}[20], \mathrm{E}_{\mathrm{g}}=1.40 \mathrm{eV}[6]$ : $\mathrm{E}_{\mathrm{a}}=4.07 \mathrm{eV}[6], \mu_{\mathrm{e}}=8,600 \mathrm{~cm}^{2} / \mathrm{V} \cdot \mathrm{sec}[21]$ and $\tau=10^{-12} \mathrm{sec}$. The pirametcrs used are those for GaAs.

* This is to be distinguished from overall efficiency calculations, in which the light which is considered is taken over a spectrum of frequencics, e.g., the solar spectrum. 
56.

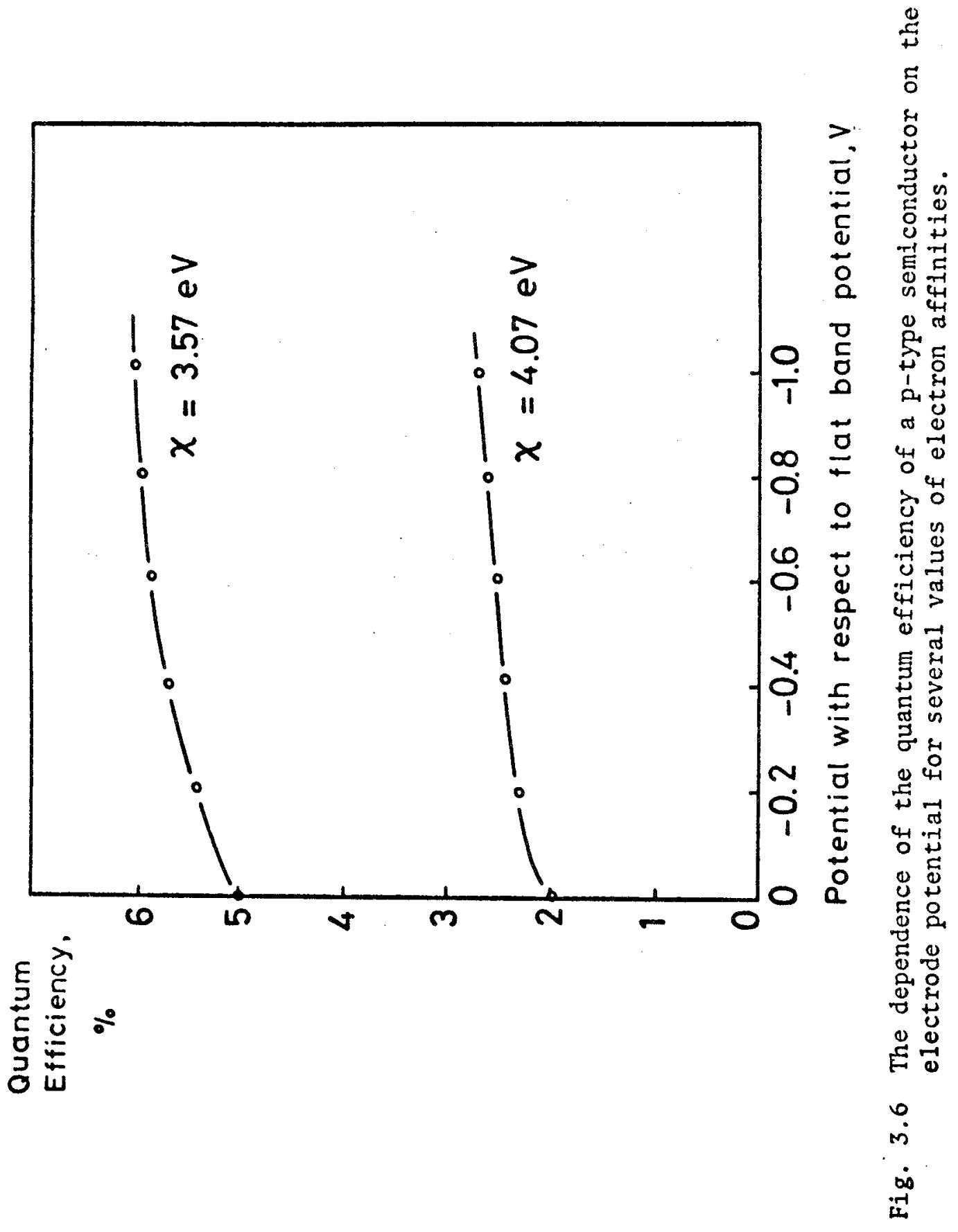




\subsubsection{Effect of the energy of the photon}

When the energy of the photon changes, the optical properties, i.e., the $R$ and the $\alpha_{p h}$, and the energy distribution of the excited electrons change. The optical constant of GaAs at several photon energies are available from Ref. 20. The quantum efficiencies at several photon energies calculated by Eq. (3.39) is given in Fig. 3.7 as a function of the energy of photon. The parameters for computation are the same as those in section 3.3 .1 .1 and $\mathrm{V}=-1.0 \mathrm{~V}$ with respect to the flat band potential.

\subsubsection{The effect of Iife time}

When the life time of excited electron changes, the number of electrons which arrive at the surface changes and, therefore, the photocurrent changes.

The quantum efficiency (calculated by Eq. (3.39)) dependence on life time is shown in Fig. 3.8.

When life time is large enough so that $\ell_{D} \gg 1 / \alpha_{p h}$, most of the excited electrons reach the surface, and saturate the photocurrent so that further increase of Iife time does not affect the photocurrent (see section 3.2.1.5). Parameters for calculation are the same as those in section 3.3 .1 .1 and $V=-1.0 \mathrm{~V}$ with respect to the flat band potential.

3.3.1.4 The effect of the electron affinity of the semiconductor

The effect of the electron affinity of the semiconductor, $E_{a}$, on the quantum efficiency (photocurrent) is considered, keeping the parameters constant. When $\mathrm{E}_{\mathrm{a}}$ changes, the relative position of the acceptor changes and this changes $N_{e}(E)$ and $G(E)$. The calculated quantum efficiencies for several values of $\mathrm{E}_{a}$ are shown in Fig. 3.6. The parameters for the calculation are the same as those in 
58.

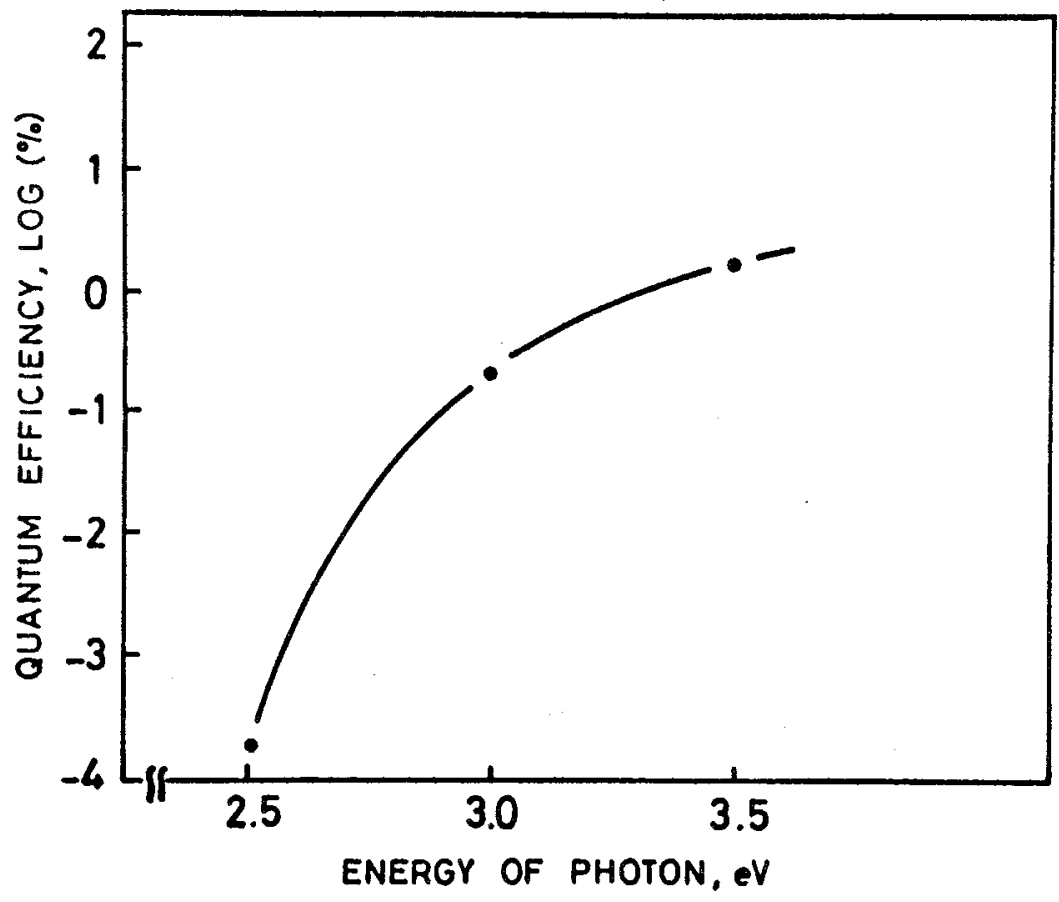

Fig. 3.7 The dependence of the quantum efficiency of a p-type semiconductor on the energy of photon.

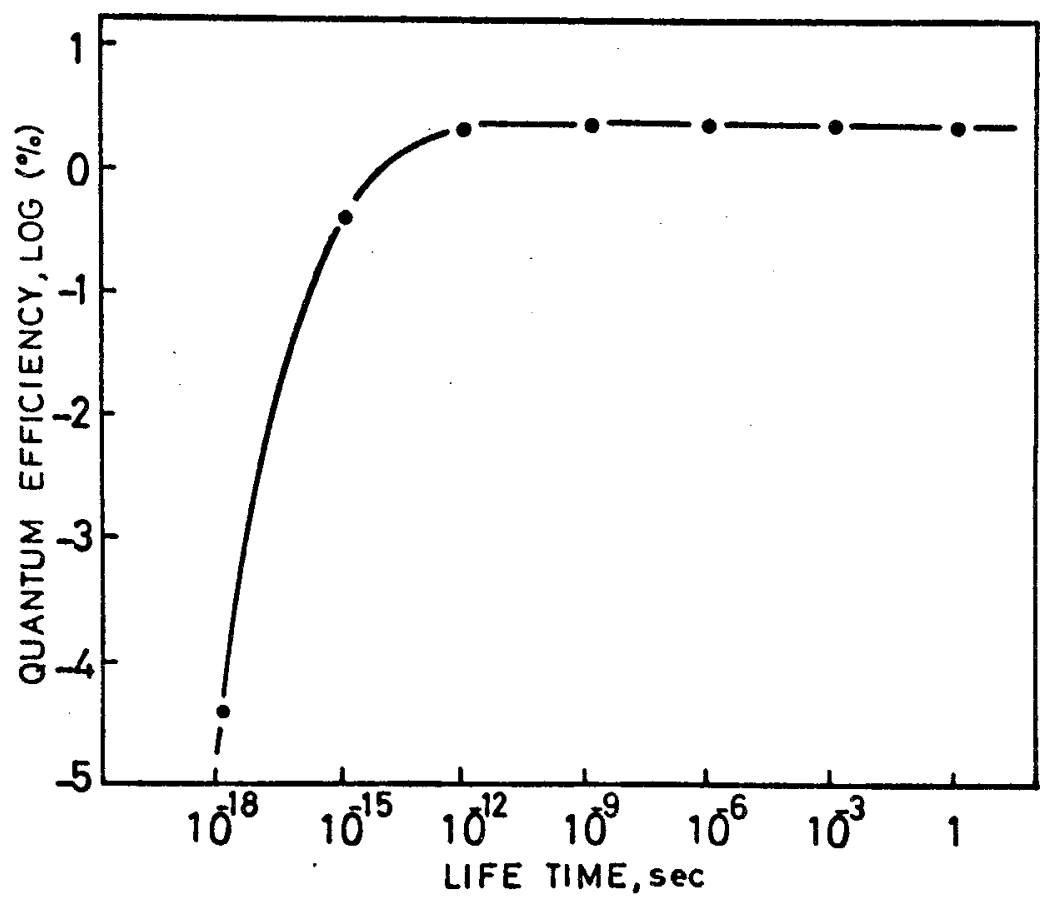

Pig. 3.8 The dependence of the quantum efficiency of a p-type semiconductor on the life time of electron. 
59.

section 3.3.1.1 except for $\mathrm{E}_{\mathrm{a}}$. The smaller the values of $\mathrm{E}_{\mathrm{a}}$, the larger are the quantum efficiencies calculated.

\subsubsection{The energy gap effect}

When the energy gap changes, the energy distribution of the excited electrons at the surface change. The calculated quantum efficiency is shown for three values of the energy gap of a typical semiconductor in Fig. 3.9. The parameters for the calculation are the same as those in section 3.3.1.1, except for $E_{g}$ and $V . \quad V$ is taken as $-1.0 \mathrm{~V}$ with respect to the flat band potential. The smaller the value of $E_{g}$, the larger the quantum efficiency.

\subsubsection{The effect of electron mobility}

The quantum efficiency calculated from Eq. (3.39) as a function of the electron mobility is shown in Fig. 3.10. When the electron mobility is large enough to have $\ell_{D} \gg 1 / \alpha_{p h}$, most of the excited electron reach the surface and it saturates the photocurrent and, therefore, further increase in $\mu_{e}$ does not affect the photocurrent. The parameters for the calculation are the same as those of section 3.3.1.1, except for $\mu_{e}$ and $V . \quad V=-1.0 \mathrm{~V}$ with respect to the flat band potential is used.

\subsubsection{Predicted Results for n-Type Semiconductors}

\subsubsection{Effect of potential}

Similarly to the results of section 3.3.1.1, the energy distribution of created holes of a semiconductor at the surface, $N_{h}(E)$, is changed when potential changes. The potential dependence of the quantum efficiency calculated by Eq. (3.39) is shown in Table 3.1(a).

The parameters for computation are the same as those of GaAs except for $\mu_{h}=400 \mathrm{~cm}^{2} / \mathrm{V} \cdot \mathrm{sec}$ and $\mathrm{E}_{\mathrm{a}}=3.5 \mathrm{eV}$. 
60.

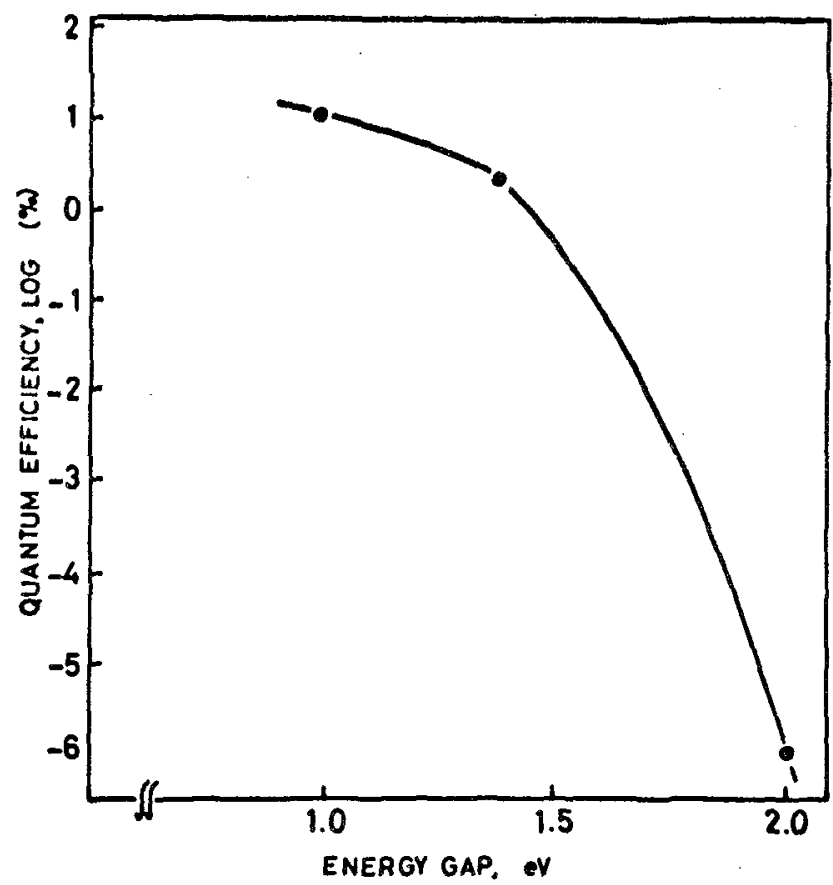

8ig. 3.9 The dependence of the quantum efficiency of a p-type semiconductor on the energy gap.

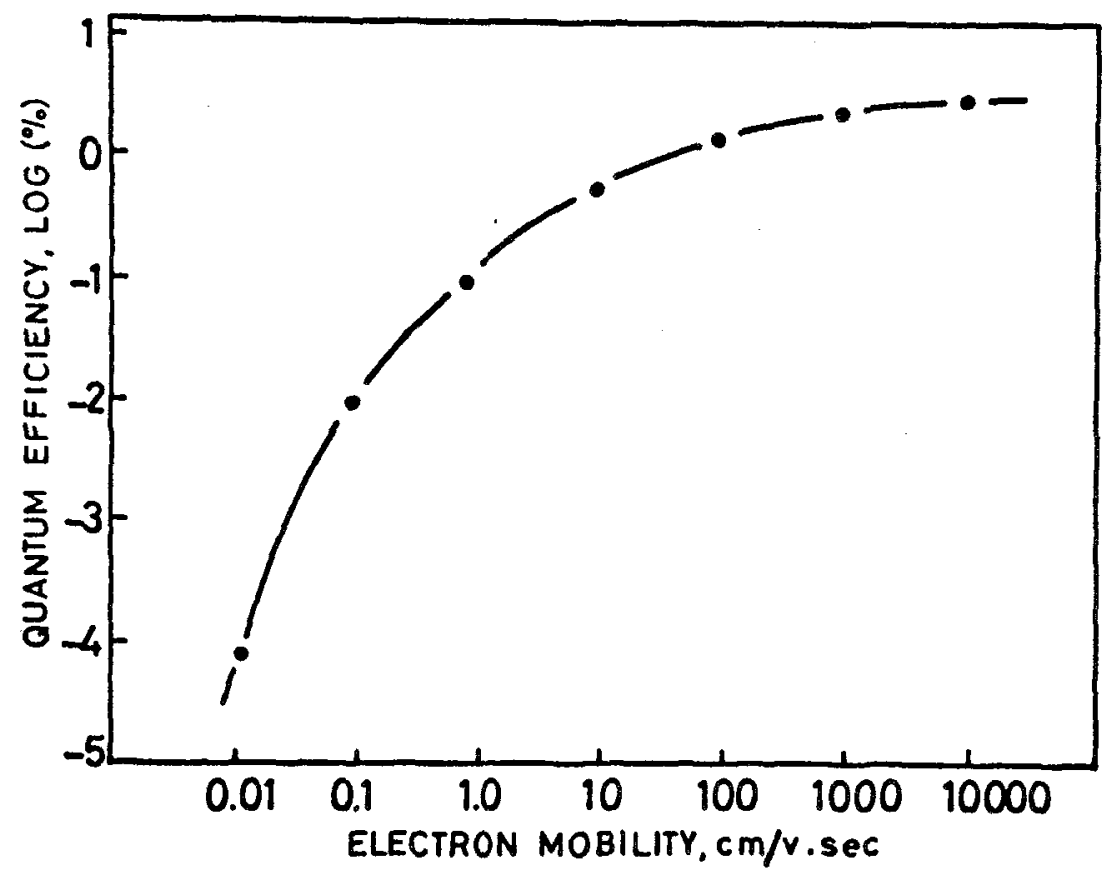

Fig. 3.10 The dependence of the quantum efficiency of a p-type semiconductor on the electron mobility. 
TABLE 3.1 COMPUTED RESULTS FOR $\mathrm{n}$-TYPE SEMICONDUCTOR

(a) Effect of Potential

Potential ( $V$ with respect to the

Quantum Efficiency

flat band potential)
0
$1.0 \times 10^{-2}$
0.2
$1.8 \times 10^{-2}$
0.4
$2.2 \times 10^{-2}$
0.6
$2.7 \times 10^{-2}$
0.8
$3.0 \times 10^{-2}$
1.0
$3.2 \times 10^{-2}$

(b) Effect of Electron Affinity

Electron Affinity (eV)

Quantum Efficiency

$$
\begin{aligned}
& 3.1 \\
& 3.3 \\
& 3.5
\end{aligned}
$$

$$
\begin{aligned}
& 4.5 \times 10^{-2} \\
& 4.1 \times 10^{-2} \\
& 3.2 \times 10^{-2}
\end{aligned}
$$

(c) Effect of Energy Gap

Energy Gap $(\mathrm{eV})$
1.0
1.2
1.4

Quantum Efficiency (\%)

$4.0 \times 10^{-2}$

$3.5 \times 10^{-2}$

$3.0 \times 10^{-2}$ 
62 .

\subsubsection{The effect of the electron affinity of the semiconductor}

When $\mathrm{E}_{\mathrm{a}}$ changes, the energy level of the donor in solution changes, and, therefore, the photocurrent (or quantum efficiency) changes. The quantum efficiencies calculated by Eq. (3.39) for several values of electron affinity are shown in Table 3.1(b). The parameters for the calculation are the same as those of section 3.3.2.1, except for $E_{a}$ and $V$. $\mathrm{V}=+1.0 \mathrm{~V}$ with respect to the flat band potential is used.

\subsubsection{The effect of the energy gap}

In this case the change of the energy gap affects not only the energy distribution of holes, $\mathrm{N}_{h}(E)$, but also the position of donors. In Table $3.1(\mathrm{c})$, the calculated quantum efficiencies for several $E_{g}$ are shown, whilst other parameters have been kept constant. A value of: $\mathrm{V}=+1.0 \mathrm{~V}$ with respect to the flat band potential is used. Gther. parameters for the calculation are the same as those in section 3.3.2.1.

3.3.2.4 Comparison with the experimental results of n-type semiconductors

The calculated results of quantum efficiencies for the n-type semiconductors, as shown in Table 3.1, are very low in all cases. The physical reasons for this, for the model taken can be seen fron: Fig. 3.5. Thus, electrons are donated from distributed energy states of a donor (c.f. the dominant contribution the cathodic photocurrent in a p-type semiconductor and in metals. It is electron transfer to non-distributed states in water). The presence of the distribution law in the n-type situation (c.f. the position of the donor in Fig. 3.5) lead to a considerable reduction of available states. Conversely, the experimental results for $\mathrm{TiO}_{2}$ (n-type) electrodes show relativeiy high quantum efficiencies, i.e., up to $60 \%$ at $3.4 \mathrm{eV}$. (See chapter five).

\subsubsection{Surface states involved in the $\mathrm{TiO}_{2}$ mechanisms}

At steady state, the number of holes which arrive at the surfacs, 
63.

and that of holes which are consumed at the surface, must be equal. The possibilities of hole consumption at the surface are:

(a) direct electron transfer from a donor in solution, as explained in section 3.2 .2 ;

(b) surface recombination with electrons in the conduction band;

(c) surface recombinations with electrons in surface states;

(d) recombination with valence electrons, e.g., CdS +2 holes $\rightarrow \mathrm{Cd}^{++}+\mathrm{S}$.

The reaction mechanism for oxygen evolution on $\mathrm{TiO}_{2}$ without illumination was studied by Boddy [22] and it was concluded that electron tunneling from a surface state to the bulk of the electrode was the rate determining step. Correspondingly, the unexpectedly high quantum efficiency of the oxygen evolution reaction on $\mathrm{TiO}_{2}$ can be explained by considering the existence of surface states. Since the energy levels of the donors are higher than that of the top of the valence band, the electron transfer from the donor to a hole can occur easily, if surface states exist. Thus, most of the holes arriving at the surface from the bulk are expected to react with electrons of the surface states, because path (a) cannot occur as explained before; (d) does not occur, as shown by Fujishima and Honda [23] ; and (c) may occur but the contribution is small because of anodic polarization. Also, in the presence of a halide anion, halogen production occurs instead of oxygen evolution and this is explained by the reaction between holes and adsorbed halide anion [24]. (Electron transfer through surface state.)

In Fig. 3.11, the number of holes arriving at the surface per unit time per unit area divided by the number of incident photons per unit time per unit area calculated from equation $(3.31 \sim 3.33)$ is shown as a function of potential (See section 3.2.2.4). The parameters 
64.

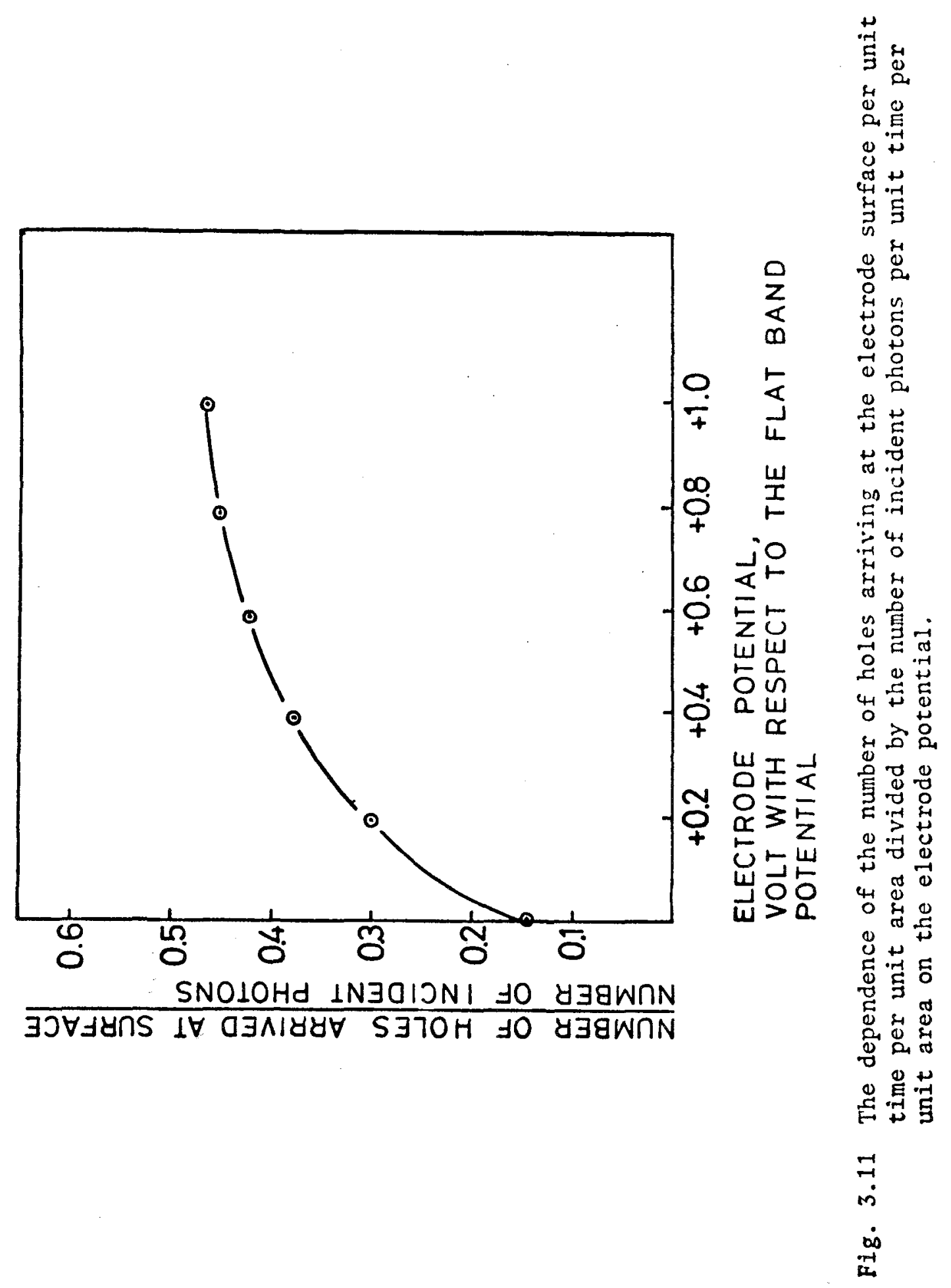


65 .

for the calculation, the results of which are shown in Fig.3.11, arc $\mathrm{E}_{\mathrm{g}}=3 \mathrm{eV}, \mathrm{h} \nu=3.5 \mathrm{eV}, \mathrm{R}=0.15[25], \alpha=5 \times 10^{3} \mathrm{~cm}^{-1}, \tau=10^{-7} \mathrm{sec}$ and $\mu_{\mathrm{h}}=1.0 \mathrm{~cm} / \mathrm{V} \cdot \mathrm{sec}^{* *}$ and $\varepsilon=89 * * *$.

These calculated values (Fig. 3.11) become quantum efficiencies if one supposes that all holes arriving at the surface react with electrons of the surface states. The other path for hole consumption at the surface, surface recombination with electron in the conduction band, will be taken as negligible because the positive electrode potential with respect to the flat band potential $(\mathrm{ca}+0.6 \mathrm{~V}$ ) makes the surface electron concentration negligible. It will thus be assumed that hole arrival at the surface is rate determining step. The hypothesis yields reasonable agreement with the observed high quantum efficiences. (See Fig. 3.11).

* The value of $\mathrm{TiO}_{2}$ film [26].

** Value of electron.

*** Value for the a-direction. 


\subsection{WHOLE CELL SYSTEM}

In the last section, expressions for the quantum efficiency of individual electrodes ( $\mathrm{n}$ - and p-type semiconductors) have been computed. Knowing the number of photons of the incident light, one can get the photocurrents by multiplying the quantum efficiency by the number of photons. However, as far as applications of the present work to energy-conversion is concerned, the photocurrent of the entire electrochemical cell, which consists of a cathode and an anode without other external potential source, has a more important practical meaning than that of a certain electrode. Thus, in the evaluation of the cell carried out below, the photocurrent-energy relation at chosen electrode potential, have been integrated over the whole solar spectrum.

\subsubsection{The Relation between the Potential of an Electrode and a $\mathrm{Ce} 11$}

The potential of a self-driving cell at a current $I, V_{\text {cell, }}$, is given by [27]:

$$
V_{\text {cel1 }}=E_{\text {so }}-E_{\text {si }}-I R_{c}
$$

where $E_{s o}$ is the potential of the cathode with respect to a reference electrode, $\mathrm{E}_{\mathrm{si}}$ is the potential of the anode with respect to the same reference electrode and $R_{c}$ is the inner cell resistance. Also, the potential of a driven cell at a current $I, V_{\text {ext }}$, (the external potential to the flow of a current) is given by [27]

$$
V_{\text {ext }}=E_{s i}-E_{s o}+I_{c}
$$

Let us define $V$ as

$$
V=E_{s o}-E_{s i}-I R_{c}
$$


67.

If $V$ has a positive value at a current $I$, this cell is a self-driving cell and if $V$ has a negative value, at a current $I$, this cell is a driven cell and the cell potential, $-V$, is required to cause a current I to flow. In Fig. 3.12 this relation is shown. Fig. 3.12 (a) represents a current-potential relationship of the system $\mathrm{H}_{2} \mathrm{O} / \mathrm{O}_{2}$ and $\mathrm{H}^{+} / \mathrm{H}_{2}$ for individual electrodes respectively, both for the cathodic and the anodic reactions. If one dips two electrodes into an acidic solution and one of them is in contact with oxygen gas and another is in contact with hydrogen gas, the system works as a se1f-driving cell. The oxygen electrode works as a cathode $\left(\frac{1}{4} \mathrm{O}_{2}+\mathrm{H}^{+}+\mathrm{e} \rightarrow \frac{1}{2} \mathrm{H}_{2} \mathrm{O}\right)$ and the hydrogen electrode works as anode $\left(\frac{1}{2} \mathrm{H}_{2} \rightarrow \mathrm{H}^{+}+\mathrm{e}\right)$ until I reaches $\mathrm{I}_{1}\left(\right.$ at $\left.\mathrm{I}_{1}, \mathrm{~V}=\mathrm{E}_{\mathrm{so}}-\mathrm{E}_{\mathrm{si}}-\mathrm{IR}_{\mathrm{c}}=0\right)$. To obtain a current $I_{2}$, one needs an extra external potential $I_{2} R_{c}$ $(=-V)$. Correspondingly, to get hydrogen from one electrode and oxygen from another in the normal dark case, one needs to supply an external potential, $V_{\text {ext }}\left(=-V=-\left(E_{s o}-E_{s i}-I R_{c}\right)\right)$.

\subsubsection{The Calculated Hydrogen Production Rate from Solar Energy Using $\mathrm{TiO}_{2}$ Photo-driven Cells}

Photocurrents from individual electrodes stimulated by solar energy at a certain potential have been calculated by integrating the photocurrent of the monochromatic light through the whole solar energy range. Thus, one can get a current-potential relationship of an individual electrode, by carrying out this process over some potential range. Then, one can get a cell potential-current relationship, if one knows the value of the flat band potential of the semiconductor electrode with respect to a reference electrode.

As examples, Eq. (3.42) has been applied to the cell $1, \mathrm{TiO}_{2} /$ solution $(\mathrm{pH}=14) /$ solution $(\mathrm{pH}=0,7,14) / \mathrm{Pt}$ and the cell $2, \mathrm{TiO}_{2} /$ solution $(\mathrm{pH}=0) /$ GaAs with the assumption that all holes arriving at 
68.

Polential,

V(NHE)

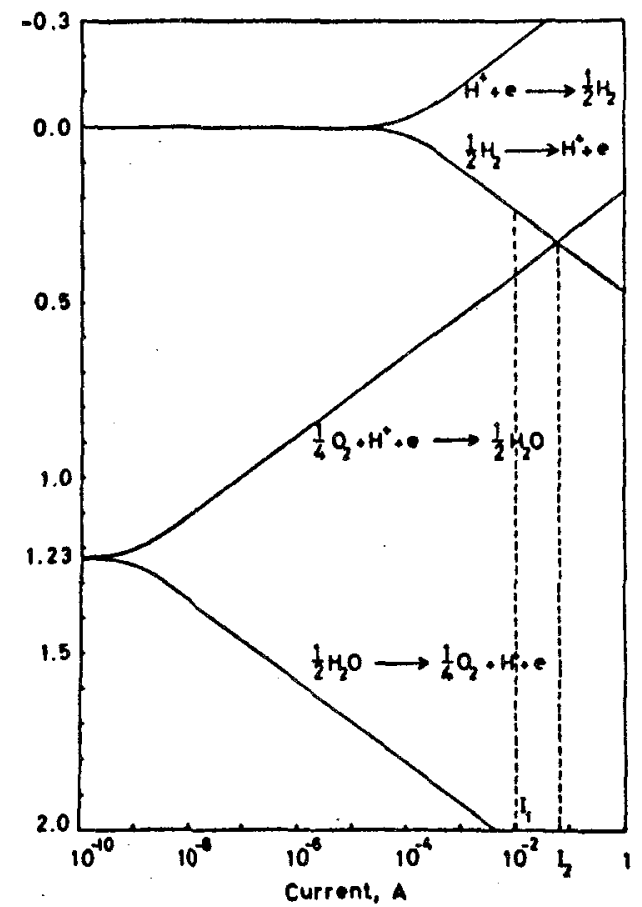

(a)

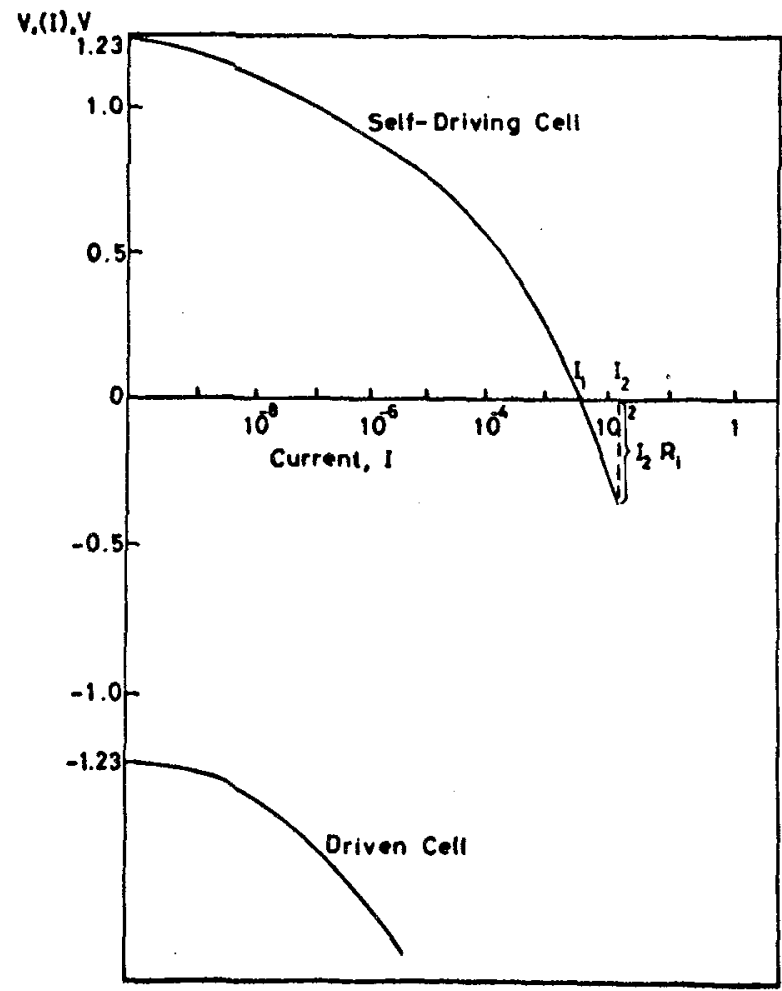

(b)

Fig. 3.12 (a) The potential-current relationships of individual electrodes.

(b) The potential-current relationships of a solfdriving cell and a driven cell. 
69.

the surface react, i.e., contribute to electricity. The parameters used were as follows. The flat band potential of $\mathrm{TiO}_{2}$ at $\mathrm{pH}=14$ and at $\mathrm{pH}=0$ and of GaAs at $\mathrm{pH}=0$ are $-0.8 \mathrm{~V}(\mathrm{NHE})[28],-0.05 \mathrm{~V}$ (NHE) [28] and 0.43V(NHE) [29]; $R$ is $100 \Omega ; i_{0}$ of Pt electrode is $10^{-4} \mathrm{~A} / \mathrm{cm}^{2}$ and optical constants of $\mathrm{TiO}_{2}$ were taken from Ref. 26. The results are shown in Fig. 3.13 and Fig. 3.14. As seen in Fig. 3.13, the maximum cell current of the cell 1 is a function of $\mathrm{pH}$ gradient. When $\mathrm{pH}$ of cathodic compartment is 0 , the maximum cell current is $0.14 \mathrm{~mA} / \mathrm{cm}^{2}$ and the maximum hydrogen production rate is $0.06 \mathrm{cc} / \mathrm{hr} . \mathrm{cm}^{2}$. This means that the efficiency of this cell is $0.3 \%$ of the total solar energy $\left(0.0739 \mathrm{~W} / \mathrm{cm}^{2}\right)$. When $\mathrm{pH}$ of cathodic compartment is 7 , the maximum cell current is $0.12 \mathrm{~mA} / \mathrm{cm}^{2}$ and when $\mathrm{pH}$ of cathodic compartment is 14 , no current is expected.

On the other hand, in the cell 2 in which both electrodes are illuminated, current flows even when $\mathrm{pH}$ gradient is zero. In this case maximum current is determined by cathodic reaction and is 0.028 $\mathrm{mA} / \mathrm{cm}^{2}$. (Fig. 3.14). 
70.

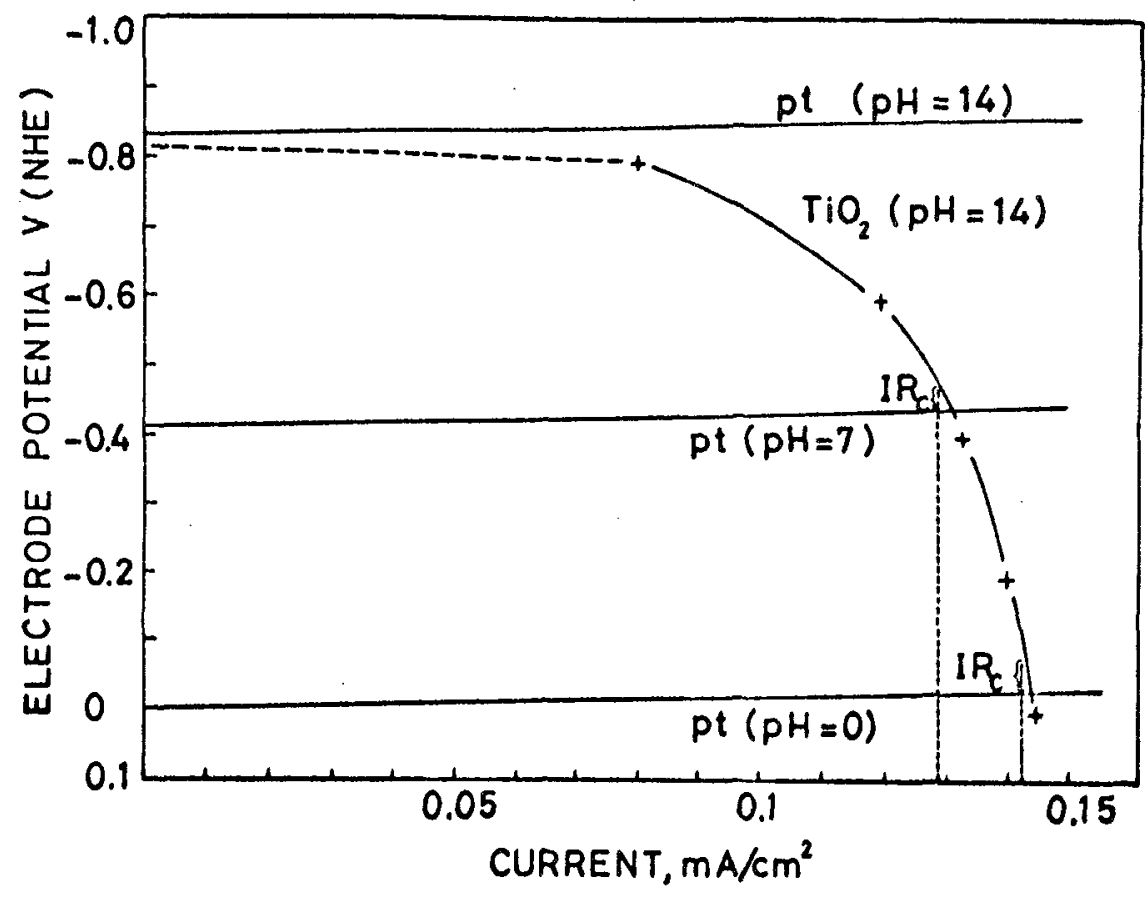

Fig. 3.13 The potential-current relationships of the cell, $\mathrm{TiO}_{2} /$ solution $(\mathrm{pH}=14) /$ solution $(\mathrm{pH}=0,7,14) / \mathrm{Pt}$.

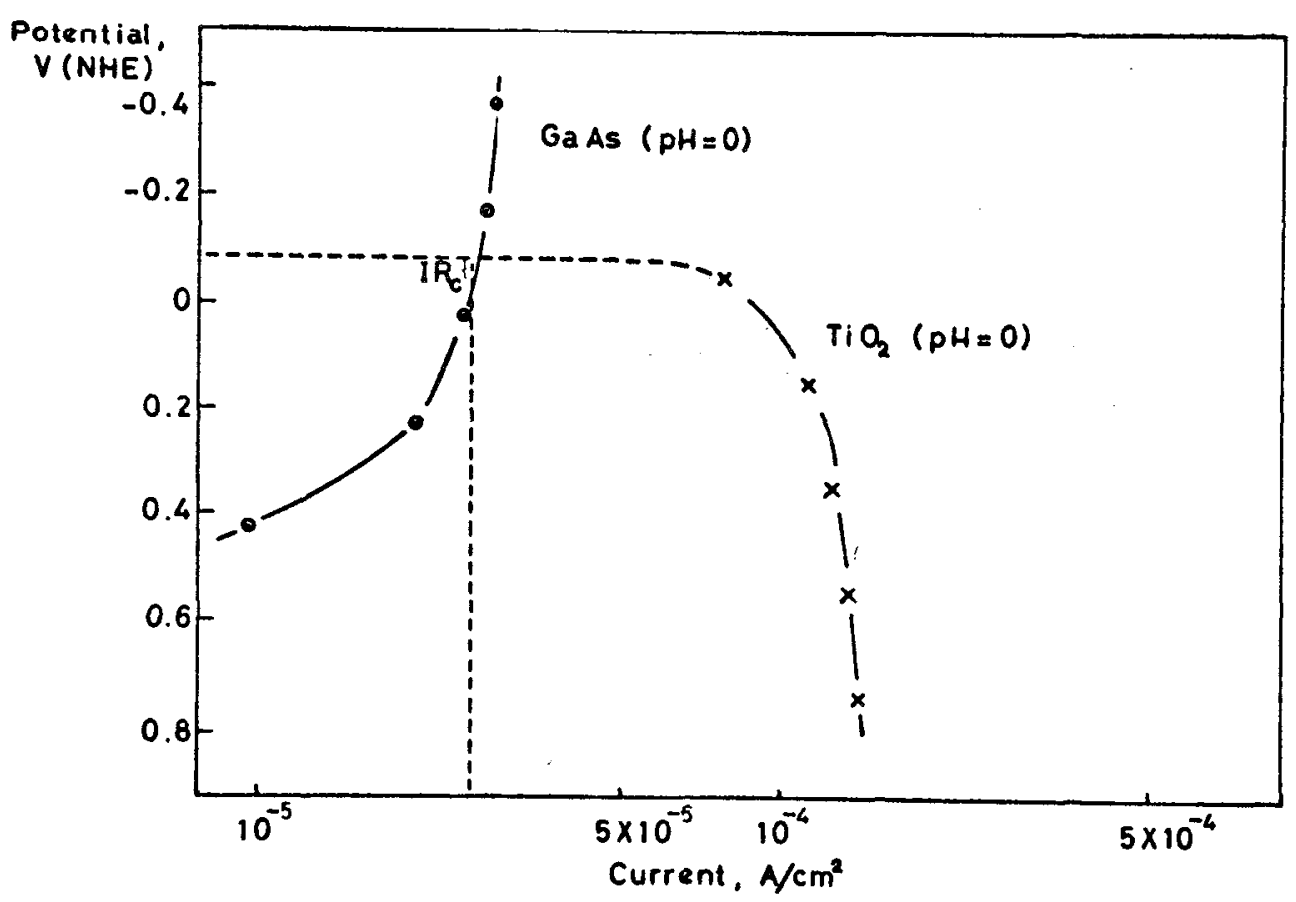

Fig. 3.14 The potential-current relationship of the cell, $\mathrm{TiO}_{2}$ /solution $(\mathrm{pH}=0) /$ GaAs. 


\subsection{OPTIMUM PROPERTIES OF ELECTRODES}

From the calculated results in section $3.3 .1,3.3 .2$ and 3.4 .2 optimum conditions of semiconductor electrodes are considered as follows and 1isted in Table 3.2 .

\subsubsection{Electron Affinity}

For p-type semiconductors, the less the electron affinity, the larger the quantum efficiency (see section 3.3.1.4). However the minimum value of electron affinity of semiconductors is about $3.5 \mathrm{eV}$.

On the other hand, for n-type semiconductors, since the energy level of donor must be higher than that of top of the valence band of semiconductor and lower than that of bottom of the conduction band of semiconductor, $-\mathrm{E}_{\mathrm{g}}<\Delta \mathrm{H}_{1}^{\prime}<0$, i.e. $\mathrm{E}_{\mathrm{a}}+\mathrm{E}_{\mathrm{g}}>5.3$ and $\mathrm{E}_{\mathrm{a}}<5.3$.

\subsubsection{Energy Gap}

The smaller the energy gap, the larger the portion of solar energy which is absorbed by the semiconductors. However, if the energy gap is too small (e.g. < leV), the life time of the carriers will be so small that the efficiencies will begin to decrease with the energy gap.

\subsubsection{Electron Mobility and Life Time}

Both properties determine the number of carriers which arrive at the surface. As shown in 3.3.1.3 and 3.3.1.6, when these values increase, the quantum efficiencies increase till some value and saturate. If $\mu$ is large, most carriers arrive at surface even when $\tau$ is small and vice versa. Therefore optimum condition of these properties is given by $\mu \times$ life time $>10^{-8}$.

\subsubsection{Flat Band Potential}

This property determines whether the cell works as a self-driven one or not. Since p-type semiconductor works as a photo-cathode, 
TABLE 3.2 OPTIMUM CONDITION OF SEMICONDUCTOR ELECTRODES

\begin{tabular}{|l|c|c|}
\hline & p-S.C & n-S.C \\
\hline $\begin{array}{l}\text { Electron } \\
\text { Affinity }\end{array}$ & $\begin{array}{l}\text { The smaller, the better } \\
\text { Minimum ca. } 3.5 \mathrm{eV}\end{array}$ & $\mathrm{E}_{\mathrm{a}}+\mathrm{E}_{\mathrm{g}}>5.3 \mathrm{eV}$ \\
$\mathrm{E}_{\mathrm{a}}<5.3 \mathrm{eV}$
\end{tabular}


73.

the more positive the flat band potential, the better. If this is more positive than $1.23 \mathrm{~V}(\mathrm{NHE})$ at $\mathrm{pH}=0$, even when counter electrode (anode) is metal and there is no $\mathrm{pH}$ gradient, the cell works as a self-driven one. If this is more positive than $0.42 \mathrm{~V}(\mathrm{NHE})$ at $\mathrm{pH}=0$, the cell works as self-driven one when the counter electrode is metal and in the solution of $\mathrm{pH}=14$.

On the other hand, n-type semiconductor works as a photo-anode and the more negative the flat band potential the better. If the value is more negative than $-0.83 \mathrm{~V}(\mathrm{NHE})$ at $\mathrm{pH}=14$, even when counter electrode (cathode) is metal and there is no $\mathrm{pH}$ gradient, the cell works as self-driven one. If this is more negative than 0.OV(NHE) at $\mathrm{pH}=14$, the cell works as self-driven one when the counter electrode is metal and in the solution of $\mathrm{pH}=0$.

Also if the flat band potential of p-type semiconductor is more positive than that of n-type semiconductor in same solution, the cell works as a self-driven cell.

\subsubsection{Surface States}

For n-type semiconductor, the existence of surface states is very important. 


\section{APPENDIX 3.1}

\section{ESTIMATION OF HEAT OF ADSORPTION OF HYDROGEN}

\section{ON SEMICONDUCTOR IN SOLUTION}

Since there is no data of the heat of adsorption of hydrogen on semiconductor, these values are roughly approximated by using Pauling's equation (3.43) [30].

$$
D_{M-H}=\frac{1}{2}\left(D_{M-M}+D_{H-H}\right)+23.01\left(X_{M}-X_{H}\right)^{2}
$$

where $D_{Y-H}$ is tine bond energy of $M-H\left(=-H_{a j s}\right), D_{Y-Y}$ is the bond energy of $M-M, D_{H-H}$ is the bond energy of $H-H$ and $X_{M}$ and $X_{H}$ are electron negativity of $M$ and $H$, respectively. Since $D_{M-M}=1 / 6 \Delta H_{\text {sub }}$, where $\Delta H_{\text {sub }}$ is the heat of sublimation, the relation between $\Delta H_{\text {ads }}$ $\left(=-D_{M-H}\right)$ and $\left(1 / 12 \Delta H_{\text {sub }}+23.01\left(X_{M}-X_{H}\right)^{2}\right)$ may be linear.

Heat of adsorption of hydrogen molecule on Pt corresponding to Eq. (3.44) is $-29 \mathrm{kcal} / \mathrm{mol}\left(\mathrm{H}_{2}\right)$ in gas phase and when a coverage of hydrogen is zero.

$$
\mathrm{H}_{2} \rightarrow 2 \mathrm{H}_{\mathrm{ad}}
$$

As mentioned by Breiter [31], the coverage by hydrogen is complete in a solution when the electrode is cathodically polarized. The heat of adsorption of a hydrogen molecule on a cathodically polarized Pt in $4.6 \mathrm{~N} \mathrm{H}_{2} \mathrm{SO}_{4}$ corresponding to Eq. (3.43) is - $3 \mathrm{kcal} / \mathrm{mole}\left(\mathrm{H}_{2}\right)$ [ 31] . Hence, because the data on the heat of adsorption of hydrogen in solution is limited, we shall obtain our values by multiplying the value of the heat of adsorption of $\mathrm{H}_{2}$ on the substance from gas phase by $3 / 29$. Then, one can estimate the heat of adsorption of hydrogen atom in solution, $\Delta \mathrm{H}_{\text {ads }}$, by using the following cycle 


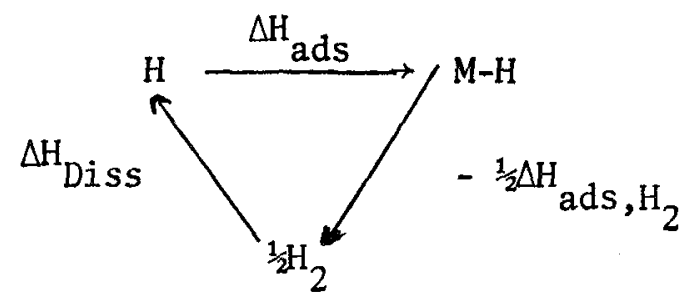

where $\Delta \mathrm{H}_{\text {ads }} \mathrm{H}_{2}$ is heat of adsorption of hydrogen molecule and $\Delta \mathrm{H}_{\text {Diss }}$ is heat of dissociation of hydrogen molecule.

Therefore,

$$
\Delta \mathrm{H}_{\text {ads }}=\Delta \mathrm{H}_{\text {ads }, \mathrm{H}_{2}}-\Delta \mathrm{H}_{\text {Diss }}
$$

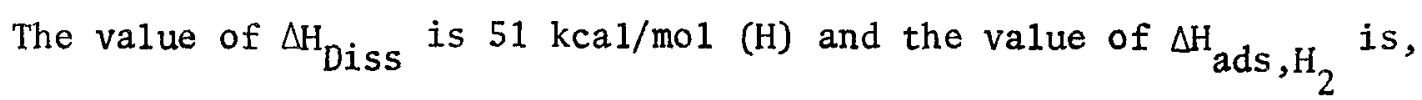
for example, $-29 \mathrm{kcal} / \mathrm{mol}$ in gas phase and $-3 \mathrm{kcal} / \mathrm{mol}$ in solution as mentioned before. Hence, the value of $\Delta \mathrm{H}_{\text {ads }}$ of $\mathrm{Pt}$ is $-66 \mathrm{kcal} / \mathrm{mol}$ in gas phase and $-53 \mathrm{kcal} / \mathrm{mol}$ in solution. The values of $\Delta H_{\text {ads }}$ in gas phase and in solution of several metals obtained by this way are shown in Table 3.3 .

The values of $-\Delta H_{\text {ads }}$ are plotted against the calculated values of $\left[1 / 12 \Delta H_{s u b}+23.01\left(\chi_{M}-\chi_{H}\right)^{2}\right]$ and from this plot, the values of $\Delta \mathrm{H}_{\text {ads }}$ of the p-type semiconductors, the heat of sublimation and the electron negativity of which are known, can be estimated. $\Delta H_{\text {sub }}$ of $\mathrm{GaP}$ is $111 \mathrm{kcal} / \mathrm{mol}$ [32] and $\Delta \mathrm{H}_{\text {sub }}$ of GaAs is $90 \mathrm{kcal} / \mathrm{mol}$ [33]. The values of electron negativity of both materials are not known and estimated by using the linear relationship between $\Delta \mathrm{H}_{\text {sub }}$ and $\chi$. The estimated $X_{\mathrm{GaP}}$ is 1.9 and $\chi_{\mathrm{GaAs}}$ is 1.75. By using these values, $\Delta \mathrm{H}_{\mathrm{ads}}$ of $\mathrm{GaP}$ and $\mathrm{GaAs}$ are estimated as $53 \mathrm{kcal} / \mathrm{mol}$. The values of $\Delta \mathrm{H}_{\text {ads }}$ in solution exist in small ranges (Table 3.3 ) and one can say they range from - $50 \mathrm{kca} 1 / \mathrm{mol}$ to $-55 \mathrm{kcal} / \mathrm{mol}$ for all substances. Consequently, A is calculated as $-6 \mathrm{kcal} / \mathrm{mol} \sim-7 \mathrm{kcal} / \mathrm{mol}$ by 
using Eq. (3.46) [3] .

$$
A=\Delta H_{a d s}\left[2 e^{-a\left(d-d_{e}\right)}-e^{-2 a\left(d-d_{e}\right)}\right]
$$

where a: Morse constant, $d$ : inter nuclear distance, $d_{e}$ : equilibriun value of $d$.

TABLE 3.3 THE ESTIMATED VALUE OF THE HEAT OF ADSORPTION OF HYDROGEN ATOM FROM SOLUTION

$$
\text { - } \Delta \mathrm{H}_{\mathrm{ads}}(\mathrm{kcal} / \mathrm{mol})
$$

\begin{tabular}{ccc} 
& gas phase* & in solution \\
\hline $\mathrm{Pt}$ & 66 & 53 \\
$\mathrm{Pd}$ & 65 & 53 \\
$\mathrm{Rh}$ & 64 & 52 \\
$\mathrm{Ni}$ & 67 & 53 \\
$\mathrm{Cu}$ & 68 & 53 \\
$\mathrm{Fe}$ & 69 & 53 \\
$\mathrm{~W}$ & 75 & 55 \\
\hline
\end{tabular}

* B.E. Conway and J.0'M. Bockris, J. Chem. Phys., 26, 532 (1957). 


\section{APPENDIX 3.2}

\section{ESTIMATION OF THE HEAT OF ADSORPTION OF HYDROXYL}

GROUPS FROM SOLUTION ONTO TiO

Rüetschi and Delahay calculated the energy of the $\mathrm{M}-\mathrm{OH}$ bond by using the following thermodynamic cycle [34] .

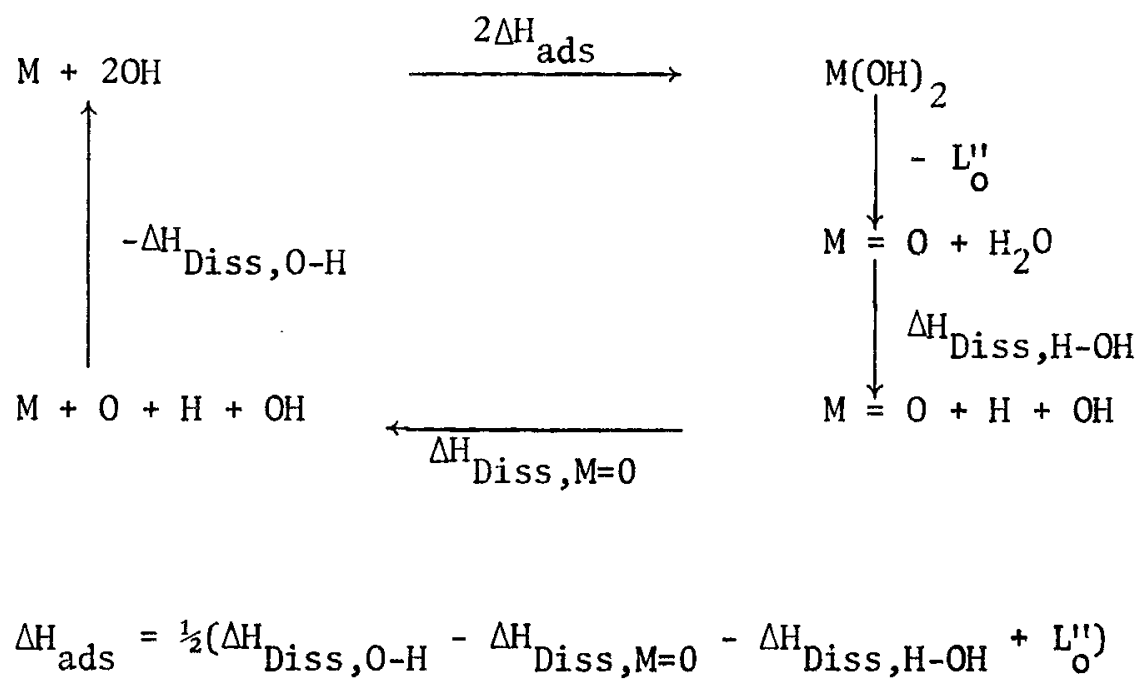

where $\Delta H_{\text {Diss, } 0-H}, \Delta H_{\text {Diss, } M=0}$ and $\Delta H_{\text {Diss, } H-O H}$ represent the heat of dissociation of $\mathrm{O}-\mathrm{H}, \mathrm{M}=0$ and $\mathrm{H}-\mathrm{OH}$ bond, respectively, and $\mathrm{L}_{0}^{\prime \prime}$ is the heat of hydration of $M=0$. The values of $\Delta H_{D i s s, O H}$, and $\Delta H_{D i s s, H-O H}$ are $101.19 \mathrm{kcal} / \mathrm{mol}$ [ 34] and $119.95 \mathrm{kcal} / \mathrm{mol}$ [34], respectively. By assuming, as a zeroeth approximation, $L_{0}^{\prime \prime}=0[34]$,

$$
\Delta H_{\text {ads }}=\frac{1}{2}\left(-\Delta H_{\text {Diss }, M=0}-18.76\right)
$$

In the case of $\mathrm{TiO}_{2}$, this is reduced when it is used as electrode, and it can be assumed that the effective form is $\mathrm{TiO}_{1.98^{\circ}}$ The standard free energy change per mole of the compound corresponding to the reaction

$$
\mathrm{TiO}_{1.98}+\frac{1}{2}(0.02) \mathrm{O}_{2} \rightarrow \mathrm{TiO}_{2}
$$


78 .

is $0.94 \mathrm{kcal}$ [35]. Therefore, the heat of dissociation of the [ $\left(\mathrm{TiO}_{1.98}\right)_{50}$ ] - bonded to 0 , is $47 \mathrm{kcal}$. By using this value and Eq. (3.48), one can get the value of $-33 \mathrm{kcal}$ for the heat of adsorption of $\mathrm{OH}$ onto $\mathrm{TiO}_{1.98^{\circ}}$ In this case, the coverage effect is already taken into account and, therefore, this value can be taken as the value in solution. In Table 3.4, the values of the heat of adsorption of $\mathrm{OH}$ onto $\mathrm{TiO}_{\mathrm{x}}$ (making $\left.(\mathrm{TiO})_{\mathrm{y}}-\mathrm{OH}\right)$ are listed $(\mathrm{x}=1.90 \sim 1.996)$.

From these values in the table, $-30 \mathrm{kcal} / \mathrm{mol} \sim-35 \mathrm{kcal} / \mathrm{mol}$ is the range of values for $\Delta H_{\text {ads }}$ of the $\mathrm{OH}$ group on a semiconductor in solution.

Consequently, $\mathrm{A}^{\prime}$ is calculated as $-3 \mathrm{kcal} / \mathrm{mol} \sim-4 \mathrm{kcal} / \mathrm{mol}$ by using Eq. (3.46).

TABLE 3.4 THE ESTIMATED VALUES OF HEAT OF ADSORPTION OF

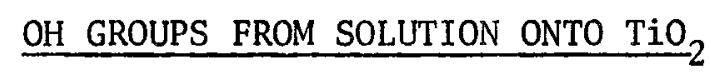

\begin{tabular}{lcc}
$x$ in $\mathrm{TiO}_{x}$ & $\mathrm{y}$ in $\left(\mathrm{TiO}_{\mathrm{x}}\right)_{\mathrm{y}}-\mathrm{OH}$ & $-\Delta \mathrm{H}_{\mathrm{ads}}, \mathrm{kcal} / \mathrm{mol}$ \\
\hline 1.90 & 10 & 35 \\
1.95 & 20 & 34 \\
1.975 & 40 & 33 \\
1.98 & 50 & 33 \\
1.996 & 250 & 31
\end{tabular}


1. H. Gerischer, "Physical Chemistry: An Advanced Treatise", Vo1. IXA, Chap. 5, Ed. H. Eyring, Academic Press, New York (1970).

2. J.O'M. Bockris, N. Bonciocat and F. Gutmann, "An Introduction to Electrochemical Science", Wykeham Press, London (1973).

3. D.B. Matthews and J.O'M. Bockris, "Modern Aspects of Electrochemistry", Vo1. 6, Chap. 4, Eds. J.0'M. Bockris and B.E. Conway, Plenum Press, New York (1971).

4. J.0'M. Bockris, S.U.M. Khan and K. Uosaki, J. Res. Inst. Cat. Hokkaido Univ., 24, 1 (1976). Modified version of chapter three of this thesis.

5. R. Schroeder and E.R. Lippincott, J. Phys. Chem., 61, 921 (1959).

6. G.W. Gobeli and F.G. Allen, "Semiconductors and Semimeta1s", Vo1. 2, Chap. 11, Eds. R.K. Willardson and A.C. Beer, Academic Press, New York (1966).

7. L.V. Azaroff and J.J. Brophy, "Electronic Processes in Materials", Chap. 7, McGraw-Hi11 Book Co., New York (1963).

8. V.A. Myamlin and Yu. V. P1eskov, "E1ectrochemistry of Semiconductors", (Eng1ish Edition), Chap I, P1enum Press, New York (1967) .

9. R.H. Kingston and S.F. Neustädter, J. Appl. Phys. 26, 718 (1955).

10. S.M. Ryvkin, "Photoelectric Effects in Semiconductors", (Eng1ish Edition) Chap. XIII, Consultants Bureau, New York (1964).

11. M. Green, "Modern Aspects of Electrochemistry", Vo1. 2, Chap. 5, Ed. J.O'M. Bockris, Butterworths Publications Ltd., London (1959).

12. J.0'M. Bockris and M.A. Habib, J. Electroanal. Chem.68, 367 (1976). 
80 .

13. K. Fueki, D.F. Feng and L. Kevan, J. Phys. Chem., 74, 1976 (1970).

14. J.O'M. Bockris and A.K.N. Reddy, "Modern Electrochemistry", Vol. 2, Chap. 7, Plenum Press, New York (1970).

15. J.A.A. Ketelaar, "Chemical Constitution", p.28 p.29, E1sevier, Amsterdam (1958).

16. L.M. Branscomb, Phys. Rev., 148, 11 (1966).

17. J.A. Kerr, Chem. Rev., 66, 465 (1966).

18. NRC of U.S.A., "International Critical Table", Vo1. VII, McGrawHi11 Book Co., New York (1929).

19. R.W. Gurney, Proc. Roy. Soc. (London) 134A, 137 (1932).

20. B.0. Seraphin and H.E. Bennett, "Semiconductor and Semimetals", Vo1. 3, Chap. 12, Ed. R.K. Willardson and A.C. Beer, Academic Press, New York (1967).

21. J.I. Pankove, "Optical Processes in Semiconductors", PrenticeHa11, Inc., New Jersey (1971).

22. P.J. Boddy, J. Electrochem. Soc., 115, 199 (1968).

23. A. Fujishima, K. Honda and S. Kikuchi, Kogyo Kagaku Easer:?, 72, 108 (1969).

24. D.M. Shub, A.A. Remnev and V.I. Veselovskii, EZektrokhimiya, 9, $1043(1973)$.

25. T. Ohnishi, Y. Nakato and H. Tsubomura, Ber. Bunsenges Phys. Chem., 79, 523 (1975).

26. F. Mö11ers, H.J. Tolle and R. Memming, J. Electrochem. Soc., $121,1160(1974)$.

27. J.O'M. Bockris and A.K.N. Reddy, "Modern Electrochemistry", Vo1. 2, Chap. 9, P1enum Press, New York (1970).

28. T. Watanabe, A. Fujishima and K. Honda, Chem. Lett., 897 (1974).

29. D.J. Benard and P. Handler, Surface Sci., 40, 141 (1973). 
81.

30. L. Pauling, "Nature of the Chemical Bond", Cornell University Press, Ithaca, N.Y. (1960).

31. M.W. Breiter, Ann. N.Y. Acad. Sci., 101, 709 (1963).

32. K.A. Gingerich and V. Piacente, J. Chem. Phys., 54, 2498 (1971).

33. C.Y.C. Lou, U.S. At. Energy Comm. UCRL-19685 (1970) •

34. P. Rüetschi and P. Delahay, J. Chem. Phys., 23, 556 (1955).

35. R.R. Merritt and B.G. Hyde, Phiz. Trans. Roy. Soc. (London), 274, $627(1973)$. 
CHAPTER FOUR

EXPERIMENTAL 
82.

CHAPTER FOUR

EXPERIMENTAL

\subsection{PHOTOELECTROCHEMICAL SYSTEM AND MEASUREMENTS}

\subsubsection{Electrochemica1 Ce11}

A picture of the electrochemical cell employed in this research is shown in Fig. 4.1 and detailed explanations of parts of the cell are given in Fig. 4.2. A platinum electrode (area: $10 \mathrm{~cm}^{2}$ ) and a saturated calomel electrode (Philips R11) were used as a counter electrode and a reference electrode respectively.

Al1 stopcocks and taps were made of teflon to avoid the use of grease.

\subsubsection{Electrode Holder}

To avoid contact of the metal used to form an ohmic contact with the solution, the back face and side of the semiconductor electrode were covered with an epoxy resin and to minimize the contact of the epoxy resin with the solution, a teflon electrode holder was used (Fig. 4.3). The absence of a leak, and therefore a solution contact with the metal used to obtain an ohmic contact was verified by the absence of a significant dark current, which was found to be present when the ohmic contact metal was in contact with the solution.

Electrode areas used were either $0.50 \mathrm{~cm}^{2}$ or $0.125 \mathrm{~cm}^{2}$.

\subsubsection{Electrochemical Apparatus}

PAR model 173 potentiostat/galvanostat with model 176 currentpotential converter was used to control the electrode potential. In some cases, the electrode potential was swept by a Wenking SMP69 potential stepping motor control and the current-potential 


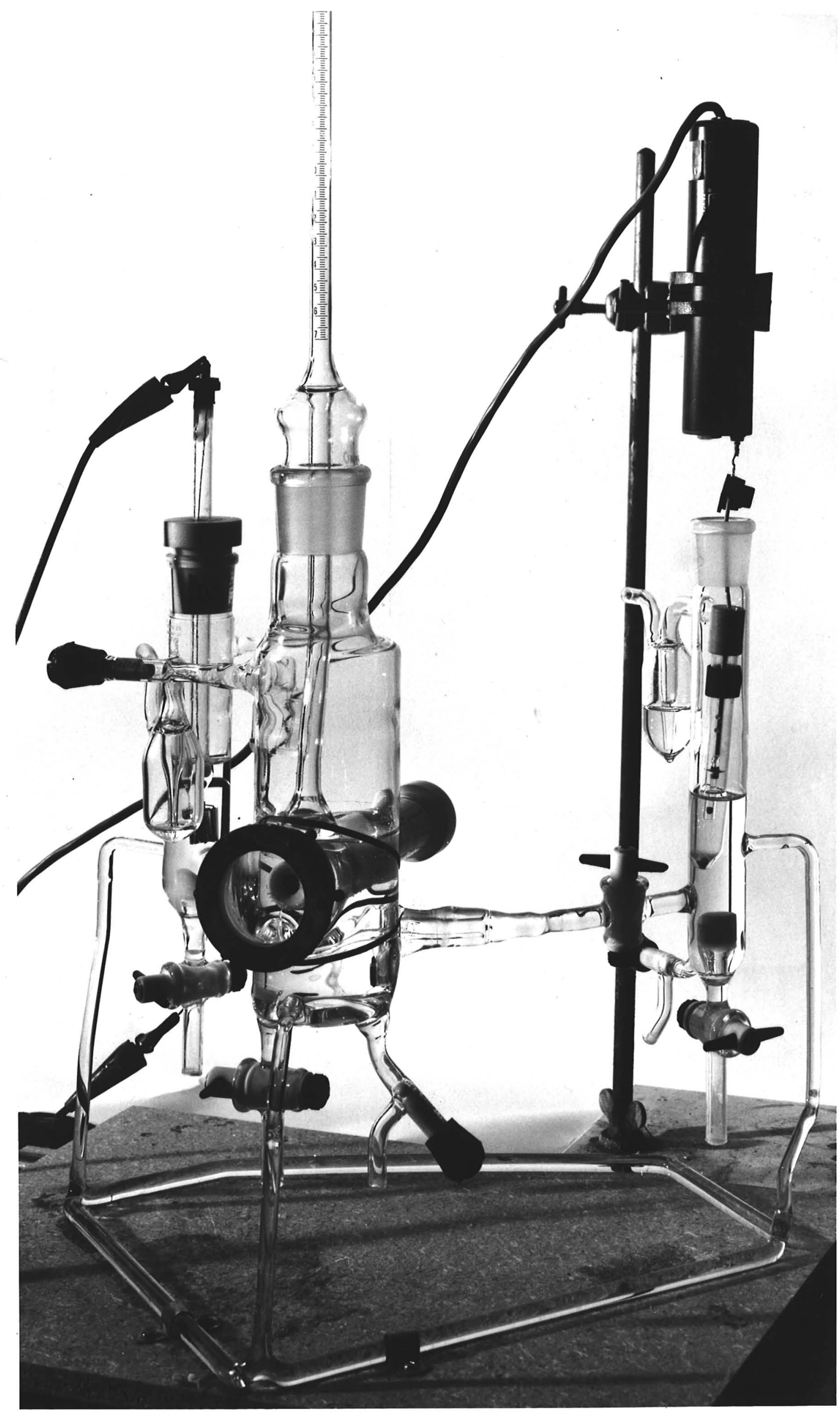

Fig. 4.1 The photoelectrochemical cell. 

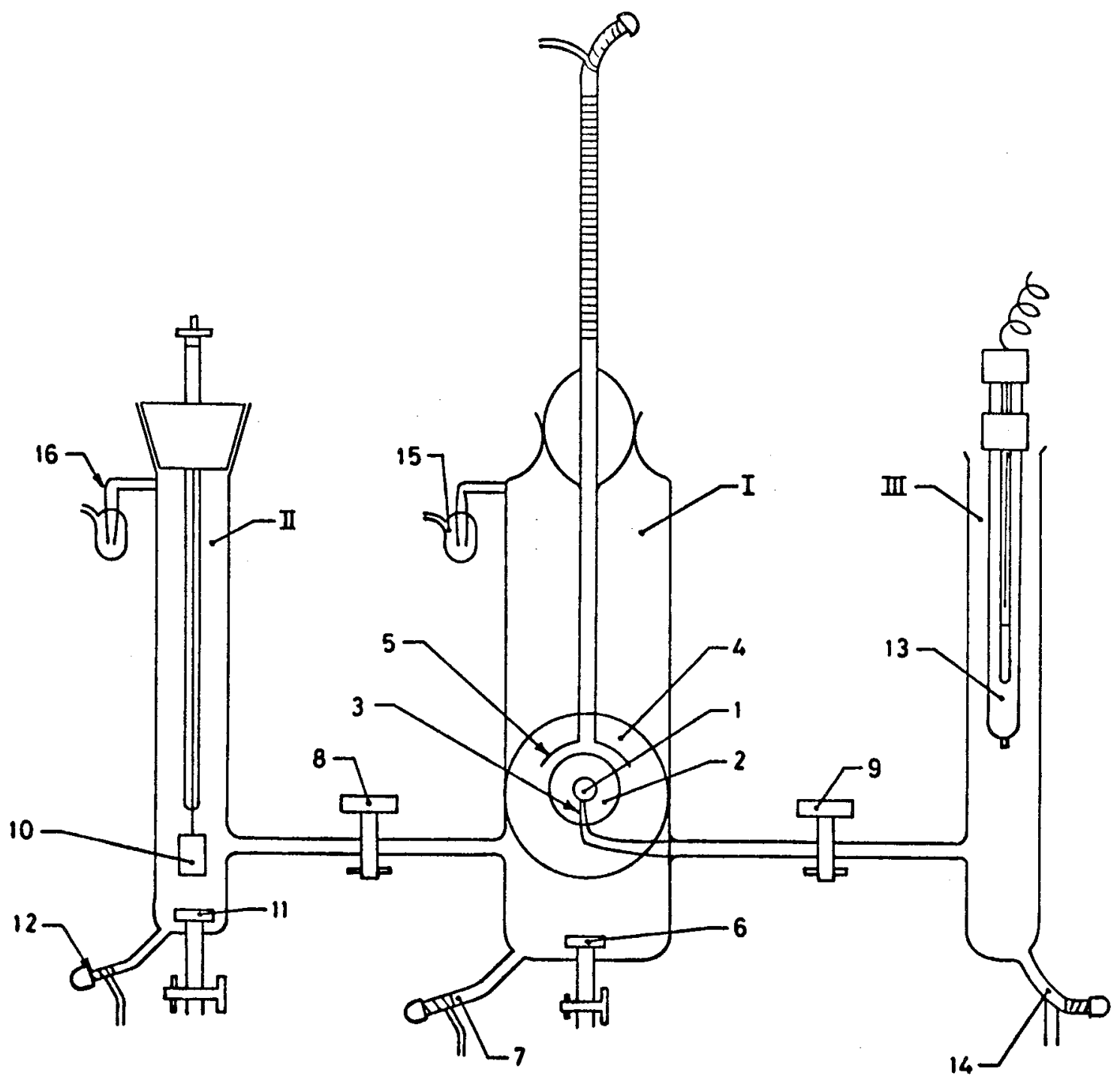

Rig. 4.2 The photoelectrochemical cell (Front View).

I. Working electrode (main) compartment ( $d=50 \mathrm{~mm})$. II. Counter electrode compartment $(d=25 \mathrm{~mm})$.

III. Reference electrode compartment $(d=20 \mathrm{~mm})$.

1. Working (semiconductor electrode). 2. Teflon electrode holder. 3. Luggin capillary. 4. Quartz optical flat. 5. Gas collector. 6, 11. Frit (gas inlet). 7, 12, 14. Drain. 8, 9. Stop cock. 10. Pt counter electrode. 13. Reference electrode (SCE). 15, 16. Gas bubbler. 
85.

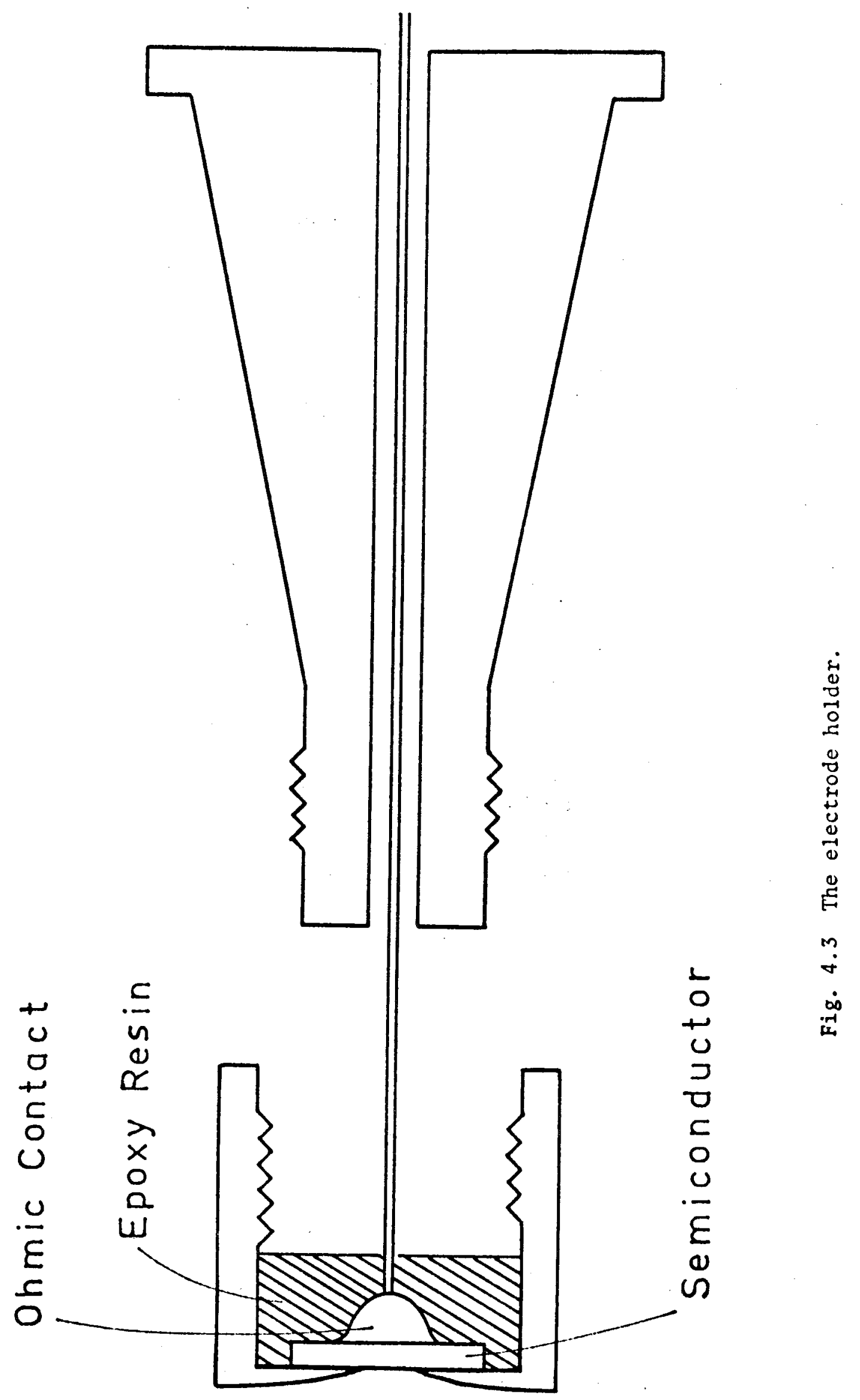


86.

relationship was recorded by a Hewlett-Packard Model 7004B X-Y recorder.

The time dependence of the photocurrent was recorded by a Hitachi QQD25 recorder.

Sometimes, a Keithley 616 digital electrometer was connected to the current-potential converter to increase the accuracy of the readings of the latter device.

\subsubsection{Optical Apparatus}

A $150 \mathrm{~W}$ xenon lamp (XBO $150 \mathrm{~W} / \mathrm{II}$ of 0sram, Germany) or a $900 \mathrm{Vi}$ xellon lamp (Canrad-Hanovia 538C1) were used as a light source and a Jarrel1-Ash quarter-meter grating monochrometer (Cat. No. 82-410) was employed to obtain monochromatic light.

A lamp house of the $900 \mathrm{~W}$ lamp had a shutter to measure a transient behaviour and a quartz lens $(d=5 \mathrm{~cm}, f=10 \mathrm{~cm})$ to provide a paralle1 light.

An IR absorbing filter (Oriel G-776-7100) was placed between tise electrochemical cell and the light house, when current-potential nicajurements were carried out without the monochrometer.

However, a quartz lens $(d=5 \mathrm{~cm}, f=5 \mathrm{~cm})$ was employed to concentrate the light on the electrode surface, when the photocurrat was measured under monochromatic light, since the intensity of light was otherwise too weak. Also, in this case, two long pass filters (Oriel G-772-3900 and Oriel G-772-5400) were used with tie Is aos riv filter to cut the second order diffraction light. The conditions used in this respect were:

$$
\begin{array}{ll}
3000 \AA \sim 5000 \AA & \text { IR absorbing filter only } \\
5000 \AA \sim 7000 \AA & \text { IR absorbing filter }+ \text { G-772-3900 filter } \\
7000 \AA \sim 7500 \AA & \text { IR absorbing filter + G-772-5400 filter } \\
7500 \AA \sim & \text { G-772-5400 filter only }
\end{array}
$$


The intensity of light was measured by a Hewlett-Packard model 8334 radiant flux meter with a $8334 \mathrm{~A}$ radiant flux detector or Carl Zeiss vacuum thermocouple (VT Q3/A) with a Keithley 149 millimicrovoltometer. Although the error of relative intensity was as 1 ow as $5 \%$, the absolute value of the intensity may involve $\pm 20 \%$ error.

\subsubsection{Experimental Set Up}

The whole photoelectrochemical system which consisted of an electrochemical cell, a light source, a monochrometer, a potentiostat, a potential sweeper, an $X-Y$ or an $X-t$ recorder, filters and lenses is shown in Fig. 4.4.

To obtain a reasonable accuracy, the electrochemical cell, the lens, the filters, the monochrometer and the light source were set on an optical bench.

\subsubsection{Transient Measurements}

The transient behaviaur of the photocurrents under potentiostatic condition was measured.

In these measurements, a cathode ray oscilloscope (Tecktronix $5103 \mathrm{~N}$ with $5 \mathrm{~A} 20 \mathrm{~N}$ differential amplifier, 5B12N dual time base and D13 dual beam storage was connected to the current-potential converter instead of a recorder. (See Fig. 4.4).

A signal from a control box was given to a c.r.o. to trigger a sweep and also to a solenoid to open or close a shutter (Copal No.0) of the light source.

Since a shutter was used, the phenomena, the time constant of which were less than $10^{-3} \mathrm{sec}$, could not be recorded. 


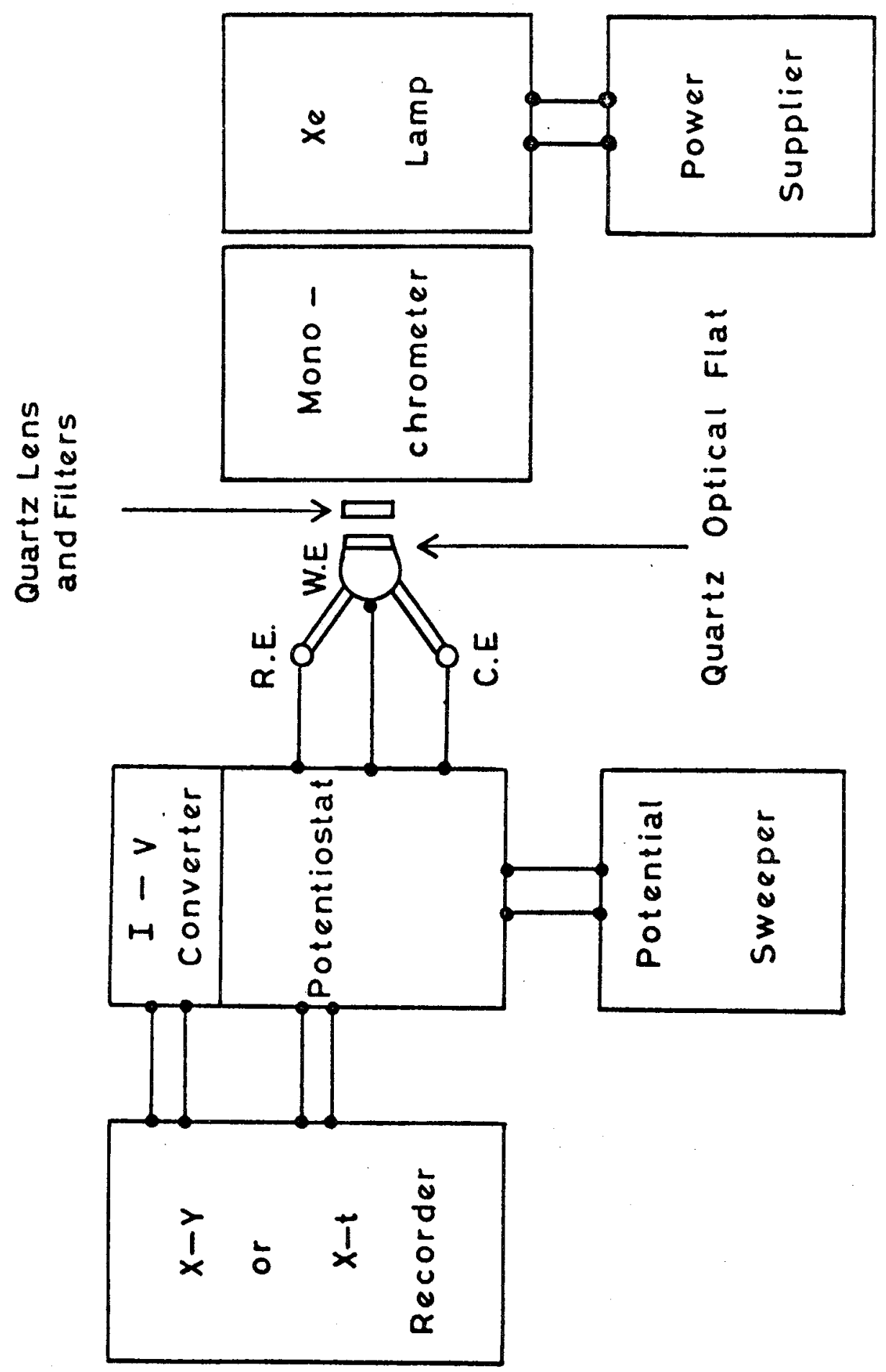

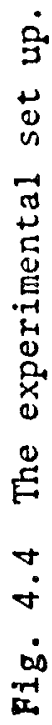




\subsection{IMPEDANCE MEASUREMENTS}

\subsubsection{Impedance Measurement Cel1}

A cell for impedance measurements is shown in Fig. 4.5 and has three compartments and four electrodes, i.e., working, counter for DC and AC respectively, and reference electrode. The working electrode was surrounded by a cylindrical counter electrode (for $A C$ ), the apparent area of which was $60 \mathrm{~cm}^{2}$ and which consisted of platinized platinum (see Fig. 4.5)

The counter electrode for DC was platinum and the reference electrode was a saturated calomel electrode (Philips R11).

The same electrode holder that used for the photoelectrochemical measurements was used for the impedance measurements.

Hydrogen gas was passed in the main compartment (I in Fig. 4.5) before and during measurement.

\subsubsection{Principle of Measurement}

The direct method was employed $[1,2]$.

Electric circuit for measurement is shown in Fig. 4.6. A dry ce11 ( $6 \mathrm{~V}$ ) was employed as a DC source for the working electrode and the applied electrode potential was controlled by a ten turn variable resistor, whilst monitoring the electrode potential with respect to a saturated calomel electrode by a Keithley 616 Digital electrometer.

As an AC source, Mini-Lab Model bwd 603A (B.W.D. Electronics) was used.

A capacitor $(10 \mu F)$ was employed to prevent the flow of DC through the $\mathrm{AC}$ circuit and a choke coil (35H) was used to prevent the $\mathrm{AC}$ current flowing through the DC circuit.

A resistor $(100 \mathrm{~K} \Omega$ or $1 \mathrm{M} \Omega)$, the resistance of which, $R$, was at least one hundred times larger than the cell impedance, $Z_{\text {cell }}$, was 

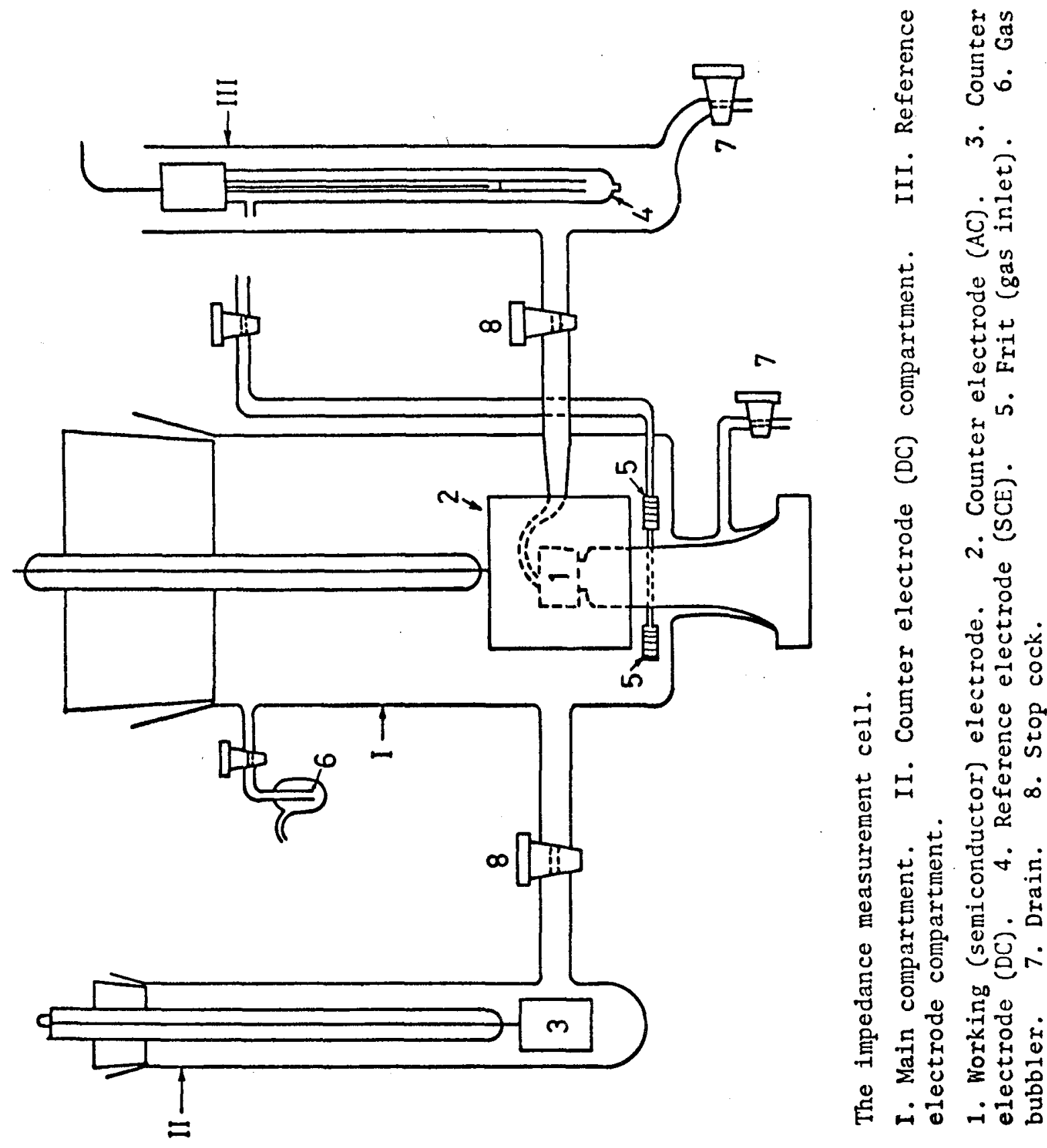

$\dot{+}$
$\dot{0}$
$0-1$
0 
91.

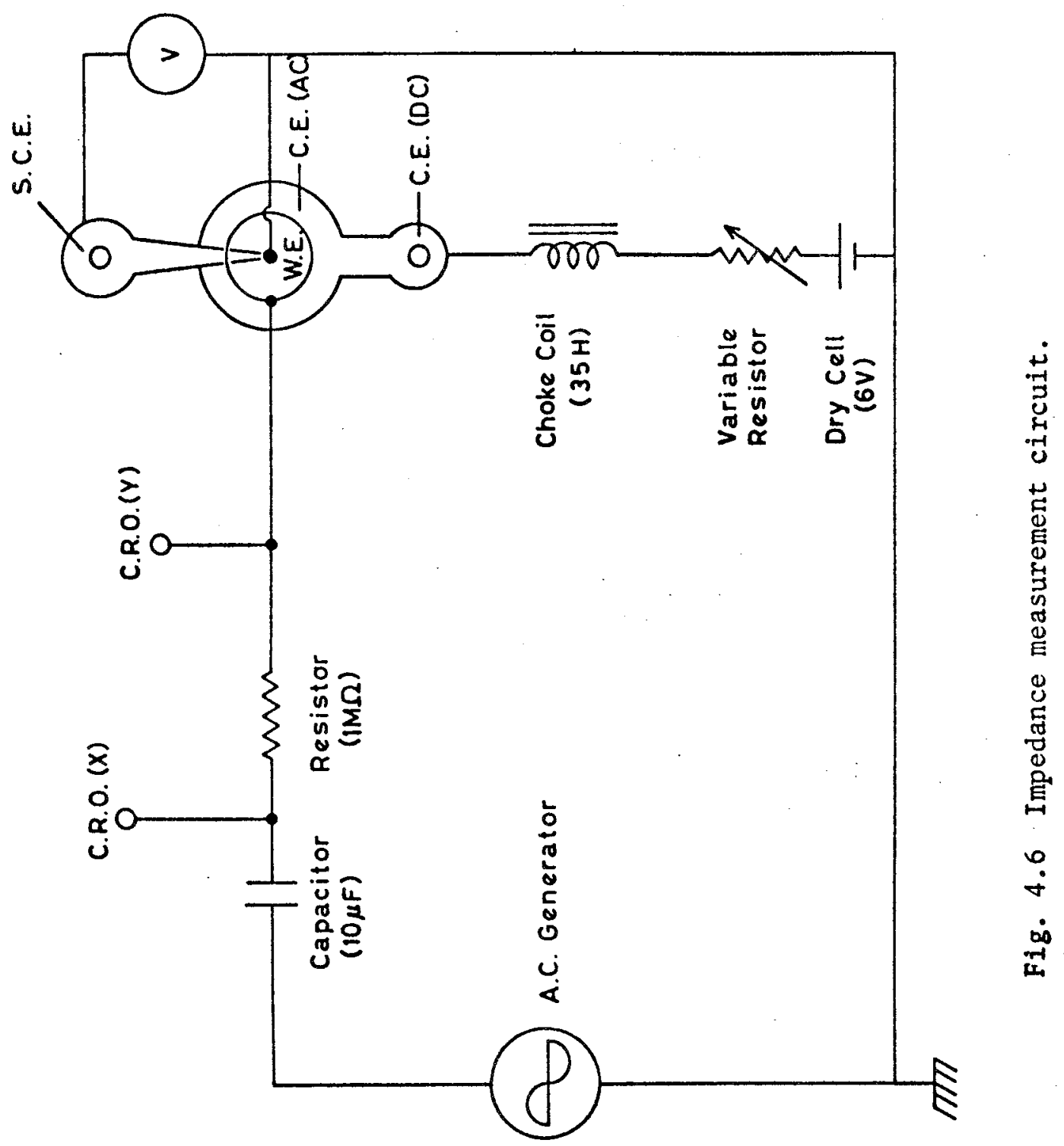


92.

connected in series to the cell so that the alternating current, I, became constant, and independent of the cell voltage. Measurements were carried out only when the impedance of choke coil was at least one hundred times larger than that of the cell.

Signals were taken from two points in the circuit shown in Fig. 4.6 onto $X$ and $Y$ inputs of a cathode ray oscilloscope (Tektronix $5103 \mathrm{~N}$ with $5 \mathrm{~A} 20 \mathrm{~N}$ and $5 \mathrm{~A} 21 \mathrm{~N}$ differential amplifiers) and a Lissajou's figure appeared on the screen. Since the $X$ and $Y$ inputs showed $I\left(Z_{c e 11}+R\right)$ and $I Z_{c e 11}$, respectively, and $R \gg Z_{c e 11}$, the absolute value of the cell impedance and the phase difference due to the cell could be ascertained.

Assuming a series equivalent circuit (all measurements were carried out under nearly ideally polarized conditions), one can calculate the cell capacitance which is the space charge capacitance of the semiconductor electrode, because the area of counter electrode for $\mathrm{AC}$ was so large ( $>500$ times of that of working electrode) that the impedance of this electrode was negligible and the double layer capacitance is also large compared with space charge capacitance so that the impedance due to double layer capacitance is negligible.

The accuracy of this method is relatively low compared with the bridge method $[1,2]$ and it is rarely employed in the measurement of double layer capacitance on metal electrodes, in which the impedance due to double layer capacitance is so small that to measure phase difference accurately is very difficult, because the phase difference, $\theta$, is given by

$$
\tan \theta=\frac{1 / \omega C}{R}
$$

where $\omega$ is an angular frequency, $C$ is capacitance and $R$ is resistance. 
93.

However, in the semiconductor electrode's case, a capacitance due to space charge layer is relatively low $(1 / 10 \sim 1 / 100$ of double layer capacitance) so that the phase difference can be measured with reasonable accuracy. Actually, most of the semiconductors examined here had low resistances and low capacitances and therefore the impedance of the cell were mainly due to capacitive part. 


\subsection{PREPARATION AND PRETREATMENT OF SEMICONDUCTORS}

\subsection{1 n-Type Semiconductors}

\subsubsection{Titanium Dioxide $\left(\mathrm{TiO}_{2}\right)$}

\subsubsection{1 $\mathrm{TiO}_{2}$ single crystals}

$\mathrm{TiO}_{2}$ single crystals cut perpendicular to the c-axis ( $(001)$

face; 1mm thick) with mirror finish obtained from Nakazuni Crystals Corporation were used.

Pure $\mathrm{TiO}_{2}$ is an insulator $\left(\rho \approx 10^{11} \mathrm{ohm} \cdot \mathrm{cm}\right)$ without treatment and has to be reduced in order to increase the non-stoichiometry of the oxide (and thus augment its conductivity) if it is to be used as an electrode.

A $\mathrm{TiO}_{2}$ single crystal was reduced in the vicinity of $800^{\circ} \mathrm{C}$ in a flowing hydrogen atmosphere in a quartz tube for five hours [3] . After reduction, the $\mathrm{TiO}_{2}$ crystal showed blue black colour.

There are many ways to make an ohmic contact with a $\mathrm{TiO}_{2}$ crystal [4]. The direct melting method was employed because of its ease [5] . A $\mathrm{TiO}_{2}$ crystal on which about $0.5 \mathrm{~g}$ of indium was set was placed on a watch glass which was in turn supported by a heater and the crystal was heated until the indium melted. After this, the heater was turned off and allowed to cool. (Quenching makes a mechanically weak contact). Thereafter, a copper wire was soldered onto the indium. A currentpotential relation showed a good ohmic contact and a specific conductivity was calculated as $2.0 \mathrm{ohm} . \mathrm{cm}$ from these observations.

\subsection{Titanium anodic oxide film}

A titanium rod $(\mathrm{d}=0.62 \mathrm{~cm})$ of Alfa Inorganics was cut about $5 \mathrm{~mm}$ thick, polished, degreased with chloroform vapor, rinsed with distilled water and fixed in an electrode holder. The electrode area 
was $0.125 \mathrm{~cm}^{2}$.

Anodic oxidation and photoelectrochemical measurements were carried out in a solution, $15 \% \mathrm{H}_{2} \mathrm{SO}_{4}, 2 \% \mathrm{Na}_{3} \mathrm{PO}_{4}, 5 \% \mathrm{Na}_{2} \mathrm{HPO}_{4}$, saturated $\mathrm{H}_{3} \mathrm{BO}_{3}[6]$.

The titanium electrode was anodically polarized at $10.24 \mathrm{~V}(\mathrm{NHE})$ to grow the oxide film on the surface. Photocurrents were measured at $2.24 \mathrm{~V}(\mathrm{NHE})$ and the electrode was sometimes cathodically polarized at $-1.76 \mathrm{~V}(\mathrm{NHE})$ to reduce the oxide.

\subsection{Titanium oxide film by high temperature oxidation}

The same titanium rod mentioned in section 4.3.1.1.2 was cut about $5 \mathrm{~mm}$ thick and treated in the same way as shown in section 4.3.1.1.2.

These specimens were heated in an electric furnace in air at $600^{\circ} \mathrm{C}$ for 15 minutes, 30 minutes, 1 hour, 2 hours and 3 hours.

Independently, partly reduced $\mathrm{TiO}_{2}$ films, i.e., films formed after heating in air for a certain time, and then heating in hydrogen at $800^{\circ} \mathrm{C}$ for 2 hours, were made.

Platinum wire was spotwelded to the side of each specimen where the oxide film was removed by polishing before making contact.

\subsection{Titanium oxide film by chemical vapor deposition (CVD)}

A $\mathrm{TiO}_{2}$ film was made on a titanium rod which was the same rod and was treated in the same way as mentioned in section 4.3 .1 .1 .2 or on a cadmium sulfide single crystal obtained from Teikoku Tsushin Kogyo Co. Ltd. $((0001)$ face; specific resistance $=0.26 \mathrm{ohm} . \mathrm{cm} ;$ carrier density $\left.=8.0 \times 10^{16} \mathrm{~cm}^{-3}\right)$ by using titanium tetraisoproponate $\left(\mathrm{Ti}\left(\mathrm{i}-\mathrm{OC}_{3} \mathrm{H}_{7}\right)_{4}\right)$ of Alfa Products (AR grade) and water in accordance with the following equation [6]

$$
\mathrm{Ti}\left(\mathrm{i}-\mathrm{OC}_{3} \mathrm{H}_{7}\right)_{4}+2 \mathrm{H}_{2} \mathrm{O} \stackrel{\text { heat }}{\longrightarrow} \mathrm{TiO}_{2}+4 \mathrm{C}_{3} \mathrm{H}_{7} \mathrm{OH}
$$


96.

As shown in Fig. 4.7, titanium tetra isoproponate and water were heated in water baths and high purity nitrogen gas was used as a carrier gas. The substrate (titanium rod or CdS single crystal) was heated to about $200^{\circ} \mathrm{C}$. $\quad \mathrm{Ti}\left(\mathrm{i}-\mathrm{OC}_{3} \mathrm{H}_{7}\right)_{4}$ was kept about $80^{\circ} \mathrm{C}$.

Contacts were made by spotwelding a platinum wire onto the side of titanium rod or by soldering a copper wire with indium onto CdS single crystal.

\subsubsection{Meta1 Titanate}

\subsection{Cobalt titanate polycrystal [7]}

Cobalt oxide (II,III) $\left(\mathrm{CO}_{3} \mathrm{O}_{4}\right)$ of The British Drug House Ltd. was heated in air at $1000^{\circ} \mathrm{C}$ for 2 hours to obtain cobalt oxide (II) (CoO) . Cobalt oxide (II) ( $\mathrm{CoO}$ ) was ground and mixed with equimolar amounts of titanium dioxide powder (Research Organic/Inorganic Chemical Corp. 99.99\%). This mixture was heated in nitrogen atmosphere at $1000^{\circ} \mathrm{C}$ for 24 hours. After heating the colour of the sample changed from black to dark green. The sample was ground thoroughly by an agate mortar and a pellet $(d=1.25 \mathrm{~cm}$, 3mm thick) was made by press at $2000 \mathrm{~kg} / \mathrm{cm}^{2}$ for 10 minutes. This pellet was heated in a nitrogen atmosphere at $1100^{\circ} \mathrm{C}$ for 48 hours.

Since this specimen had too high a resistance, it was reduced in a hydrogen atmosphere at $800^{\circ} \mathrm{C}$ for 5 hours. The colour of the pellet changed from dark green to black.

A contact was made by ineans of indium and a copper ire scidere: on indium.

\subsection{Iron titanate polycrystal [8]}

Equimolar amounts of iron oxide $\left(\mathrm{Fe}_{2} \mathrm{O}_{3}\right)$ powder of Koch-Light Laboratories ( $>99.99 \%$ ) and titanium dioxide powder of Research Organic/Inorganic Chemical Co. (> $99.99 \%)$ were mixed and heated in 


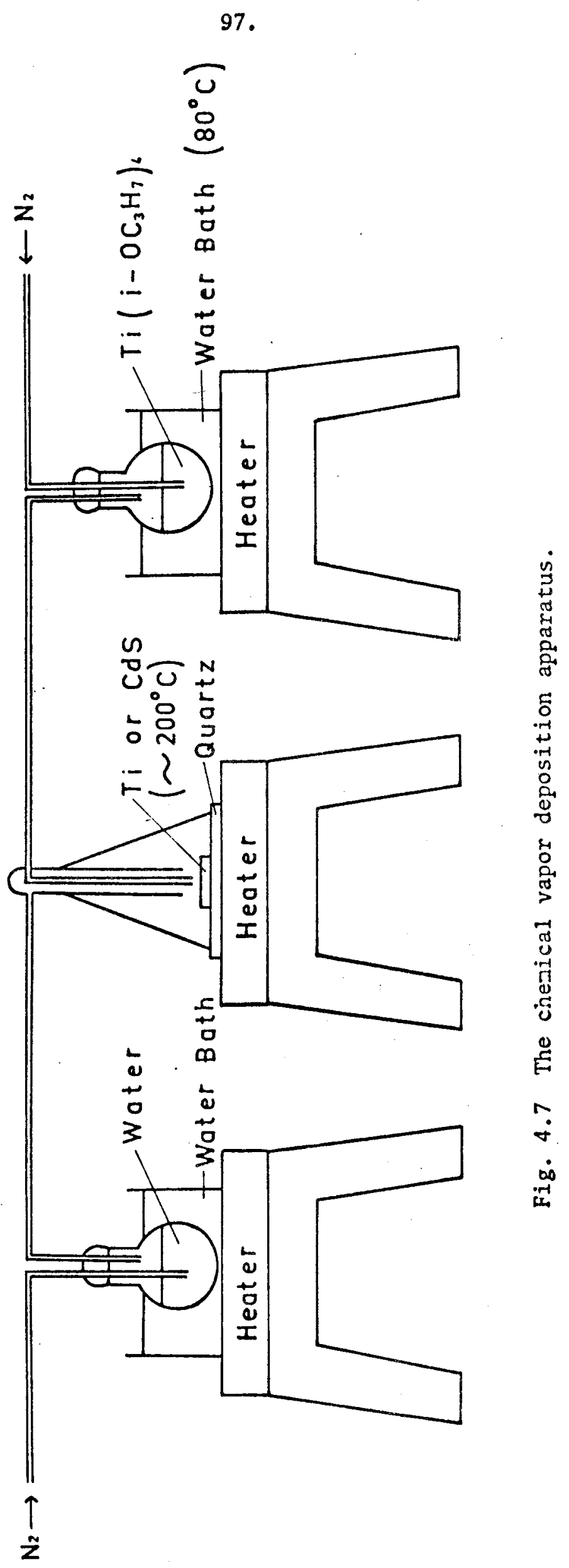


98 .

oxygen atmosphere at $1000^{\circ} \mathrm{C}$ for three days. The sample was reground and pelleted $(d=1.25 \mathrm{~cm})$ by pressing at $2000 \mathrm{~kg} / \mathrm{cm}^{2}$. This pellet was heated in oxygen atmosphere at $1000^{\circ} \mathrm{C}$ for three days.

Since the resistance of the sample was too high (about $2 \times 10^{8}$ ohm. $\mathrm{cm}$ ), it was partially reduced by heating in hydrogen at $800^{\circ} \mathrm{C}$ for $30 \mathrm{~min}$. After the reduction, the resistance became $1000 \mathrm{ohm} . \mathrm{cm}$. An ohmic contact was made by using indium and a copper wire was soldered on indium.

\subsection{2 p-Type Semiconductors}

\subsubsection{Zinc Telluride ( $\mathrm{ZnTe})$}

A ZnTe single crystal (Ag doped), grown by the Bridgeman method and donated by Mr. H. Kimura of Mitsubishi Electric Co. Ltd., was cut parallel to the cleaved face (100). After being etched in $\mathrm{K}_{2} \mathrm{Cr}_{2} \mathrm{O}_{7}-$ $\mathrm{HNO}_{3}$ aqueous solution, the specimen was dipped in $\left.\mathrm{H}_{[\mathrm{AuCl}}\right]_{4}$ solution to make an ohmic contact [9]. Except some places to which contact had to be made, the specimen was covered with paraffin. The paraffin was removed by rinsing in trichloroethylene after the contact was made. The current-potential relation showed a good ohmic contact and the specific resistance was calculated from the relation as 0.2 ohm.cm. Then, only one face of the specimen which should be used as an electrode surface was polished by emery paper from 400 to 600 grade. The specimen was mounted in a teflon electrode holder with an epoxy resin. The electrode area was $0.125 \mathrm{~cm}^{2}$. The electrode surface was etched in $\mathrm{HF}-\mathrm{HNO}_{3}$ solution before each experiment [10] .

\subsubsection{Cadmium Te1luride (CdTe)}

A CdTe single crystal (undoped), also grown by the Bridgeman method and donated by Mr. H. Kimura of Mitsubishi Electric Co. Ltd., was cut parallel to the cleaved face (100). Since the specimen had 
99.

a relatively high resistance (about $10^{4} \mathrm{ohm} . \mathrm{cm}$ ), it was heated in Te vapor at $500^{\circ} \mathrm{C}$ for 8 hours to increase the non-stoichiometry (Cd vacancies), i.e., the conductivity [11]. After this treatment, the crystal was etched in $\mathrm{K}_{2} \mathrm{Cr}_{2} \mathrm{O}_{7}-\mathrm{HNO}_{3}$ solution [12], dipped in $\mathrm{AgNO}_{3}$ solution and, then, heated at $200^{\circ} \mathrm{C}$ for 30 minutes to let the silver diffuse into the crystal. Finally a gold film was made on the crystal by dipping in $\mathrm{H}\left[\mathrm{AuCl}_{4}\right.$ solution and this gave an ohmic contact [13]*. During these processes (etching and dipping in $\mathrm{AgNO}_{3}$ and $\mathrm{H}\left[\mathrm{AuCl}_{4}\right]$, the crystal was covered with paraffin except some spots where contact had to be made. The specific resistance was calculated as $10^{3} \mathrm{ohm} . \mathrm{cm}$ from the I-V relation which showed a good ohmic contact. Then a face to be used as an electrode surface was polished by emery paper from 400 to 600 grade. The specimen was mounted in an electrode holder and the electrode surface was etched in $\mathrm{HF}-\mathrm{HNO}_{3}$ solution before each experiment. The electrode area was $0.125 \mathrm{~cm}^{2}$.

\subsubsection{Gallium Arsenide (GaAs)}

GaAs single crystal wafer ((100) face; $\mathrm{Zn}$ doped; carrier density $=2 \times 10^{19} \mathrm{~cm}^{-3} ; 0.5 \mathrm{~mm}$ thick) was donated by Dr. 0. Mizuno of Nippon Electric Co. Ltd.

It was etched by dipping into $\mathrm{CH}_{3} \mathrm{OH}-\mathrm{Br}_{2}(5 \%)$ solution, for 1 minute [12] before an ohmic contact was made by soldering with indium [14]. A copper wire was soldered on indium. I-V relation showed a good ohmic contact and gave $0.2 \mathrm{ohm} . \mathrm{cm}$ as a specific resistance.

* This method was proposed to make an ohmic contact to p-type ZnTe. It worked very well in this case. Without $\mathrm{AgNO}_{3}$ treatment, the linearity of I-V relation was not very good. 
100.

The specimen was mounted in a teflon holder with epoxy resin and the electrode area was $0.125 \mathrm{~cm}^{2}$.

The electrode surface was etched in $\mathrm{CH}_{3} \mathrm{OH}-\mathrm{Br}_{2}$ (5\%) solution before each experiment.

\subsubsection{Indium Phosphide (InP)}

InP single crystal wafer ((100) face; $Z$ n doped; carrier density $=5.6 \times 10^{18} \mathrm{~cm}^{-3} ; 0.8 \mathrm{~mm}$ thick) which was also donated by Dr. 0 . Mizuno was treated exactly in the same way as that of GaAs except that an ohmic contact was made by the use of In- $\mathrm{Zn}$ alloy instead of In [15]. Quite a good ohmic contact was obtained and specific resistance was $0.21 \mathrm{ohm} . \mathrm{cm}$.

\subsubsection{Gallium Phosphide (GaP)}

GaP single crystal wafer ( $\mathrm{z}$ doped; carrier density $=6.7 \mathrm{x}$ $10^{17} \mathrm{~cm}^{-3} ;$ (111) face; $0.4 \mathrm{~mm}$ thick) was donated by Dr. K. Akita of Fujitsu Lab. Ltd.

$\mathrm{HNO}_{3}-\mathrm{HC} \ell(2: 1)$ mixture was used as an etching solution and the crystal was kept in the solution for two minutes [12]. An ohmic contact was obtained by the use of In-Zn alloy [16] and a copper wir was soldered on the alloy with the alloy and the specific resistance was $2.0 \mathrm{ohm} . \mathrm{cm}$.

The wafer was mounted in the same way as explained in section. 4.3.2.1 and etched in $\mathrm{HNO}_{3}-\mathrm{HCl}$ (2:1) solution before each experiment.

\subsubsection{Silicon Carbide (SiC)}

Silicon Carbide single crystal ( $(000 \overline{1})$ face; Al doped; carrier density $=4 \times 10^{18} \mathrm{~cm}^{-3} ; 0.2 \mathrm{~mm}$ thick) grown by epitaxial growth method was donated by Prof. von Münch of Technische Universität, Hannover.

Si-Al eutectic alloy is usually employed to obtain an ohmic 
101.

contact for SiC [17]. However, Acme conductive adhesive (E-solder 3021 : made of epoxy resin, silver and gold) was found to give a good ohmic contact if heated in hydrogen atmosphere at $300^{\circ} \mathrm{C}$ for 2 hours. A good linear I-V curve was obtained (See Fig. 4.8) and the specific resistance was calculated as $0.31 \mathrm{ohm} . \mathrm{cm}$. When the heating was not sufficient, non-ohmic I-V curve with high resistance was obtained (see Fig. 4.8).

The crystal was mounted in a teflon electrode holder with epoxy resin and the electrode area was $0.125 \mathrm{~cm}^{2}$.

To make sure there was no $\mathrm{SiO}_{2}$ film on the surface, the electrode was dipped in $\mathrm{HF}$ for $1 \mathrm{~min}$. before each experiment.

\subsubsection{Silicon (Si)}

Silicon single crystal wafer ((100) face; B doped; $0.2 \mathrm{~mm}$ thick) was donated by Toyo Silicon Co. Ltd.

In-Zn alloy was used to obtain an ohmic contact. Only when Zn content was relatively high, a good ohmic contact was obtained. Therefore, $\mathrm{Zn}$ was added until I-V relation showed a good linear relation (see Fig. 4.9). The specific resistance was $1.2 \mathrm{ohm} . \mathrm{cm}$.

The crystal was mounted in a teflon electrode holder with epoxy resin and etched in HF solution before each experiment.

\subsubsection{Summary of p-type semiconductors}

Suppliers, etchants, ohmic contacts and some properties of p-type semiconductors studied in this research are listed in Table 4.1. 

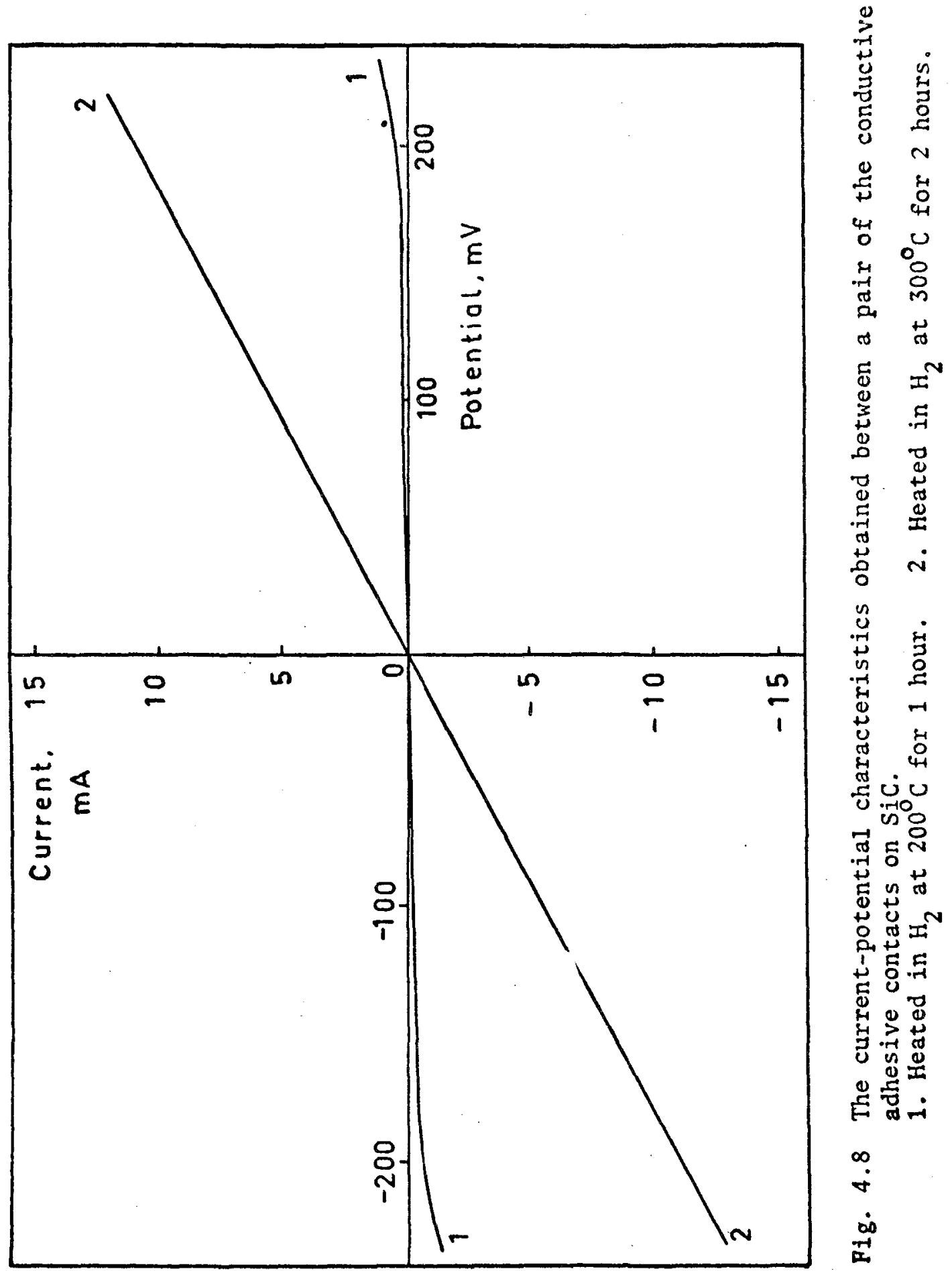


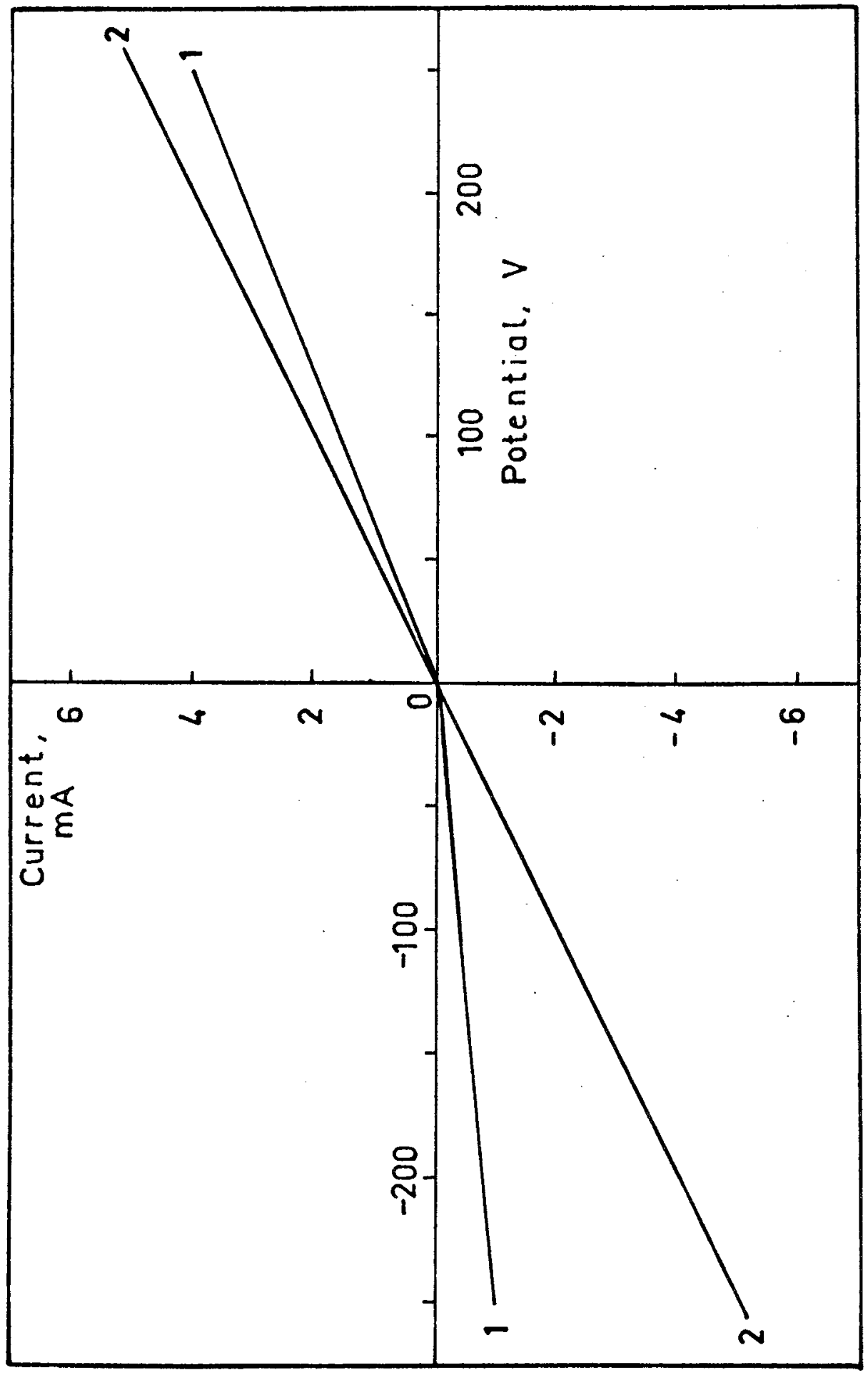

官

$\infty$

푤

:

芩

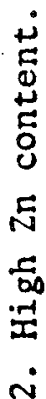

吾

동

实

毞䓵

急 它

\%

$\infty_{i=1}^{\infty}$ 
TABLE 4.1 LIST OF P-TYPE SEMICONDUCTORS

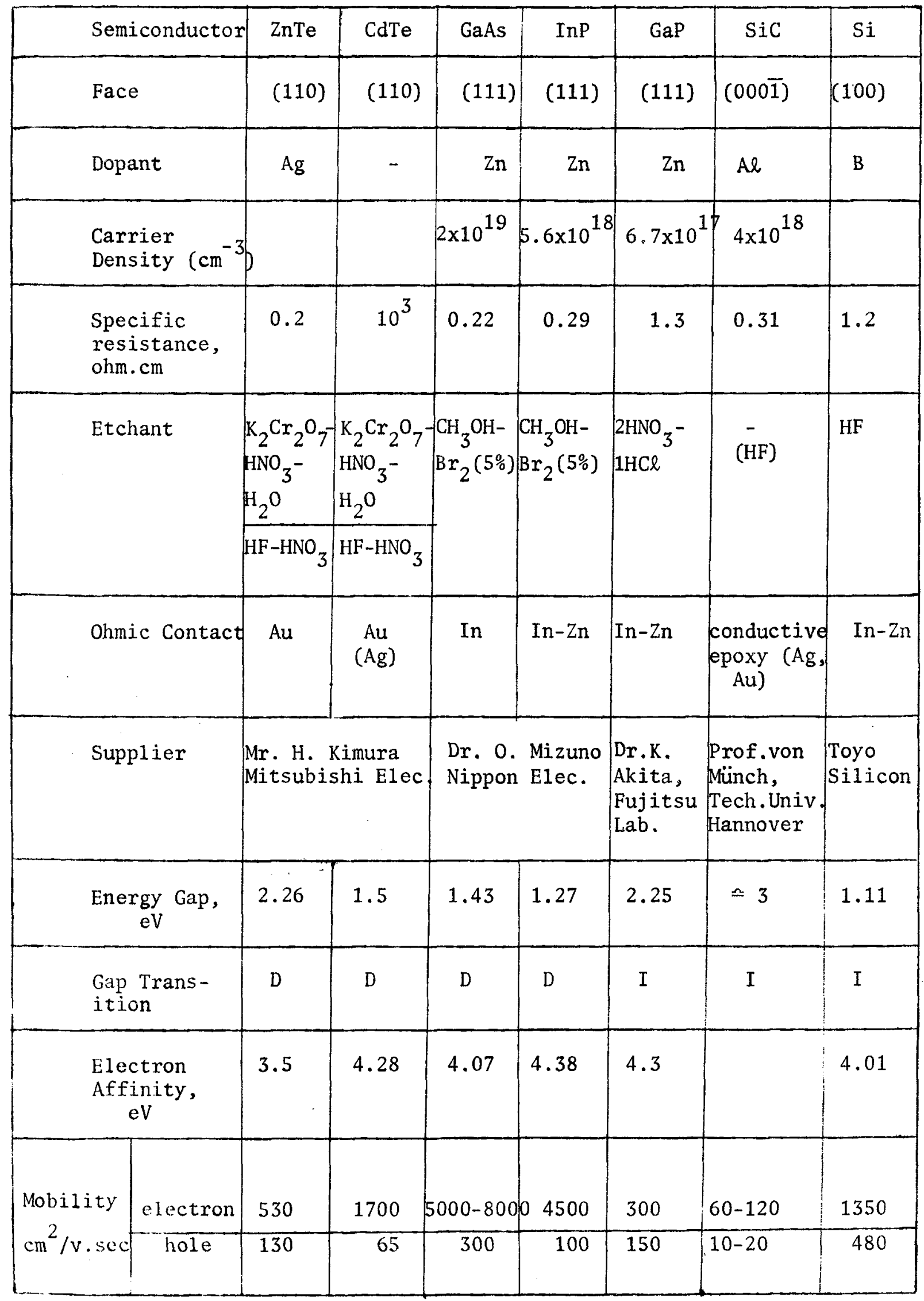




\section{BIBLIOGRAPHY OF CHAPTER FOUR}

1. H. Gerischer, Z. Elektrochem., 59, 9 (1954).

2. M. Sluyters-Rehbach and J.H. Sluyters, "Electroanalytical Chemistry: A Series of Advance", Vol. 4, Chap. 1, Ed. A.J. Bard, Marce1 Dekker, Inc., New York (1970).

3. D.C. Cronemeyer, Phys. Rev., 87, 8176 (1952).

4. W.C. Dunlop, "An Introduction to Semiconductors", Chap. 9, John Wiley and Sons Inc., New York (1957).

5. D.M. Shub, A.A. Remnev and V.I. Veselovskii, Elektrokhimiya, $\underline{9}, 676(1973)$

6. K.L. Hardee and A.J. Bard, J. EZectrochem. Soc., 122, 739 (1975).

7. T. Kubo, M. Kato, K. Nakazato and K. Fujita, Kogyo Kagaku Zasshi, 67, 1502 (1964).

8. I. Grey (C.S.I.R.O. Div. of Mineral Chem.) private communication (1976) .

9. W.D. Baker and A.G. Milnes, J. EZectrochem. Soc., 119, 1269 (1972) •

10. V.I. Sapritskii and N.G. Bardina, EZektrokhimiya, $\underline{8}, 655$ (1972).

11. H. Kimura (Mitsubishi Electric Co. Ltd.) private communication (1976)

12. H.C. Gatos and M.C. Lavine, "Prog. in Semiconductors" $\underline{9}, 1$, Eds. A.F. Gibson and R.E. Burgess (1965).

13. M. Aven and W. Garwacki, J. EZectrochem. Soc., 114, 1063 (1967).

14. J. Lowen and R.H. Rediker, J. Electrochem. Soc., 107, 26 (1960).

15. 0. Mizuno (Nippon Electric Co. Ltd.) private communication (1976).

16. H. Yoneyama, H. Sakamoto and H. Tamura, Electrochim. Acta, 20, $341(1975)$.

17. J.S. Shier, J. App Z. Phys., 41, 771 (1970). 
CHAPTER FIVE

EXPERIMENTAL RESULTS 


\section{CHAPTER FIVE}

EXPERIMENTAL RESULTS

\subsection{PHOTOEFFECTS ON ANODIC REACTION AT $n$-TYPE SEMICONDUCTORS}

The current-potential relations with and without illumination by the $150 \mathrm{~W}$ Xe lamp in solutions of several $\mathrm{pH}^{\prime} \mathrm{s}$ and the photocurrentwavelength relations at several potential in $0.1 \mathrm{~N} \mathrm{NaOH}$ were measured at $\mathrm{TiO}_{2}$ single crystal.

The current-potential with and without illumination by the $150 \mathrm{~W}$ or the $900 \mathrm{~W}$ Xe 1amp and the photocurrent-wavelength relations were measured at $\mathrm{TiO}_{2}$ films made by several ways (see section 4.3). The prevention of anodic dissolution of CdS single crystal was tried.

The current-potential with and without illumination by the $900 \mathrm{~W}$ Xe lamp and the photocurrent-wavelength relations of metal titanates were measured. These results are reported in the following sections.

\section{1 .1 Titanium Dioxide $\left(\mathrm{TiO}_{2}\right)$}

\subsubsection{TiO ${ }_{2}$ single crystals}

5.1.1.1.1 Current-potential relations in solutions of various $\mathrm{pH}^{\prime} \mathrm{s}$

Current-potential relations were measured in solutions of various $\mathrm{pH}^{\prime} \mathrm{s}$ with and without illumination by the $150 \mathrm{~W}$ Xe lamp, potentiostatically at room temperature. The results are shown in Fig. 5.1. The shape of the curves are almost the same for all solutions, although the curves are shifted along the potential axis corresponding to the change of the $\mathrm{pH}$ of the solution. Similar results were reported [1] . 


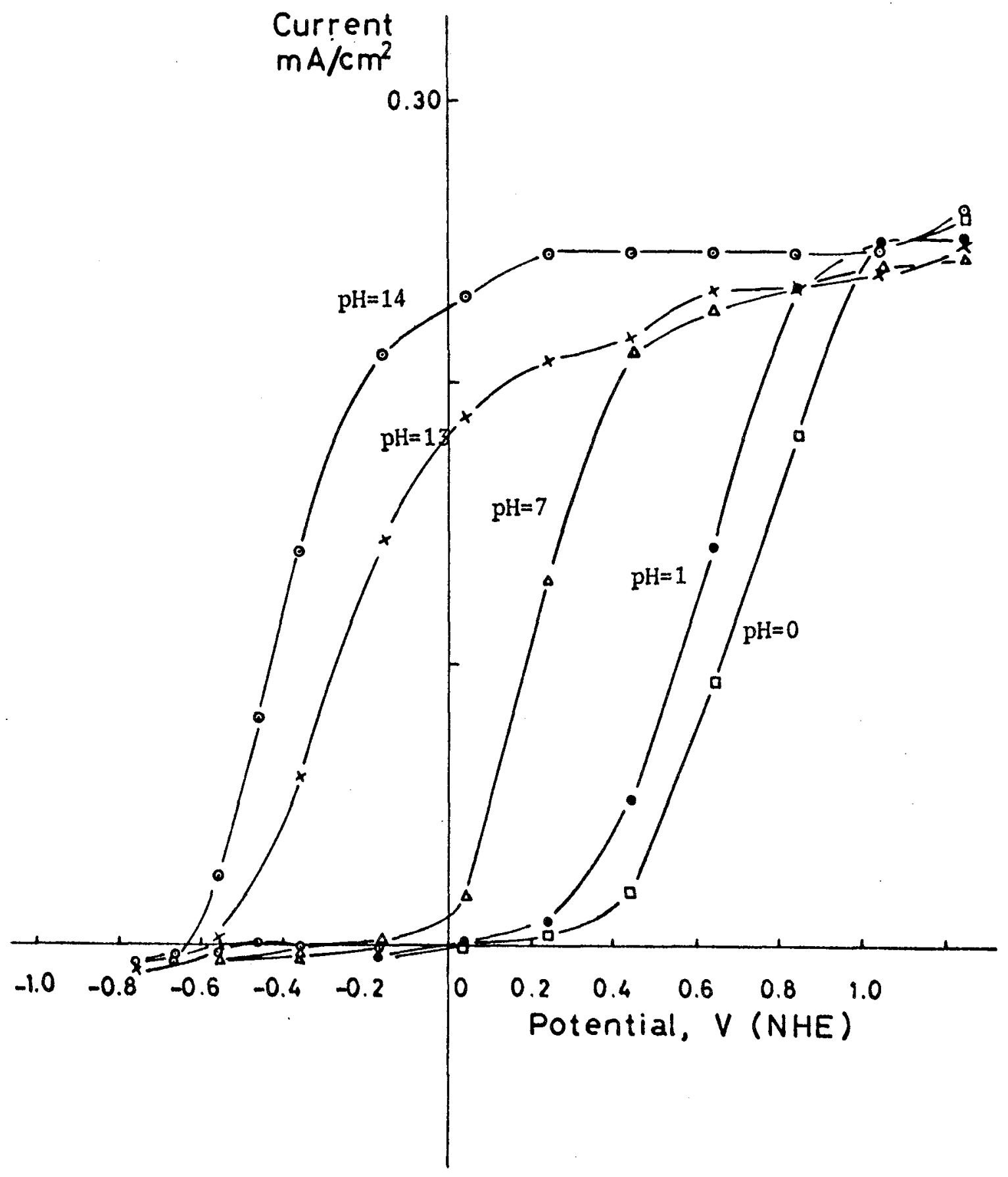

Pig, 5.1 The current-potential relations of Tio single crystal in solutions of various $\mathrm{pH}^{\prime} \mathrm{s}$ with illufination by a $150 \mathrm{~W} \mathrm{Xe}_{\mathrm{e}}$ lamp. Intensity of Iight: $0.013 \mathrm{~W} / \mathrm{cm}^{2}$. 
108.

\subsection{Photocurrent (quantum efficiency) - photon energy relations at several potentials}

Photocurrents were measured under monochromatic light illumination $(3200 \AA \sim 3900 \AA)$ at several potentials $(-0.45 \mathrm{~V} \sim 1.25 \mathrm{~V}$ (NHE)). The quantum efficiencies calculated from measured values of the photocurrents and measured values of the number of photons per unit time per unit area are shown in Fig. 5.2 as a function of wavelength of light at several potentials. At all potentials examined, there are maxima in the quantum efficiency-wavelength relation and these shift towards higher energy part of the spectrum when the potential becomes more negative. The more negative the electrode potential the larger the ratio of the quantum efficiency at high, compared with that at low, energies of the incident light.

\section{1 .1 .1 .3 Stability}

The stability was examined by measuring the photocurrent at fixed potential (1.24 $\mathrm{V}$ (NHE)) in $1 \mathrm{~N} \mathrm{NaOH}$ for certain time. As shown in Fig. 5.3, the photocurrent was quite stable for over 20 hours. This result is quite different from the results of Harris et al. [2]. They reported the photocurrent decreased with time in all cases they examined. Typical result of theirs is also shown in Fig. 5.3.

\subsubsection{Titanium anodic oxide film}

After 30 minutes anodic polarization at $10.24 \mathrm{~V}(\mathrm{NHE}), 40 \mu \mathrm{A} / \mathrm{cm}^{2}$ was observed as dark current at that potential. Then, the photocurrent* under $150 \mathrm{~W}$ Xe lamp illuminating was measured at $2.24 \mathrm{~V}$ (NHE) and it was $3.2 \mu \mathrm{A} / \mathrm{cm}^{2}$ (dark current was $0.6 \mu \mathrm{A} / \mathrm{cm}^{2}$ ). Further anodic polarization at $10.24 \mathrm{~V}$ (NHE) for 8 minutes did not affect the photocurrent

* The photocurrent is the difference between the current with light and that without 1 ight. 


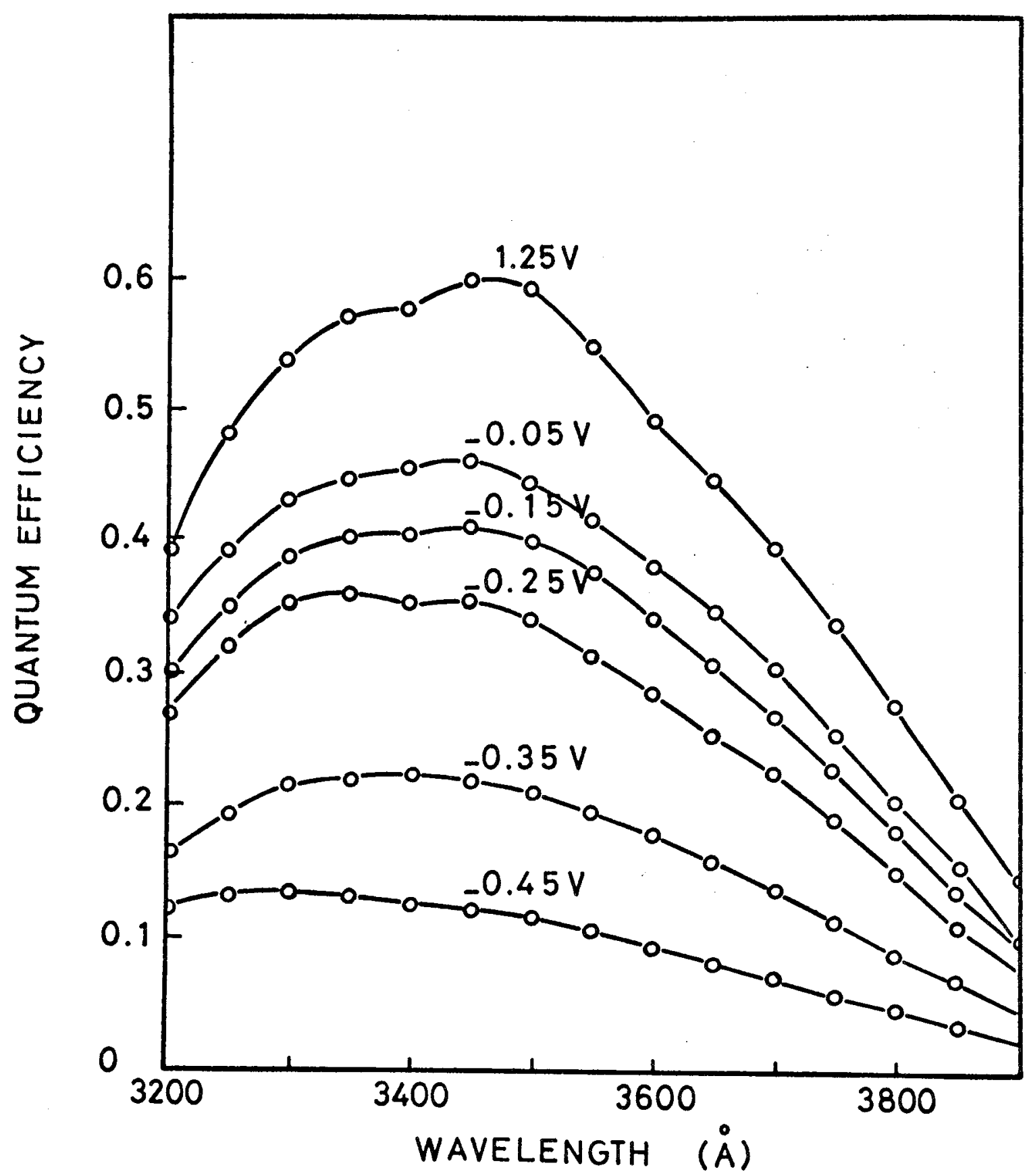

Pig. 5.2 The quantum efficiency-wavelength relations of $\mathrm{TiO}_{2}$ single crystal at several electrode potentials in 2 $0.1 \mathrm{~N} \mathrm{NaOH}$ solution. The electrode potentials are given with respect to NHE. 
110.

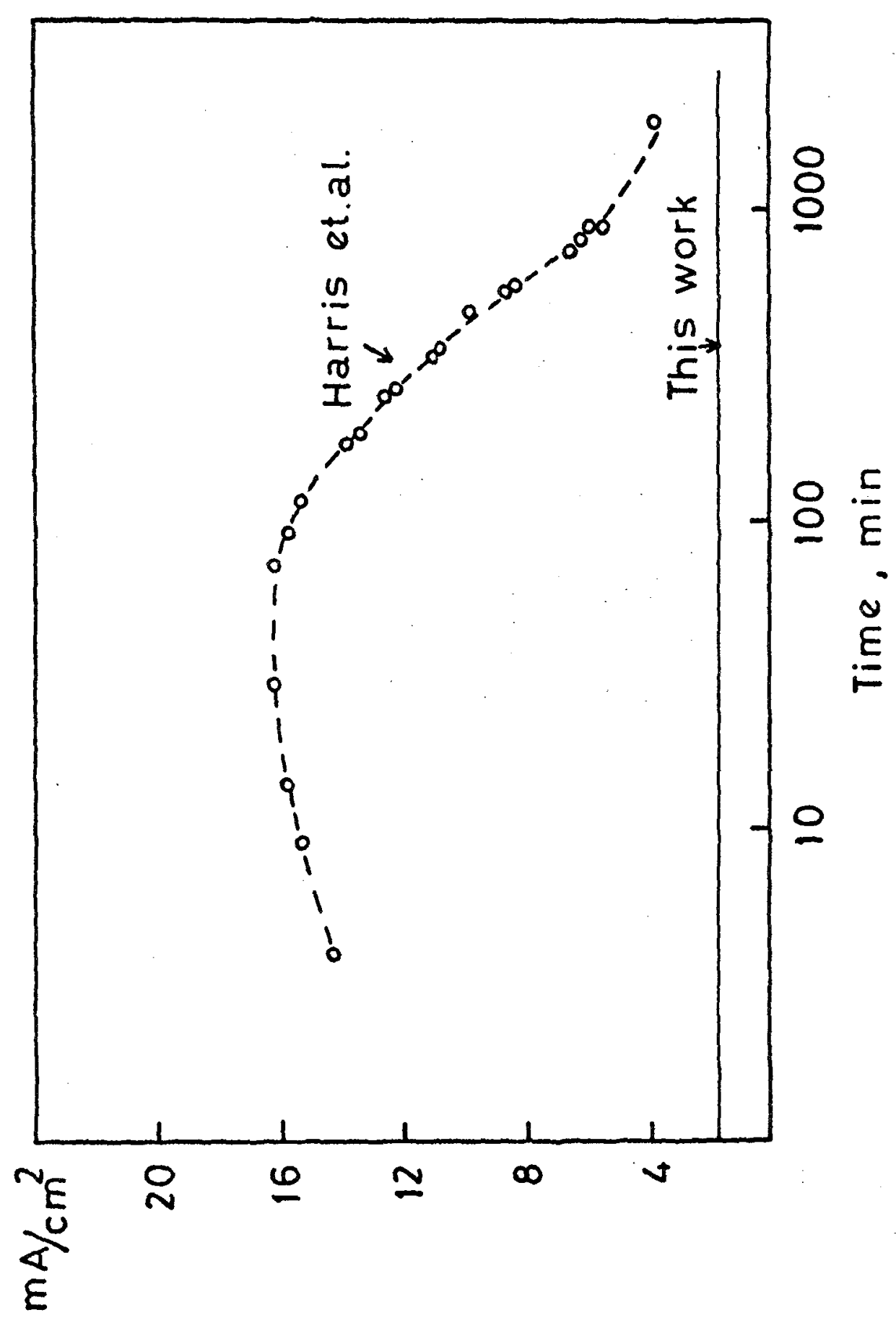

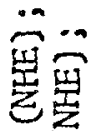

$>$

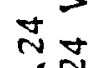

$-\frac{\pi}{4}$

苾

隶

zक

z江

z

$\underset{0}{E}$

苨

穴

n

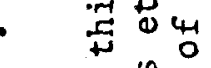

0 )

ฐ

垔苋

它出焉

미 d

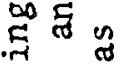

था

กิด्र

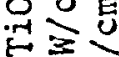

$4+\infty$

4 00

in $\dot{0}$

点

प्त क्त

与n

บ 0

足芒

어

A.

0 का

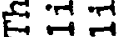

in

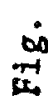


111.

(at 2.24V) at all. However, after a short time of cathodic polarization at $-1.76 \mathrm{~V}$ for $2 \mathrm{~min} .(70 \mathrm{~mA})$, the photocurrent at $2.24 \mathrm{~V}$ increased to $13.8 \mu \mathrm{A} / \mathrm{cm}^{2}$ and further cathodic polarization at $-1.76 \mathrm{~V}$ for $2 \mathrm{~min}$. made the photocurrent $17.9 \mu \mathrm{A} / \mathrm{cm}^{2}$. Anodic polarization at $-10.24 \mathrm{~V}$ and cathodic polarization at $-1.76 \mathrm{~V}$ were repeated and the photocurrents (at 2.24V) change corresponding to these treatments is shown in Fig. 5.4. Apparently, the photocurrent increased after cathodic polarization and decreased after anodic polarization.

The current-potential relationship of this electrode is shown in Fig. 5.5(a). For the comparison, the current-potential relation of a $\mathrm{TiO}_{2}$ single crystal in the same solution is shown in Fig. 5.5(b). The values of potential at which the photoeffect first observed were almost the same for both cases. However, although the photocurrent saturated about $1.24 \mathrm{~V}$ (NHE) in single crystal's case, the photocurrent did not reach the saturated value even at $2.24 \mathrm{~V}$ in the anodic oxide film's case.

The quantum efficiency wavelength relation at $2.24 \mathrm{~V}$ is shown in Fig. 5.6. The energy of light corresponding to quantum efficiency maximum is higher (wavelength is shorter) than that of the case of single crystal (see Fig. 5.2).

After cathodic polarization, the photocurrent at $2.24 \mathrm{~V}$ increased as shown above but the photocurrent decreased with time and showed stable current after $6 \sim 8$ minutes.

5.1.1.3 Titanium oxide films by high temperature oxidation Potential-current relationships of $\mathrm{TiO}_{2}$ films obtained by high temperature oxidation and of the partly reduced $\mathrm{TiO}_{2}$ films were measured with and without $900 \mathrm{~W}$ Xe lamp illumination. Typical results are shown in Fig. 5.7. Although the relation of the reduced sample 


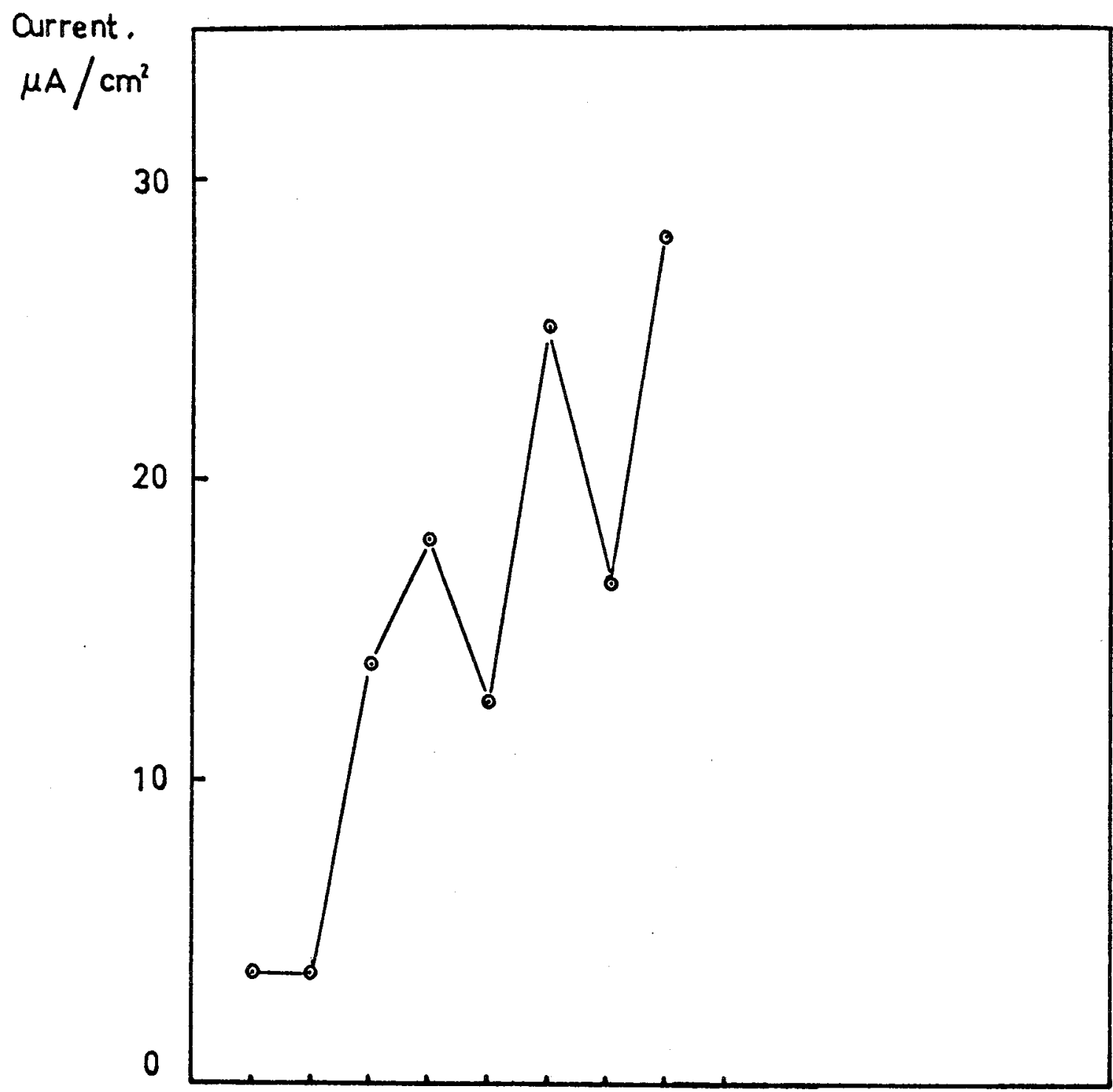

A A C C A C A C Polarization

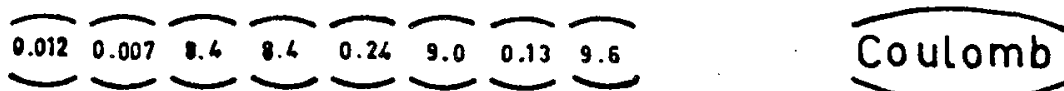

Fig. 5,4 The polarization effect on the photocurrent of titanium anodic oxide film in a solution $\left(15 \% \mathrm{H}_{2} \mathrm{SO}_{4}-2 \% \mathrm{Na}_{3} \mathrm{PO}_{4}-\right.$ $5 \% \mathrm{Na}_{2} \mathrm{HPO}_{4}$ - saturated $\mathrm{H}_{3} \mathrm{BO}_{3}$ ) at $2.24 \mathrm{~V}$ (NHE). Intensity of light: $0.025 \mathrm{~W} / \mathrm{cm}^{2}$. A means anodic polarization and $C$ means cathodic polarization. 
113.

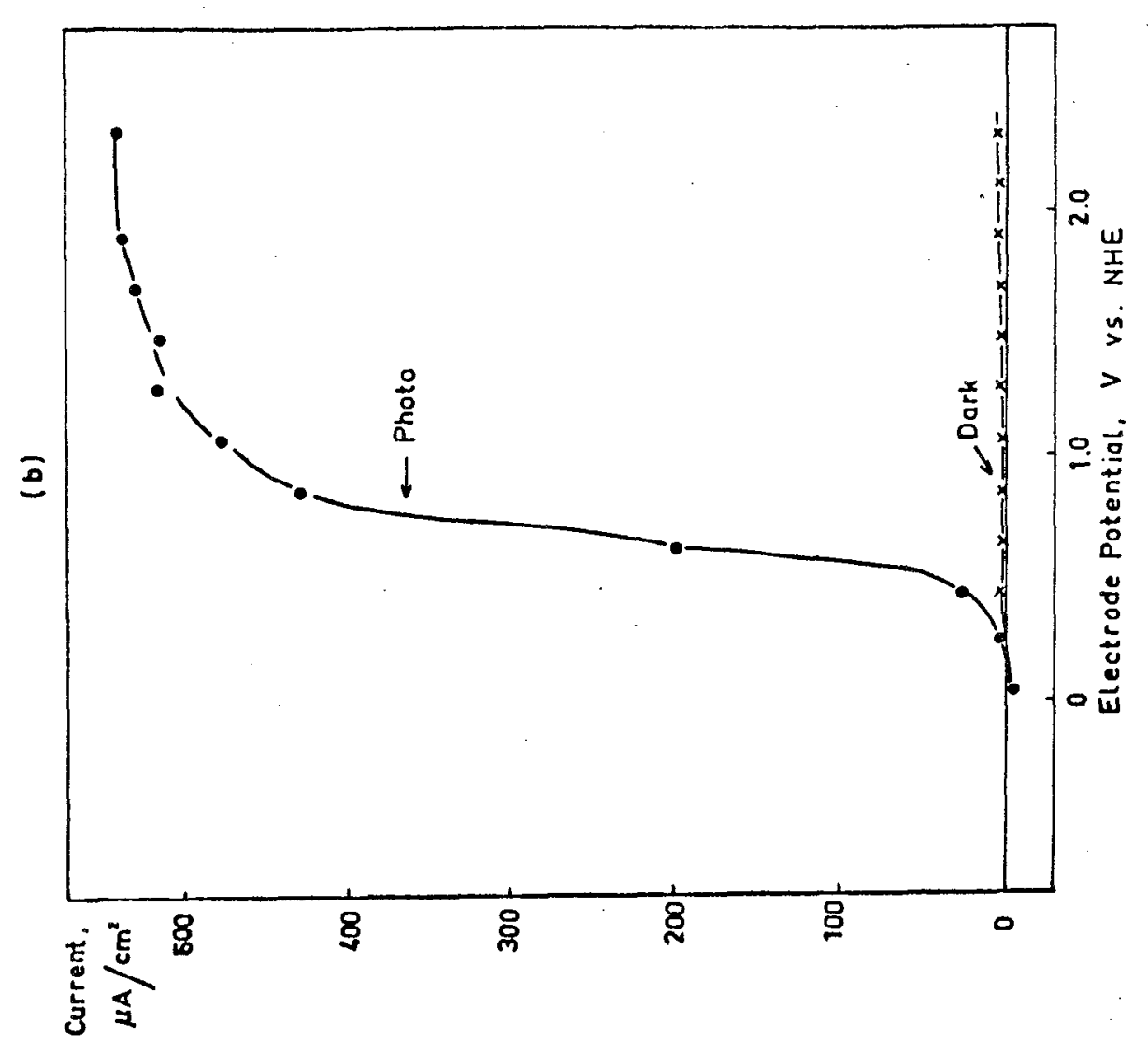

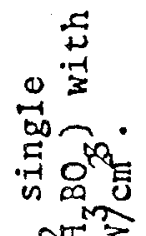

on 0

$\because \stackrel{2}{2}$

령

范

हु , 苟

E का

苟员出

范管

ํㅐㅇ io

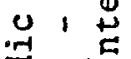

总品

军龸家

需

$\underset{-1}{+\infty}$

$4 \mathrm{O}^{\circ}=$

도요

ต ㅇำ

0 in

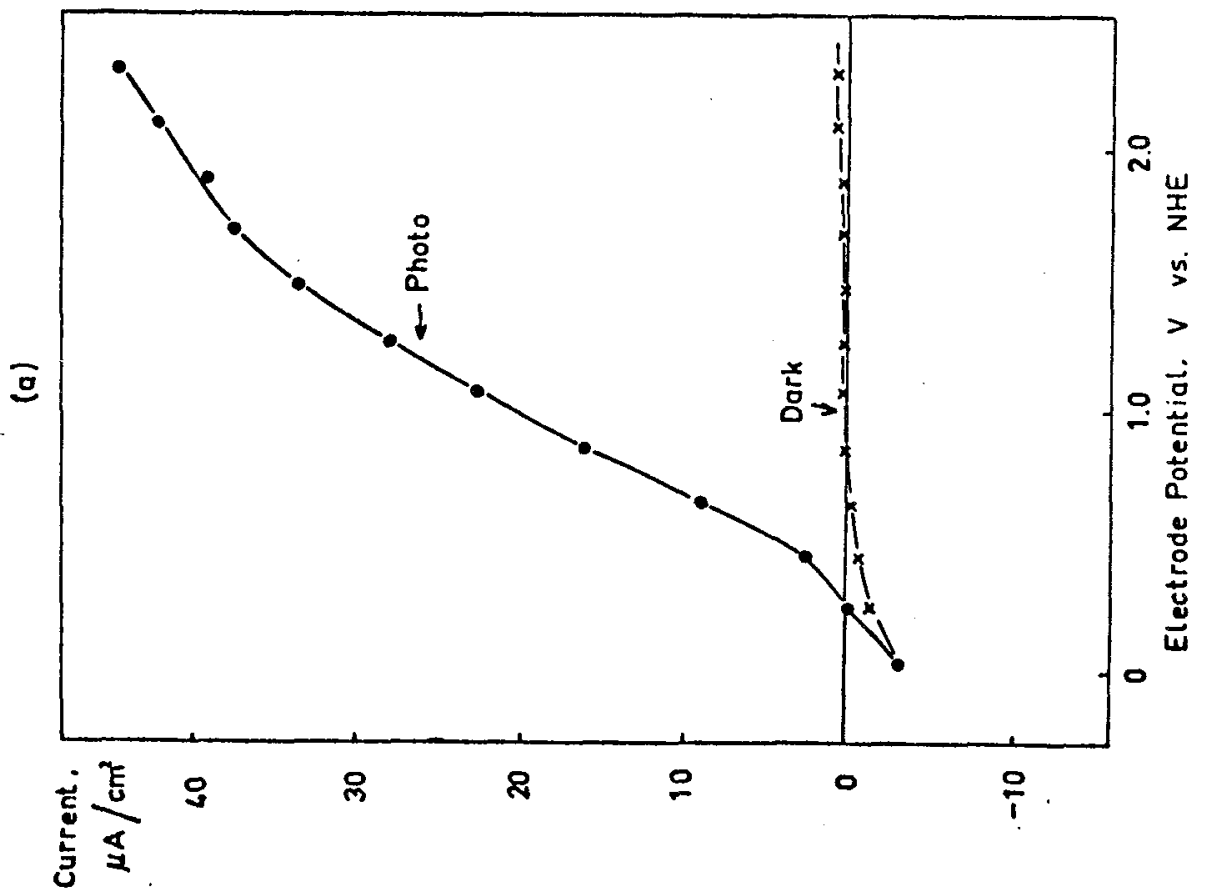

范

ब

4.

고

-7

范

至

证

은

\&

氜

n

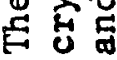

in 


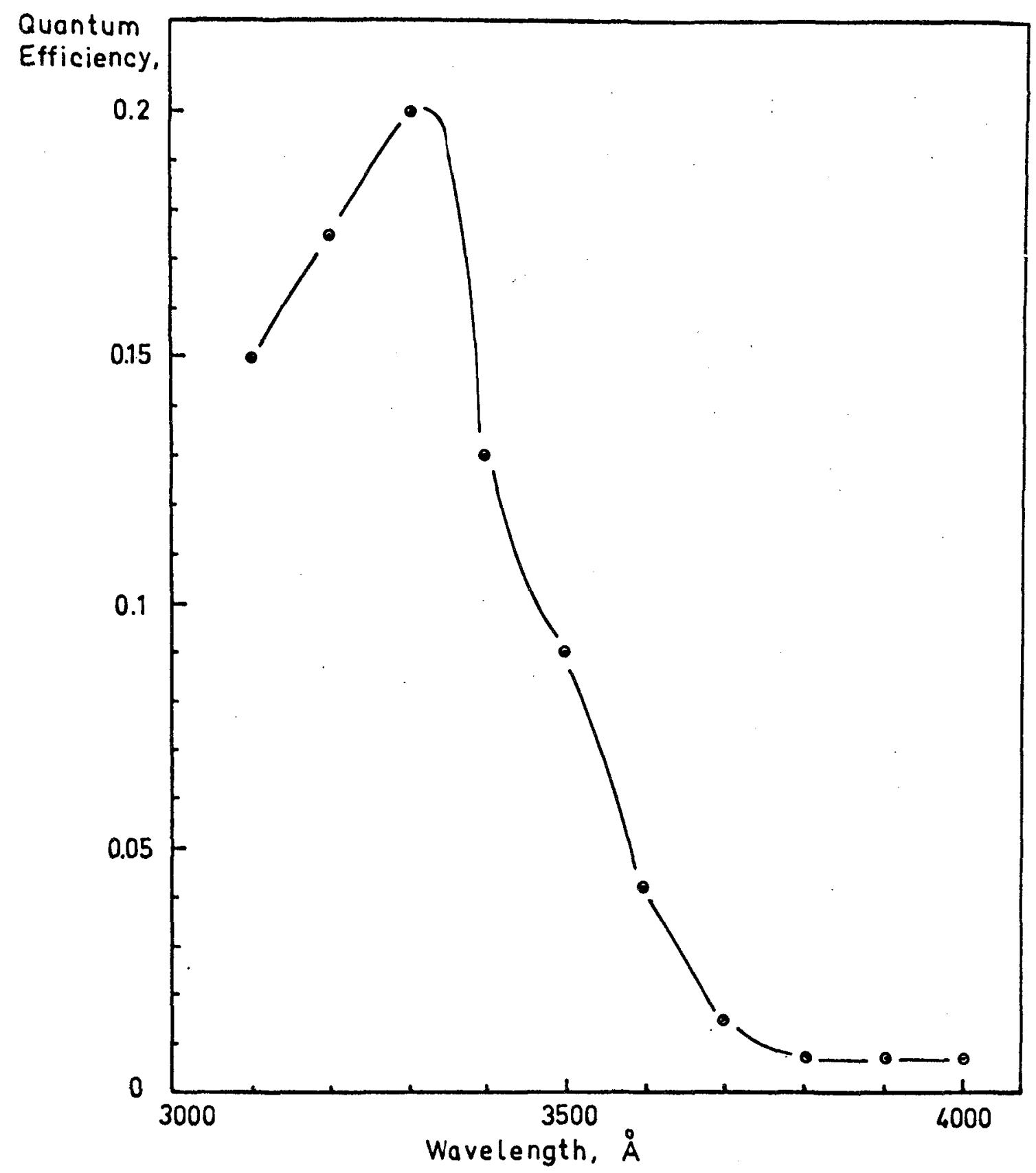

Fig. 5.6 The quantum efficiency-wavelength relation of titanium anodic oxide film at $2.24 \mathrm{~V}$ (NHE) in a solution $(15 \%$ $\mathrm{H}_{2} \mathrm{SO}_{4}-2 \% \mathrm{Na}_{3} \mathrm{PO}_{4}-5 \% \mathrm{Na}_{2} \mathrm{HPO}_{4}$ - saturated $\mathrm{H}_{3} \mathrm{BO}_{3}$ ). 


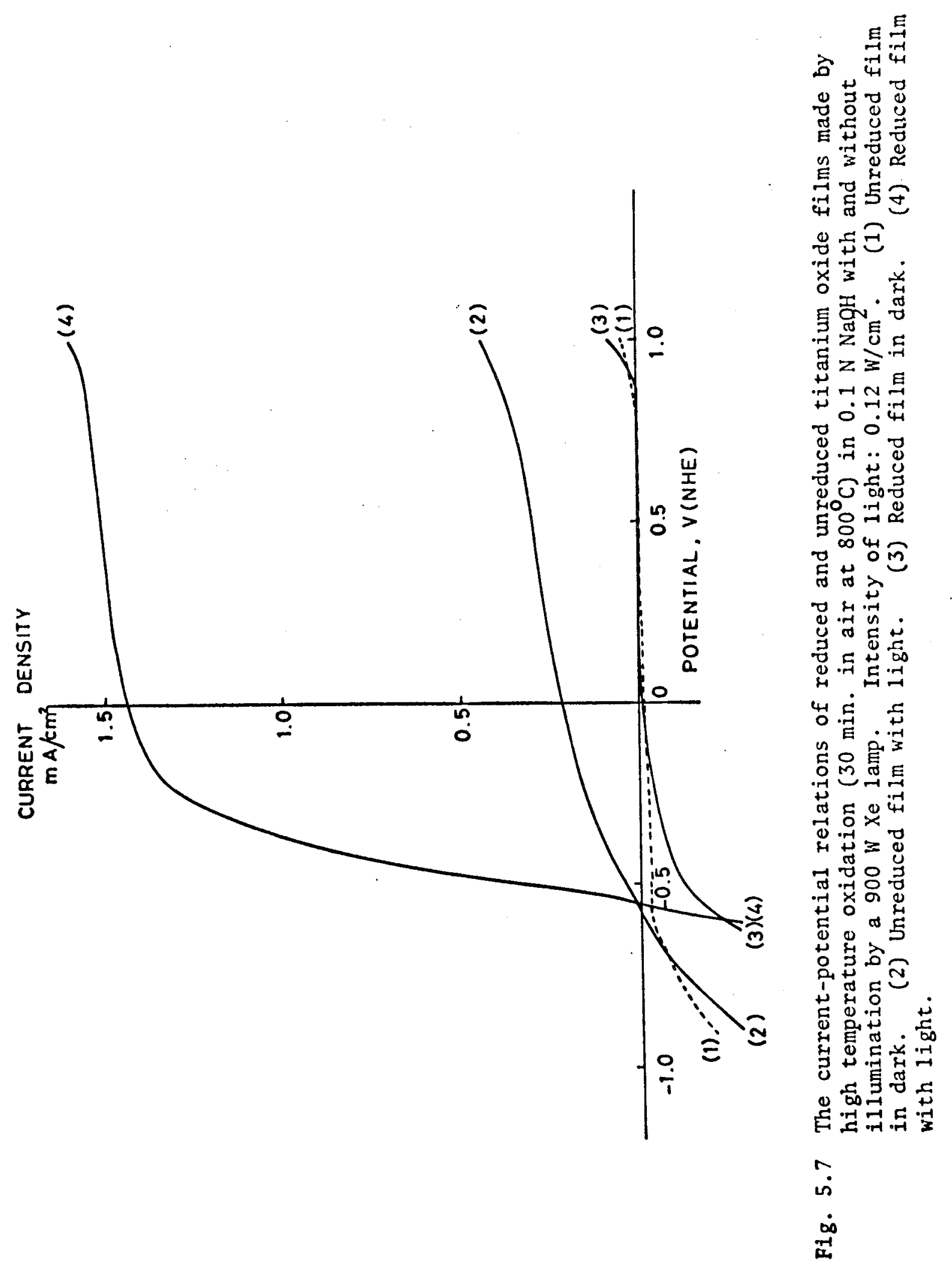


116.

under illumination is similar to that of the single crystal (see Fig. 5.1), i.e. a sharp increase and saturation, the relation of the unreduced sample is similar to that of anodic oxide film (see Fig. $5.5(a))$

Photocurrents at $1.0 \mathrm{~V}$ (NHE) are plotted against heating times for the unreduced and reduced samples in Fig. 5.8. As shown in this figure, the photocurrents of the oxidized $\mathrm{Ti}$ (unreduced) are about $20 \%$ of those of $\mathrm{TiO}_{2}$ single crystal which was $2.7 \mathrm{~mA} / \mathrm{cm}^{2}$ and did not depend on heating time much. However, the situation for reduced samples was different. The photocurrents increased when oxidation time increased and saturated after 1 hour oxidation. Also the photocurrents of the specimens oxidized more than 1 hour and reduced were about the same as those of the $\mathrm{TiO}_{2}$ single crystals. Fujishima et al. reported similar results for $\mathrm{TiO}_{2}$ films made by heating in a gas burner [3] .

The photocurrents under monochromatic 1ight $(3000 \AA \sim 4200 \AA)$ of $900 \mathrm{~W}$ Xe lamp at 1.0V (NHE) were measured for reduced and unreduced oxidized samples and the quantum efficiencies were calculated by using the measured value of photocurrents and the number of photons. Typical results of quantum efficiency dependence on wavelength are shown in Fig. 5.9. The maxima observed in this relation shift towards longer wavelength when the oxidation time increase.

\subsubsection{Cadmium Sulfide Single Crystal Coated with TiO 2 Film}

The photocurrents of $\mathrm{TiO}_{2}$ film on $\mathrm{Ti}$ and $\mathrm{TiO}_{2}$ film on CdS single crystal were measured under illumination of monochromatic light $(3000 \AA \sim 5500 \AA)$ in $1 \mathrm{~N} \mathrm{NaOH}$ at $1.0 \mathrm{~V}$ (NHE). The photocurrents of CdS single crystal was also measured in the same condition. The quantum efficiencies calculated by using the measured values of photocurrents 


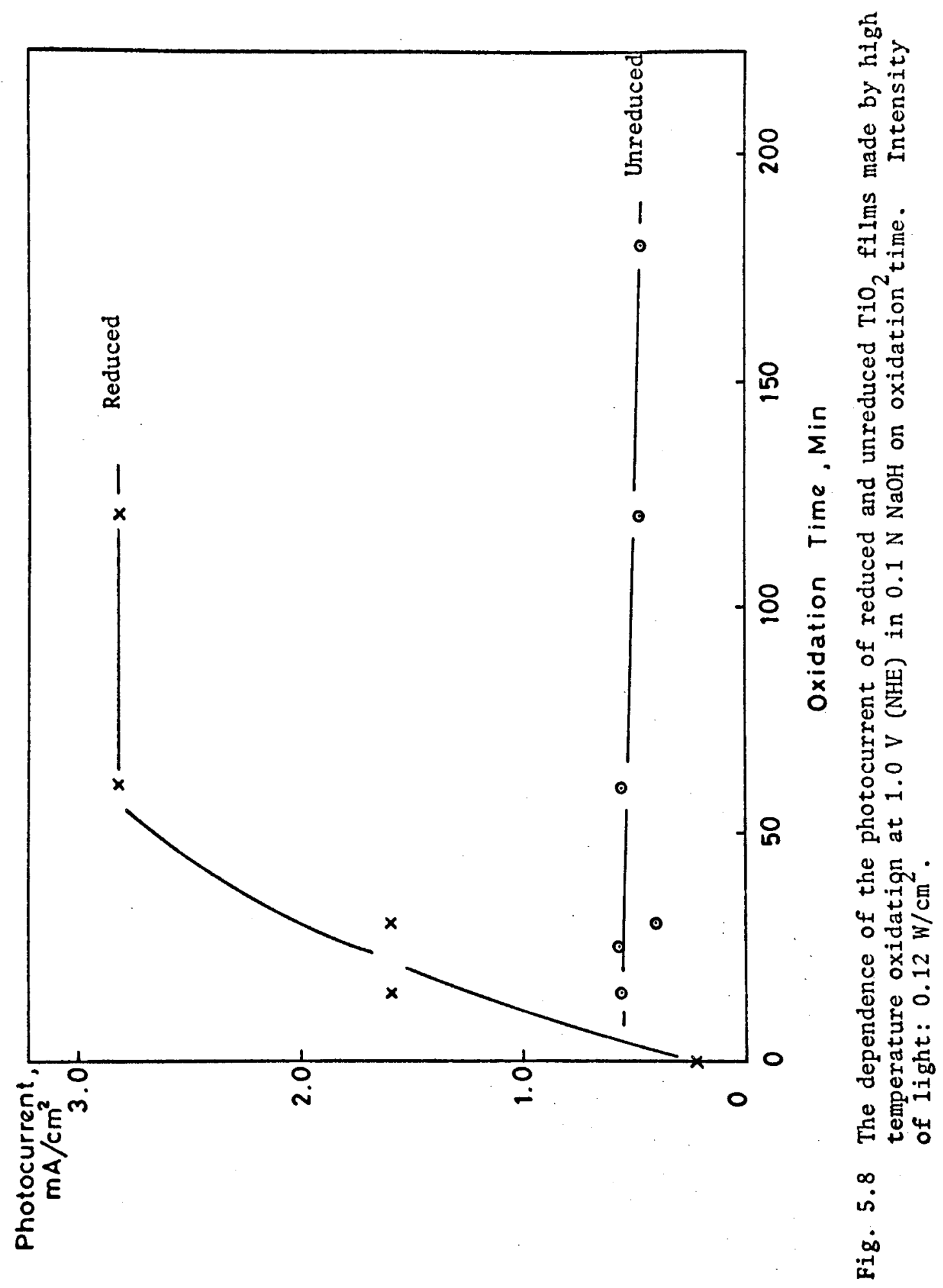




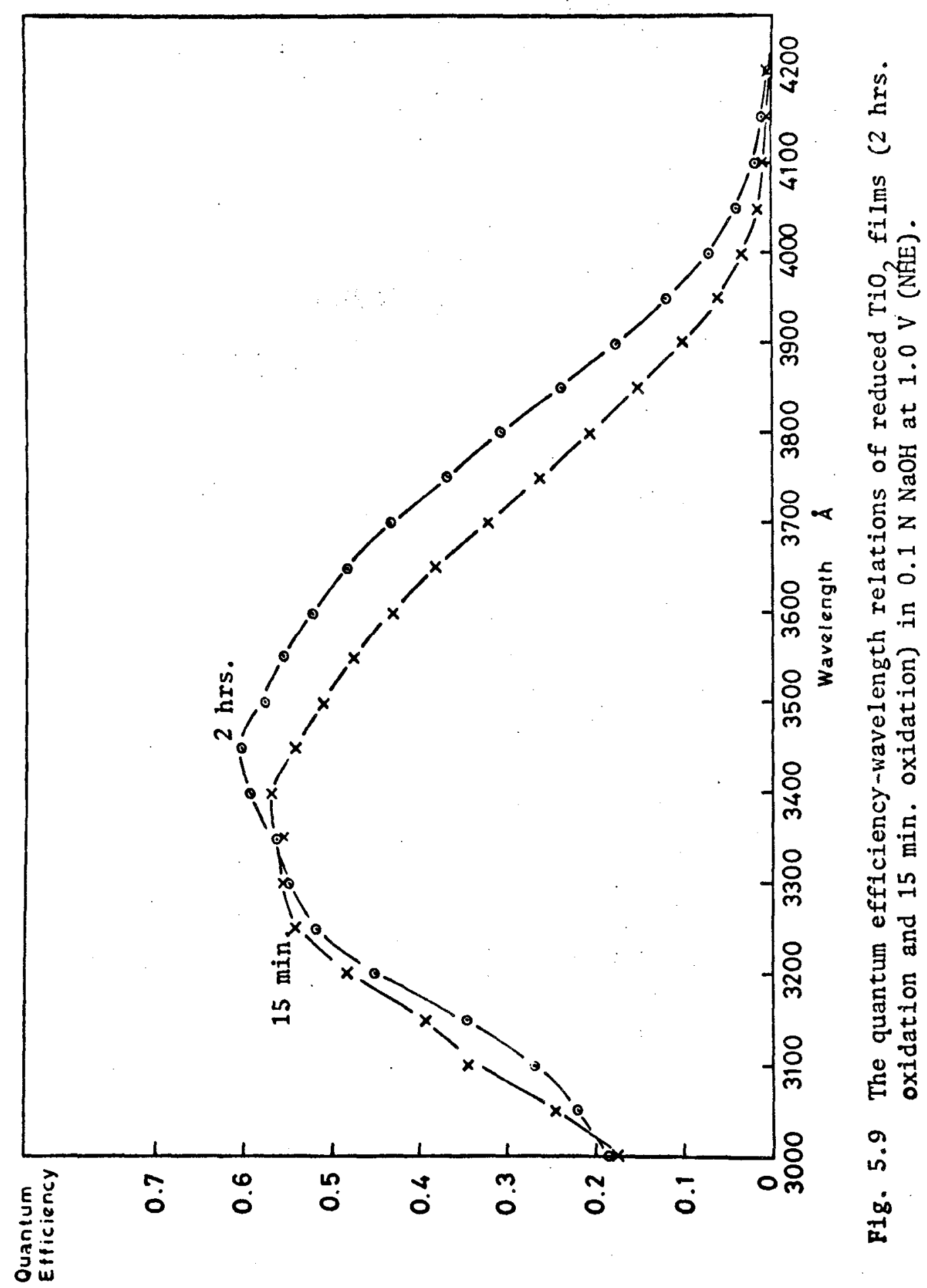


119.

and the number of photons are shown in Fig. 5.10 for $\mathrm{TiO}_{2}$ film on $\mathrm{Ti}$, CdS single crystal coated with $\mathrm{TiO}_{2}$ film and CdS single crystal. As shown in Fig. 5.10, the photocurrents were observed at CdS single crystal coated with $\mathrm{TiO}_{2}$ film even when the energy of the light was smaller than the energy gap of $\mathrm{TiO}_{2}(3.0 \mathrm{eV} \approx 4100 \AA)$, although the quantum efficiency of CdS coated with $\mathrm{TiO}_{2}$ film was low compared with that of CdS single crystal.

The saturated value of the photocurrent on $\mathrm{Ti}$ coated with $\mathrm{TiO}_{2}$ film was about $40 \%$ of that of $\mathrm{TiO}_{2}$ single crystal and this agreed with the results of Hardee et al. [1].

The stability of the photocurrent of CdS single crystal coated with $\mathrm{TiO}_{2}$ was examined under illumination of the $150 \mathrm{~W}$ Xe lamp and shown in Fig. 5.11 with the result of CdS single crystal. The photocurrent decreased $50 \%$ during the first one hour and rate of decrease was about $20 \%$ of that of CdS single crystal used alone, i.e. improvement was considerable.

\section{1 .3 Metal Titanate}

\subsubsection{Cobalt titanate $\left(\mathrm{CoTiO}_{3}\right)$}

Cyclic voltammogramof $\mathrm{CoTiO}_{3}$ in $0.1 \mathrm{~N} \mathrm{NaOH}$ is shown in Fig. 5.12. The sweep rate was $1.5 \mathrm{~V} / \mathrm{min}$.

Photocurrents under illumination of 900W Xe lamp are also shown in Fig. 5.12 .

Photocurrents under monochromatic 1 ight was not able to be measured because of large dark current and very low photocurrent. After the experiment, black deposit was observed on the electrode surface.

In $1 \mathrm{~N} \mathrm{H}_{2} \mathrm{SO}_{4}$, gas bubbling was observed on the surface without connecting the electrode to external cixcuit. $E_{\text {corr }}$ was $-0.19 \mathrm{~V}$ (NHE). 


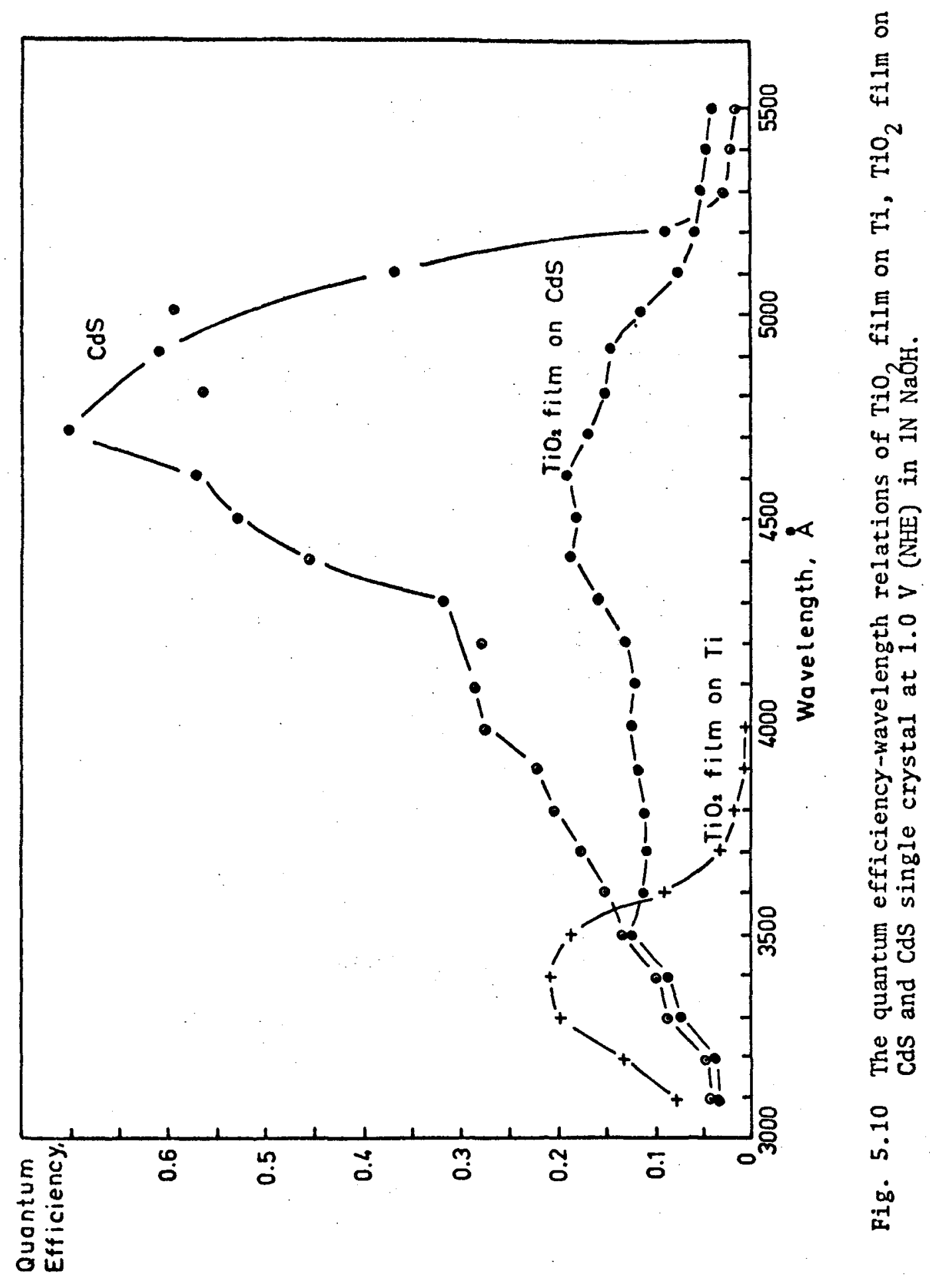


121.

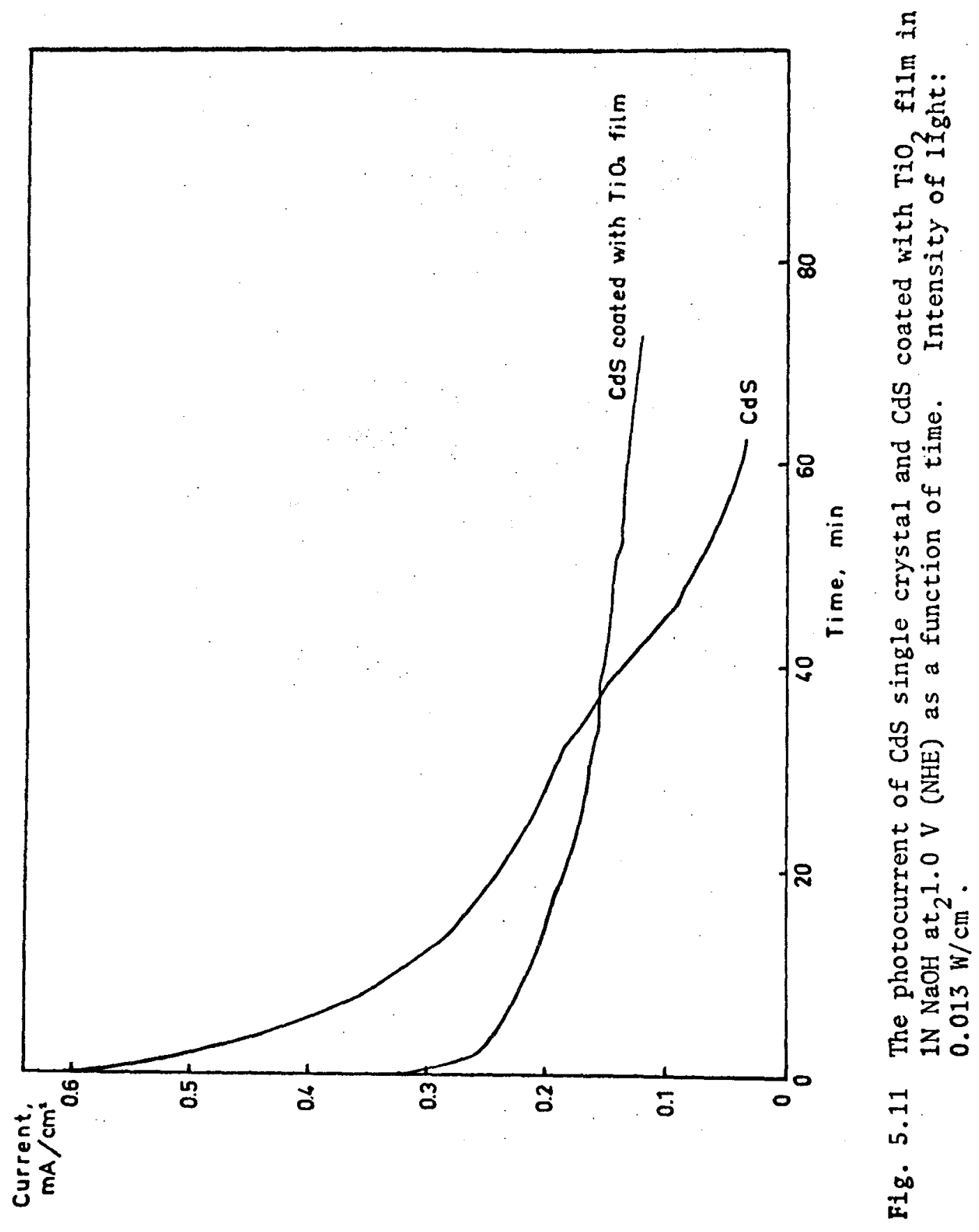




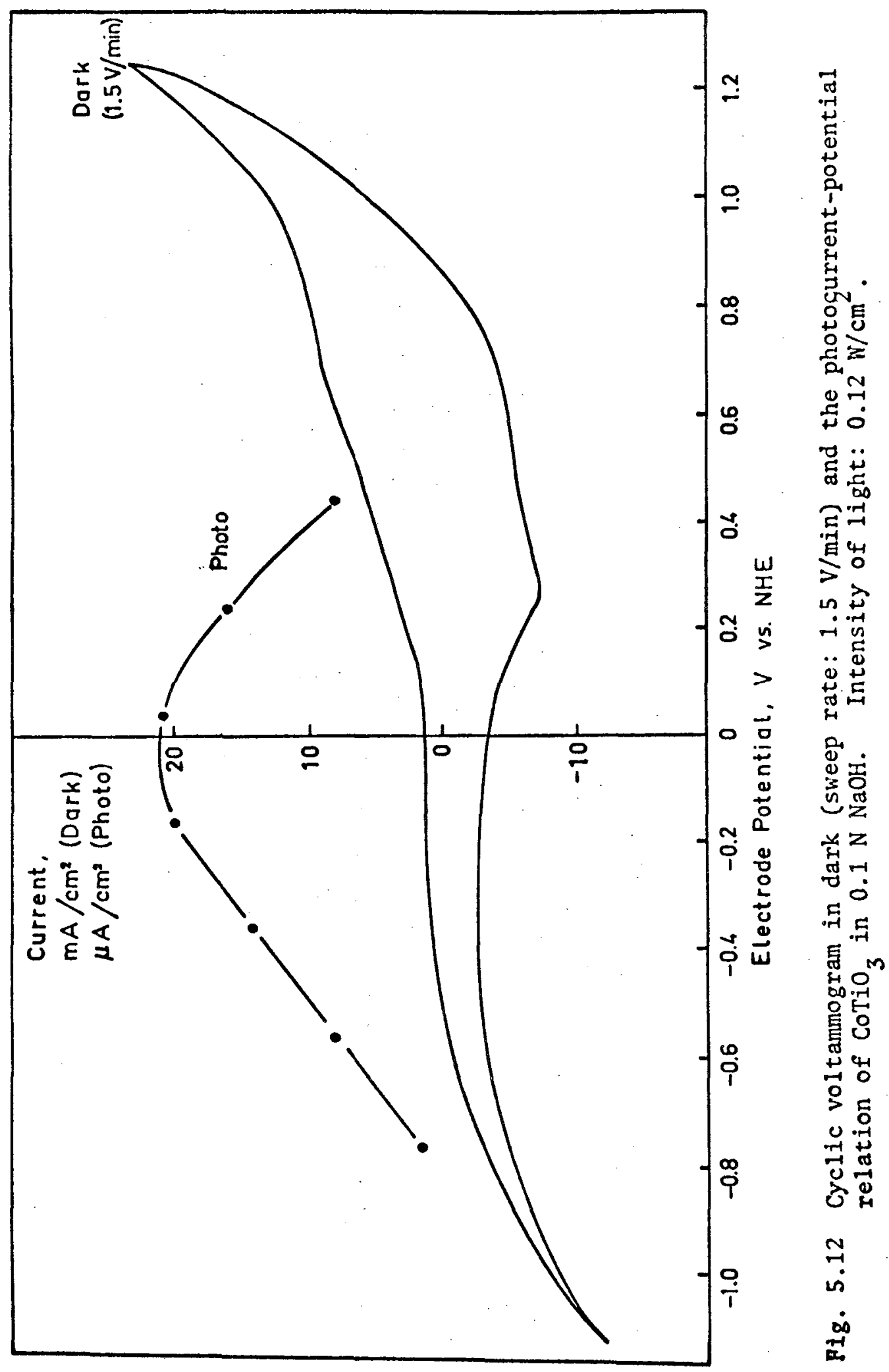


Cobalt ion was detected* in the solution.

\subsubsection{Iron titanate $\left(\mathrm{Fe}_{2} \mathrm{TiO}_{5}\right)$}

The potential-current relationships of iron titanate in $0.1 \mathrm{~N}$ $\mathrm{NaOH}$ with and without illumination are shown in Fig. 5.13.

The photocurrents were measured at $0.84 \mathrm{~V}$ (NHE) under the illumination of monochromatic 1 ight $(3000 \AA \sim 4200 \AA)$ and the quantum efficiencies calculated by the measured values of the photocurrents and the measured values of number photons are shown in Fig. 5.14. This figure shows that the energy gap of the reduced iron titanate is almost the same as that of $\mathrm{TiO}_{2}$.

The stability of photocurrent was examined under illumination of 900W Xe lamp. The electrode was polarized at $0.84 \mathrm{~V}$ (NHE). The results are shown in Fig. 5.15. Although the examined time was short (3.5 hours), the photocurrent was quite stable. Also, bubbles were observed on the electrode during this experiment. After this 3.5 hours experiment, no deposition was observed on the electrode and no $\mathrm{Fe}$ ion was detected ${ }^{\dagger}$, i.e., stability was indicated.

* After sodium hydroxide was added, the test solution was boiled. The brownish-black precipitate $\left(\mathrm{Co}(\mathrm{OH})_{3}\right.$ ) was observed [4] .

'Ammonium thiocyanate solution was added to the test solution. No change was observed [4]. 


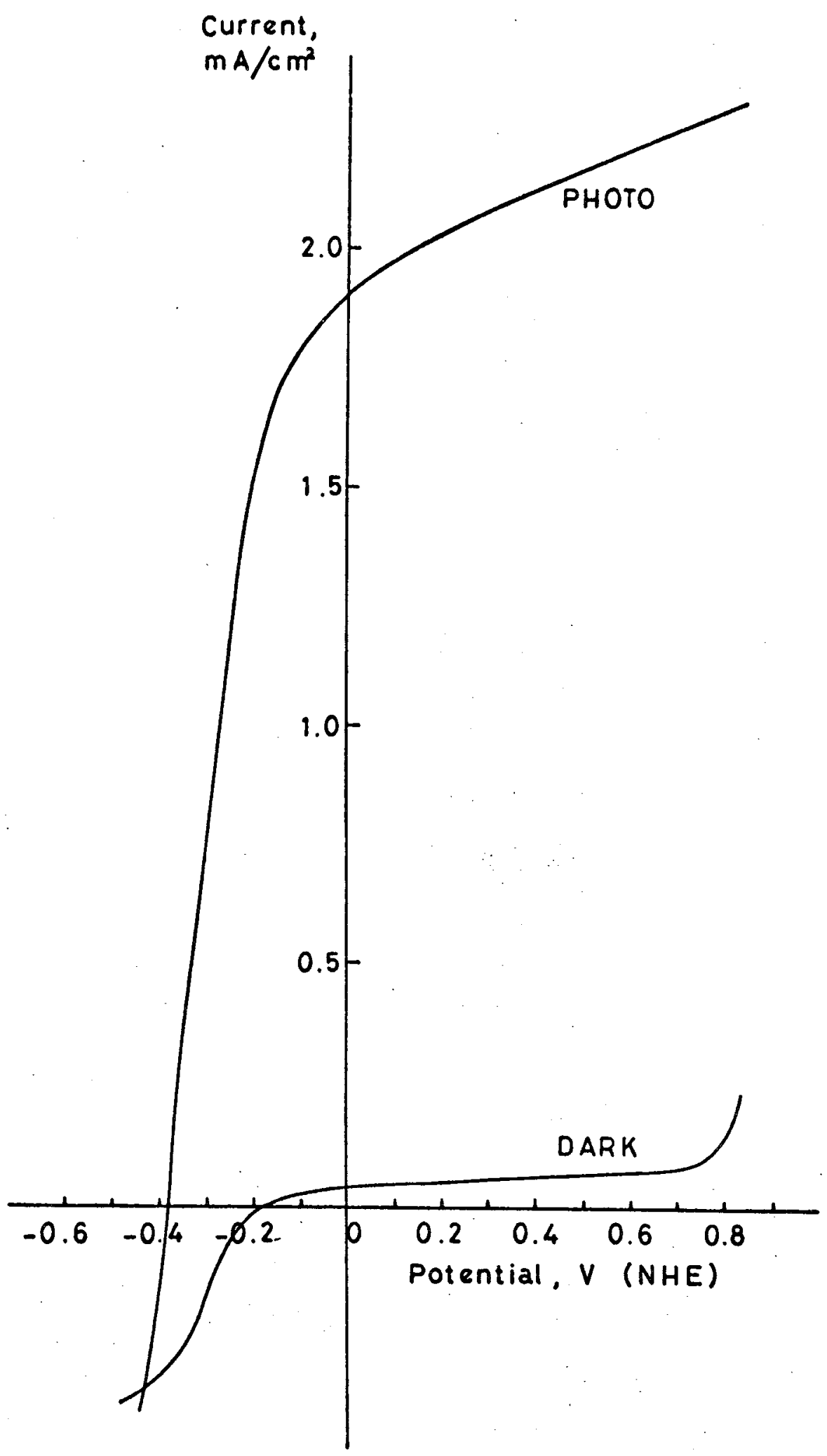

Fig. 5.13 The current-potential relations of $\mathrm{Fe}_{2} \mathrm{TiO}_{5}$ in $0.1 \mathrm{~N}$ $\mathrm{NaOH}$ with and without illumination by a $900 \mathrm{~W}$ Xe lamp. Intensity of light: $0.12 \mathrm{~W} / \mathrm{cm}^{2}$. 
125.

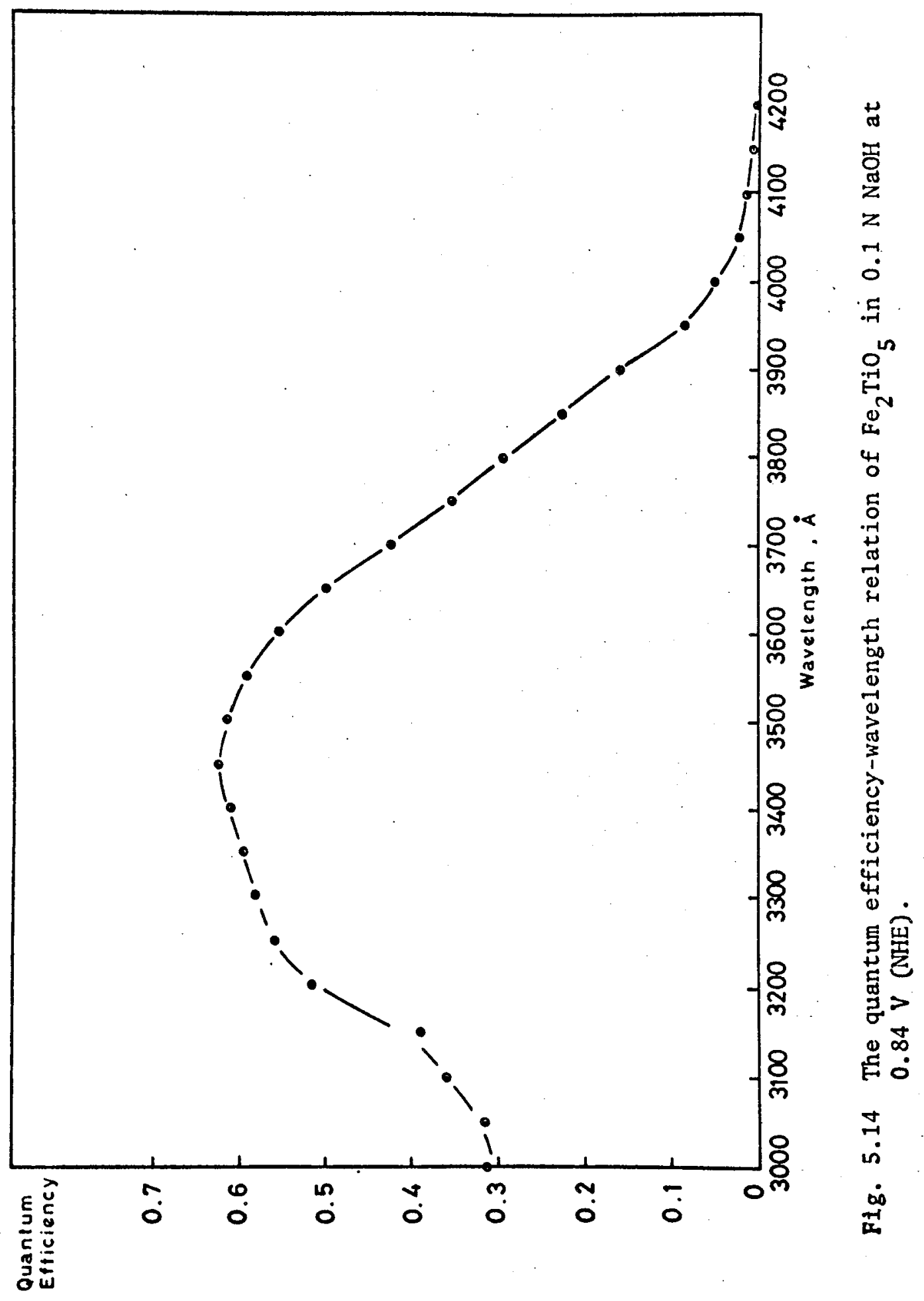


126.

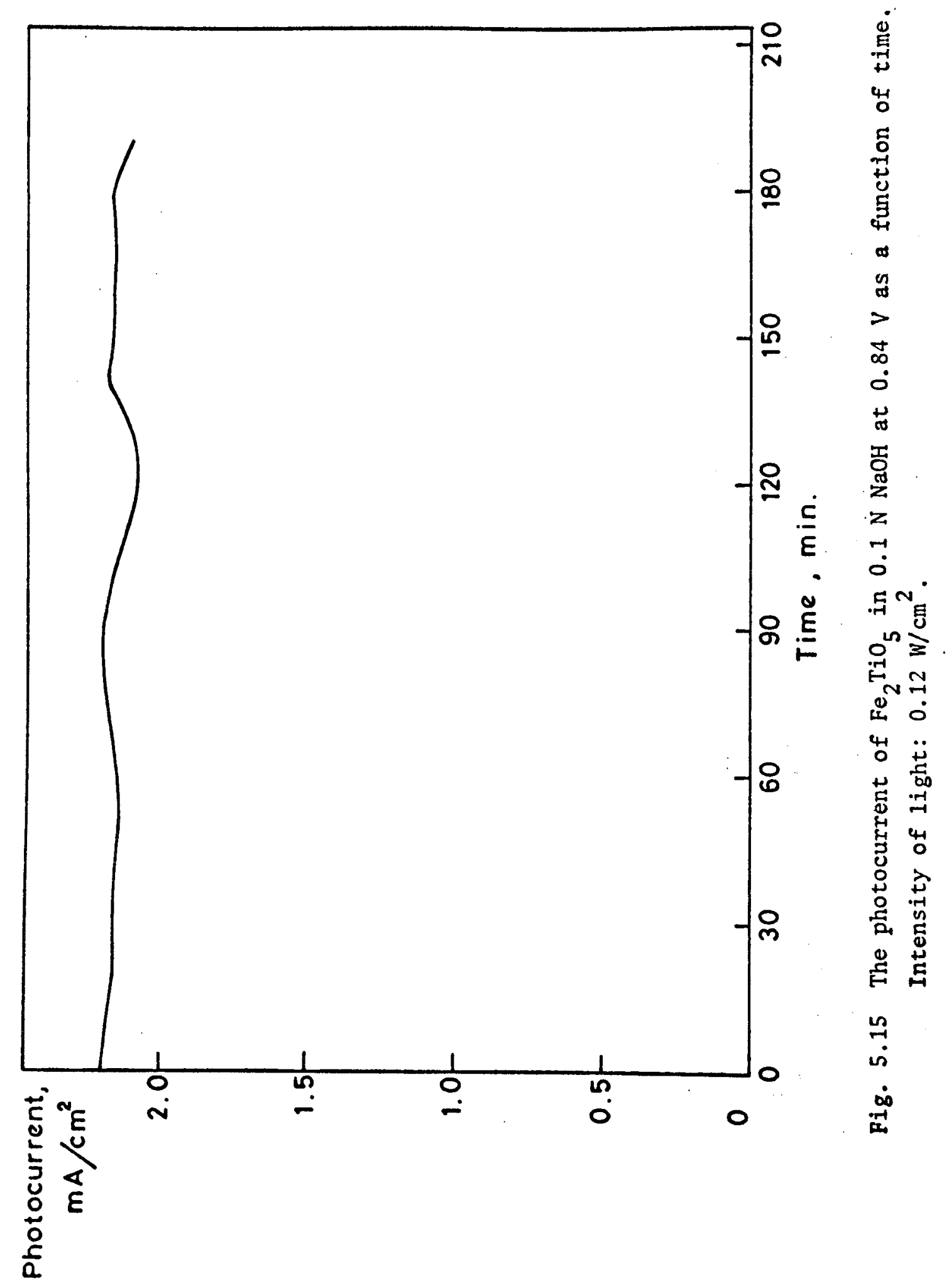




\subsection{PHOTOEFFECTS ON CATHODIC REACTION AT P-TYPE SEMICONDUCTORS}

The results of the current-potential relations with and without illumination by the $900 \mathrm{~W}$ Xe lamp (potential sweep); the photocurrent (quantum efficiency) - wavelength relation at several potentials; the flat band potentials; transient measurements ( $>3$ milli seconds) and stability test of the seven p-type semiconductors mentioned before in $1 \mathrm{~N} \mathrm{NaOH}$ and in $1 \mathrm{~N} \mathrm{H}_{2} \mathrm{SO}_{4}$ solutions are reported in the following sections.

\subsubsection{Zinc Telluride (ZnTe)}

\subsubsection{The current-potential relation}

The current-potential relations with and without illumination by the $900 \mathrm{~W}$ Xe lamp in $1 \mathrm{~N} \mathrm{NaOH}$ and in $1 \mathrm{~N} \mathrm{H}_{2} \mathrm{SO}_{4}$ are shown in Fig. 5.16. For the first sweep, a large cathodic dark current $\left(1.5 \sim 2 \mathrm{~mA} / \mathrm{cm}^{2}\right)$ was observed. The cathodic dark current became smaller on repeating the sweep (sweep rate: $1.5 \mathrm{~V} / \mathrm{min}$ ) and the current finally became stable (about $0.3 \mathrm{~mA} / \mathrm{cm}^{2}$ ). The photocurrent-potential relation was measured after the stable condition was reached.

\subsubsection{Photocurrent (quantum efficiency) - wavelength relation at several potentials}

Photocurrents (the difference between the current with light and the dark current) were measured under the illumination of monochromatic light $(3000 \AA \sim 5600 \AA)$ at several potentials $(-1.56 \mathrm{~V} \sim-0.26 \mathrm{f}$. $0 \mathrm{x}$ $\mathrm{NaOH}$ and $-0.76 \mathrm{~V} \sim-0.31 \mathrm{~V}$ for $\mathrm{H}_{2} \mathrm{SO}_{4}$. Typical results are shown in Fig.5.17*.

Quantum efficiencies were calculated by using measured values of photocurrents and the values of the number of photons. Results in $1 \mathrm{~N} \mathrm{NaOH}$ and in $1 \mathrm{~N} \mathrm{H}_{2} \mathrm{SO}_{4}$ are shown in Fig. 5.18(a) and in Fig. 5.18(b)

* Photocurrents shown in Fig. 5.17 and other similar figures in this chapter are measured values and not standardized in respect to light intensity. 
128.

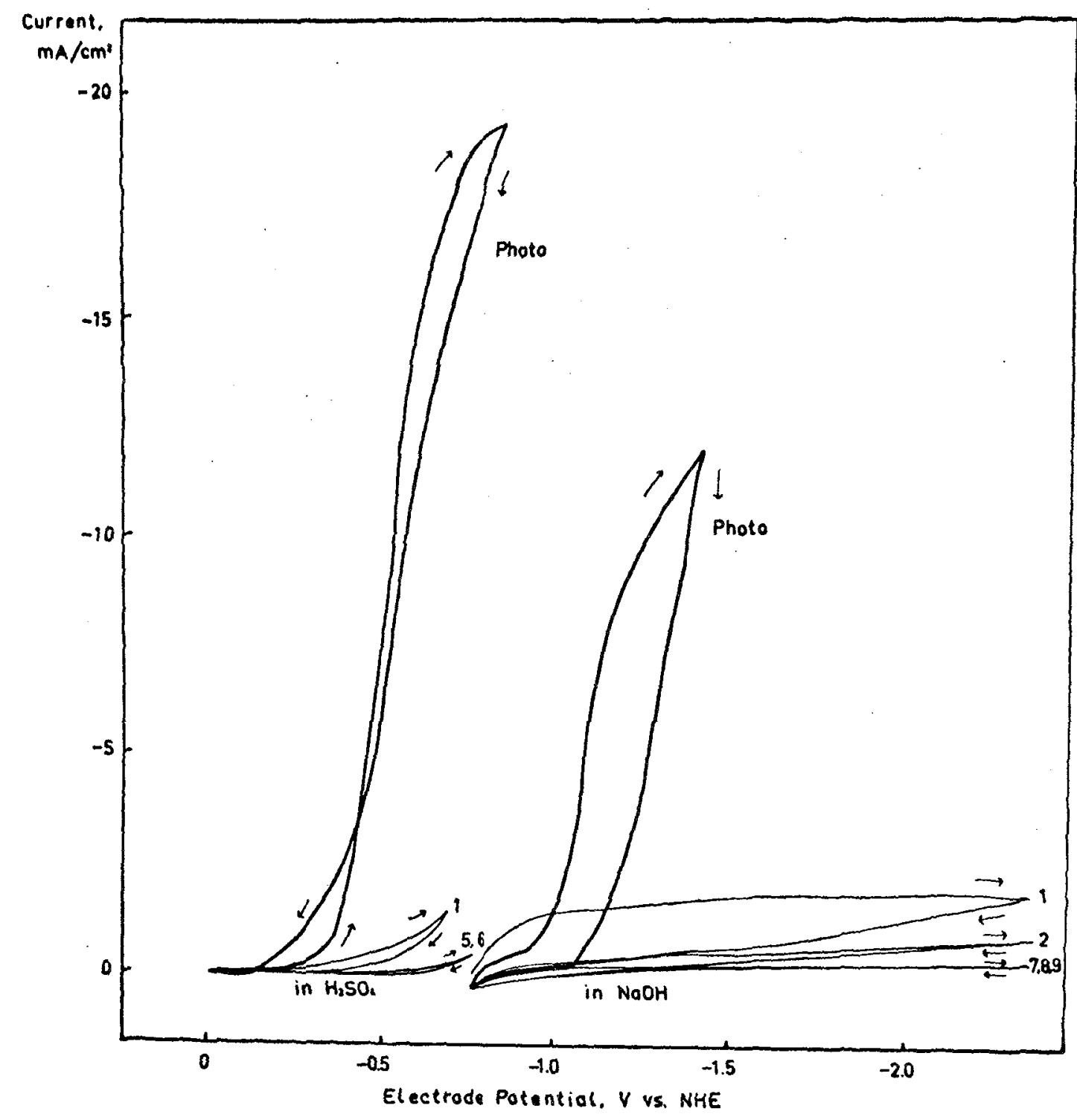

Fig, 5.16 The current-potential relations of $\mathrm{ZnTe}$ in $\mathrm{IN} \mathrm{NaOH}$ and $1 \mathrm{~N} \mathrm{H}_{2} \mathrm{SO}_{4}$ with and without illumination by a $900 \mathrm{~W}$ Xe lamp. ${ }^{4}$ Sweep rate: $1.5 \mathrm{~V} / \mathrm{min}$. Intensity of 1 ight:

$0.08 \mathrm{~W}$. Arrows show the direction of the polarization. 1. Ist sweep in dark. 2 . 2nd sweep in dark.

$5,6,7,8,9$. 5th, 6th, 7th, 8th and 9 th sweep in dark. 


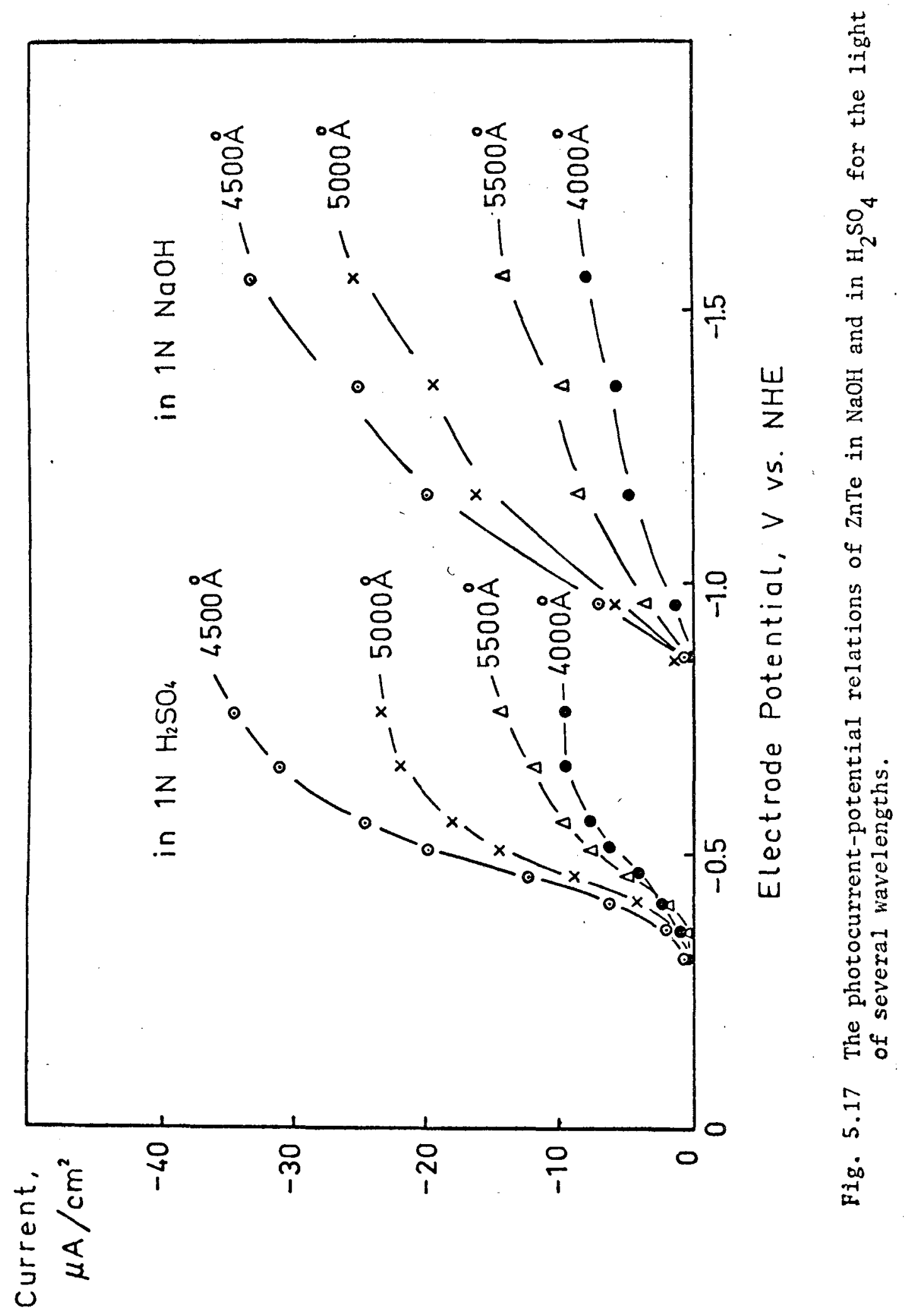




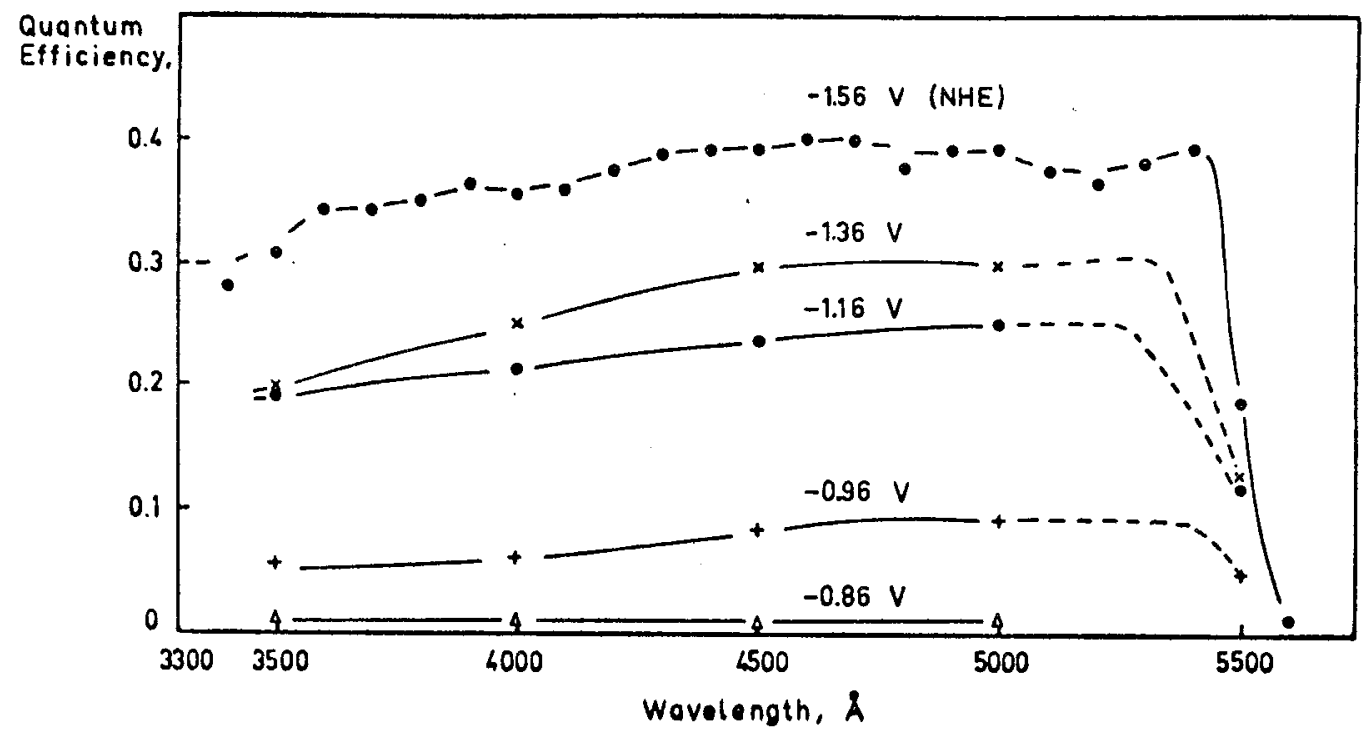

(a)

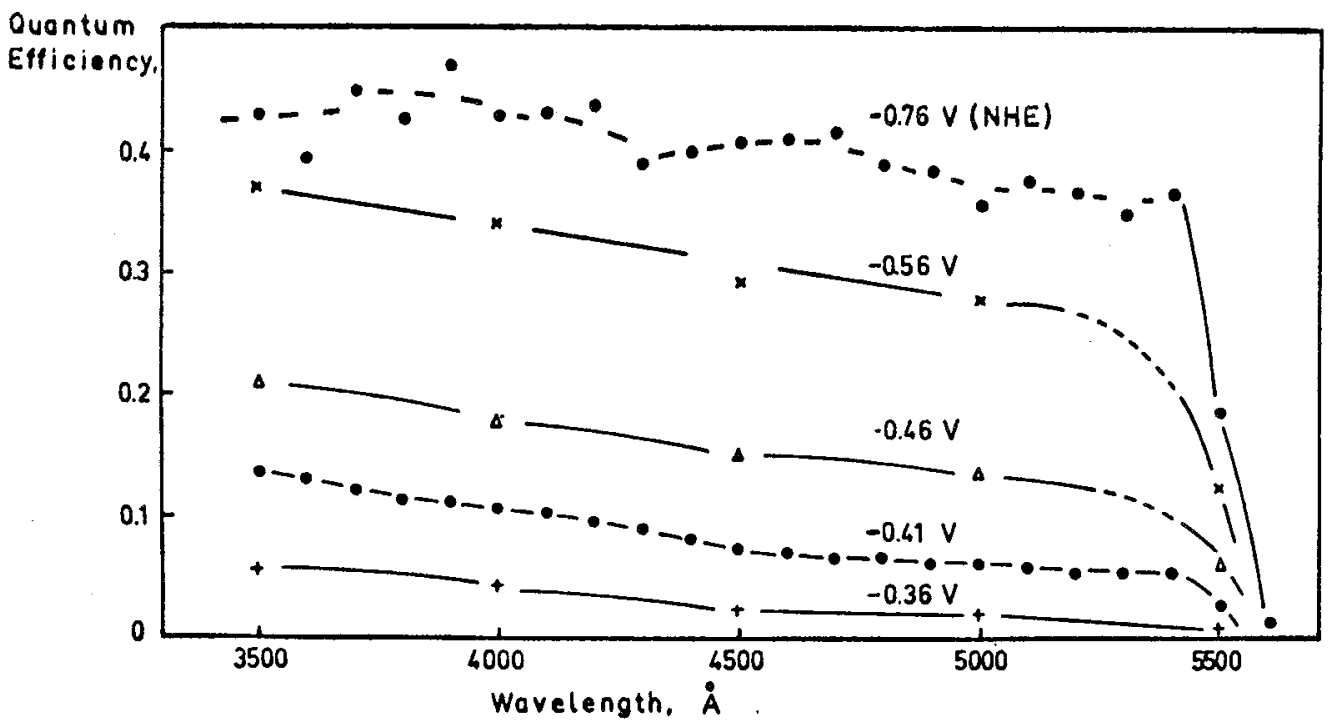

Fig. 5.18 The quantum efficiency-wavelength relations of $\mathrm{ZnTe}$ in $1 \mathrm{~N} \mathrm{NaOH}$ (a) and $1 \mathrm{~N} \mathrm{H}_{2} \mathrm{SO}_{4}$ (b) for several electrode potentials. 
131.

respectively, as a function of wavelength.

\subsubsection{The flat band potential}

Mott-Schottky plots for $\mathrm{NaOH}$ solution and $\mathrm{H}_{2} \mathrm{SO}_{4}$ solution are shown in Fig. 5.19. From these plots, the flat band potentials in $1 \mathrm{~N} \mathrm{NaOH}$ and in $1 \mathrm{~N} \mathrm{H}_{2} \mathrm{SO}_{4}$ are determined as $-0.79 \pm 0.02 \mathrm{~V}$ (NHE) and $0.04 \pm 0.02 \mathrm{~V}$ (NHE), respectively.

\subsubsection{Transient measurement}

The results of transient measurements in $1 \mathrm{~N} \mathrm{NaOH}$ and $1 \mathrm{~N}_{2} \mathrm{SO}_{4}$ are shown in Fig. 5.20 (a d) and in Fig. 5.21 (a d), respectively.

In both cases, it is clearly seen that when the electrode potential was very negative the current became very stable just after the light was on or off but when the electrode potential became relatively positive it took some time $\left(\sim 0.2 \mathrm{sec}\right.$ in $\mathrm{NaOH}$ and $\sim 0.02 \mathrm{sec}$ in $\left.\mathrm{H}_{2} \mathrm{SO}_{4}\right)$ to attain a steady state.

\subsubsection{Stability}

The photocurrents at fixed potentials in $1 \mathrm{~N} \mathrm{NaOH}$ and $1 \mathrm{~N}_{2} \mathrm{SO}_{4}$ are shown in Fig. 5.22(a) and in Fig. 5.22(b), respectively.

Although in both cases the photocurrents decreased with time, the decreasing rate in $\mathrm{H}_{2} \mathrm{SO}_{4}$ was smaller than that in $\mathrm{NaOH}$.

\subsubsection{Cadmium Telluride (CdTe)}

\subsubsection{The current-potential relation}

The current-potential relations with and without illumination by a 900W Xe lamp in $1 \mathrm{~N} \mathrm{NaOH}$ and in $1 \mathrm{~N}_{2} \mathrm{SO}_{4}$ are shown in Fig. 5.23 and in Fig. 5.24, respectively. Fig. 5.23(a) shows the I-V relation with sufficient deoxidation of solution by passing hydrogen gas and Fig. 5.23(b) shows the relation when such a treatment was insufficient.

Similarly to the ZnTe case, high cathodic dark current was observed first and the current became smaller on repeating the sweep (sweep rate $1.5 \mathrm{~V} / \mathrm{min}$ ). 


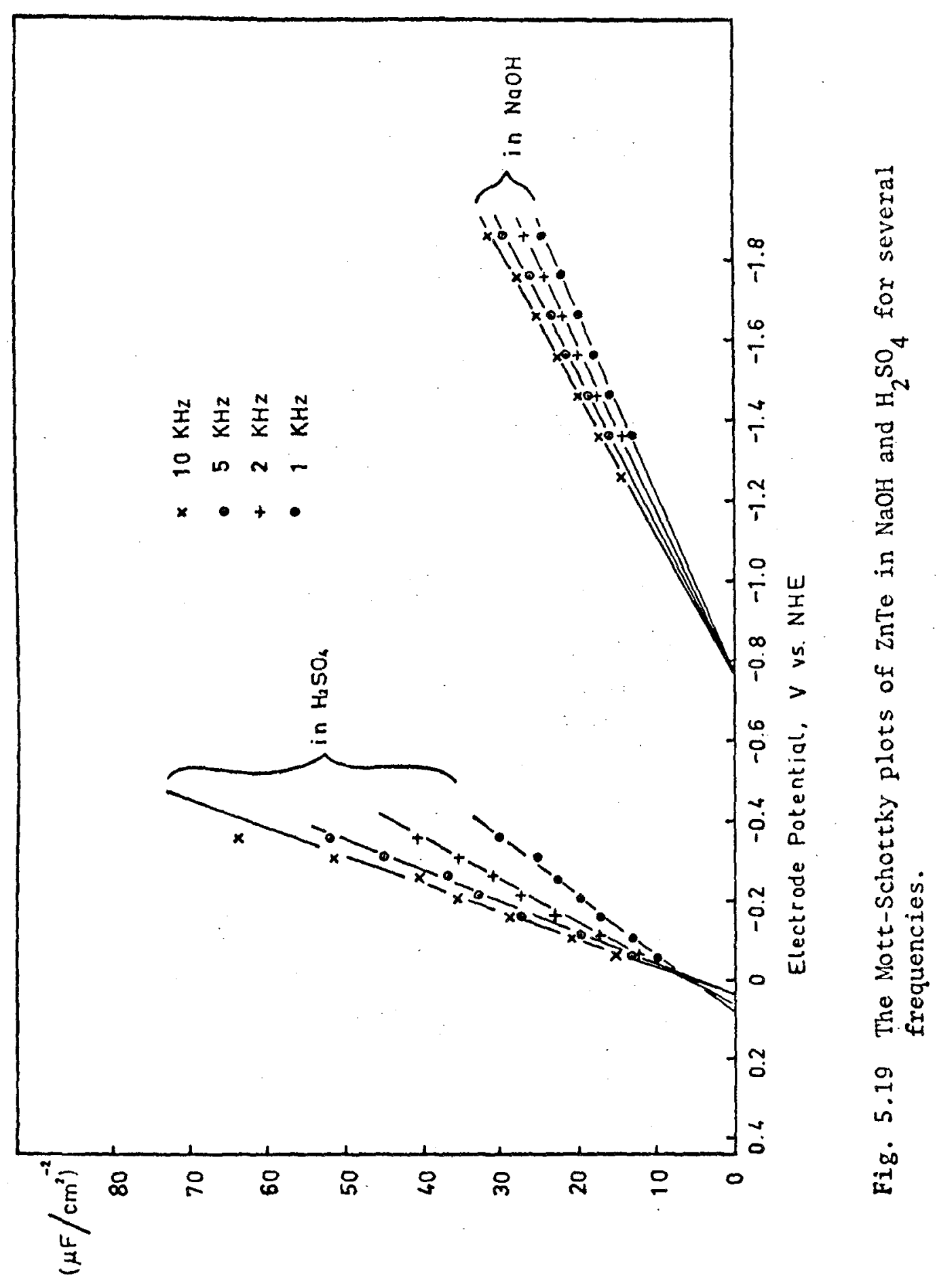



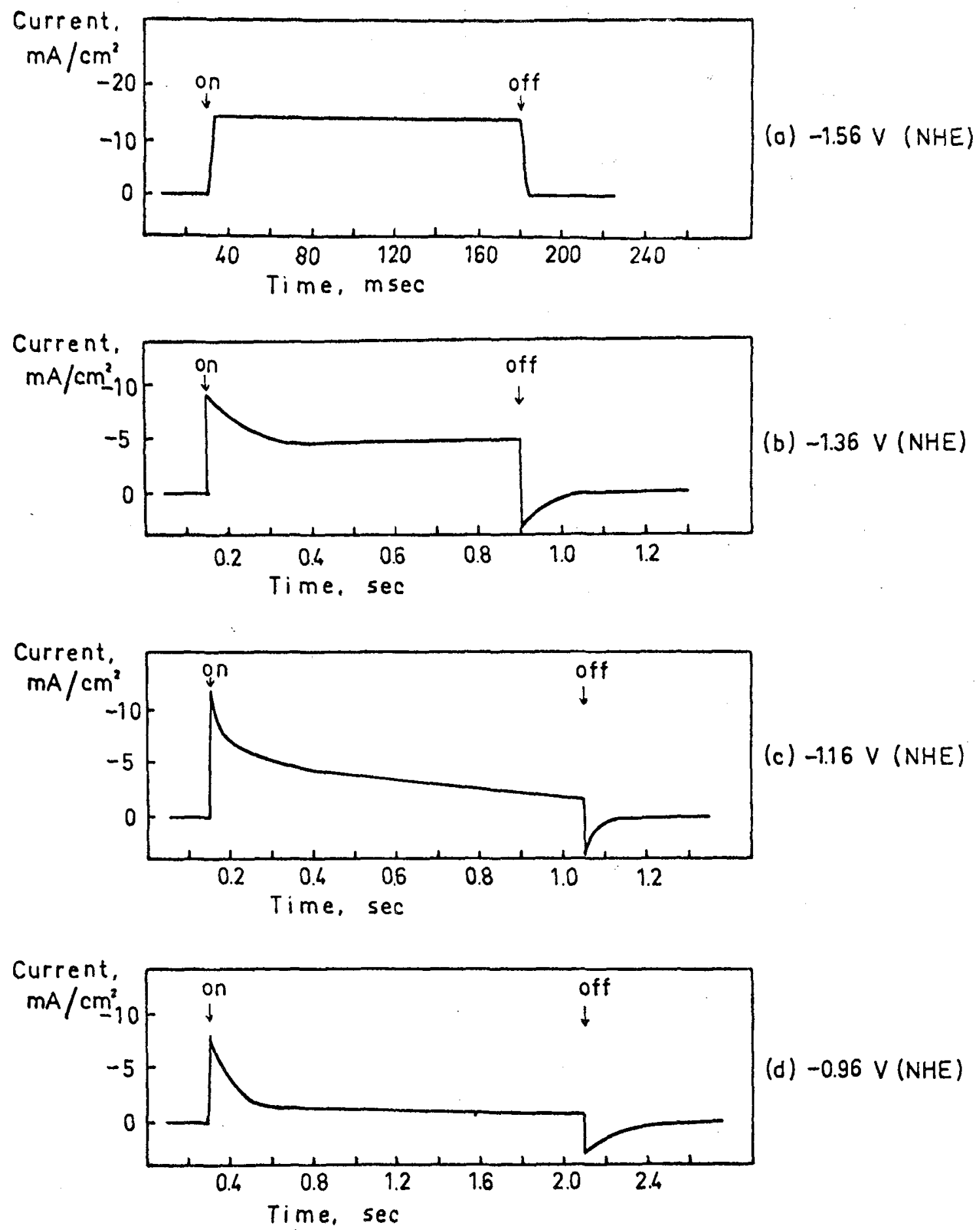

Fig. 5.20 The transient behaviour of the current of $\mathrm{ZnTe}$ after illumination and interruption of light in $1 \mathrm{~N} \mathrm{NaOH}$ at several potentials. The current before illuminatjon is taken as zero. Intensity of $1 \mathrm{ight:} 0.08 \mathrm{~W} / \mathrm{cm}^{2}$. 
134.
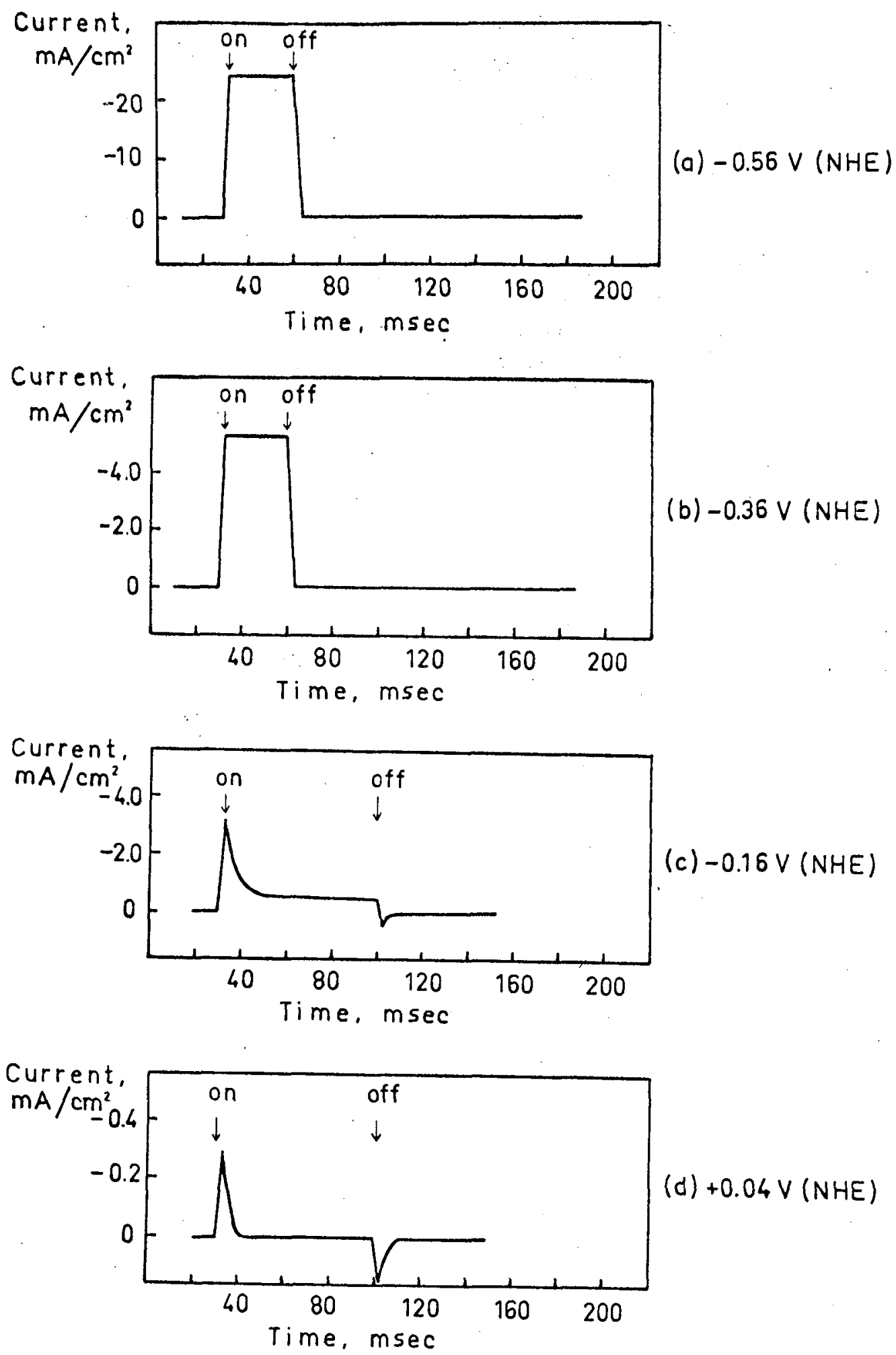

Fig. 5.21 The transient behaviour of the current of ZnTe after illumination and interruption of light in $1 \mathrm{~N} \mathrm{H}_{2} \mathrm{SO}_{4}$ at several potentials. The current before illumination is taken as zero. Intensity of light: $0.08 \mathrm{~W} / \mathrm{cm}^{2}$. 


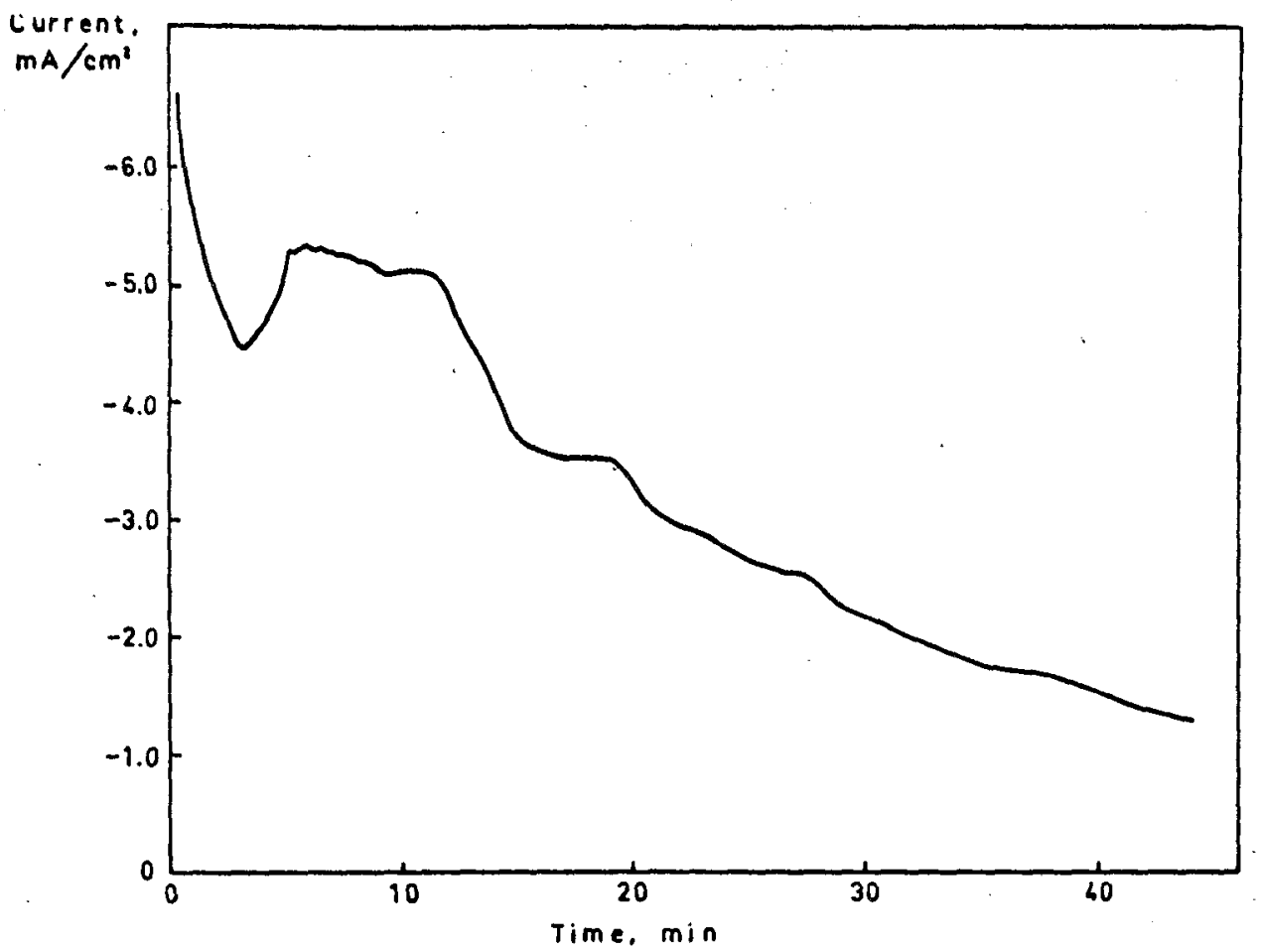

(a)

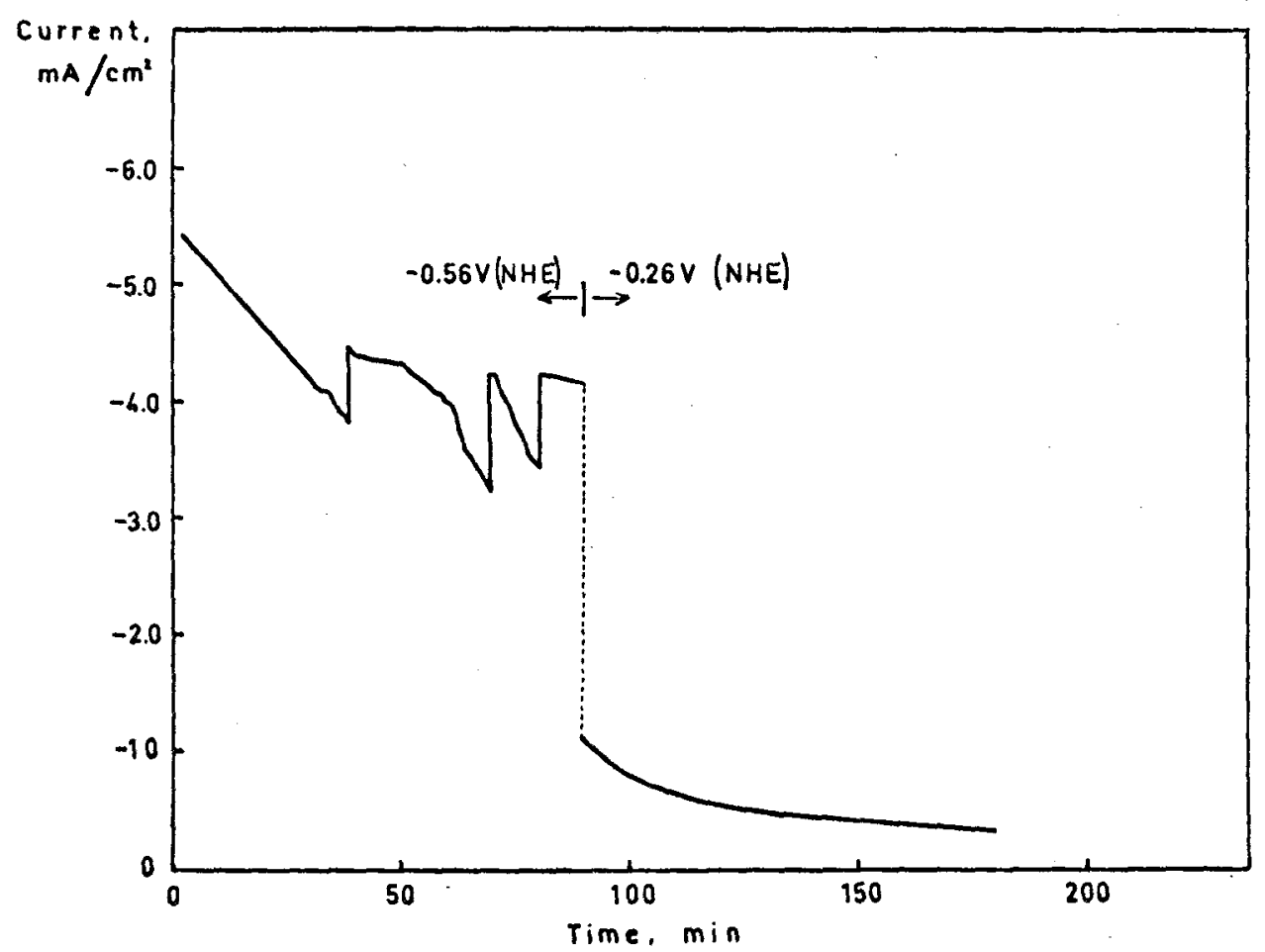

(b)

Fig. 5.22 The current of ZnTe under illumination of $900 \mathrm{~W}$ Xe lamp as a function of time. Intensity of light: $0.08 \mathrm{~W} / \mathrm{cm}^{2}$. (a) In $1 \mathrm{~N} \mathrm{NaOH}$ at $-1.26 \mathrm{~V}$ (NHE)

(b) In $1 \mathrm{~N} \mathrm{H}_{2} \mathrm{SO}_{4}$ at $-0.56 \mathrm{~V}$ and $-0.26 \mathrm{~V}$. 

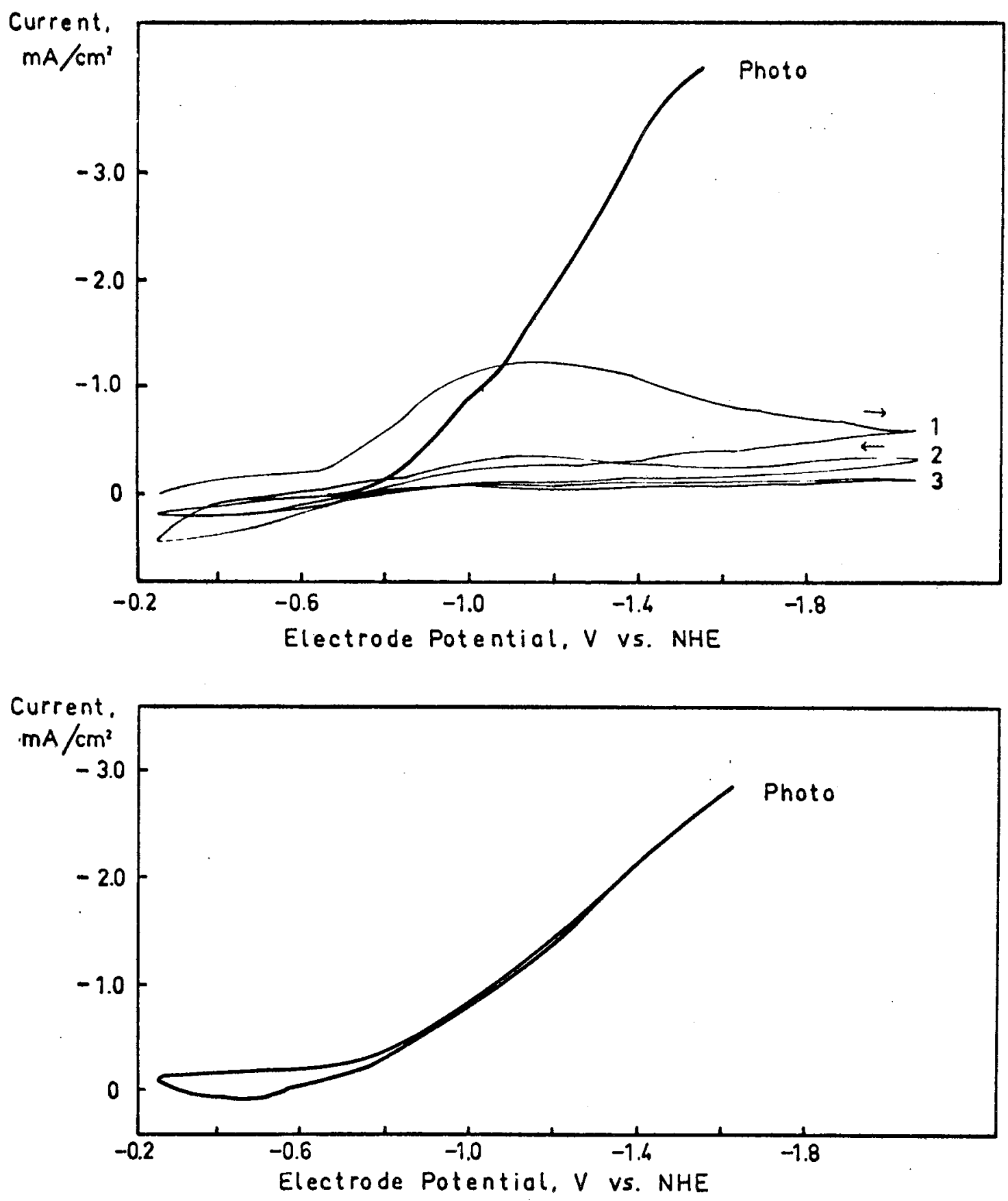

Fig. 5.23 The current-potential relations of CdTe in $1 \mathrm{~N} \mathrm{NaOH}$ with and without illumination by a $900 \mathrm{~W}$ Xe lamp. Intensity of light: $0.08 \mathrm{~W} / \mathrm{cm}^{2}$. Sweep rate: $1.5 \mathrm{~V} / \mathrm{min}$. (a) With sufficient deoxidation of solution. 1. 1st sweep in dark. 2. 2nd sweep in dark. 3. 3rd sweep in dark.

(b) Without deoxidation. 


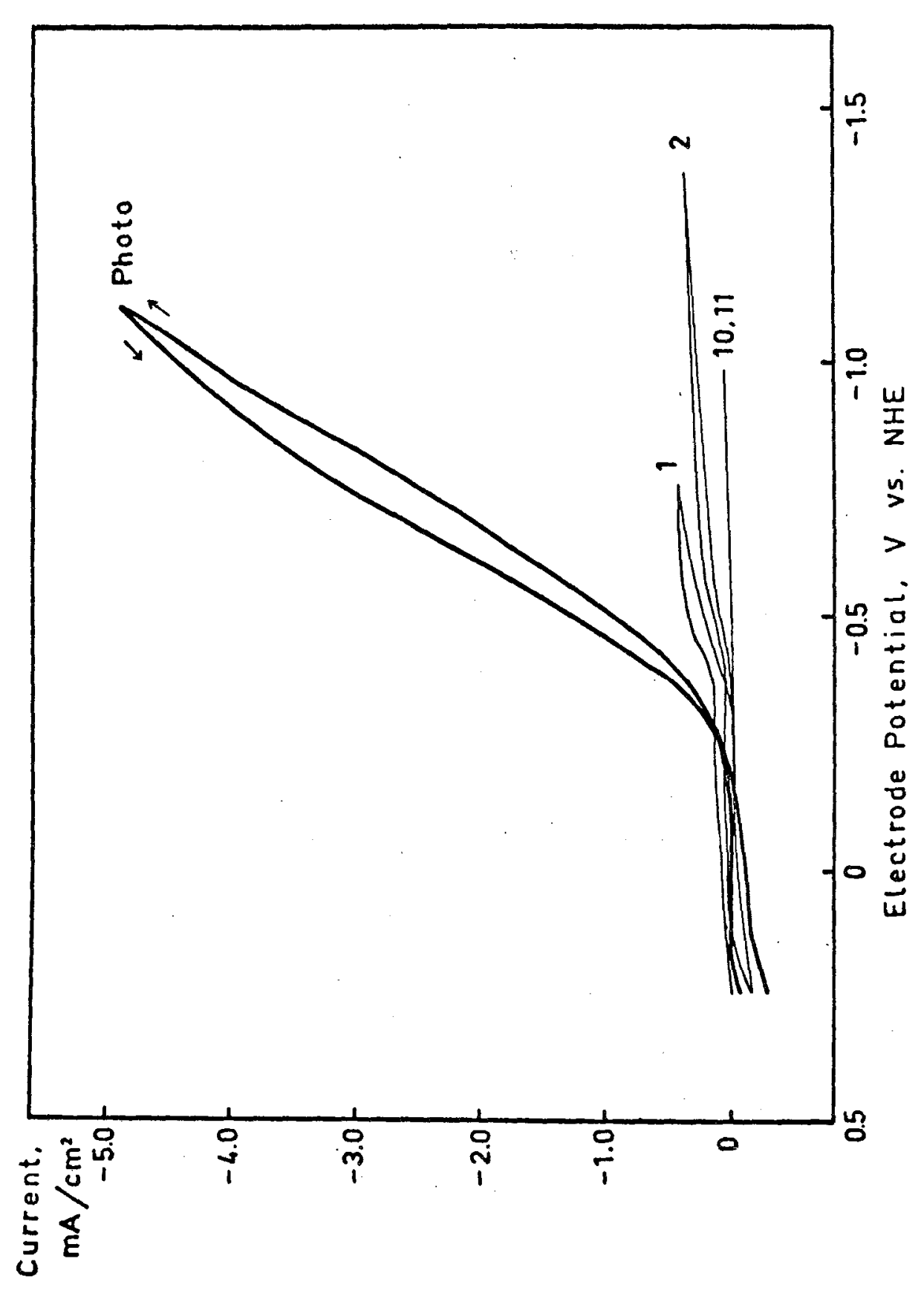

苛. 苦

-1
-00

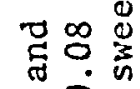

定

궁

एक्ष

品-

各分总

点

政

号吕

㟧致离

0

告害年.

당

$\stackrel{0}{\rightarrow} \stackrel{0}{\square}$

i $\geq$ is $^{\circ}$

중요렵

武

要的

分两

它..点

움웅

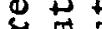

密

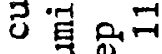

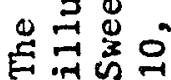

is

$\dot{0}$ 
138.

Exposure of the electrode surface to air made big effect on the photocurrent and took some time (about 40 minutes) to attain the stable condition as shown in Fig. 5.25.

The existence of oxygen changed the I-V relation significantly when the electrode potential was relatively positive. If there was no oxygen, no photocurrent was observed when the electrode potential was more positive than $-0.75 \mathrm{~V}$ (Fig. 5.23(a)). However, if oxygen existed some photocurrents (about $0.15 \mathrm{~mA} / \mathrm{cm}^{2}$ ) was observed even at $-0.25 \mathrm{~V}$ (Fig. 5.23(b)).

For these reasons, the current-potential relation under illumination was measured 2 hours after the electrode was kept in solution under hydrogen bubbling and illumination.

\subsubsection{Photocurrent (quantum efficiency) - wavelength relation at several potentials}

Photocurrents were measured under the illumination of monochromatic light $(3000 \AA \sim 9000 \AA)$ at several electrode potentials in $1 \mathrm{~N} \mathrm{NaOH}$ and in $1 \mathrm{~N}_{2} \mathrm{SO}_{4}$ and typical results are shown in Fig. 5.26(a) for $\mathrm{NaOH}$ and in Fig. 5.26(b) for $\mathrm{H}_{2} \mathrm{SO}_{4}$, respectively.

Because of the reasons mentioned before, reproducible results could not be obtained without care.

Quantum efficiencies were calculated by using measured values of photocurrents and the values of the number of photons of incident light. Results are shown in Fig. 5.27(a) for $\mathrm{NaOH}$ solution and in Fig. $5.27(b)$ for $\mathrm{H}_{2} \mathrm{SO}_{4}$ solution, respectively, as a function of wavelength,

\subsubsection{The flat band potential}

The Mott-Schottky plots in $1 \mathrm{~N} \mathrm{NaOH}$ and in $1 \mathrm{~N} \mathrm{H}_{2} \mathrm{SO}_{4}$ are shown in Fig. 5.28.

Since the resistance of this specimen was relatively high, the 
139.

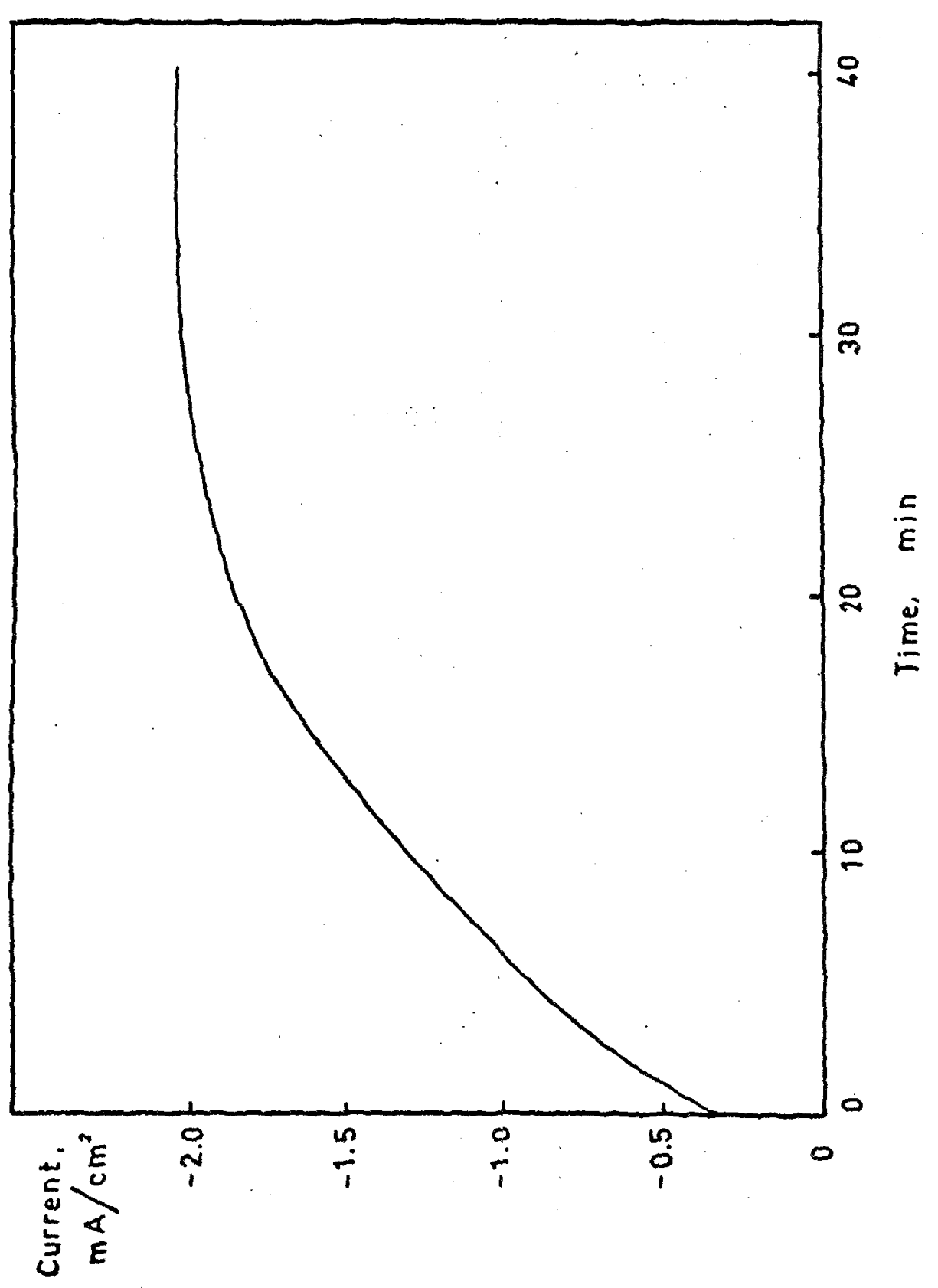

鼠兽

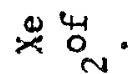

흥문 음

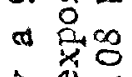

त.

동

品

녕

F

灵

c न

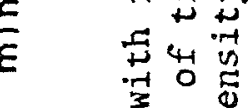

客密

z

盯苟我

Eक त्व

용

둥

武兽

岁忌出

$+>$ in

용요

4 .

0.

总山

ֻี

$\dot{\infty}$ 
อ
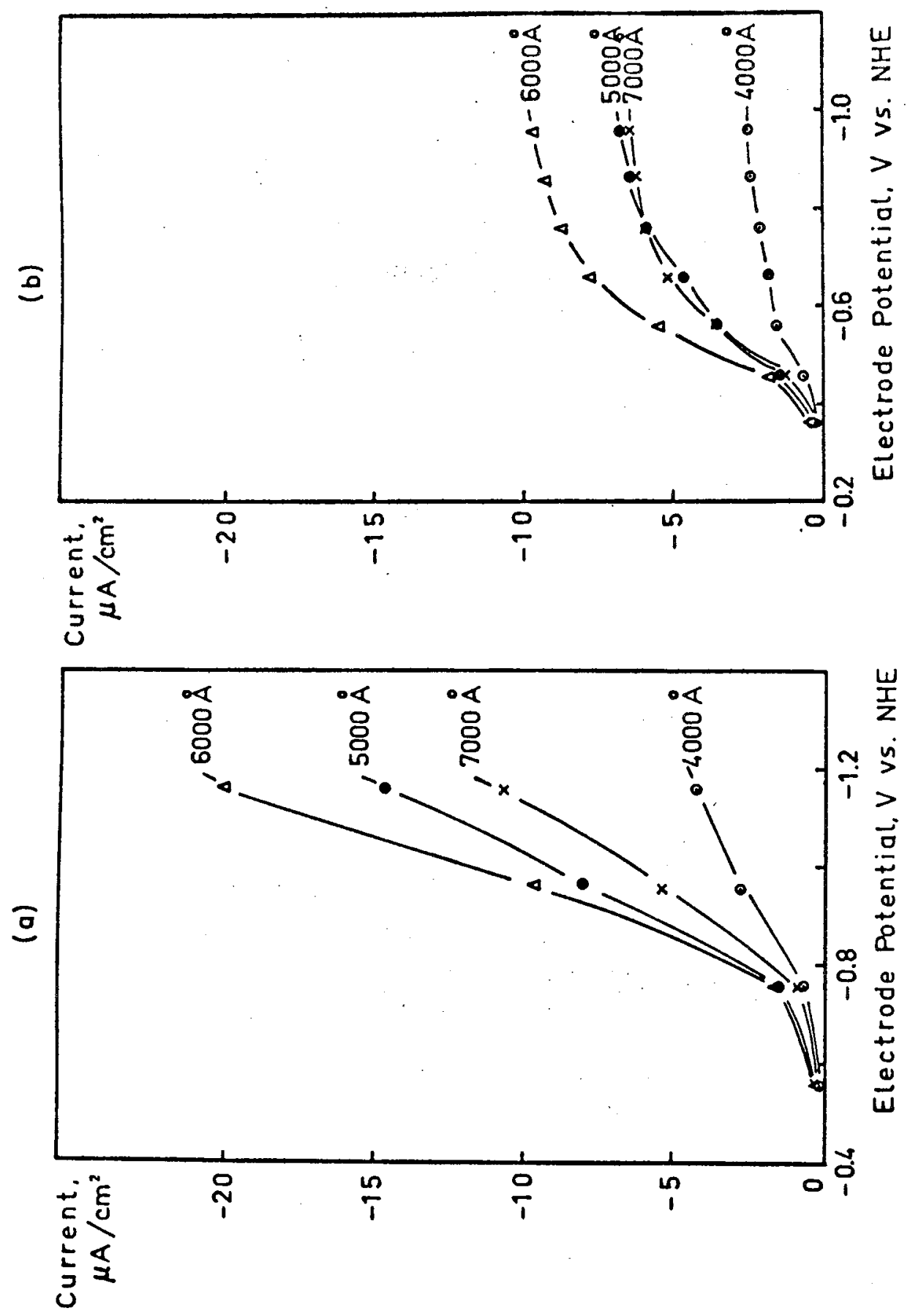

$\frac{z}{\mathrm{z}} \mathrm{n}^{\mathrm{N}}$

v

$>\quad \exists$

范

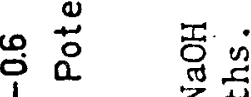

o z 辛

군

岁

$w$

要

U

43

n in

-

出

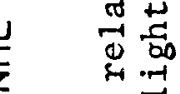

7

茎

更

出

도

艺.

。

留

号

葆示

空

点

i

$\dot{0}$ 
141.
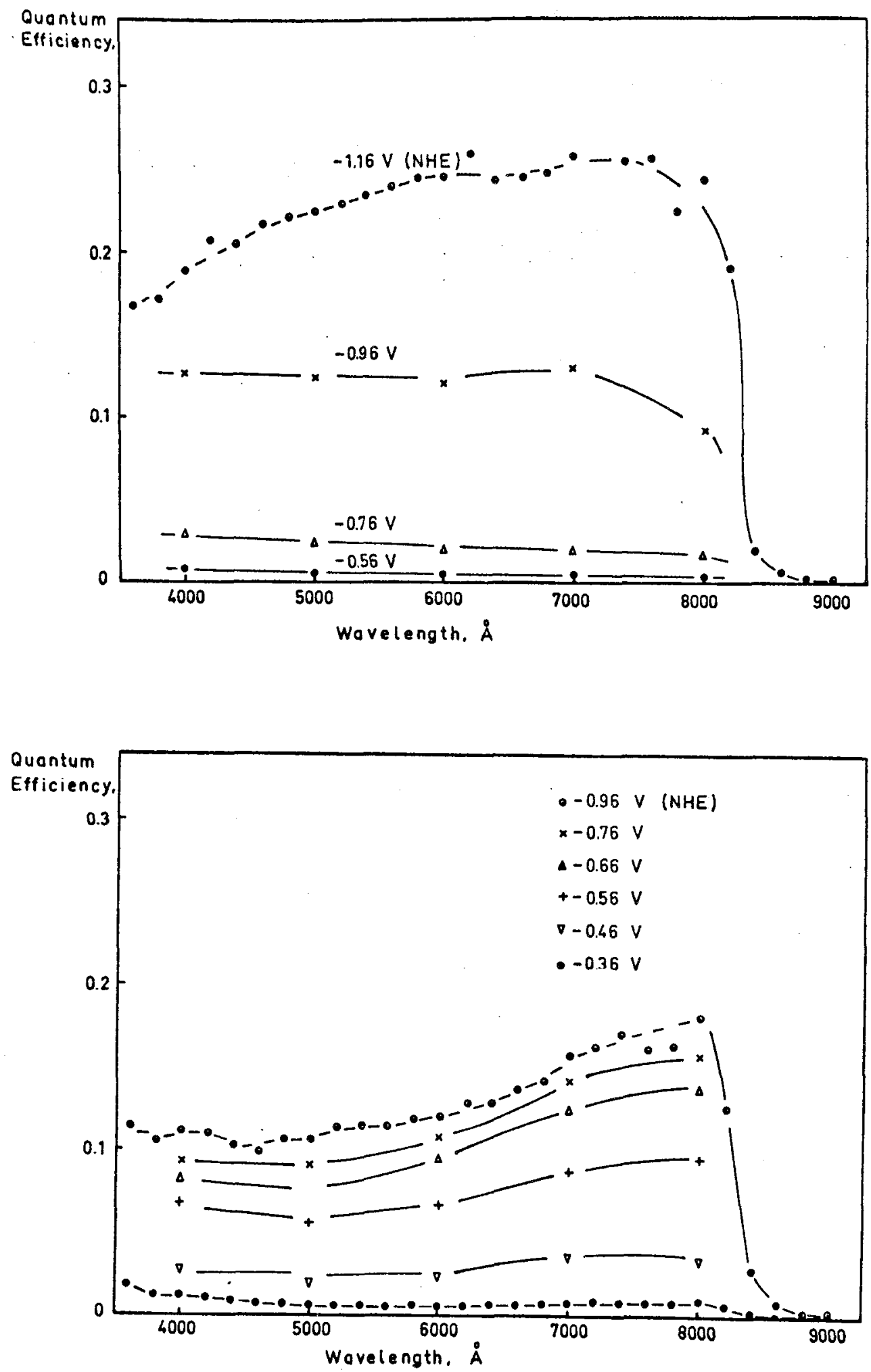

(b)

Fig, 5.27 The quantum efficiency-wavolength rolations of Cd'Te in $1 \mathrm{~N} \mathrm{NaOH} \mathrm{(a)} \mathrm{and} 1 \mathrm{~N} \mathrm{H}_{2} \mathrm{SO}_{4}$ (b) at several eloctrode potentials. 


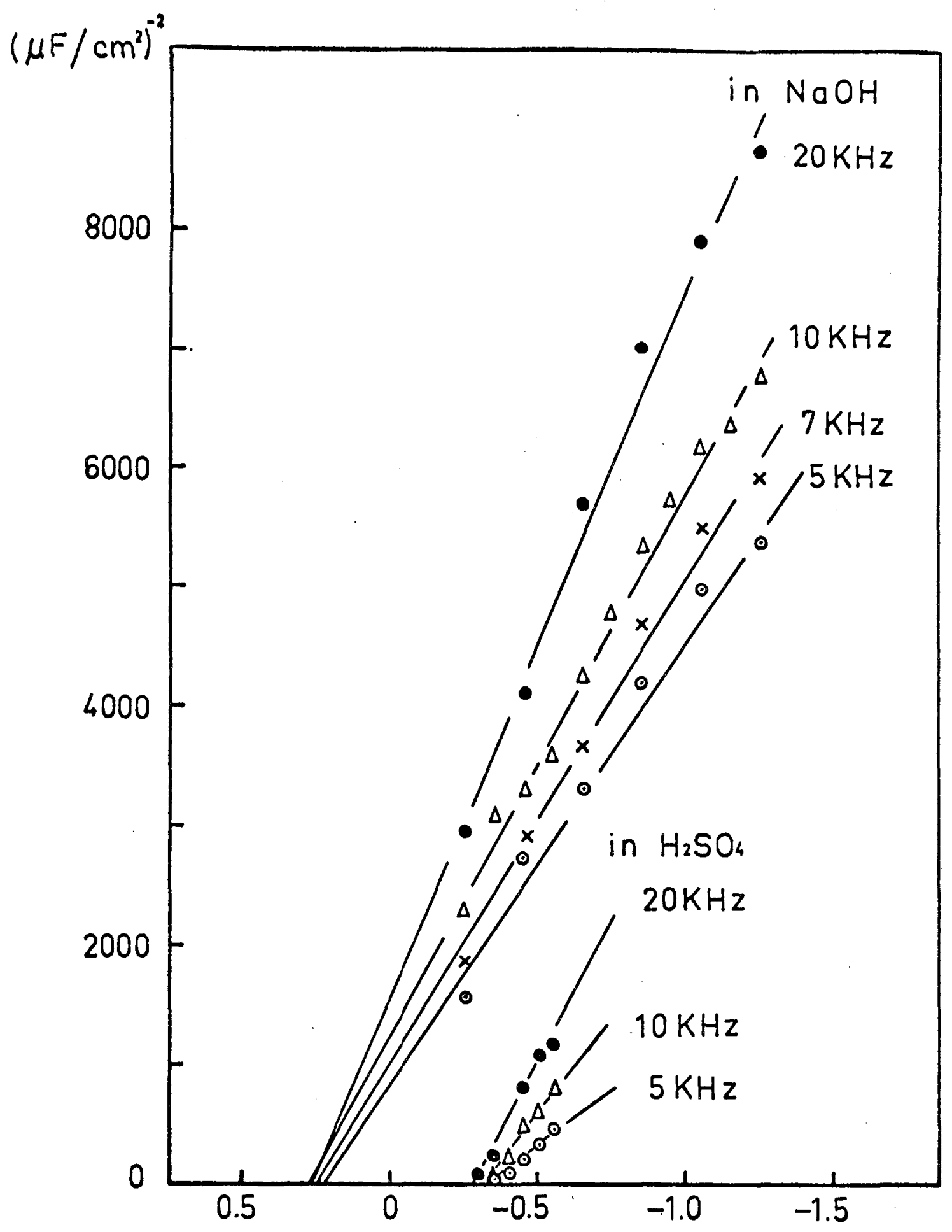

Electrode Potential, $V$ vs. NHE

Fig. 5.28 The Mott-Schottky plots of CdTe in $\mathrm{NaOH}$ and $\mathrm{H}_{2} \mathrm{SO}_{4}$
at several frequencies. 
143.

accuracy of the measurements was relatively low. (Impedance due to resistance was from same order of magnitude to ten times of an impedance due to capacitance).

From these plots, the flat band potentials were calculated as $0.21 \mathrm{~V} \pm 0.02 \mathrm{~V}$ (NHE) in $1 \mathrm{~N} \mathrm{NaOH}$ and $-0.35 \mathrm{~V} \pm 0.05 \mathrm{~V}$ (NHE) in $1 \mathrm{~N}$ $\mathrm{H}_{2} \mathrm{SO}_{4}$, respectively.

\subsubsection{Transient measurement}

The results of transient measurements in $1 \mathrm{~N} \mathrm{NaOH}$ and in $1 \mathrm{~N}_{2} \mathrm{SO}_{4}$ at several potentials are shown in Fig. $5.29(\mathrm{a} \sim \mathrm{e})$ and in Fig. 5.30 (a e), respectively.

As observed in $\mathrm{ZnTe}$ case, the more negative the potential was, the more quickly the steady state was established.

\section{2 .2 .5 Stability}

The stability was examined by measuring the photocurrent at fixed potential for certain time. The results are shown in Fig. 5.31 for $\mathrm{NaOH}$ solution (over 20 hours) and for $\mathrm{H}_{2} \mathrm{SO}_{4}$ solution (over $100 \mathrm{~min}$ ). In both cases, the photocurrents were relatively stable compared with those of $\mathrm{ZnTe}$. During the stability tests, gas which evolved from the CdTe electrode was collected and the amount of the gas showed that the cathodic current was due to hydrogen evolution reaction.

\subsubsection{Gallium Arsenide (GaAs)}

\subsubsection{The current-potential relation}

The current-potential relations of GaAs in $1 \mathrm{~N} \mathrm{NaOH}$ and in $1 \mathrm{~N}_{2} \mathrm{SO}_{4}$ with and without illumination by a $900 \mathrm{~W}$ Xe lamp in $1 \mathrm{~N} \mathrm{NaOH}$ and in $1 \mathrm{~N}$ $\mathrm{H}_{2} \mathrm{SO}_{4}$ are shown in Fig. 5.32(a) and in Fig. 5.32(b), respectively. The relations in dark are quite different from those of $\mathrm{ZnTe}$ and CdTe. In $\mathrm{ZnTe}$ and $\mathrm{CdTe}$ case, only small dark cathodic currents were observed even at very negative potential (see Fig. 5.16, 5.23 and 


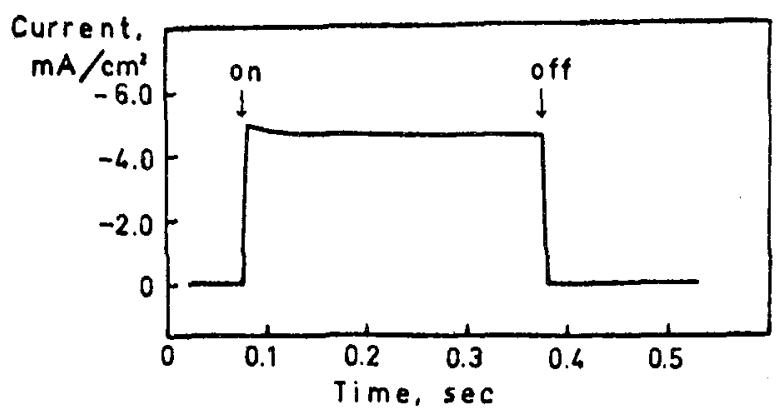

(a) $-1.46 \vee$ (NHE)

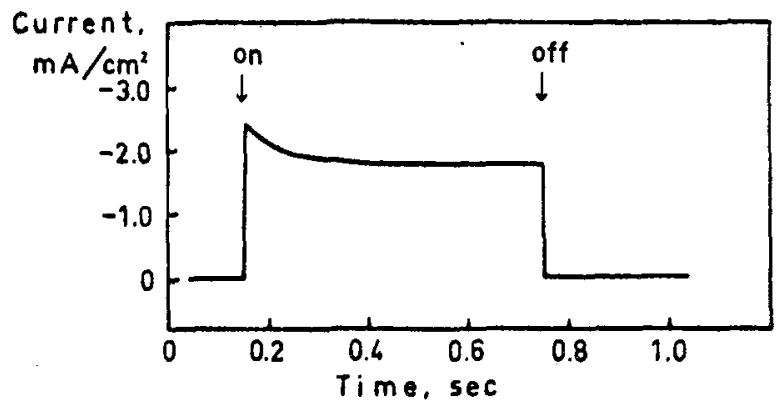

(b) $-1.26 \mathrm{~V}$ (NHE)

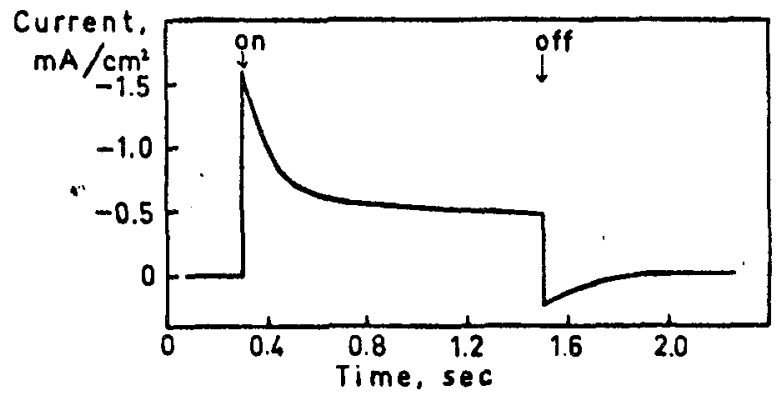

(c) $-1.06 \vee$ (NHE)

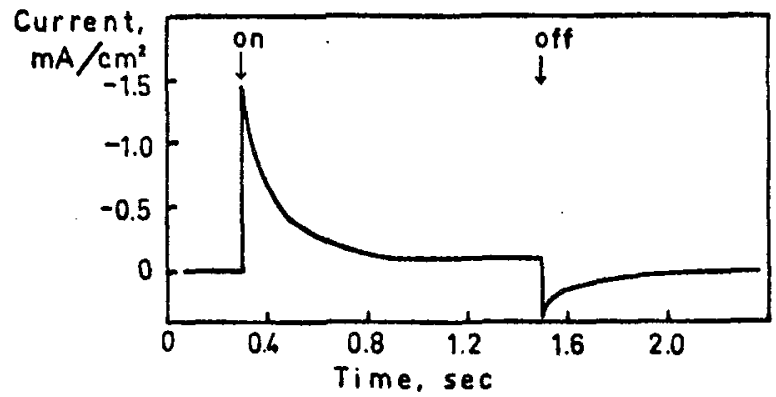

(d) $-0.86 \vee$ (NHE)

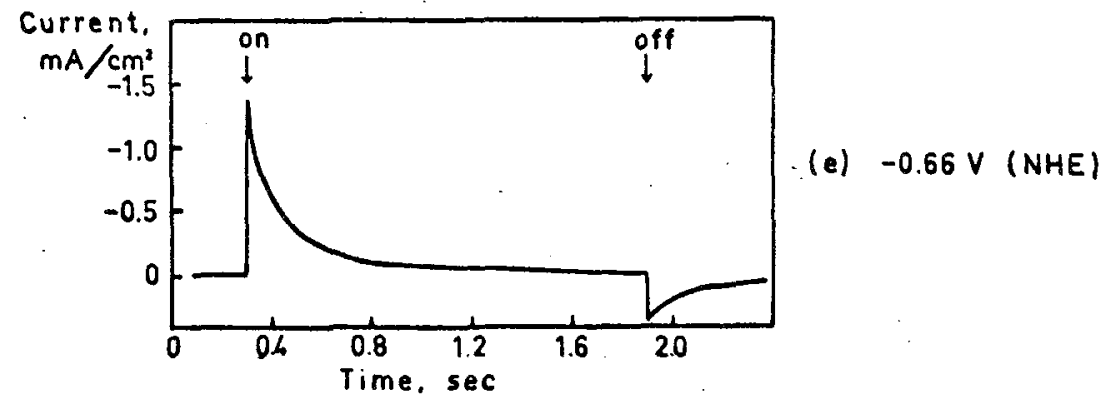

Fig. 5.29 The transient behaviour of the current of CdTe after illumination and interruption of light $(0.08 \mathrm{~W} / \mathrm{cm})$ in IN $\mathrm{NaOH}$ at several electrode potentials. The current before illumination is taken as zero. 


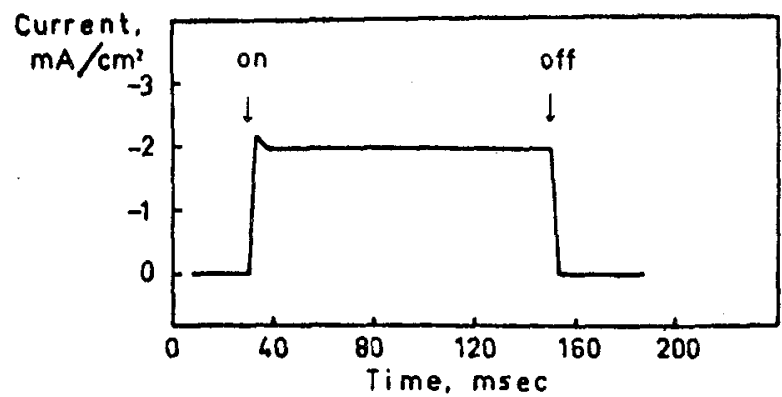

(a) $-0.76 \vee(\mathrm{NHE})$

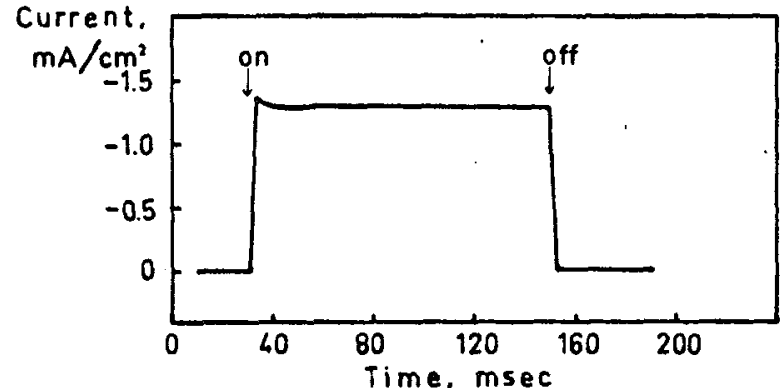

(b) $-0.56 \vee(N H E)$

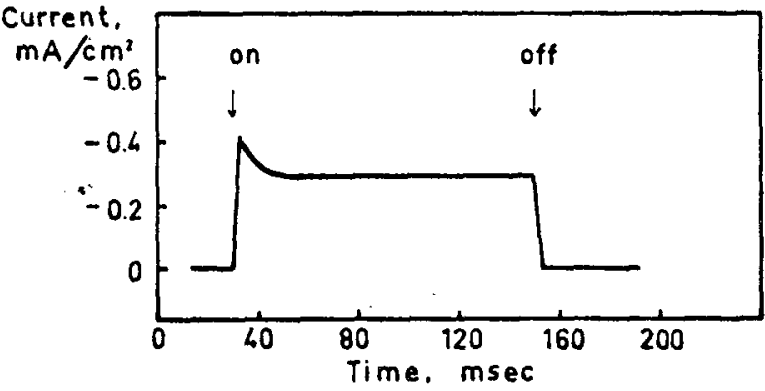

(c) $-0.36 \vee(N H E)$

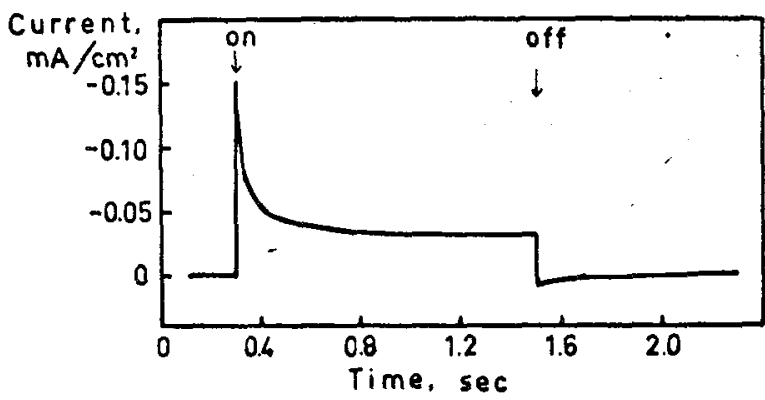

(d) $-0.16 \vee(N H E)$

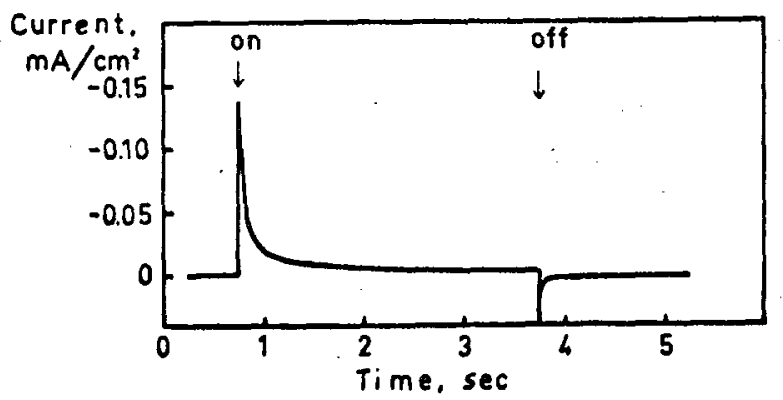

(e) $+0.06 \vee$ (NHE)

Fig. 5.30 The transient behaviour of the current of CdTe after illumination and interruption of light $(0.08 \mathrm{~W} / \mathrm{cm})$ in $1 \mathrm{~N}_{2} \mathrm{SO}_{4}$ at several electrode potentials. The current before lllumination is taken as zero. 
146.

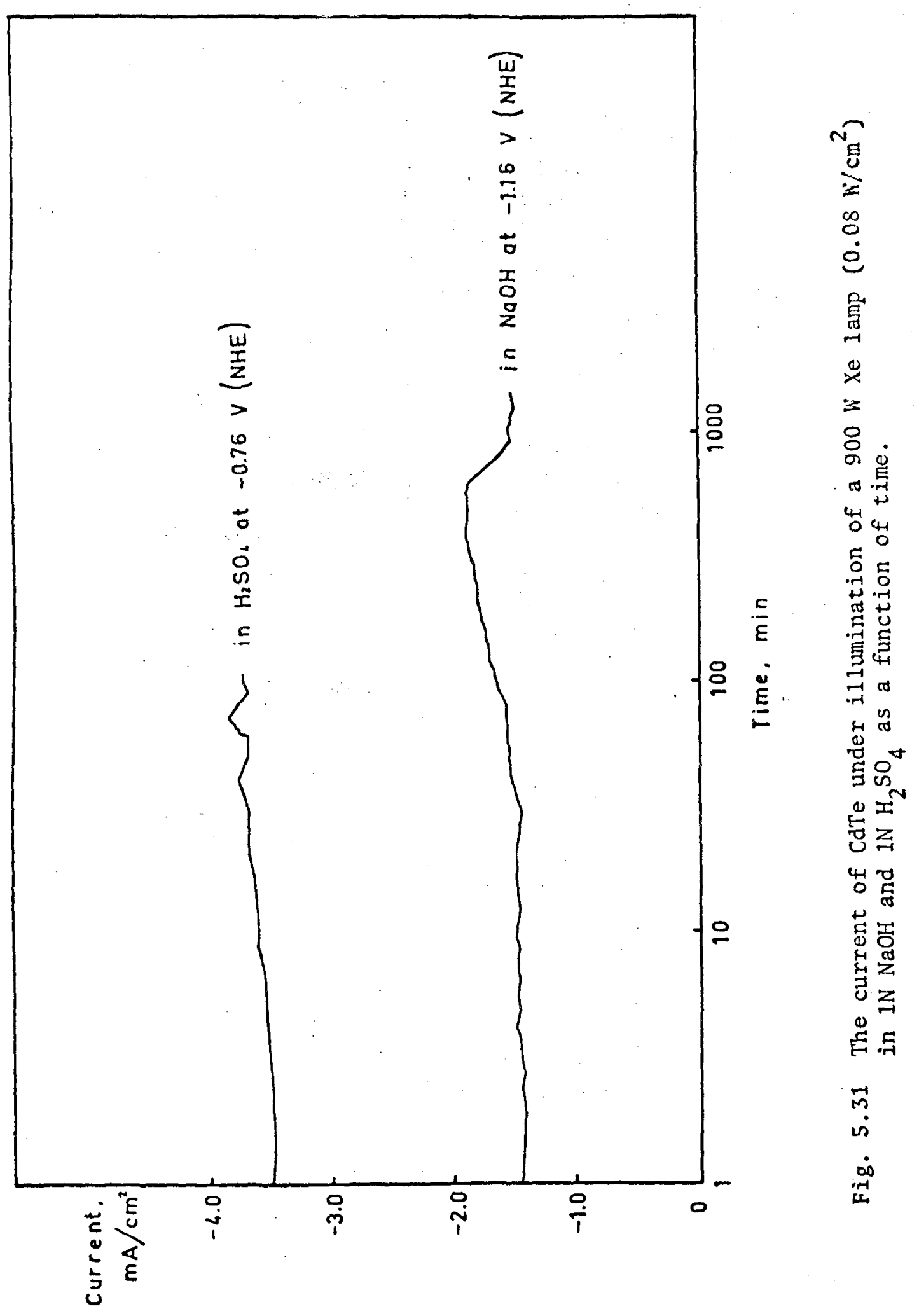


147.

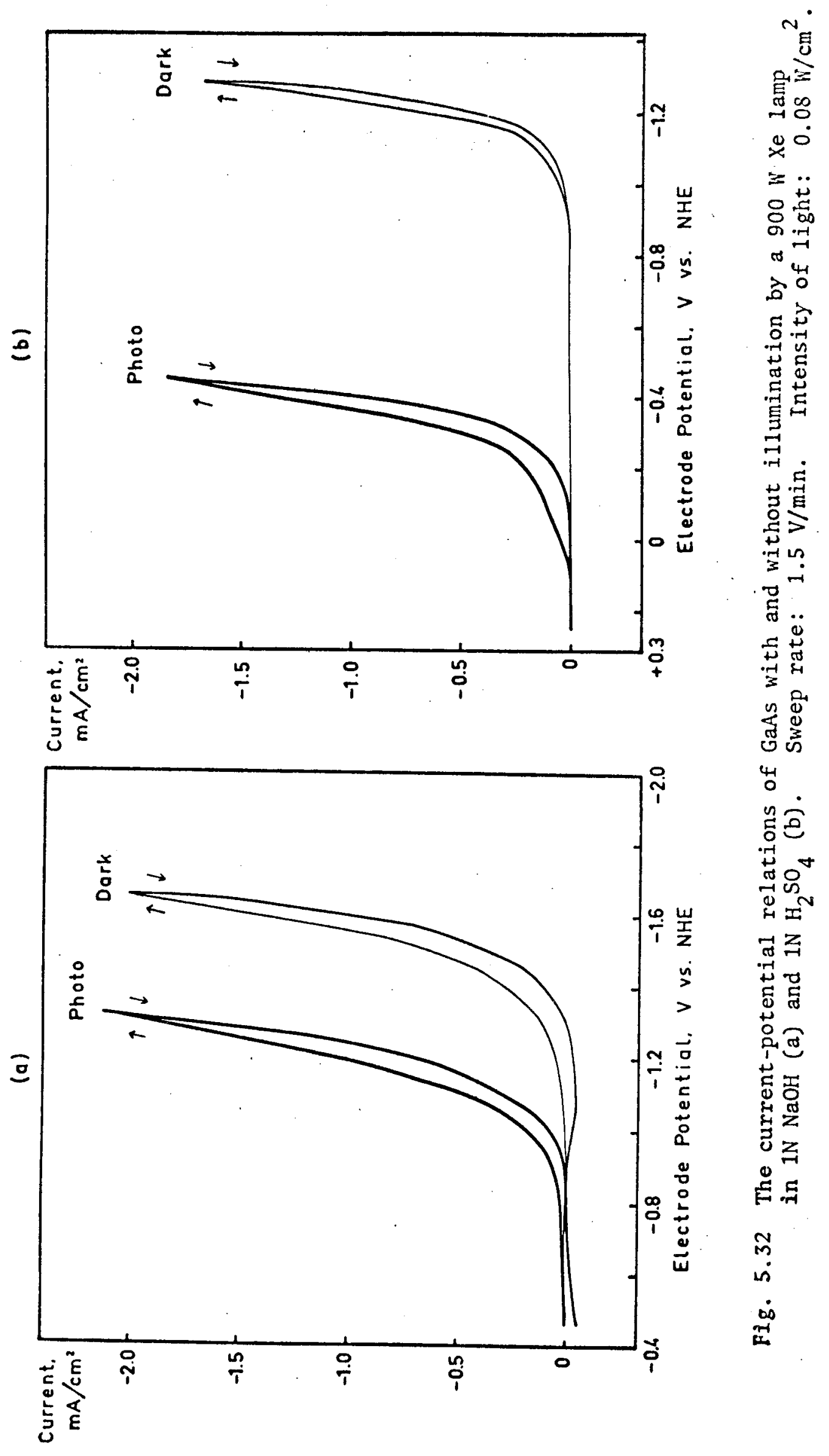


148.

and 5.24). On the other hand, here, the behaviour of dark current was similar to that of metal, i.e. Tafel behaviour.

\subsubsection{Photocurrent (quantum efficiency) - wavelength} relation at several potentials

The photocurrents which were the difference between the currents with monochromatic light $(3000 \AA \sim 9000 \AA)$ and those without light were measured at several potentials $(-0.96 \sim 1.36 \mathrm{~V}$ (NHE) for $\mathrm{NaOH}$ and -0.36 $\sim-1.16 \mathrm{~V}$ for $\mathrm{H}_{2} \mathrm{SO}_{4}$ ). Typical results are shown in Fig. 5.33(a) for $\mathrm{NaOH}$ and in Fig. 5.33(b) for $\mathrm{H}_{2} \mathrm{SO}_{4}$, respectively.

Quantum efficiencies were calculated by using the measured values of photocurrents and the measured values of number of incident photons. Results in $\mathrm{NaOH}$ and in $\mathrm{H}_{2} \mathrm{SO}_{4}$ are shown in Fig. 5.34(a) and Fig. 5.34(b), respectively.

\subsubsection{The flat band potential}

The Mott-Schottky plots in $1 \mathrm{~N} \mathrm{NaOH}$ and in $1 \mathrm{~N} \mathrm{H}_{2} \mathrm{SO}_{4}$ are shown in Fig. 5.35 and the flat band potentials calculated from these plots are $-0.04 \mathrm{~V} \pm 0.03 \mathrm{~V}(\mathrm{NHE})$ in $1 \mathrm{~N} \mathrm{NaOH}$ and $0.43 \mathrm{~V} \pm 0.04 \mathrm{~V}$ (NHE) in $1 \mathrm{~N} \mathrm{H}_{2} \mathrm{SO}_{4}$, respectively.

\subsubsection{Transient measurement}

The results of transient measurements in $1 \mathrm{~N} \mathrm{NaOH}$ and in $1 \mathrm{~N} \mathrm{H}_{2} \mathrm{SO}_{4}$ are shown in Fig. 5.36 (a e) and in Fig. $5.37(\mathrm{a} \sim \mathrm{d})$, respectively. The behaviour was similar to those of $\mathrm{ZnTe}$.

\section{2 .3 .5 Stability}

The currents under illumination are shown in Fig. 5.38(a) for $\mathrm{NaOH}$ solution and in Fig. 5.38(b) for $\mathrm{H}_{2} \mathrm{SO}_{4}$ solution, respectively, as a function of time. In both cases, the currents decreased constantly with time. The interruption of illumination did not affect the stability but after keeping the electrode at open circuit condition, the current recovered. (See Fig. 5.38(b).) 


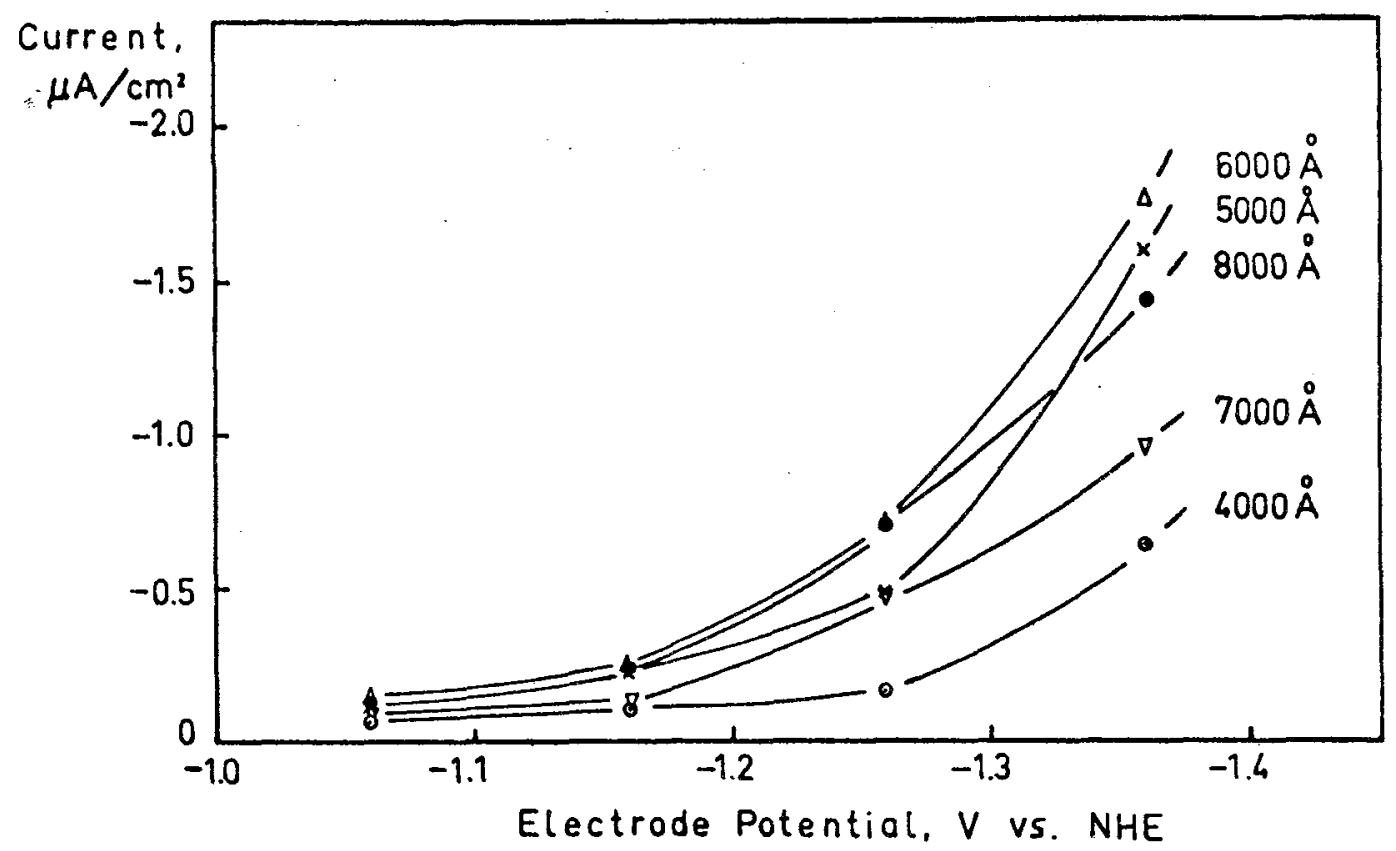

(o)

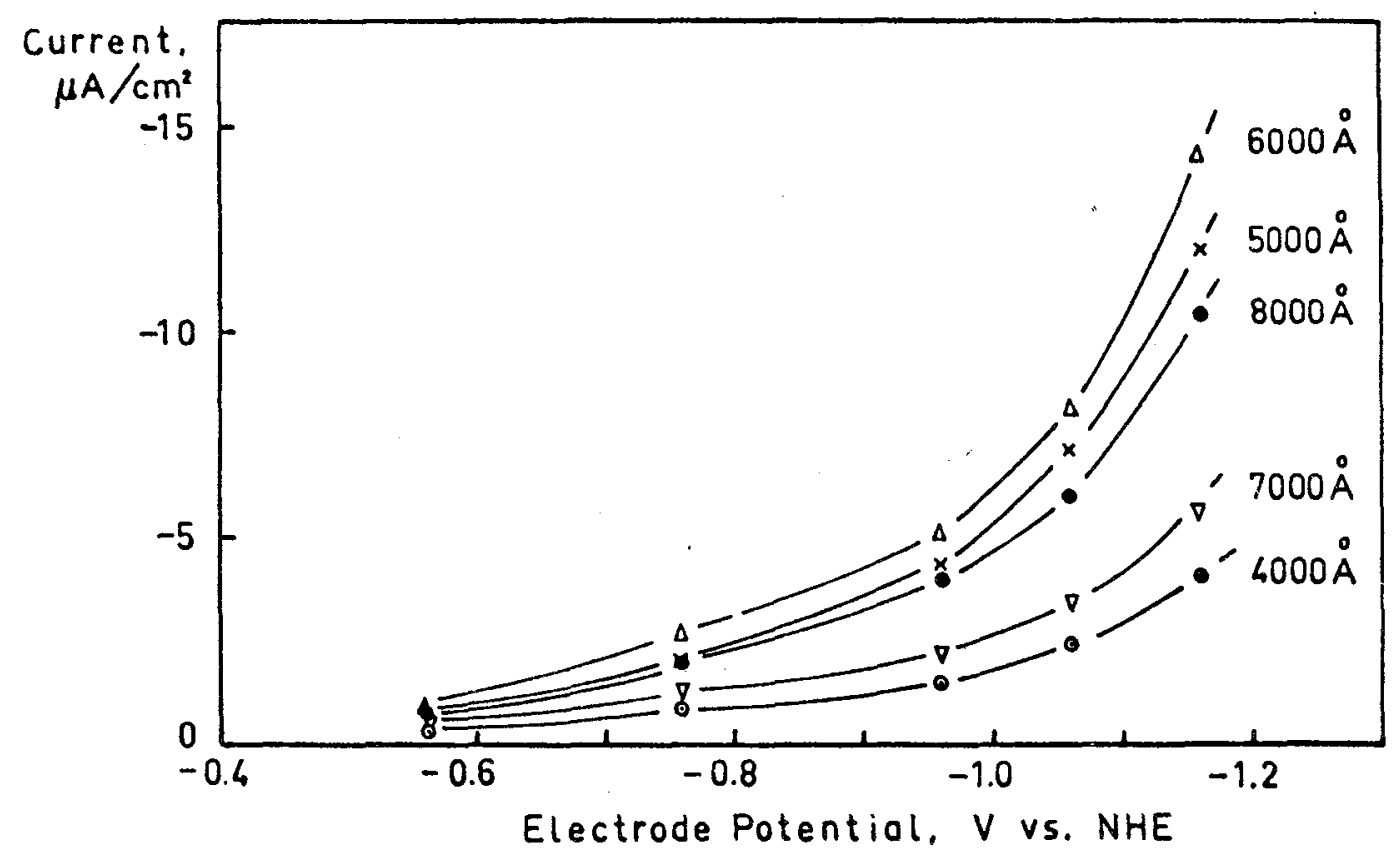

(b)

Fig. 5.33 The photocurrent-potential relations of GaAs in $1 \mathrm{~N} \mathrm{NaOH}$ (a) and $1 \mathrm{~N} \mathrm{H}_{2} \mathrm{SO}_{4}$ (b) for the light of several wavelengths. 
150.

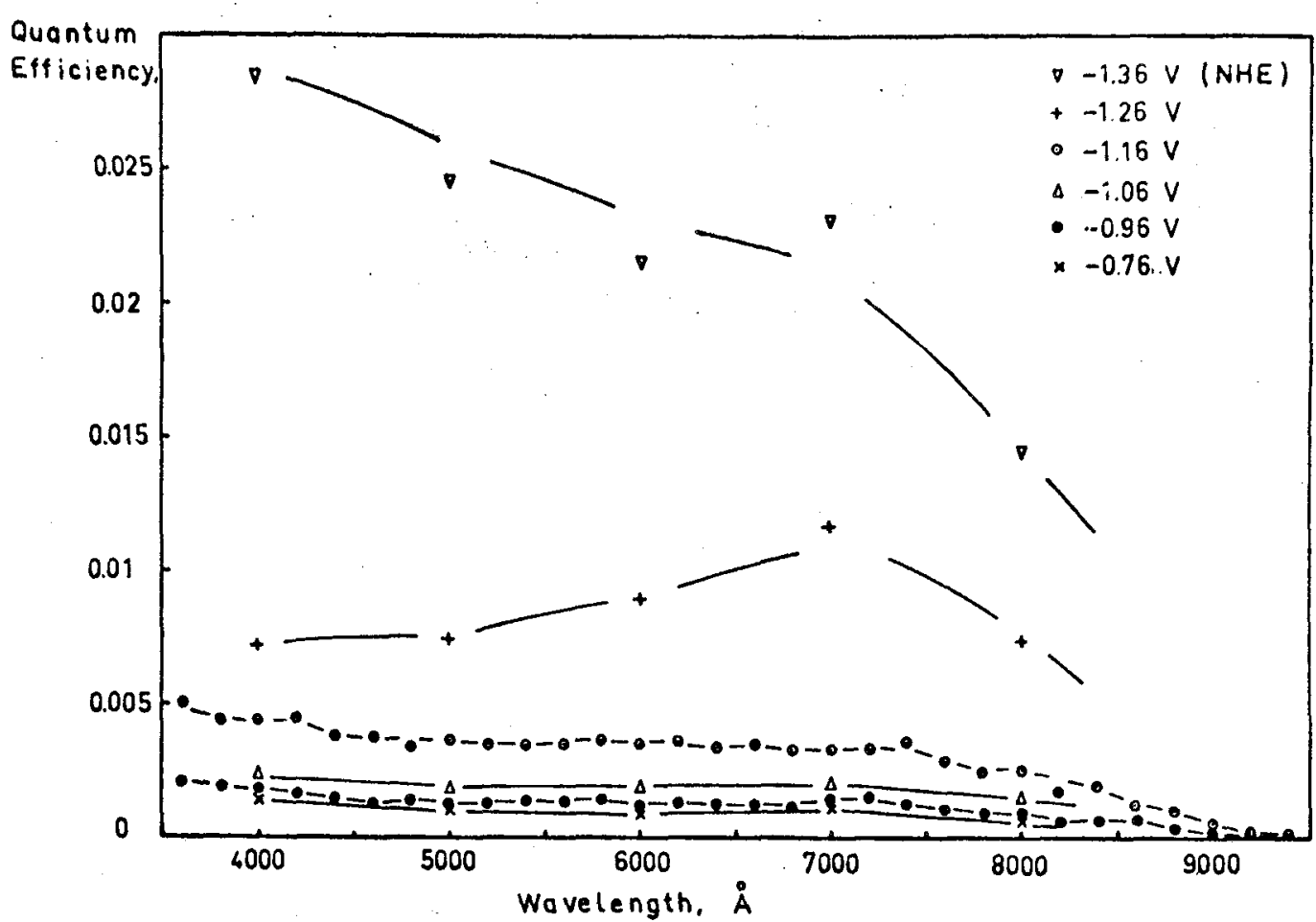

(a)

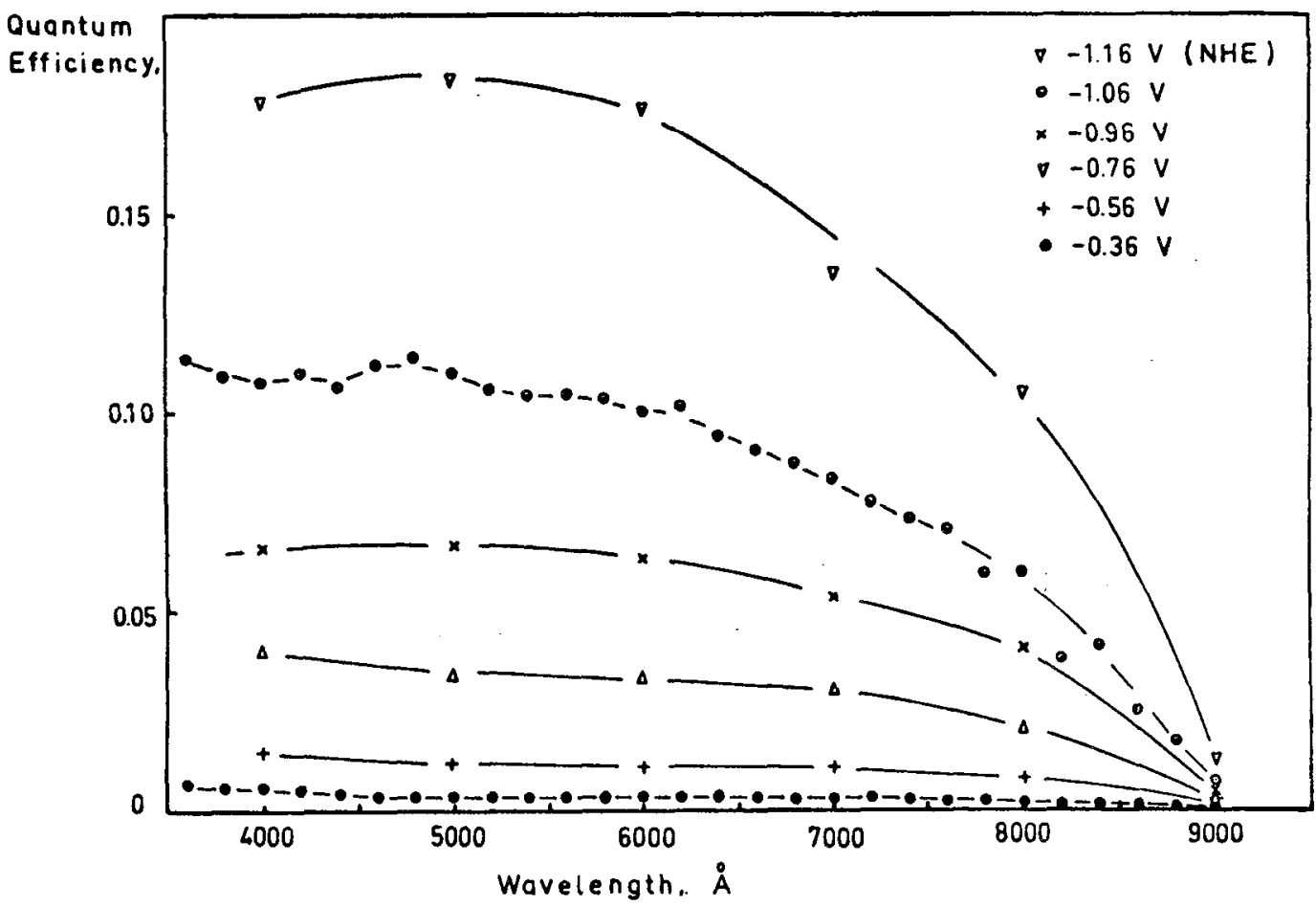

Fig. 5.34 The quartum efficiency-wavelength relations of GaAs in $1 \mathrm{~N} \mathrm{NaOH}$ (a) and $1 \mathrm{~N} \mathrm{H}_{2} \mathrm{SO}_{4}$ (b) at several electrode potentials. 


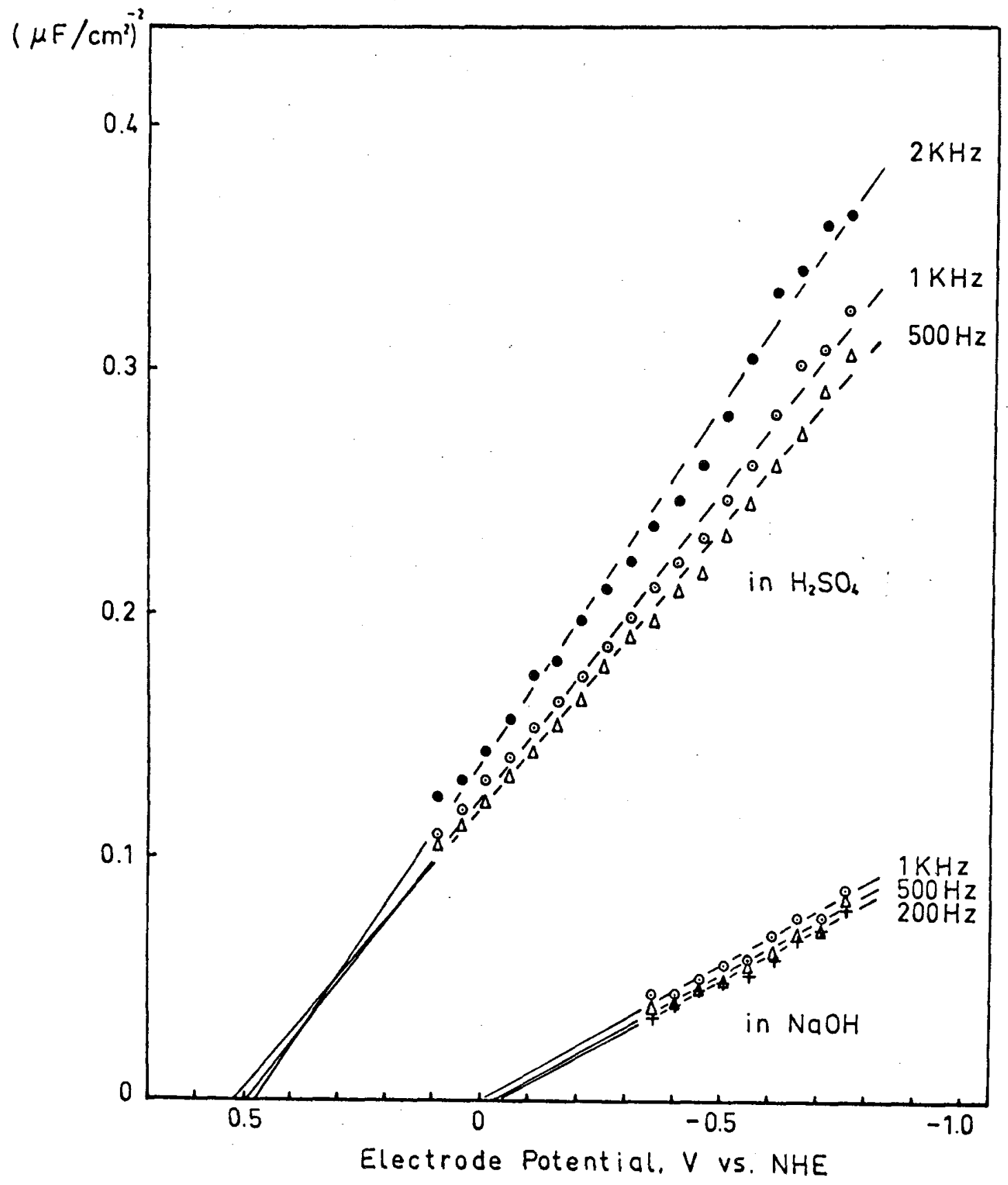

Fig. 5.35 The Mott-Schottky plots of GaAs in $1 \mathrm{~N} \mathrm{NaOH}$ and $1 \mathrm{~N}_{2} \mathrm{SO}_{4}$ at several frequencies. 

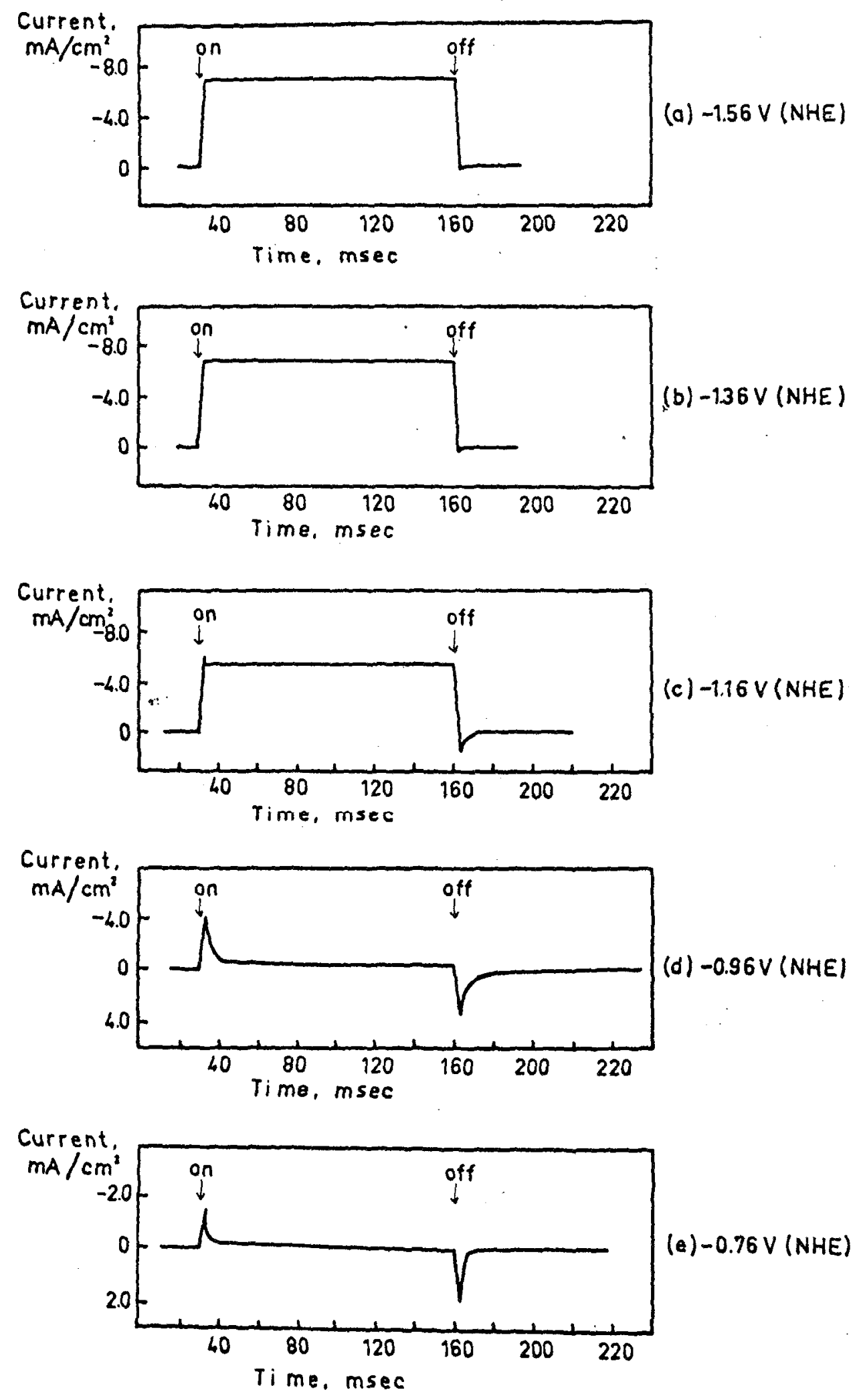

Pig. 5.36 The transient behaviour of the current of GaAs in IN NaOH after illumination and interruption of light $\left(0.08 \mathrm{~W} / \mathrm{cm}^{2}\right)$ at several electrode potentials. The current before illumination is taken as zero. 
153.

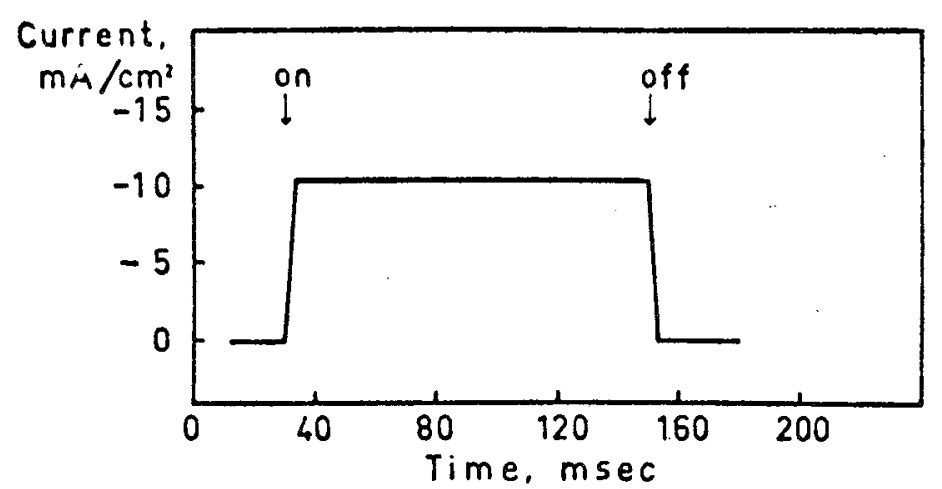

(a) $-1.16 \vee$ (NHE)

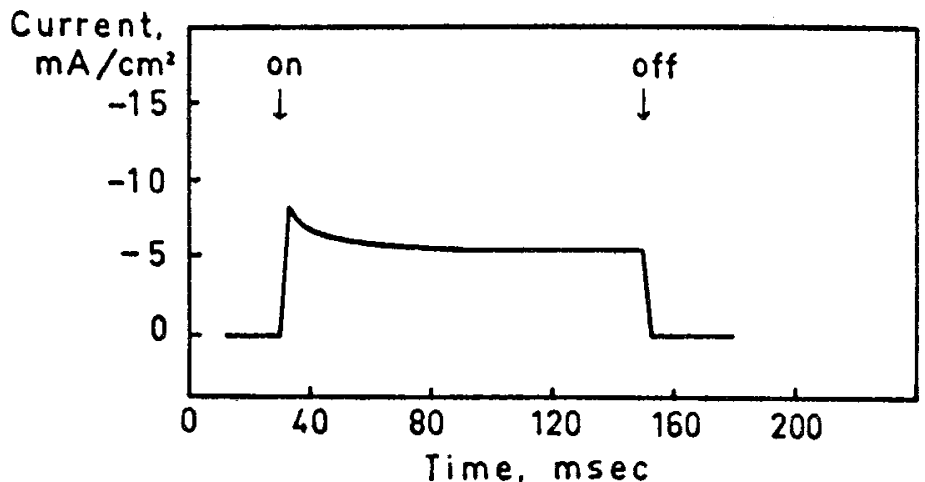

(b) $-0.76 \vee(N H E)$

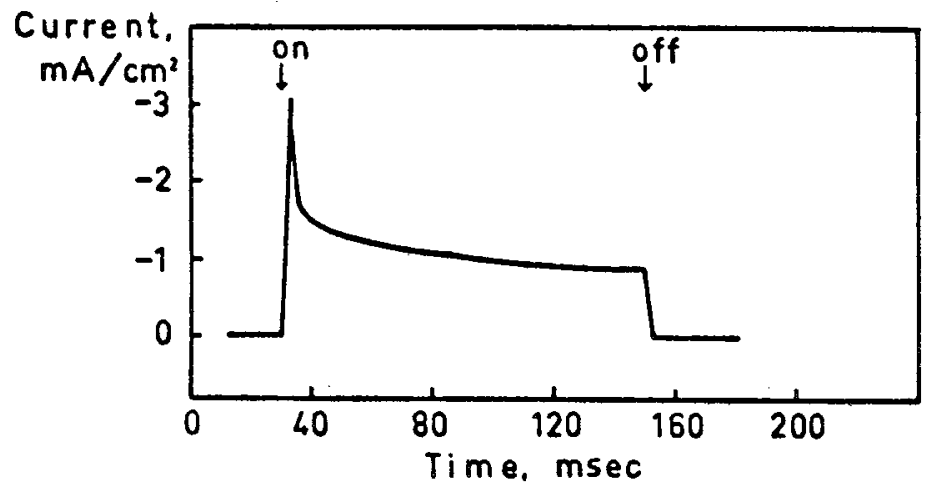

(c) $-0.36 \vee($ NHE)

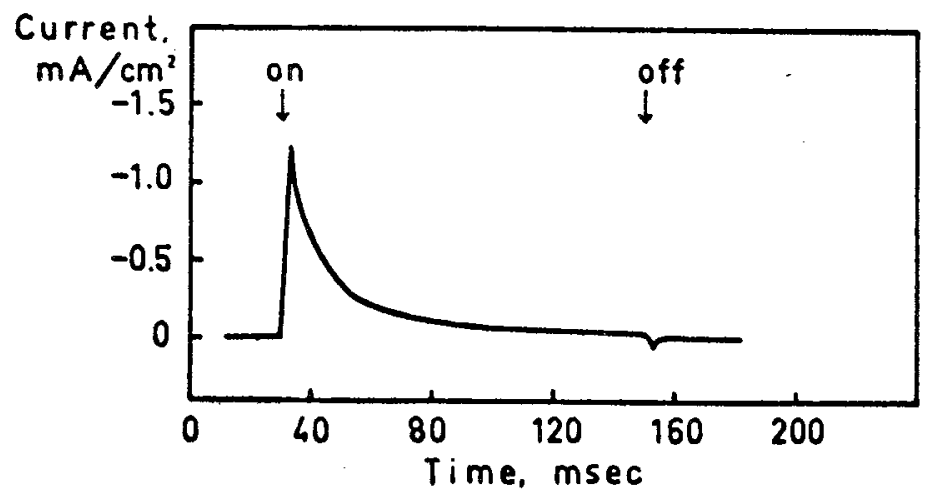

(d) +0.04 V. (NHE)

Fig. 5.37 The transient behaviour of the current of GaAs in IN $\mathrm{H}_{2} \mathrm{SO}_{4}$ after illumination and interruption of light $\left(0.08 \mathrm{~W} / \mathrm{cm}^{2}\right)$ at several electrode potentials. The current before illumination is taken as zero. 
154 .
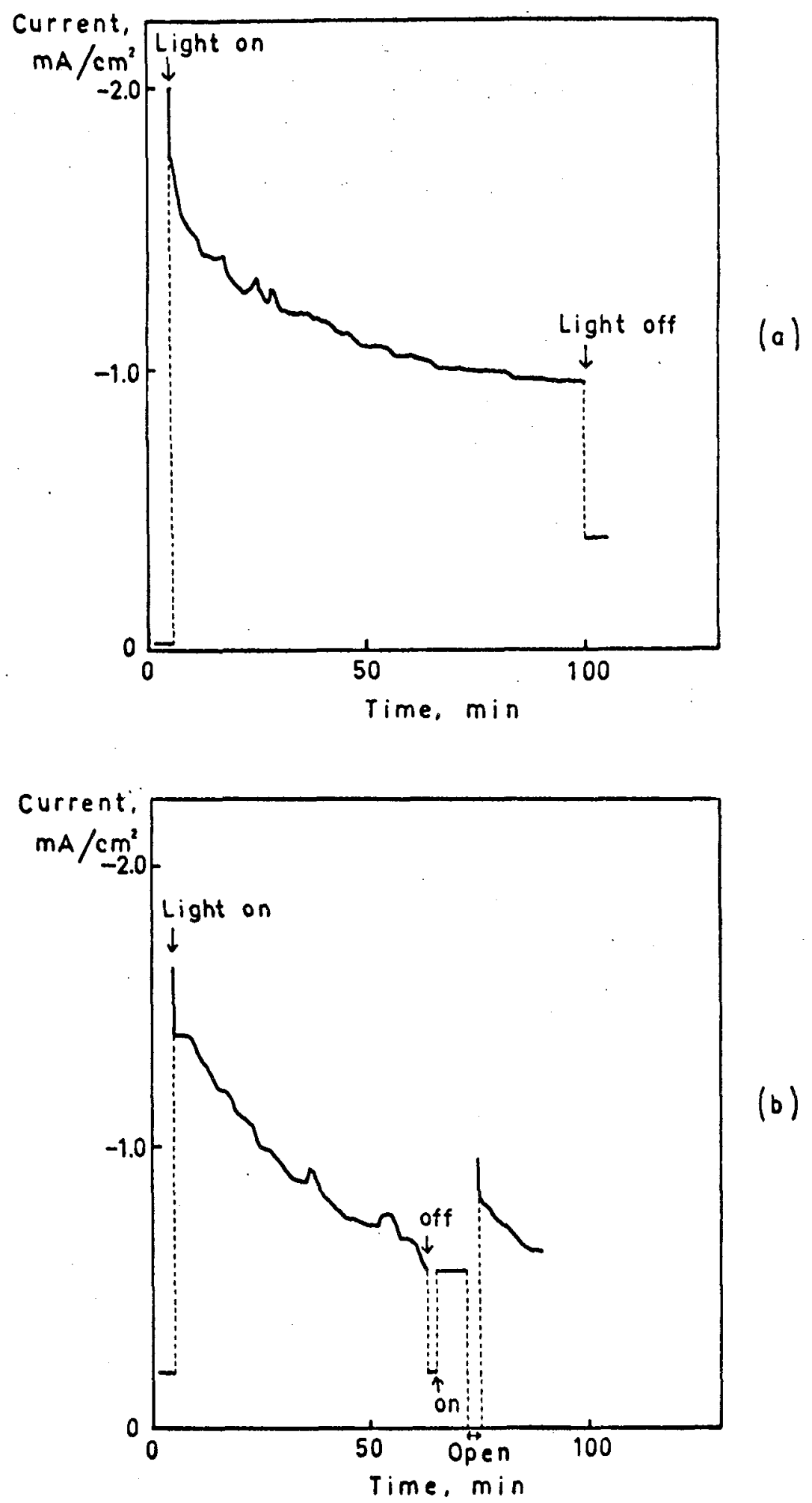

(b)

Fig. 5.38 The current of GaAs as a function of time. Intensity of light: $0.08 \mathrm{~W} / \mathrm{cm}^{2}$.
(a) In $1 \mathrm{~N} \mathrm{NaOH}$ at $-1.36 \mathrm{~V}$ (NHE)
(b) In $1 \mathrm{~N} \mathrm{H}_{2} \mathrm{SO}_{4}$ at $-0.76 \mathrm{~V}$ (NHE) 
155.

\subsubsection{Indium Phosphide (InP)}

\subsubsection{The current-potential relation}

The current-potential relations of InP with and without illumination by a $900 \mathrm{~W}$ Xe 1 amp in $1 \mathrm{~N} \mathrm{NaOH}$ and in $1 \mathrm{~N} \mathrm{H}_{2} \mathrm{SO}_{4}$ are shown in Fig. 5.39 .

In $\mathrm{H}_{2} \mathrm{SO}_{4}$, after a potential sweep under illumination, white film was observed on the electrode surface*.

The relations are similar to those of GaAs with Tafel type dark current.

\subsubsection{Photocurrent (quantum efficiency) - wavelength relation at several potentials}

The photocurrents with and without monochromatic 1ight (3000 $~$ $9000 \AA)$ at several potentials $(-1.06 \sim-1.31 \mathrm{~V}(\mathrm{NHE}))$ were measured only in $1 \mathrm{~N} \mathrm{NaOH}$ solution because in $1 \mathrm{~N} \mathrm{H}_{2} \mathrm{SO}_{4}$ solution, the currents did not show stable values. Typical results are shown in Fig. 5.40. Quantum efficiencies were calculated by using these values and the measured values of number of incident photons and are shown in Fig. 5.41 as a function of wavelength. Since the dark currents were relatively large, the accuracy of the quantum efficiences was low.

5.2.4.3 The flat band potential

The impedance measurements were carried out only in $1 \mathrm{~N} \mathrm{NaOH}$ solution because of instability of $\mathrm{InP}$ in $1 \mathrm{~N}_{2} \mathrm{SO}_{4}$.

The Mott-Schottky plots are shown in Fig. 5.42. The flat band potential obtained from different frequency measurements are different each other and became constant at higher frequencies ( $5 \mathrm{KHz}$ and $10 \mathrm{KHz}$ ). The value from higher frequency measurements is taken as the flat band potential and is $-0.07 \mathrm{~V} \pm 0.02 \mathrm{~V}$ (NHE)

* Recently, Mayumi et al. reported similar results [6] . 


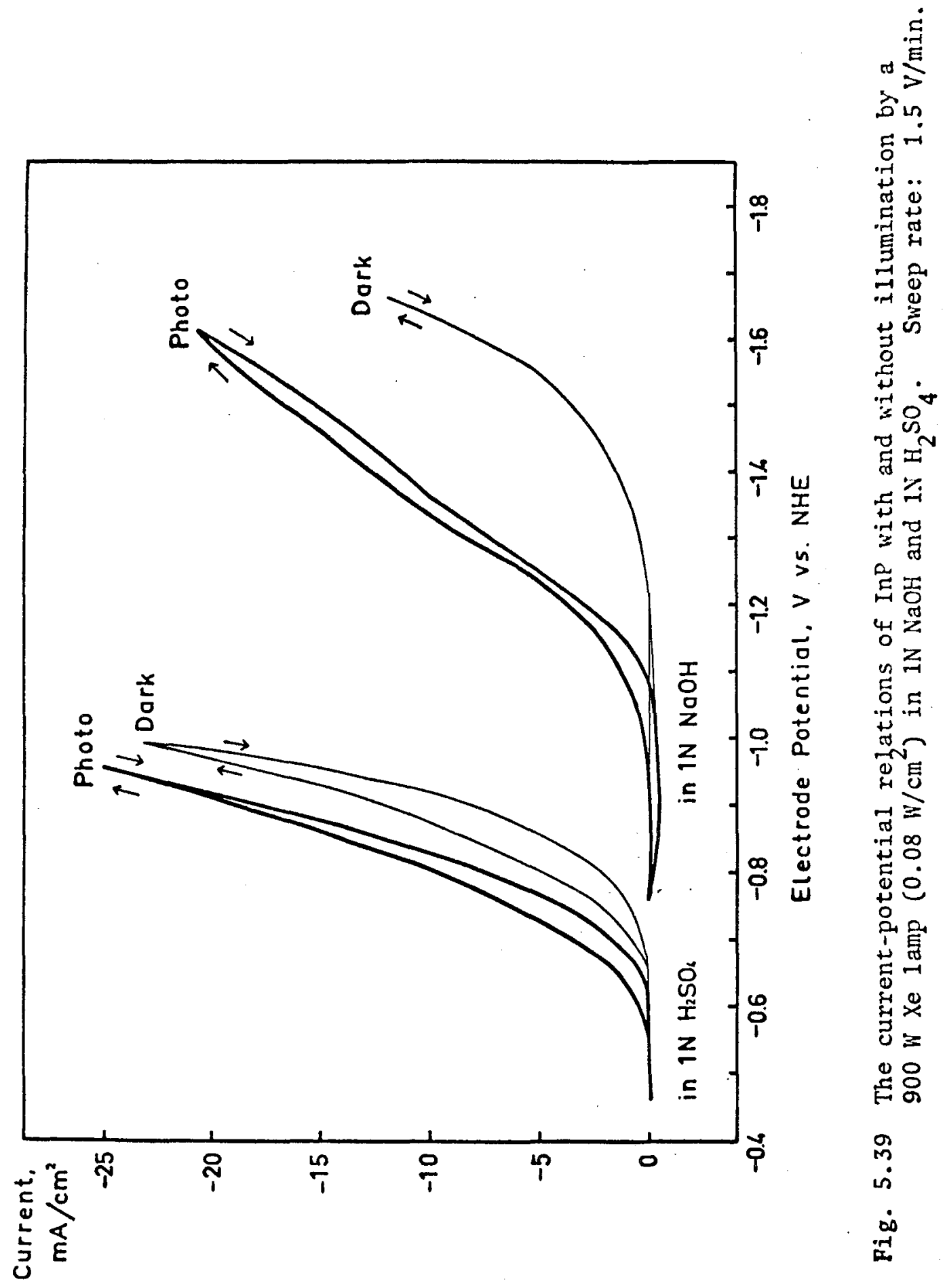




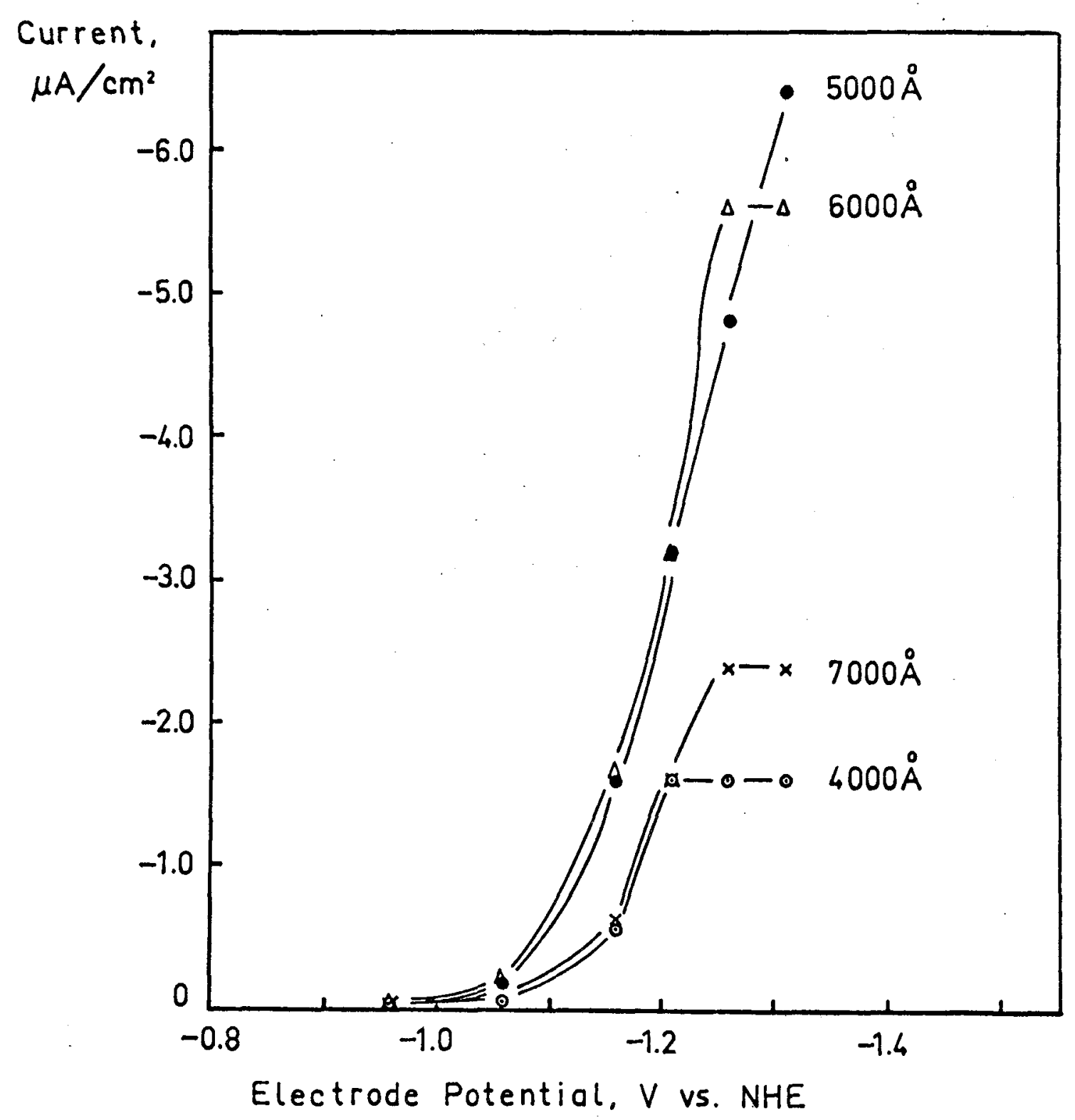

Fig. 5.40 The photocurrent-potential relations of InP in $1 \mathrm{~N} \mathrm{NaOH}$ for the light of several wavelengths. 
158.

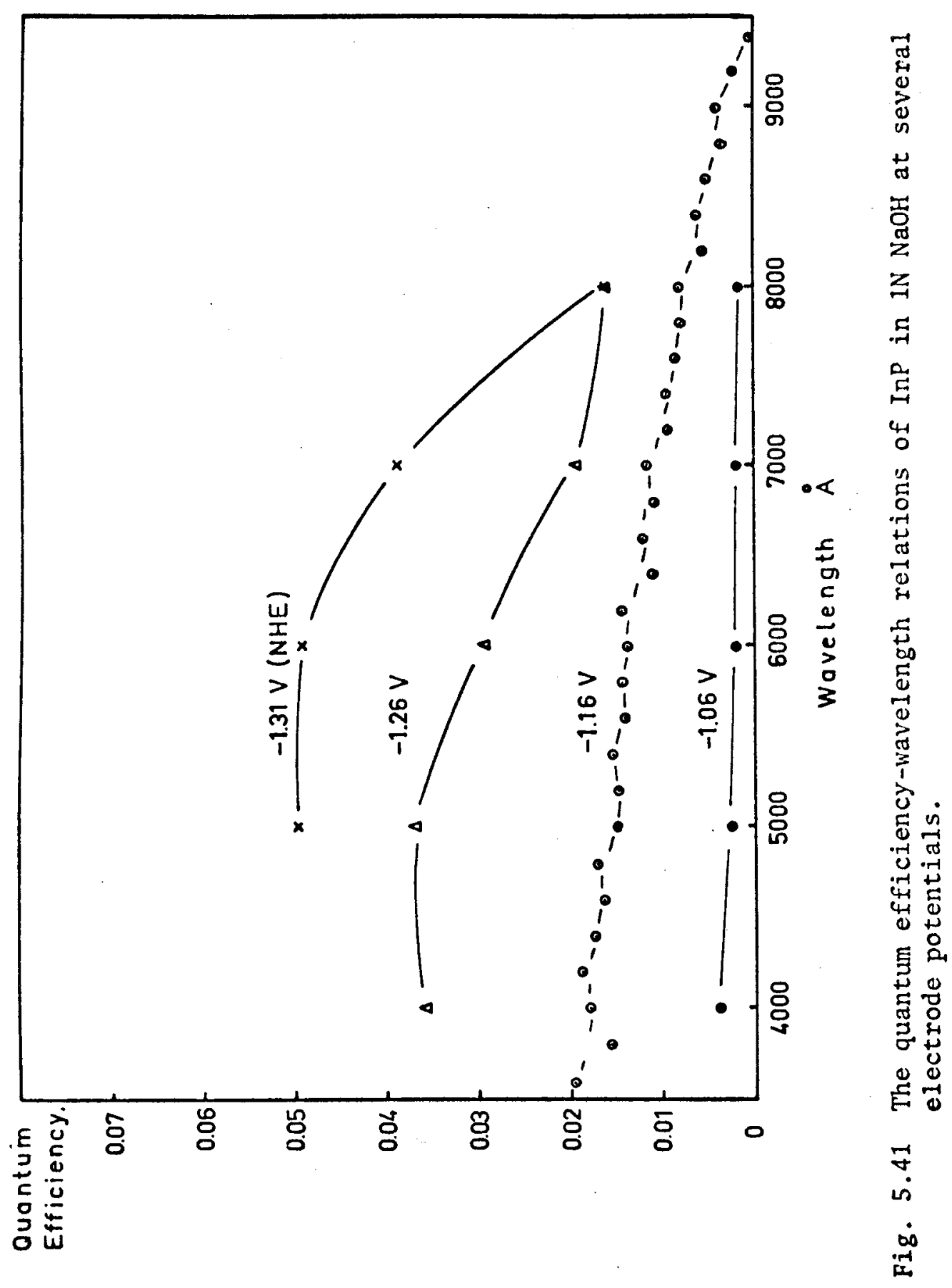


159.

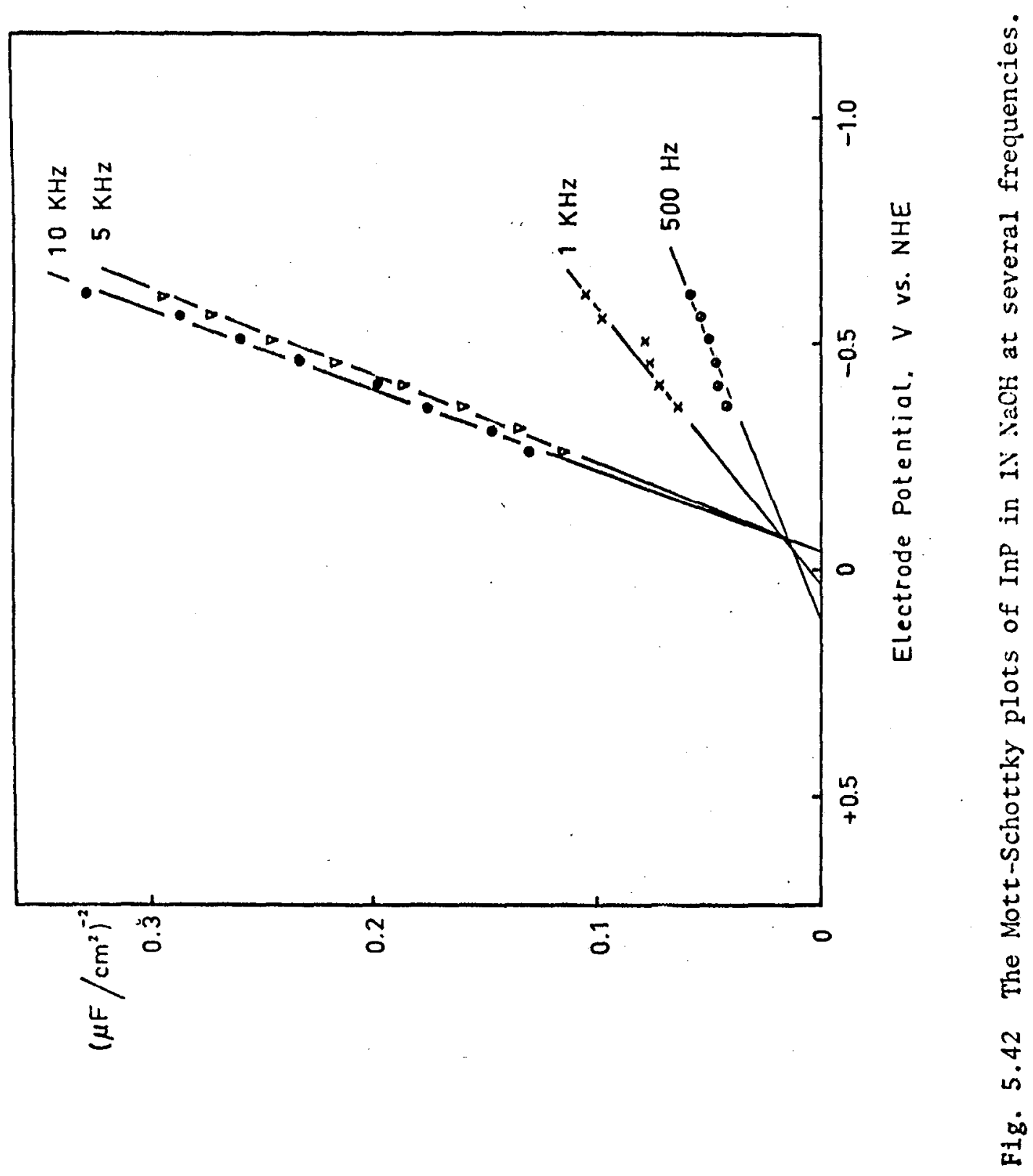




\subsubsection{Transient measurement}

Fig. 5.43 (a e) and Fig. 5.44 (a〜e) show the transient behaviour of InP in $1 \mathrm{~N} \mathrm{NaOH}$ and in $1 \mathrm{~N}_{2} \mathrm{SO}_{4}$, respectively. In $1 \mathrm{~N}_{2} \mathrm{SO}_{4}$, the measurements were carried out from positive to negative potential, because of film formation at relatively negative potential. The behaviour in $1 \mathrm{~N} \mathrm{H}_{2} \mathrm{SO}_{4}$ is different from that in $1 \mathrm{~N} \mathrm{NaOH}$. As seen in Fig. 5.44(e), the photocurrent decreased with a very long time constant in $1 \mathrm{~N} \mathrm{H}_{2} \mathrm{SO}_{4}$ at $-0.56 . \mathrm{V}$ (NHE). After this illumination, a white film was observed on the electrode surface. In $1 \mathrm{~N} \mathrm{NaOH}$ solution, no such film was observed at any potential examined and the more negative the electrode potential was, the more quickly the photocurrent became steady.

\section{2 .4 .5 Stability}

The currents under illumination by a $900 \mathrm{~W}$ Xe lamp at fixed potentials in $1 \mathrm{~N} \mathrm{NaOH}$ and in $1 \mathrm{~N}_{2} \mathrm{SO}_{4}$ are shown in Fig. 5.45(a) and in Fig. 5.45(b), respectively, as a function of time.

In $\mathrm{NaOH}$ solution, the photocurrents were relatively stable for over 2 hours. On the other hand, the photocurrent was constantly decreasing with time in $1 \mathrm{~N} \mathrm{H}_{2} \mathrm{SO}_{4}$ solution for over 2.5 hours.

After the measurements, no significant surface change was observed in $\mathrm{NaOH}$ case but the electrode surface was covered with white film in $\mathrm{H}_{2} \mathrm{SO}_{4}$ solution case.

\subsubsection{Gallium Phosphide (GaP)}

\subsubsection{The current-potential relation}

The current-potential relations with and without illumination by a $900 \mathrm{~W}$ Xe 1 amp in $1 \mathrm{~N} \mathrm{NaOH}$ and in $1 \mathrm{~N} \mathrm{H}_{2} \mathrm{SO}_{4}$ are shown in Fig. 5.46. The dark current was very small in both cases $\left(<10 \mu \mathrm{A} / \mathrm{cm}^{2}\right.$ at $-1.4 \mathrm{~V}$ (NHE)) . 
161.

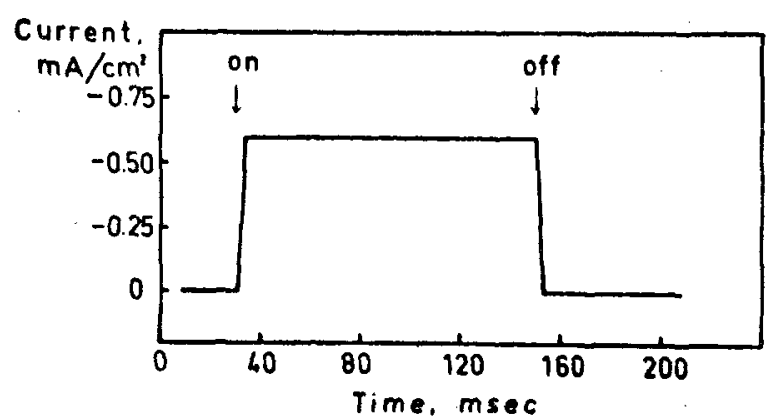

(0) $-1.56 \vee$ (NHE)

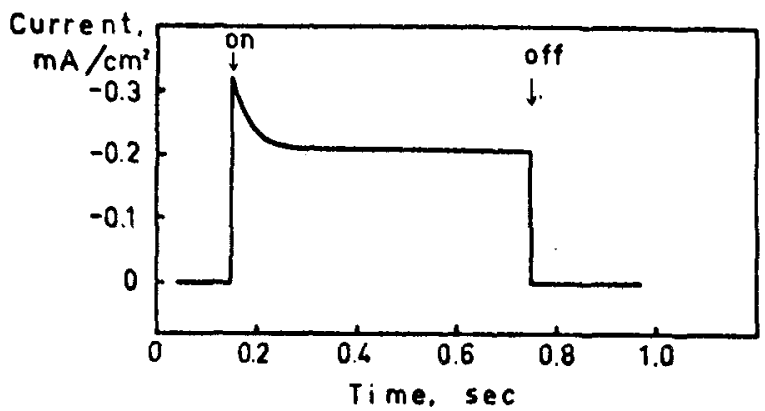

(b) $-1.36 \vee(N H E)$

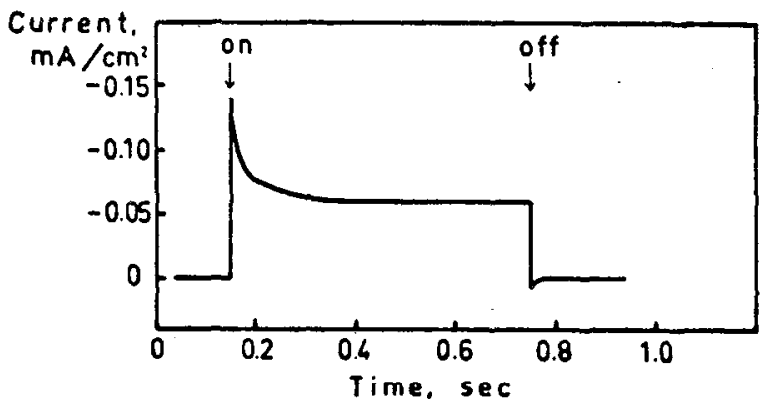

(c) $-1.16 \vee$ (NHE)

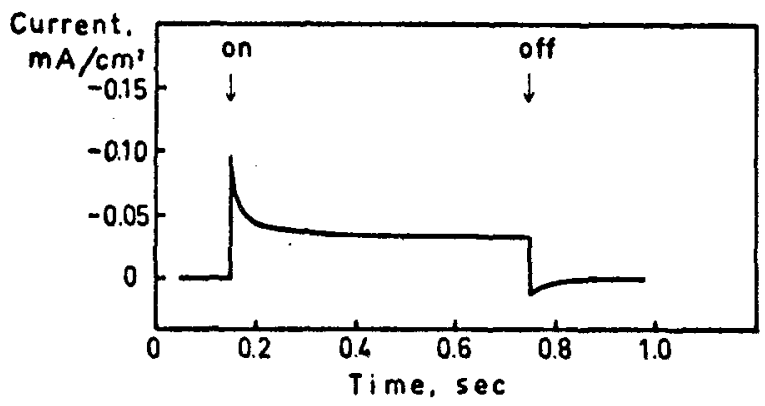

(d) $-0.96 \vee$ (NHE)

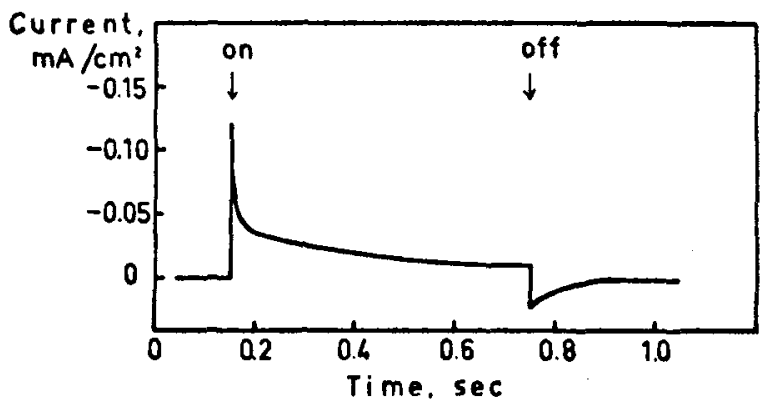

(e) $-0.76 \vee$ (NHE)

Fig. 5.43 The transient behaviour of the current of InP in $1 \mathrm{~N} \mathrm{NaOH}$ after illumination and interruption of light $\left(0.08 \mathrm{~W} / \mathrm{cm}^{2}\right)$ at several electrode potentials. The current before illumination is taken as zero. 
162.

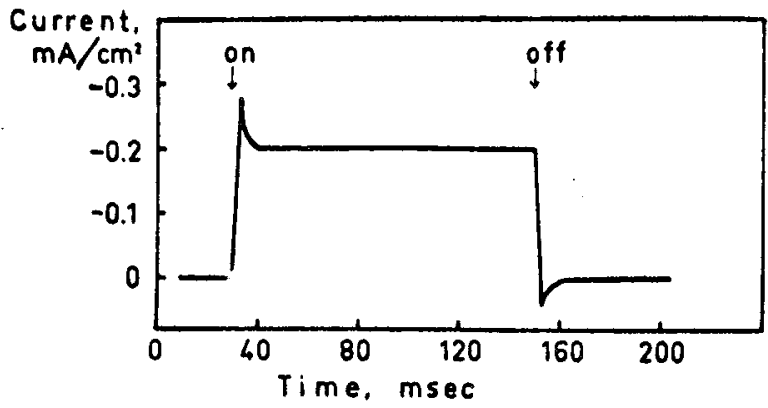

(a) $+0.26 \vee(\mathrm{NHE})$

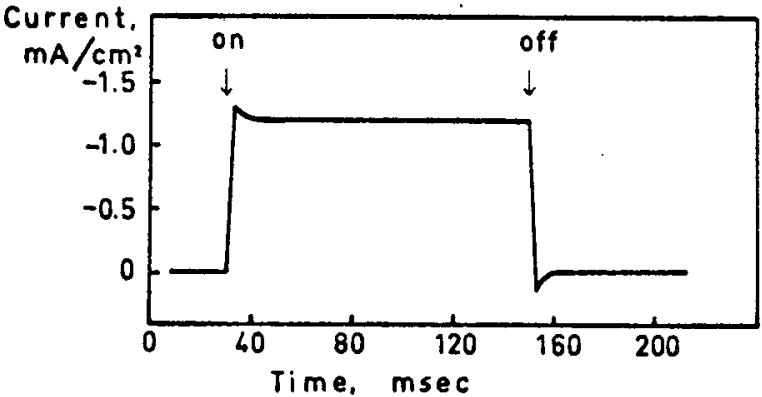

(b) $+0.06 \vee(\mathrm{NHE})$

Current,

$\mathrm{mA} / \mathrm{cm}^{2}$

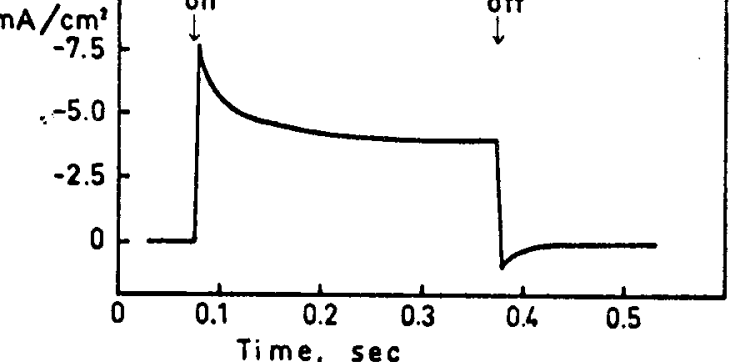

(c) $-0.16 \vee(\mathrm{NHE})$

Current

Time, sec

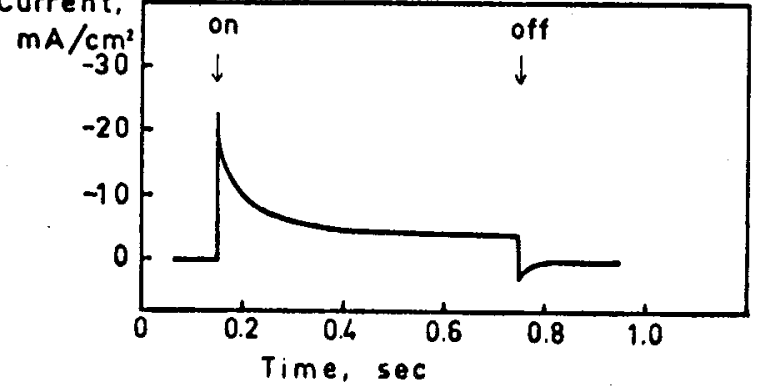

(d) $-0.36 \vee$ (NHE)

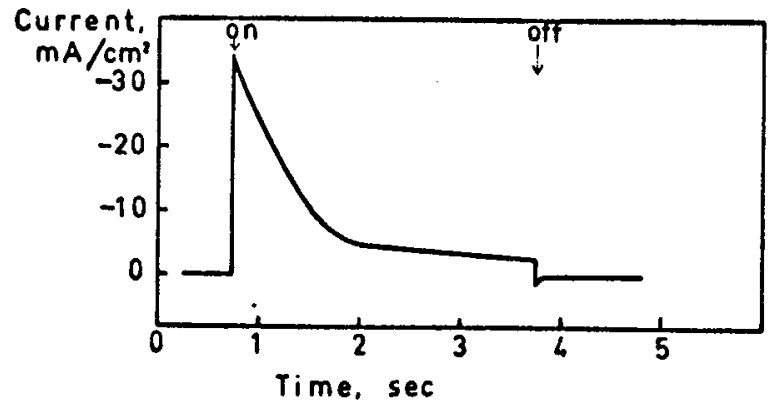

(e) $-0.56 \vee$ (NHE)

Fig. 5.44 The transient behaviour of the current of InP in $1 \mathrm{~N} \mathrm{H}_{2} \mathrm{SO}_{4}$ after illumination and interruption of light $\left(0.08 \mathrm{w} / \mathrm{cm}^{2}\right)$ at several electrode potentials. The current before illumination is taken as zero. 
163.
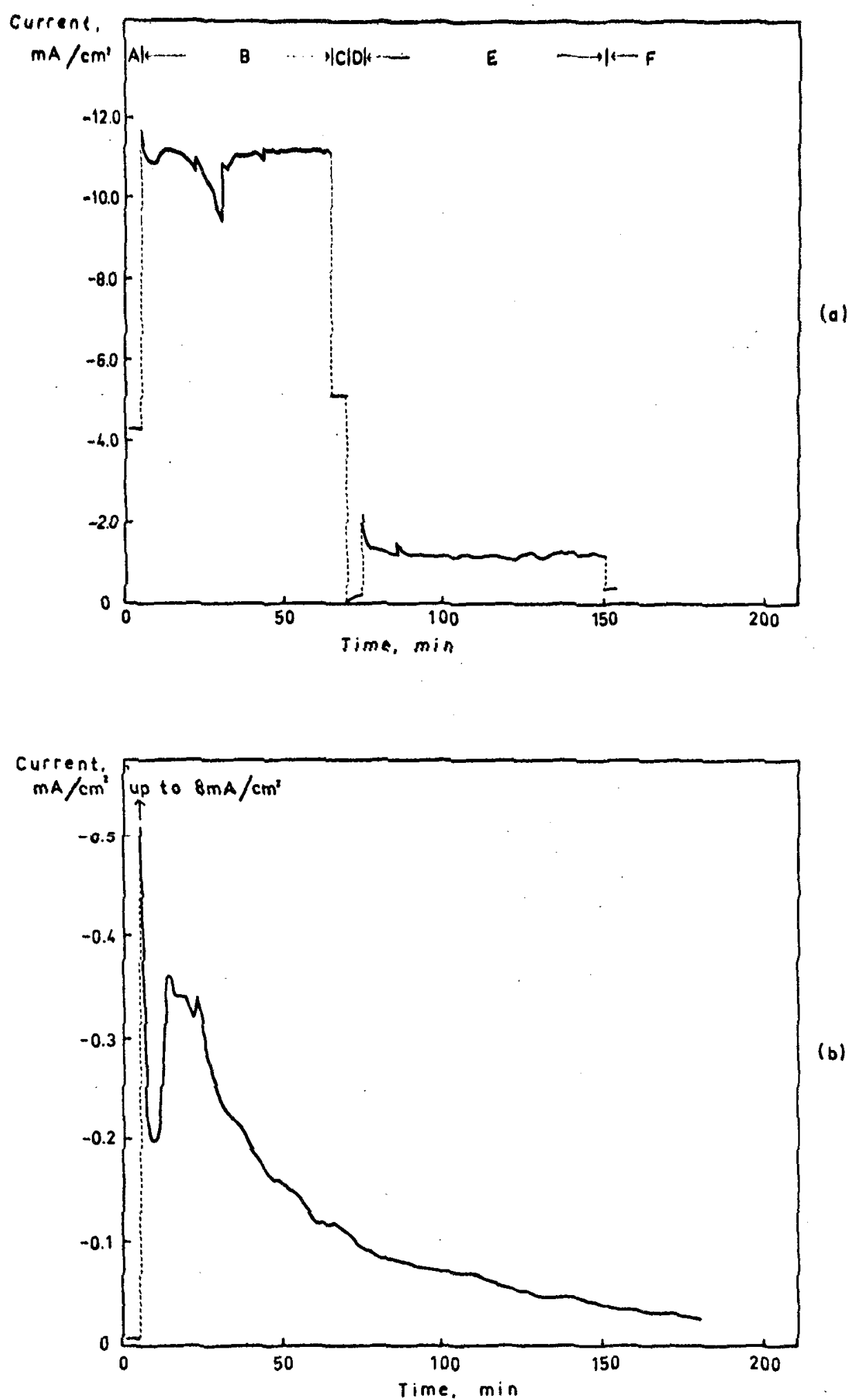

(b)

Fig. 5.45 The current of InP as a function of time. Intensity of light: $0.08 \mathrm{~W} / \mathrm{cm}^{2}$.

(a) In $1 \mathrm{~N} \mathrm{NaOH}$. A. $-1.36 \mathrm{~V}$ (NHE) (Dark). B. $-1.36 \mathrm{~V}$ (Light). C. $-1.36 \vee$ (Dark). D. $-1.16 \vee$ (Dark). E. $-1.16 \mathrm{~V}$ (Light). F. - $1.16 \mathrm{~V}$ (Dark). (b) In $1 \mathrm{~N} \mathrm{H}_{2} \mathrm{SO}_{4}$ at $-0.46 \mathrm{~V}(\mathrm{NHE})$. 


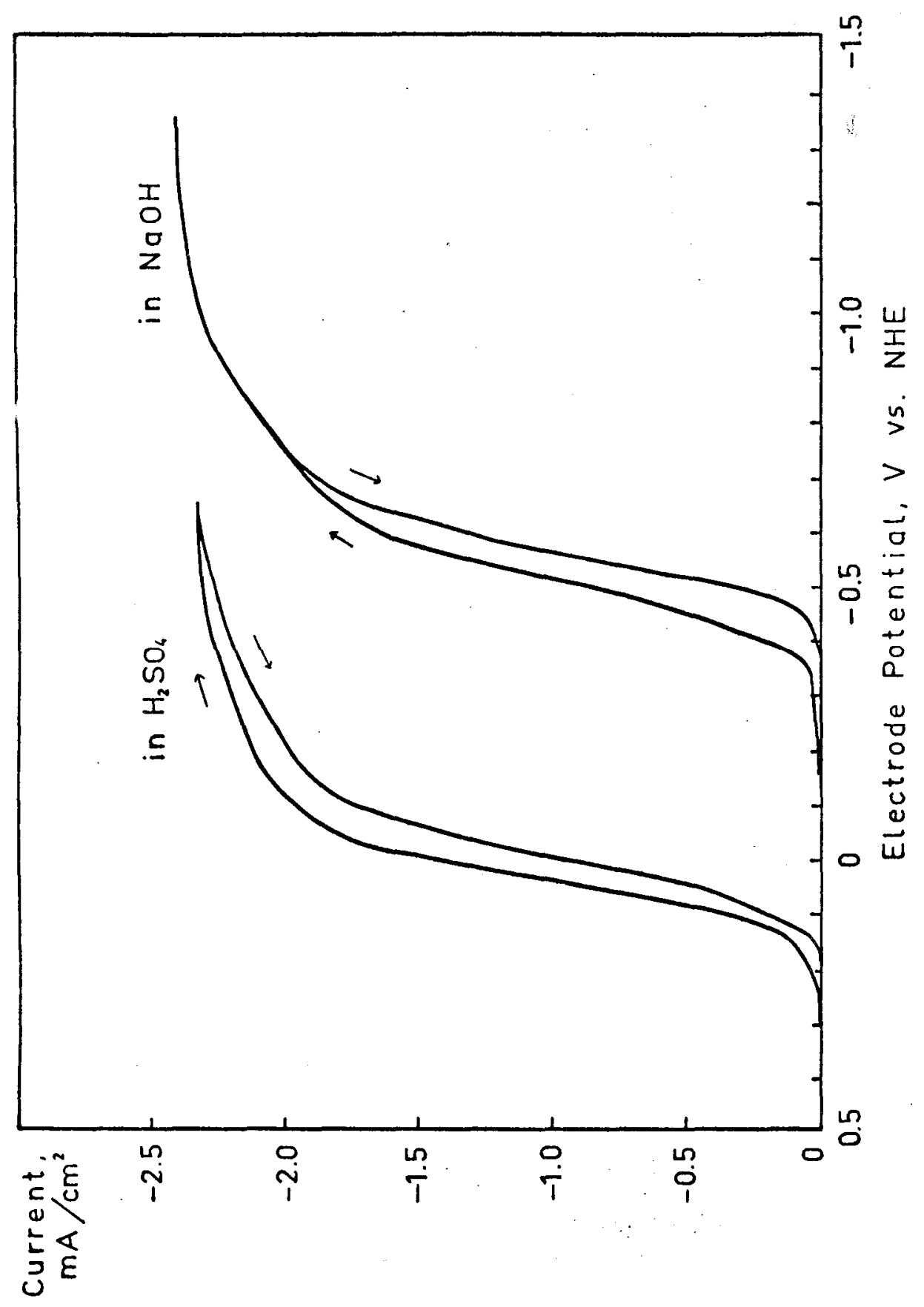

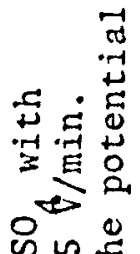

N.

Z... .

$\because 0$

.

导怘

两

焉 $v$

$z$

$z \dot{0}$

ธอี อ

편

تึㅇㅇㅇ

4

结会式

.

o

$\stackrel{\pi}{\infty} \geq$

당

땡용

它

苟完完

品

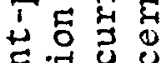

要出

进苦

ठ

总焉总总

is

$\underset{1}{\infty 1}$ 
165.

\subsubsection{Photocurrent (quantum efficiency) - wavelength relations at several potentials}

Photocurrents under illumination by several wavelengths of monochromatic light $(3000 \AA \sim 6000 \AA)$ were measured at several potentials and typical results are shown in Fig. 5.47.

Quantum efficiencies were calculated and shown in Fig. 5.48(a) and Fig. $5.48(\mathrm{~b})$ as a function of wavelength for $\mathrm{NaOH}$ solution and for $\mathrm{H}_{2} \mathrm{SO}_{4}$ solution, respectively.

\subsubsection{The flat band potential}

Mott-Schottky plots for $1 \mathrm{~N} \mathrm{NaOH}$ solution and $1 \mathrm{~N}_{2} \mathrm{SO}_{4}$ solution are given in Fig. 5.49. From these plots, the flat band potentials in $1 \mathrm{~N} \mathrm{NaOH}$ and in $1 \mathrm{~N} \mathrm{H}_{2} \mathrm{SO}_{4}$ are calculated as $0.18 \pm 0.02 \mathrm{~V}$ (NHE) and $1.13 \pm 0.02 \mathrm{~V}$ (NHE), respectively.

\subsubsection{Transient measurement}

Fig. $5.50(\mathrm{a} \sim \mathrm{d})$ and Fig. $5.51(\mathrm{a} \sim \mathrm{f})$ show the transient behaviours of photocurrent in $1 \mathrm{~N} \mathrm{NaOH}$ and in $1 \mathrm{~N}_{2} \mathrm{SO}_{4}$, respectively.

\subsubsection{Stabi1ity}

Photocurrents at several fixed potentials in $1 \mathrm{~N} \mathrm{NaOH}$ and in $1 \mathrm{~N}$ $\mathrm{H}_{2} \mathrm{SO}_{4}$ are shown in Fig. $5.52(\mathrm{a})$ and in Fig. $5.52(\mathrm{~b})$, respectively, as a function of time.

In bath cases, the more negative a potential was, the more stable a photocurrent was.

\subsubsection{Silicon Carbide (SiC)}

\subsubsection{The current-potential relation}

The current-potential relations of SiC with and without illumination by a $900 \mathrm{~W}$ Xe lamp in $1 \mathrm{~N} \mathrm{NaOH}$ and in $1 \mathrm{~N}_{2} \mathrm{SO}_{4}$ are shown in Fig. 5.53(a) and in Fig. 5.53(b), respective1y. (Potential sweep rate: $1.5 \mathrm{~V} / \min$ ). 


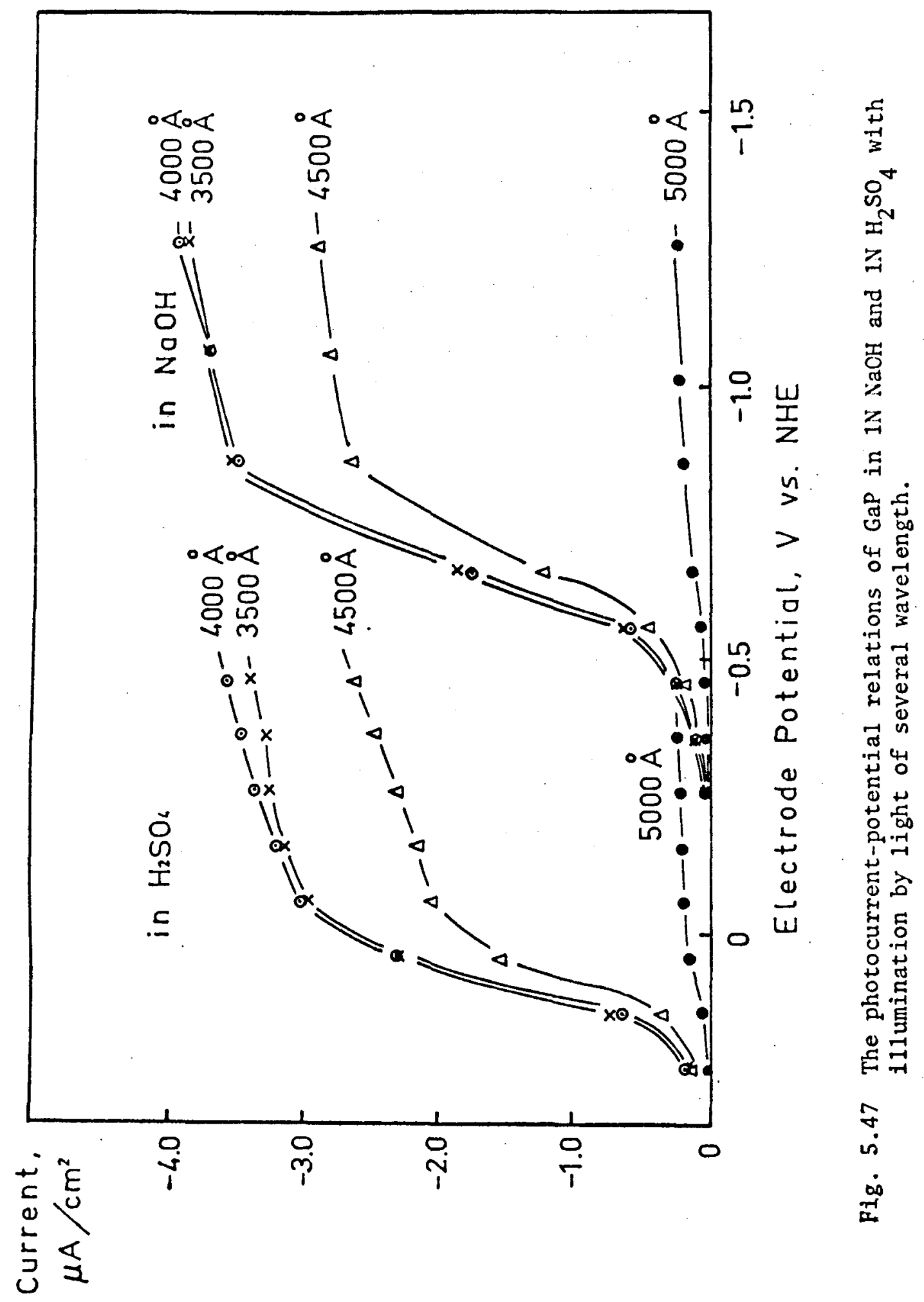



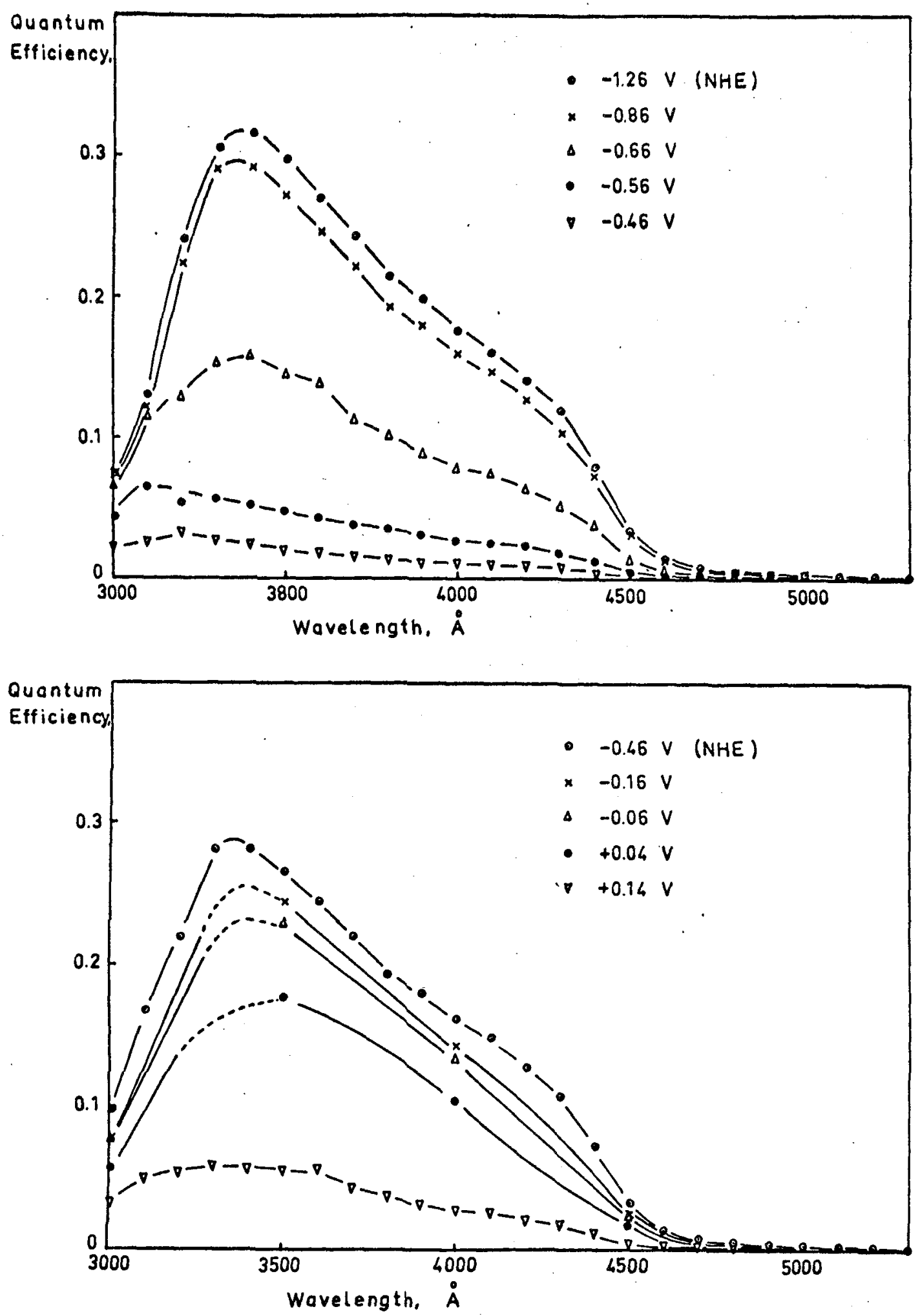

(b)

Fig. 5.48 The quantum efficiency-wavelength relations of GaP in $1 \mathrm{~N} \mathrm{NaOH}$ (a) and $1 \mathrm{~N} \mathrm{H}_{2} \mathrm{SO}_{4}$ (b) at several electrode potentials. 
168.

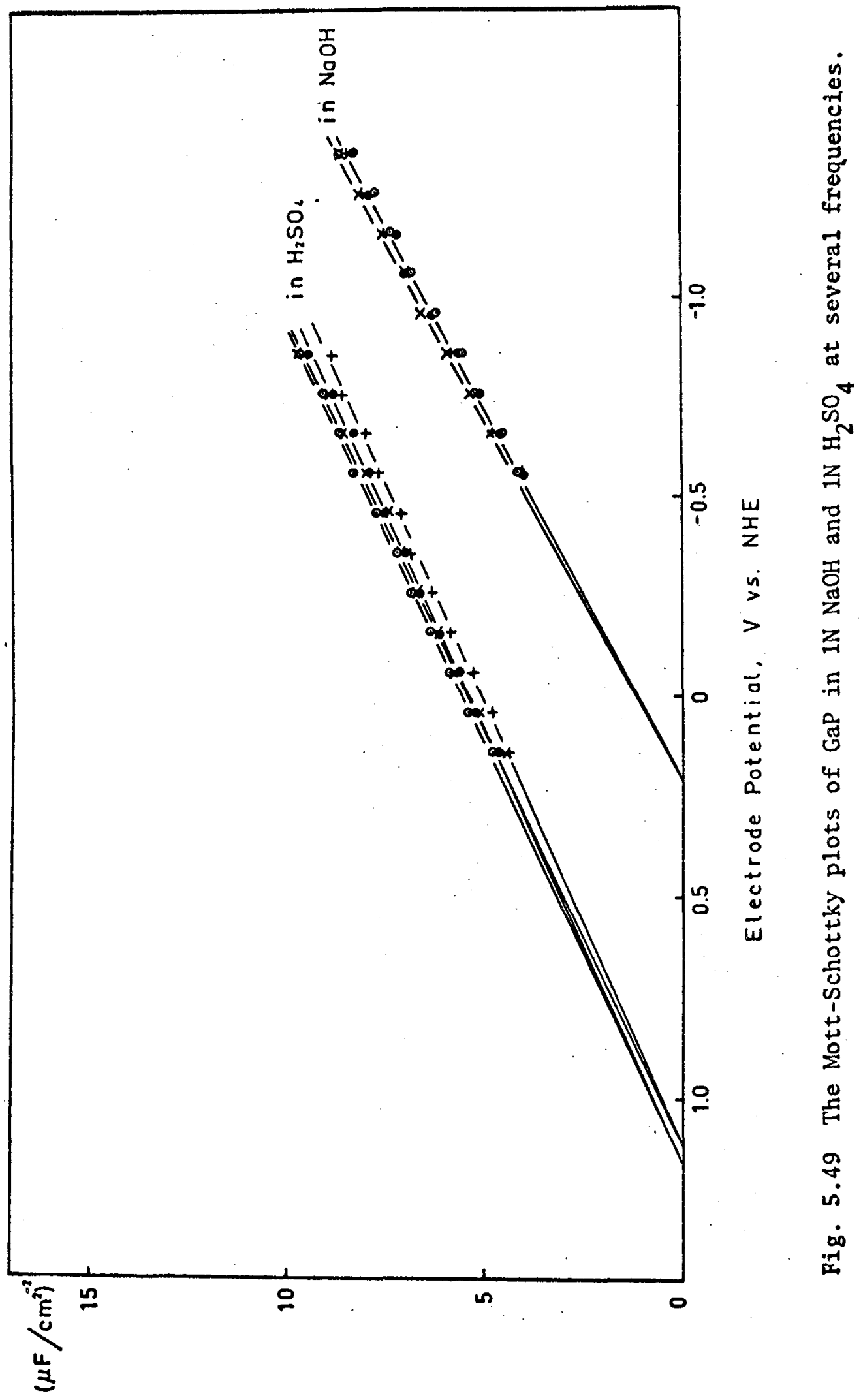


169.

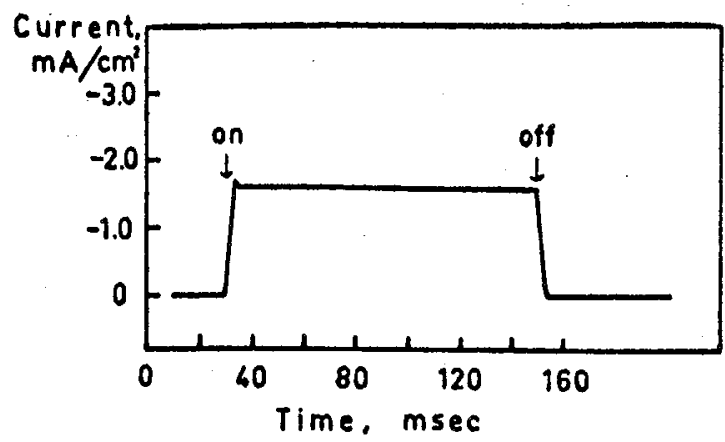

(0) -0.56 V v5. NHE

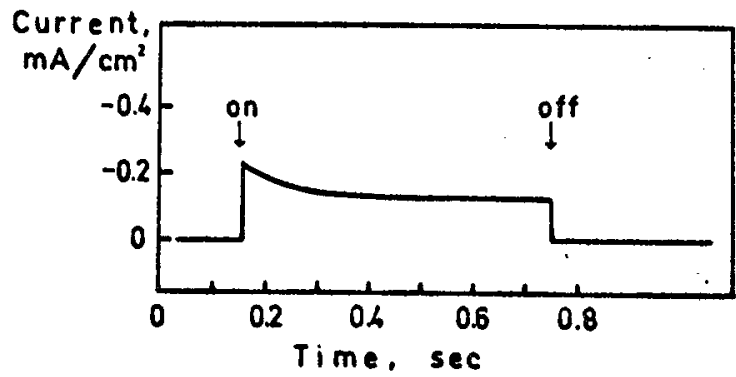

(b) $-0.36 \mathrm{~V}$ vs. NHE

$\therefore$

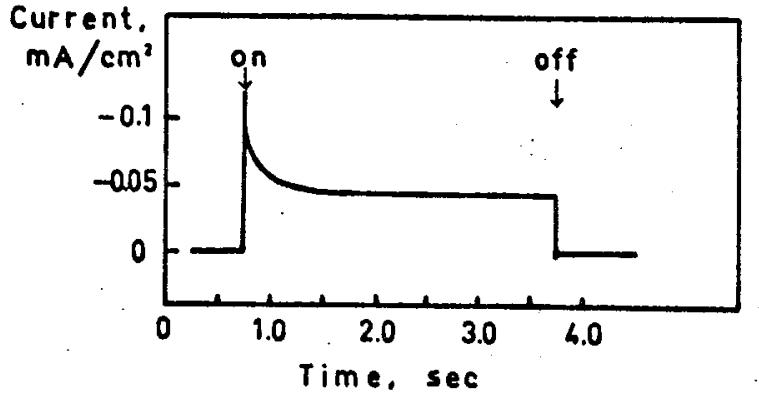

(c) $-0.16 \mathrm{~V}$ vs. NHE

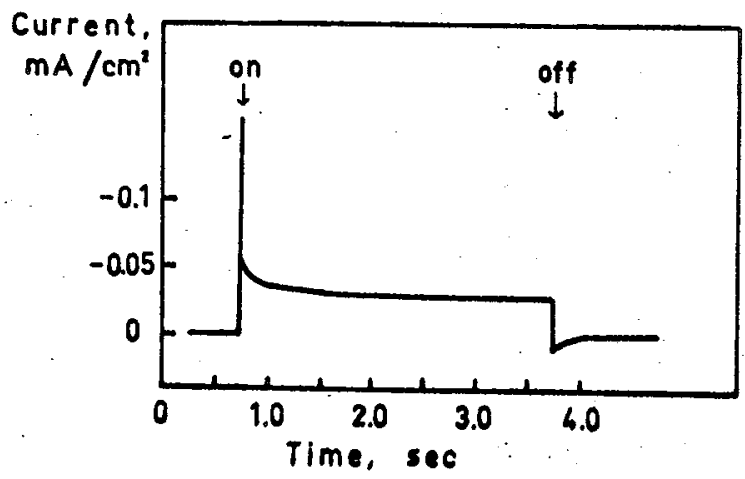

(d) $-0.06 \mathrm{~V}$ vs. NHE

Pig. 5.50 Tho transiont bohaviour of the curront of Gap in IN NaOH after illumination and interruption of light $\left(0.08 \mathrm{~W} / \mathrm{cm}^{2}\right)$ at several electrode potentials. The current before illumination is taken as zero. 

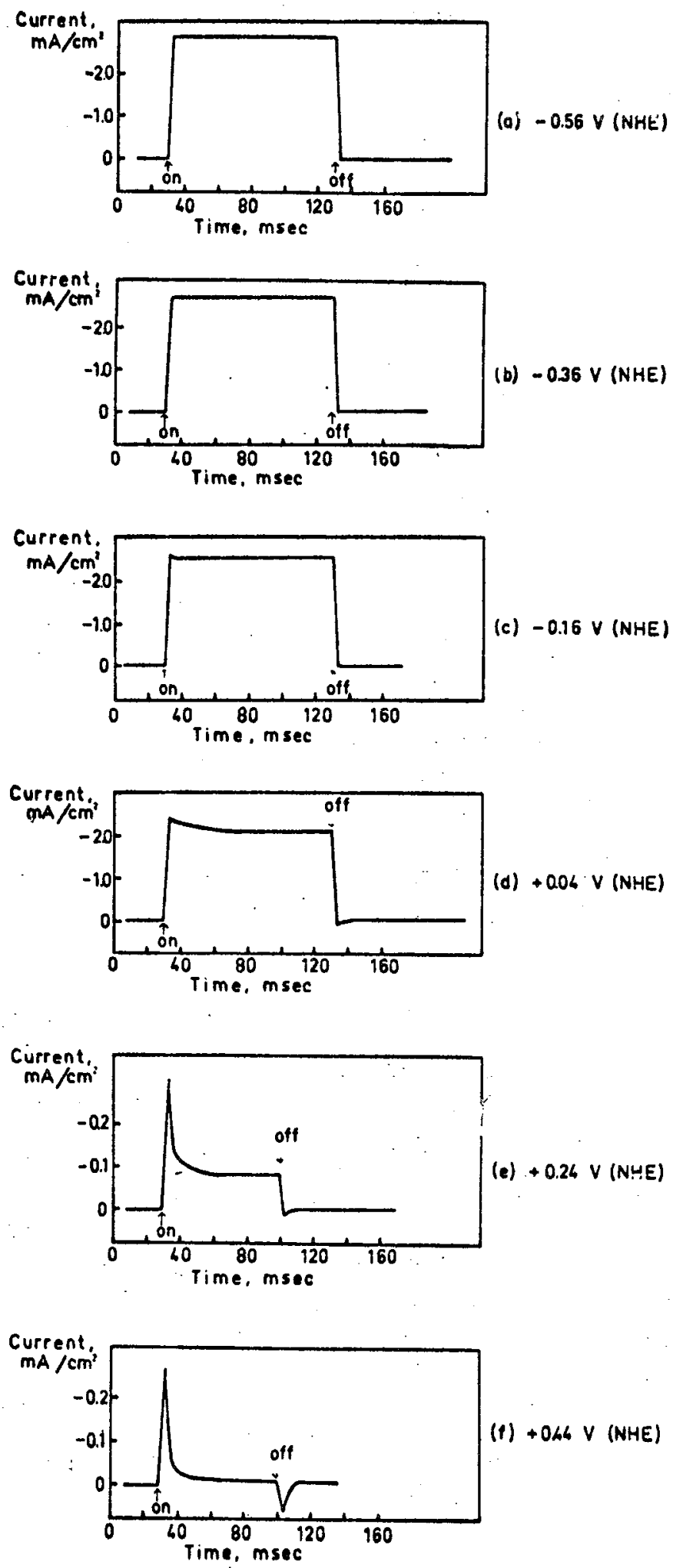

Fig. 5.51 The transient behaviour of the current of GaP in IN $\mathrm{H}_{2} \mathrm{SO}_{4}$ after illumination and interruption of light $\left(0.08 \mathrm{w} / \mathrm{cm}^{2}\right)$ at several electrode potentials. The current before illumination is taken as zero. 
171.

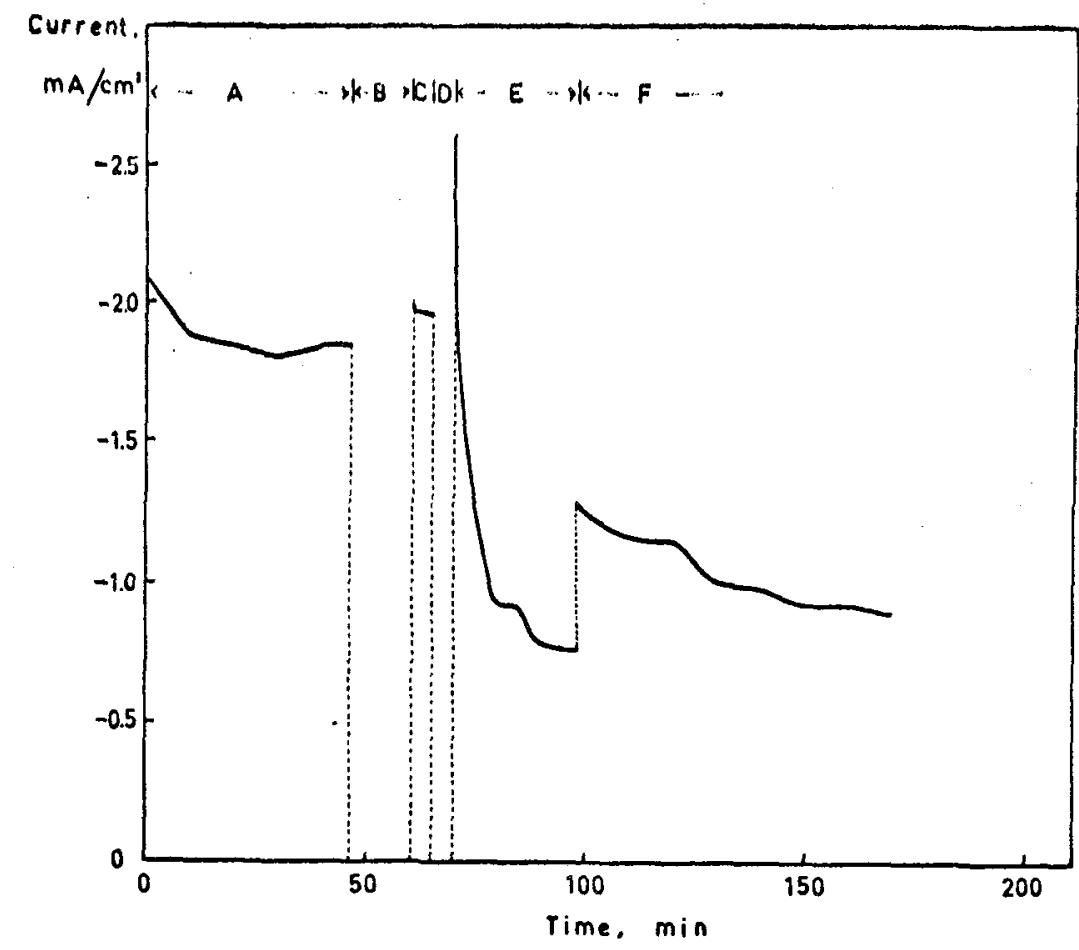

(a)

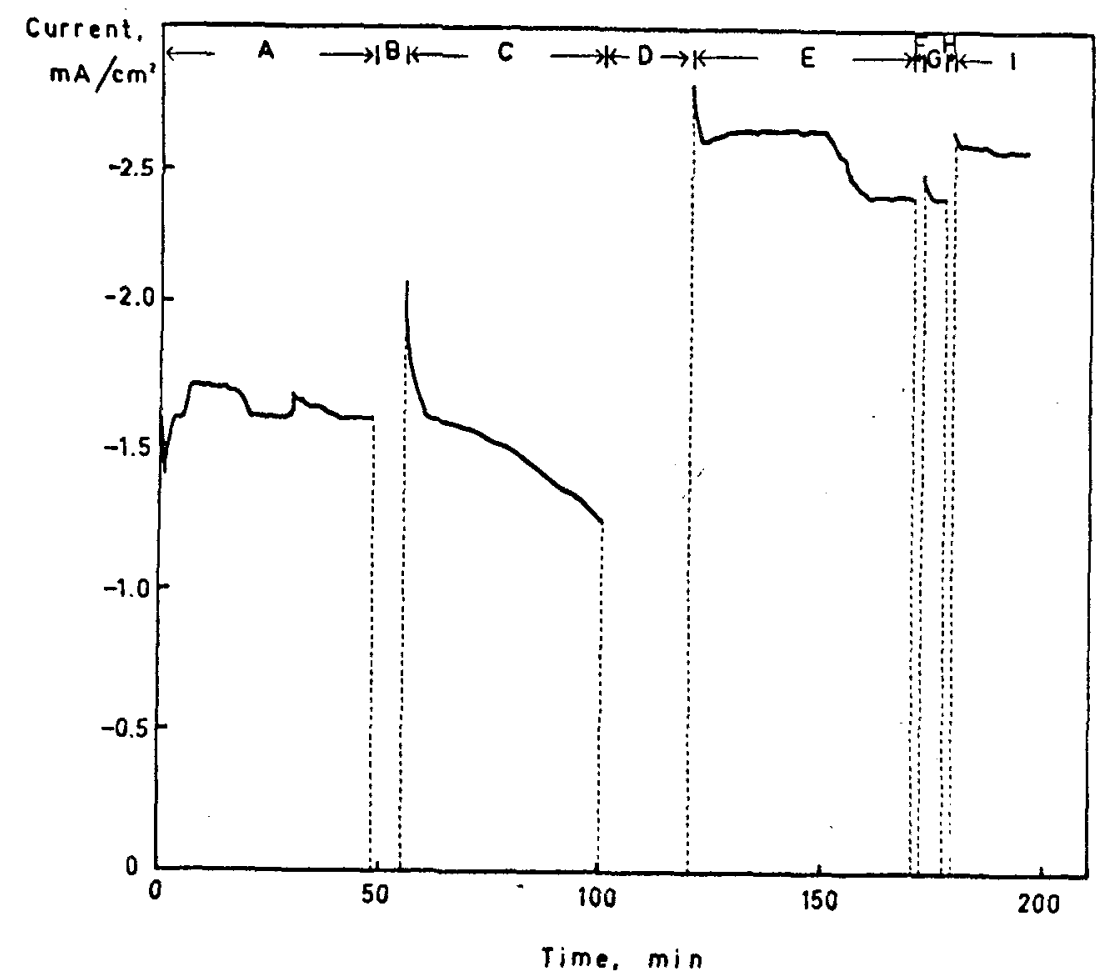

(b)

Fig. 5.52 The current of $\mathrm{GaP}$ as a function of time. Intensity of light: $0.08 \mathrm{~W} / \mathrm{cm}^{2}$.

(a) In $1 \mathrm{~N} \mathrm{NaOH}$. A. $-0.76 \mathrm{~V}$ (NHE) (Light). B. $-0.76 \mathrm{~V}$ (Dark). C. $-0.76 \mathrm{~V}$ (Light). $\quad$ D. $-0.76 \mathrm{~V} \rightarrow-0.26 \mathrm{~V}$ (Dark). E. $-0.26 \mathrm{~V}$ (Light). Light was concentrated on the electrode surface by means of lens, otherwise the photocurrent was $8 \mathrm{\mu A} / \mathrm{cm}^{2}$. F. $-0.56 \mathrm{~V}$ (Light).

(b) In $1 \mathrm{~N} \mathrm{H}_{2} \mathrm{SO}_{4}$. A. $0.04 \mathrm{~V}$ (NHE) (Light). B. $0.04 \mathrm{~V}$ (Dark). ${ }^{4}$ C. $0.04 \mathrm{~V}$ (Light). $\quad$ D. $0.04 \mathrm{~V} \rightarrow-0.26 \mathrm{~V}$ (Dark). E. $-0.26 \mathrm{~V}$ (Light). F. $-0.26 \mathrm{~V}$ (Dark). G. $-0.26 \mathrm{~V}$ (Light). H. Open (Dark). I. $-0.26 \mathrm{~V}$ 


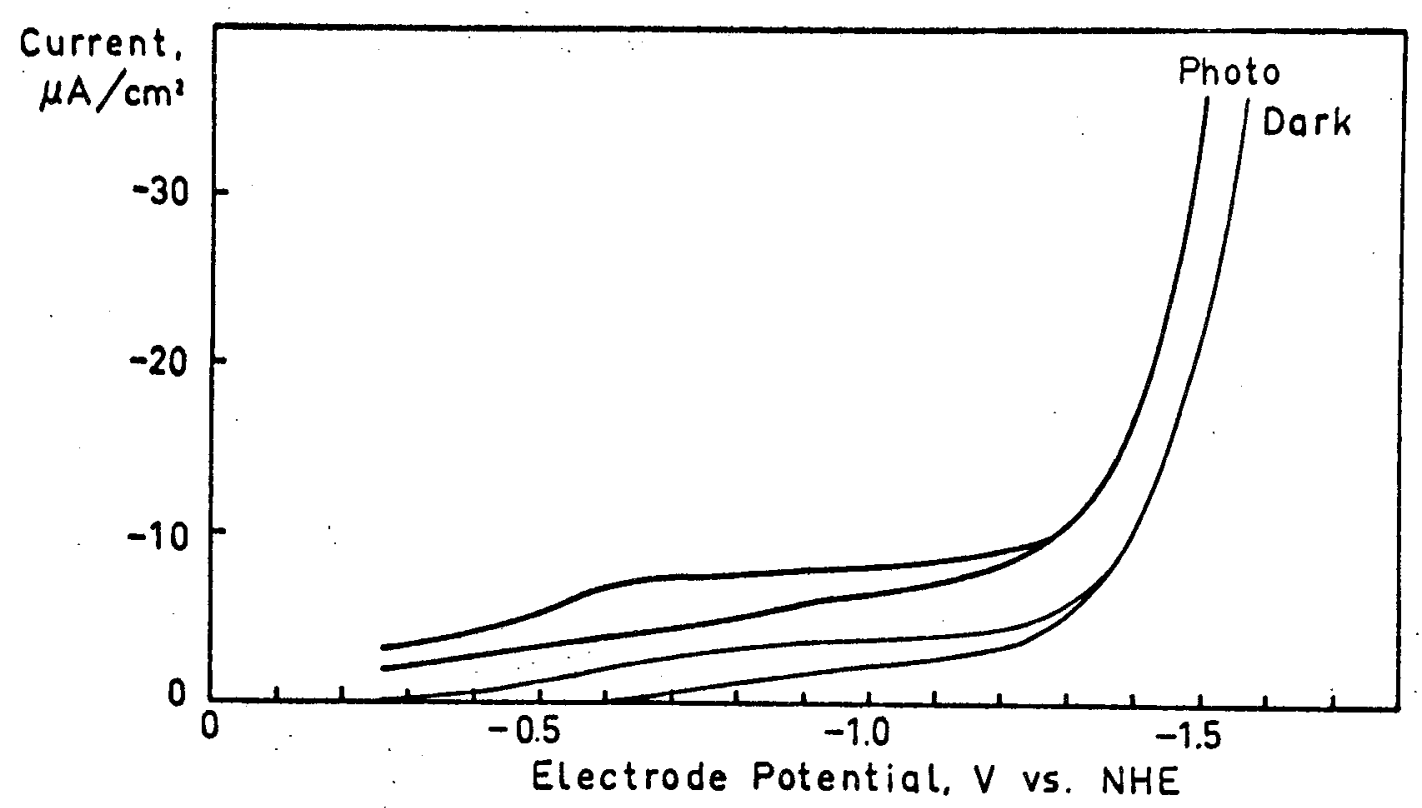

(a)

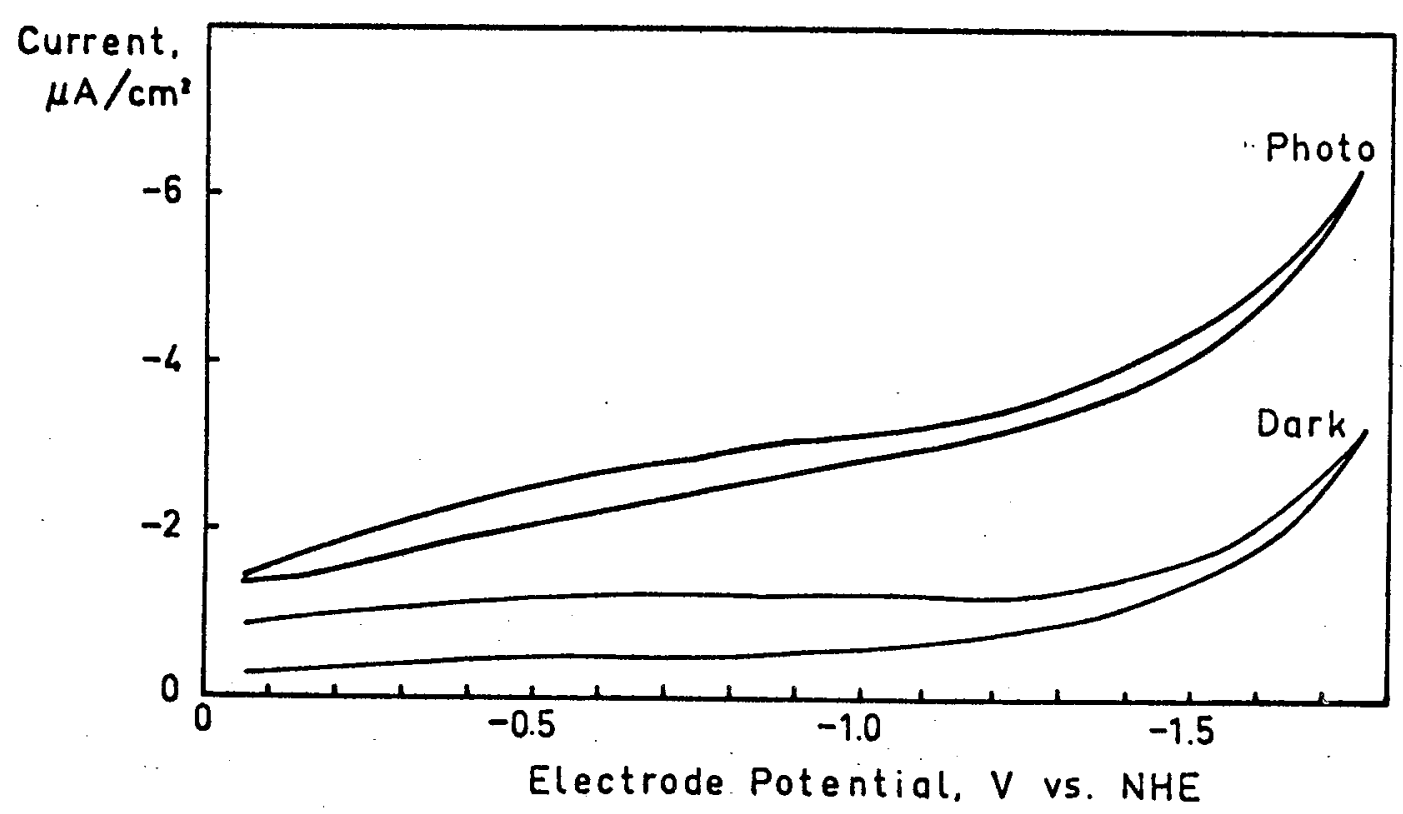

(b)

Pig. 5,53 The current-potential relations of SiC in $1 \mathrm{~N} \mathrm{NaOH} \mathrm{(a)}$ and $1 \mathrm{~N} \mathrm{H}_{2} \mathrm{SO}_{4}$ (b) with and without illumination by a $900 \mathrm{~W} \mathrm{Xe}$ lamp $\left(0.08 \mathrm{~W} / \mathrm{cm}^{2}\right)$, Sweep rate: $1.5 \mathrm{~V} / \mathrm{min}$. 
173.

The current difference between with and without illumination, i.e., photocurrent, was very small compared with the results of other semiconductors mentioned before in this chapter. Also the relations in $1 \mathrm{~N} \mathrm{NaOH}$ were different from those in $1 \mathrm{~N} \mathrm{H}_{2} \mathrm{SO}_{4}$. In $1 \mathrm{~N} \mathrm{NaOH}$, current increased quickly when the potential became more negative than - $1.16 \mathrm{~V}(\mathrm{NHE})$. On the other hand, in $1 \mathrm{~N} \mathrm{H}_{2} \mathrm{SO}_{4}$, the currents were very small even at very negative potential $\left(1.6 \mu \mathrm{A} / \mathrm{cm}^{2}\right.$ (dark), $4.8 \mu \mathrm{A} / \mathrm{cm}^{2}$ (with light) at - $1.16 \mathrm{~V}(\mathrm{NHE})$ ).

\subsubsection{Photocurrent (quantum efficiency) - wavelength relations at several potentials}

Because the differences between the current with 1 ight and without 1 ight were very small $(0.009 \sim 0.003 \mu \mathrm{A})$, the accuracy of the photocurrent, i.e., quantum efficiency, was relatively low.

Typical results of photocurrents are shown in Fig. 5.54(a) and in Fig. 5.54(b) for $\mathrm{NaOH}$ solution and for $\mathrm{H}_{2} \mathrm{SO}_{4}$ solution, respectively, as a function of potential.

Quantum efficiencies in $1 \mathrm{~N} \mathrm{NaOH}$ and in $1 \mathrm{~N} \mathrm{H}_{2} \mathrm{SO}_{4}$ were calculated by using the values of photocurrents and the values of number of incident photons and are shown in Fig. 5.55(a) and in Fig. 5.55(b), respectively.

\subsubsection{The flat band potential*}

The Mott-Schottky plots in $1 \mathrm{~N} \mathrm{NaOH}$ and in $1 \mathrm{~N} \mathrm{H}_{2} \mathrm{SO}_{4}$ are shown in Fig. 5.56(a) and in Fig. 5.56(b), respectively.

The flat band potentials obtained from these plots are $1.38 \pm$ $0.12 \mathrm{~V}(\mathrm{NHE})$ in $\mathrm{NaOH}$ and $1.68 \pm 0.02 \mathrm{~V}(\mathrm{NHE})$ in $\mathrm{H}_{2} \mathrm{SO}_{4}$, respectively.

* M. Gleria et al. reported that they could not obtain the flat band potential of p-type SiC [6]. 

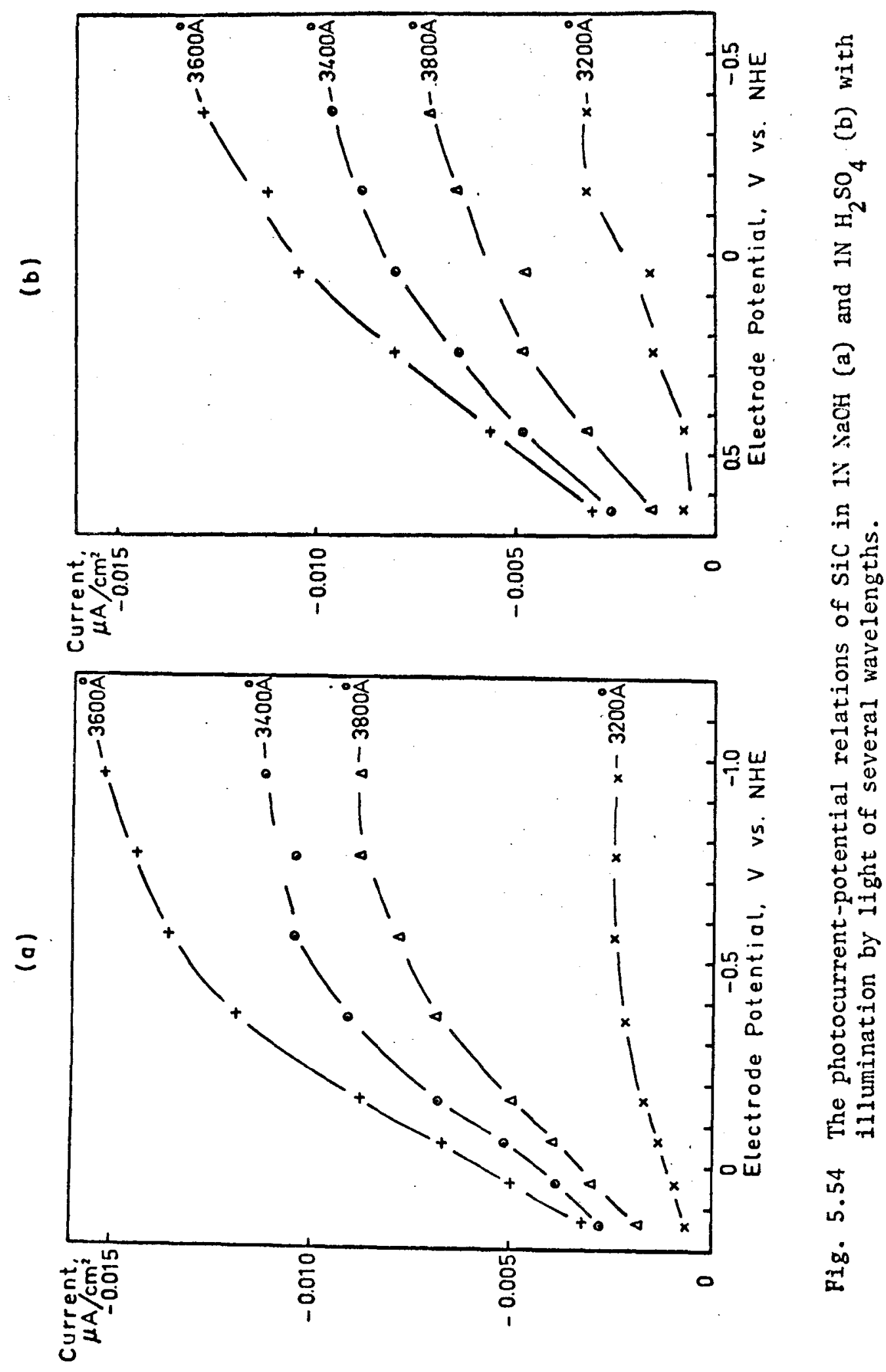


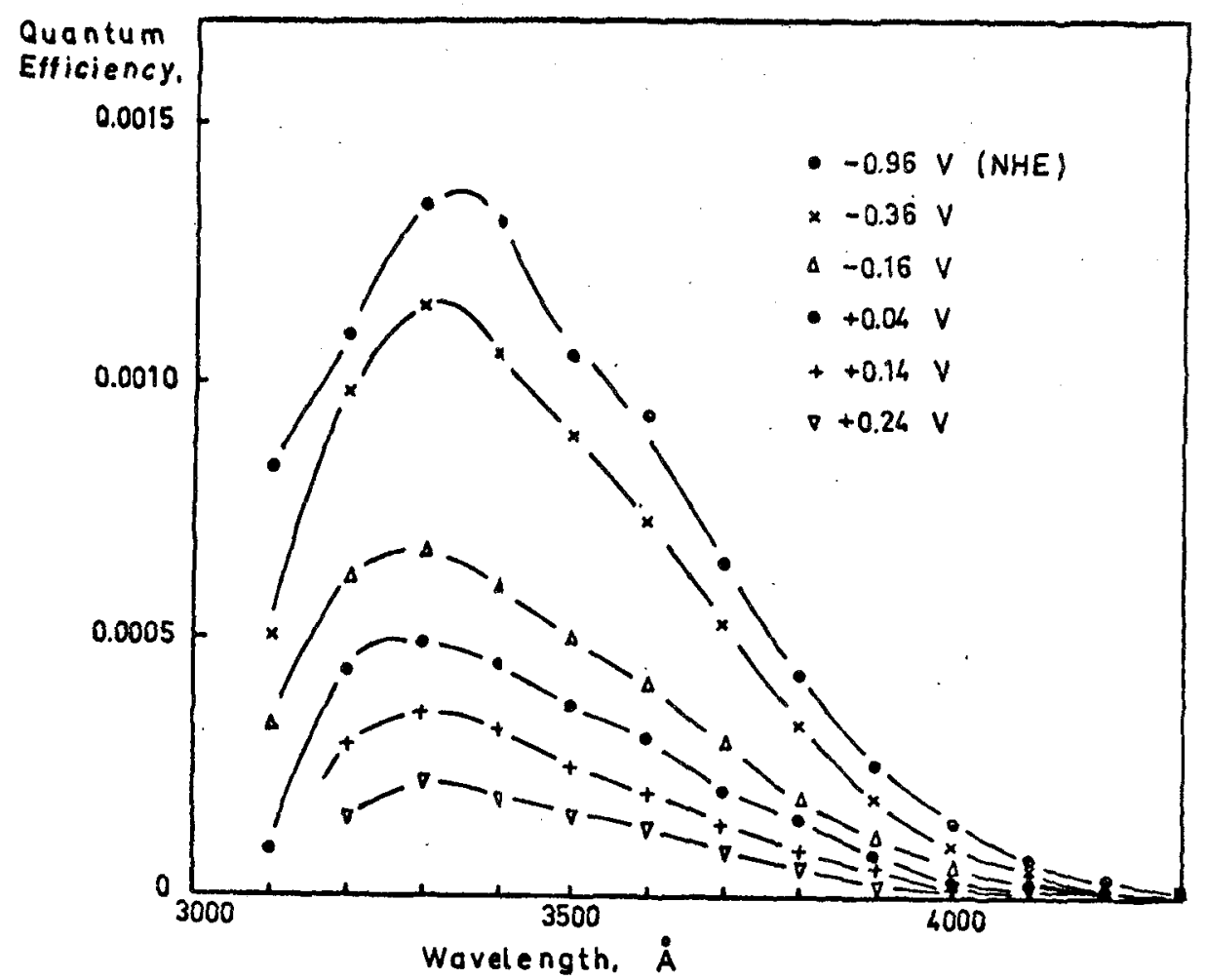

(a)

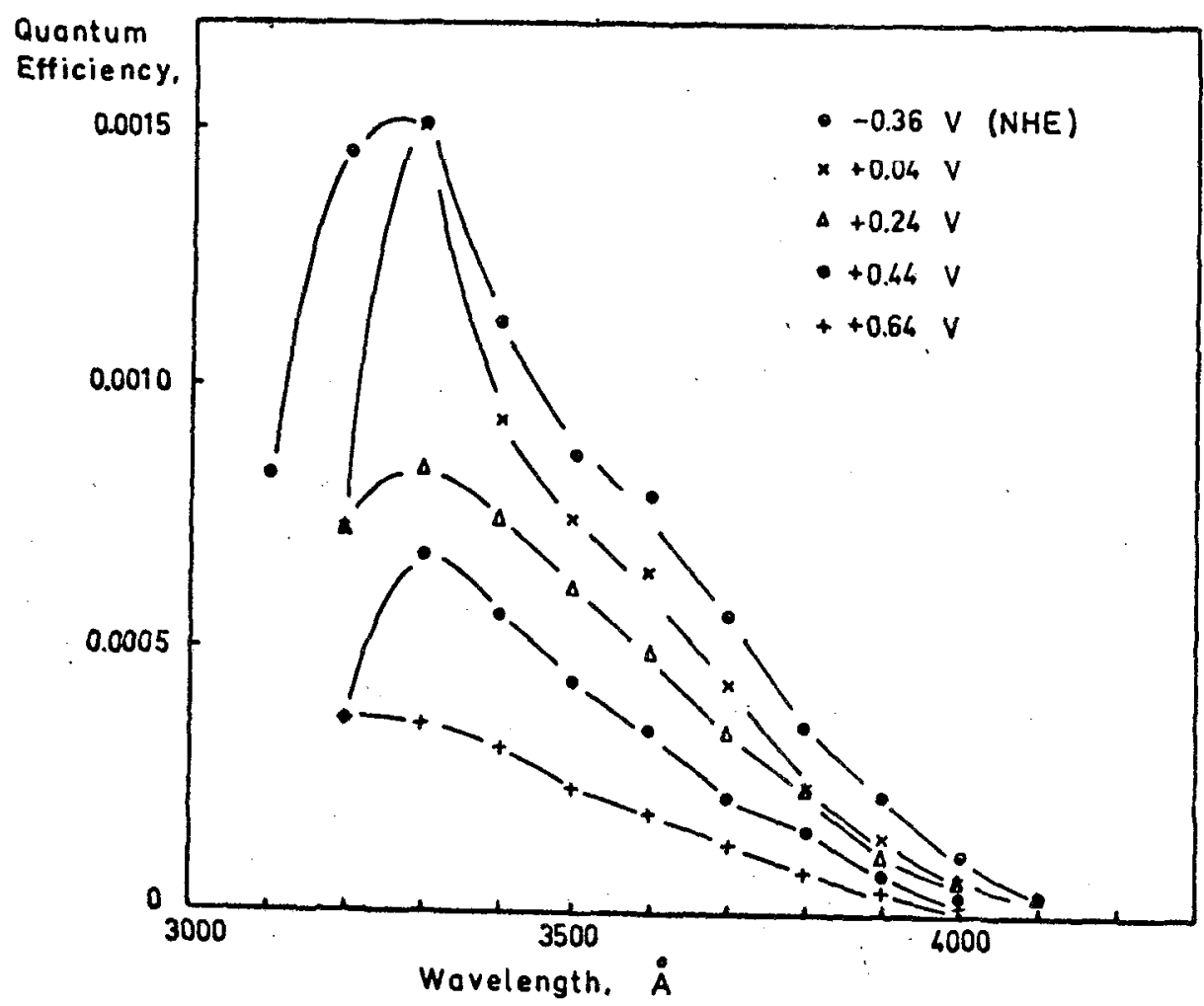

(b)

Pig. 5.55 The quantum efficiency-wavelength relations of SiC in $1 \mathrm{~N} \mathrm{NaOH} \mathrm{(a)} \mathrm{and} 1 \mathrm{~N} \mathrm{H}_{2} \mathrm{SO}_{4}$ (b). 

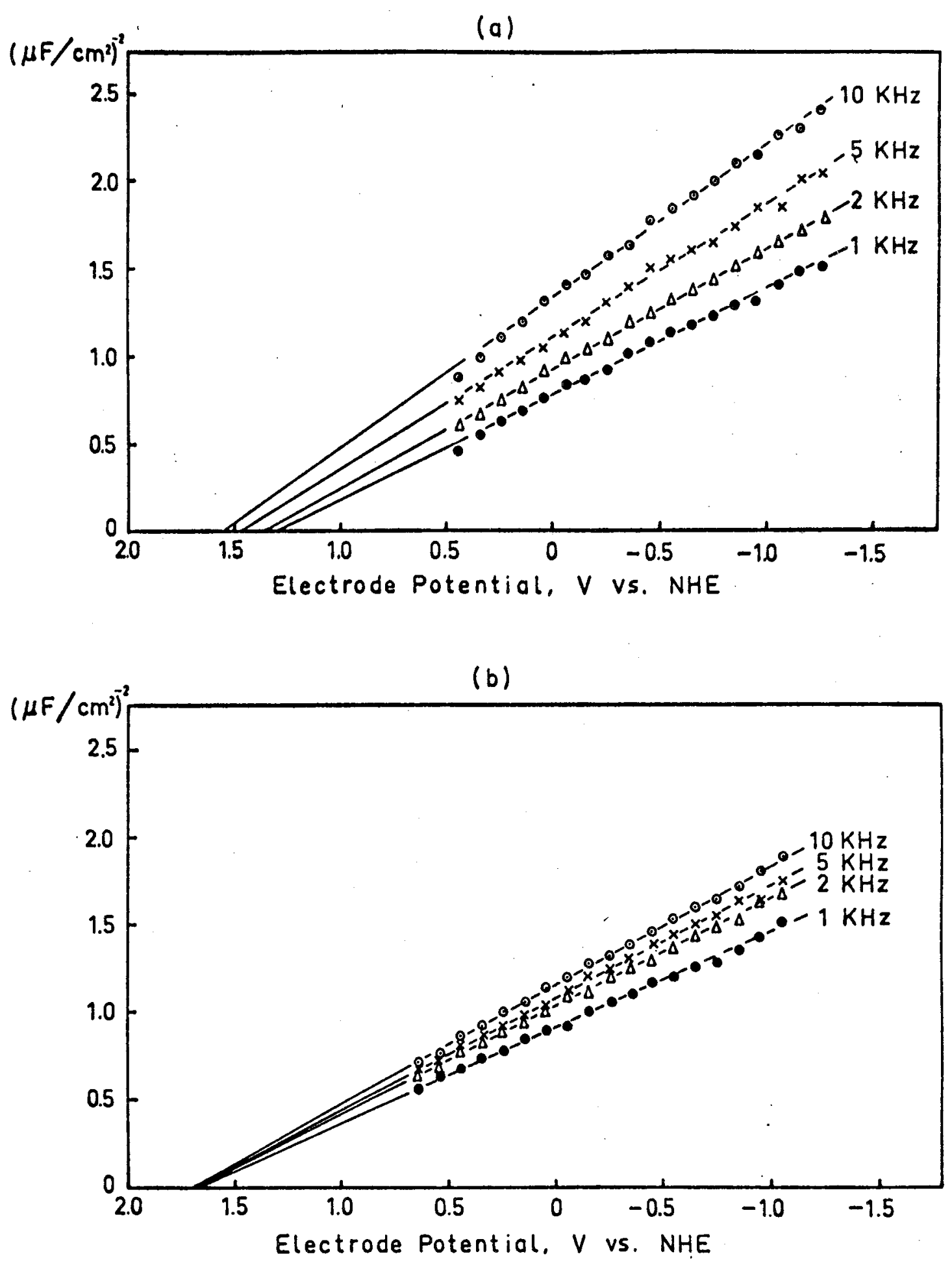

Fig. 5.56 The Mott-Schottky plots of SiC in $1 \mathrm{~N} \mathrm{NaOH} \mathrm{(a)} \mathrm{and}$ $1 \mathrm{~N} \mathrm{H}_{2} \mathrm{SO}_{4}(\mathrm{~b})$ at several frequencies. 


\subsubsection{Transient measurement}

Because of low $S / N$ ratio, satisfactory result was not obtained in $1 \mathrm{~N} \mathrm{H}_{2} \mathrm{SO}_{4}$.

The results in $1 \mathrm{~N} \mathrm{NaOH}$ solution are shown in Fig. $5.57(\mathrm{a} \sim \mathrm{d})$.

\subsubsection{Stability}

The stability of the photocurrents were examined in $1 \mathrm{~N} \mathrm{NaOH}$ and in $1 \mathrm{~N}_{2} \mathrm{SO}_{4}$ and the results are shown in Fig. 5.58 for $\mathrm{NaOH}$ solution and for $\mathrm{H}_{2} \mathrm{SO}_{4}$ solution.

Although the photocurrents were very small, the photocurrents were quite stable over 1 hour for both cases.

\subsubsection{Silicon (Si)}

\subsubsection{The current-potential relation}

The current-potential relations of silicon in $1 \mathrm{~N} \mathrm{NaOH}$ and in $1 \mathrm{~N}_{2} \mathrm{SO}_{4}$ are shown in Fig. 5.59(a) and Fig. 5.59(b), respectively.

After the experiment, some film $\left(\mathrm{SiO}_{2}\right)$ was observed on the electrode surface and this film could not completely be removed, although dipping in HF solution seemed to remove some part of the film. Therefore, these current-potential relations should be considered as only typical results.

\subsubsection{Photocurrent (quantum efficiency)-wavelength} relation at several potentials

The photocurrents under illumination by monochromatic light $(3500 \AA \sim 9700 \AA)$ at severa 1 potentials $(-0.76 \sim-1.56 \mathrm{~V})$ were measured in $1 \mathrm{~N} \mathrm{NaOH}$ and typical results are shown in Fig. 5.60. The quantum efficiencies were calculated from these values. The results are shown in Fig. 5.61. Since the film covered the electrode surface, these results may not represent the silicon electrode.

\subsubsection{The flat band potential}

Reliable results of impedance were not able to be obtained in this work because of the reason mentioned above. 
178.

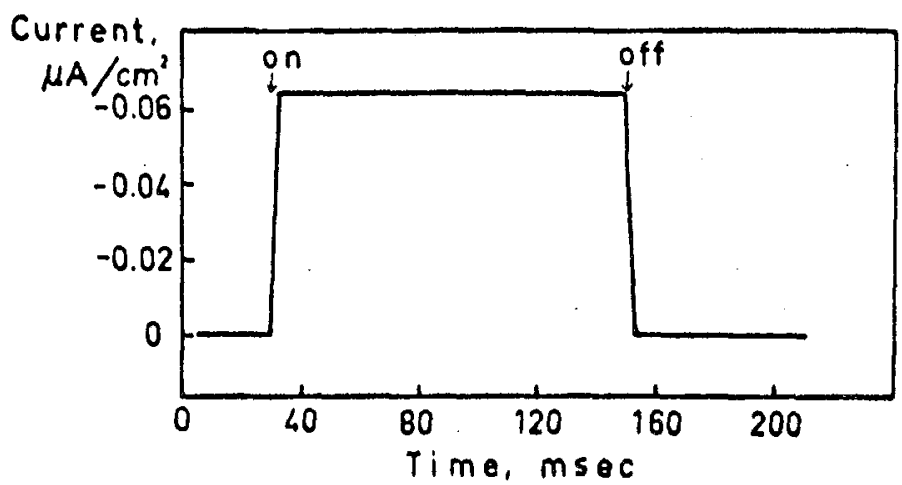

(a) $-1.16 \vee($ NHE)

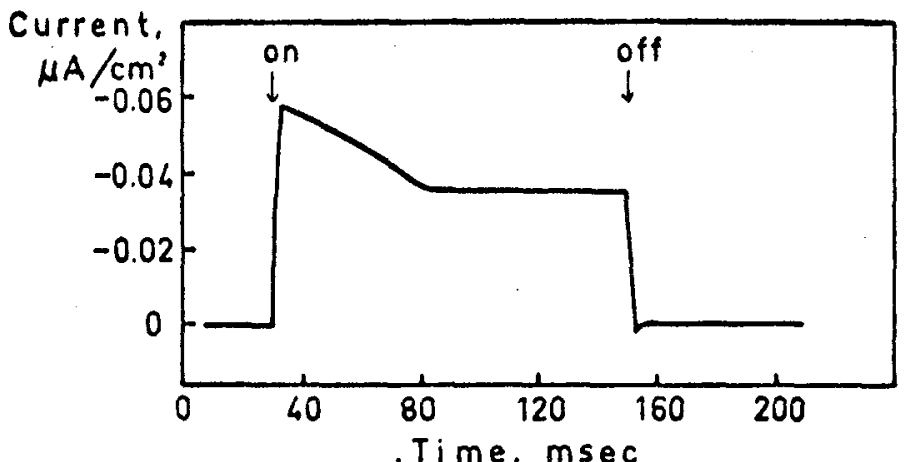

(b) $-0.76 \vee$ (NHE)

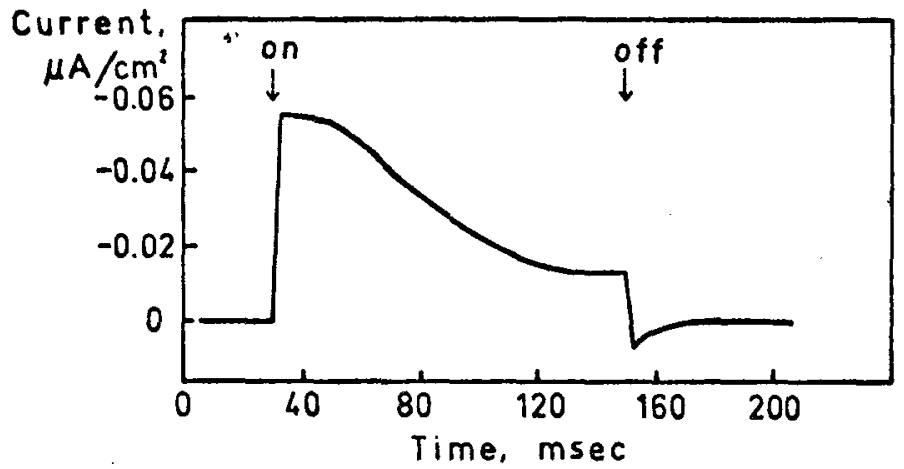

(c) $-0.36 \vee(N H E)$

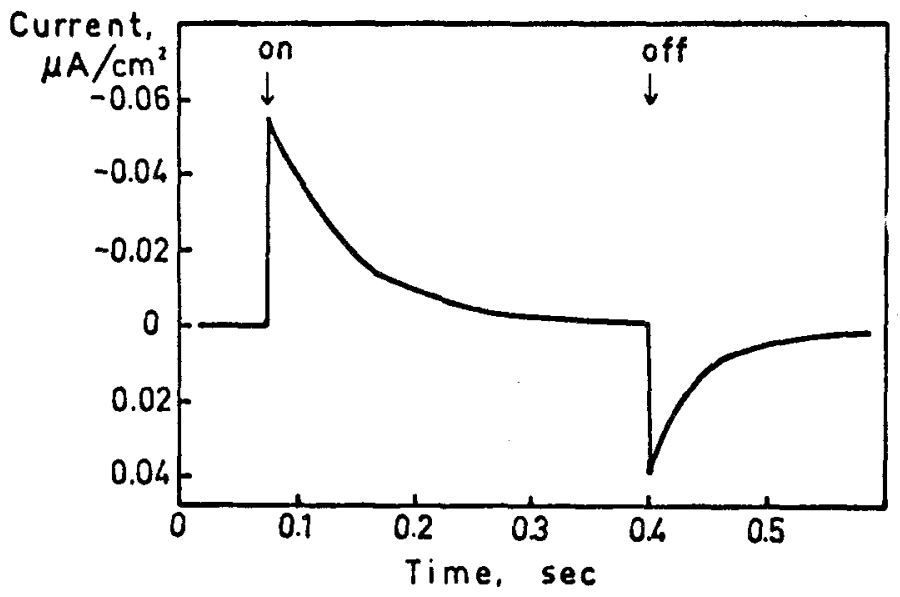

(d) +0.04 V (NHE)

Fig. 5.57 The transient behaviour of the current of SiC in $1 \mathrm{~N} \mathrm{NaOH}$ after illumination and interruption of light $\left(0.08 \mathrm{~W} / \mathrm{cm}^{2}\right)$ at several electrode potentials. 


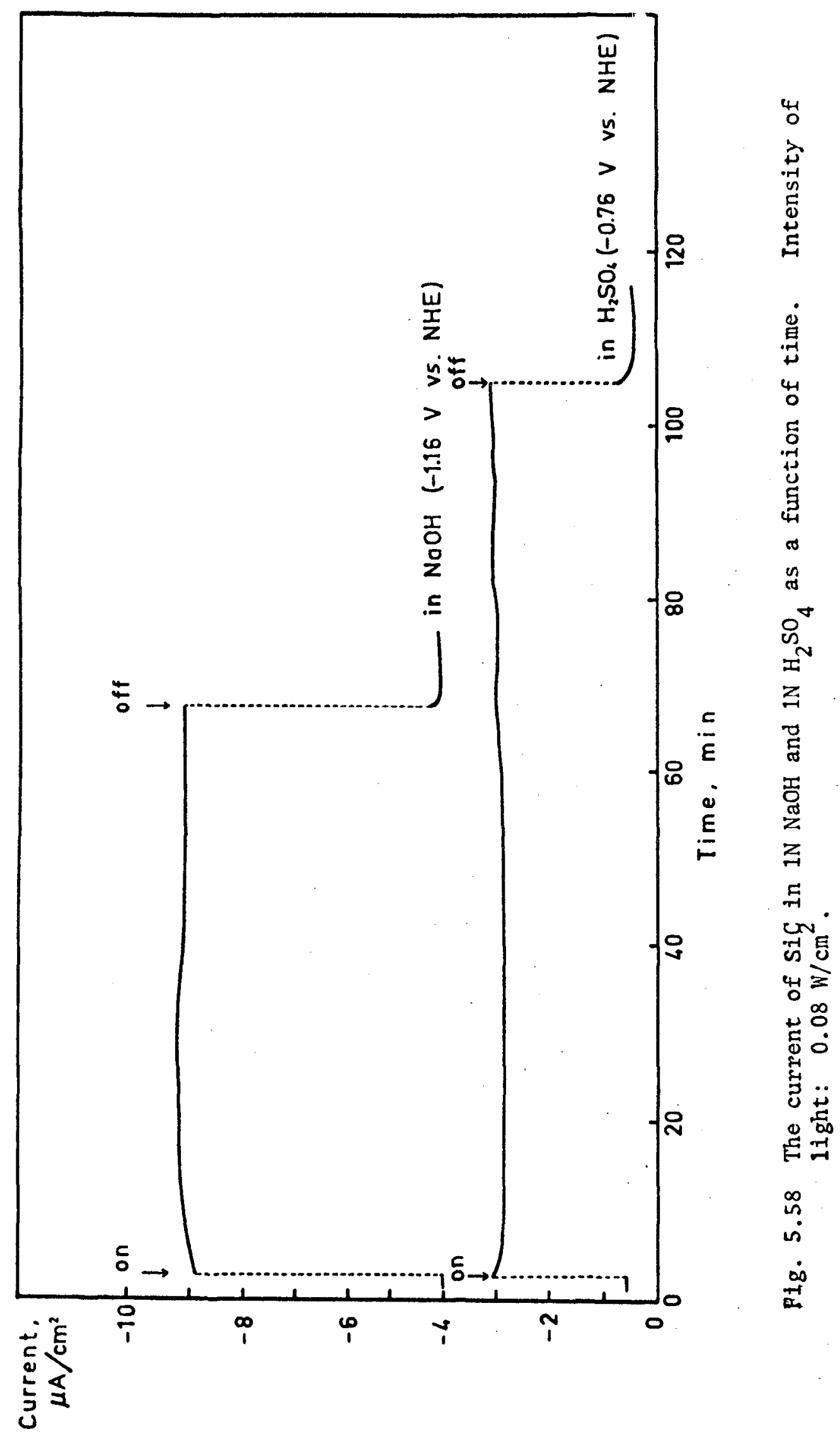


180.

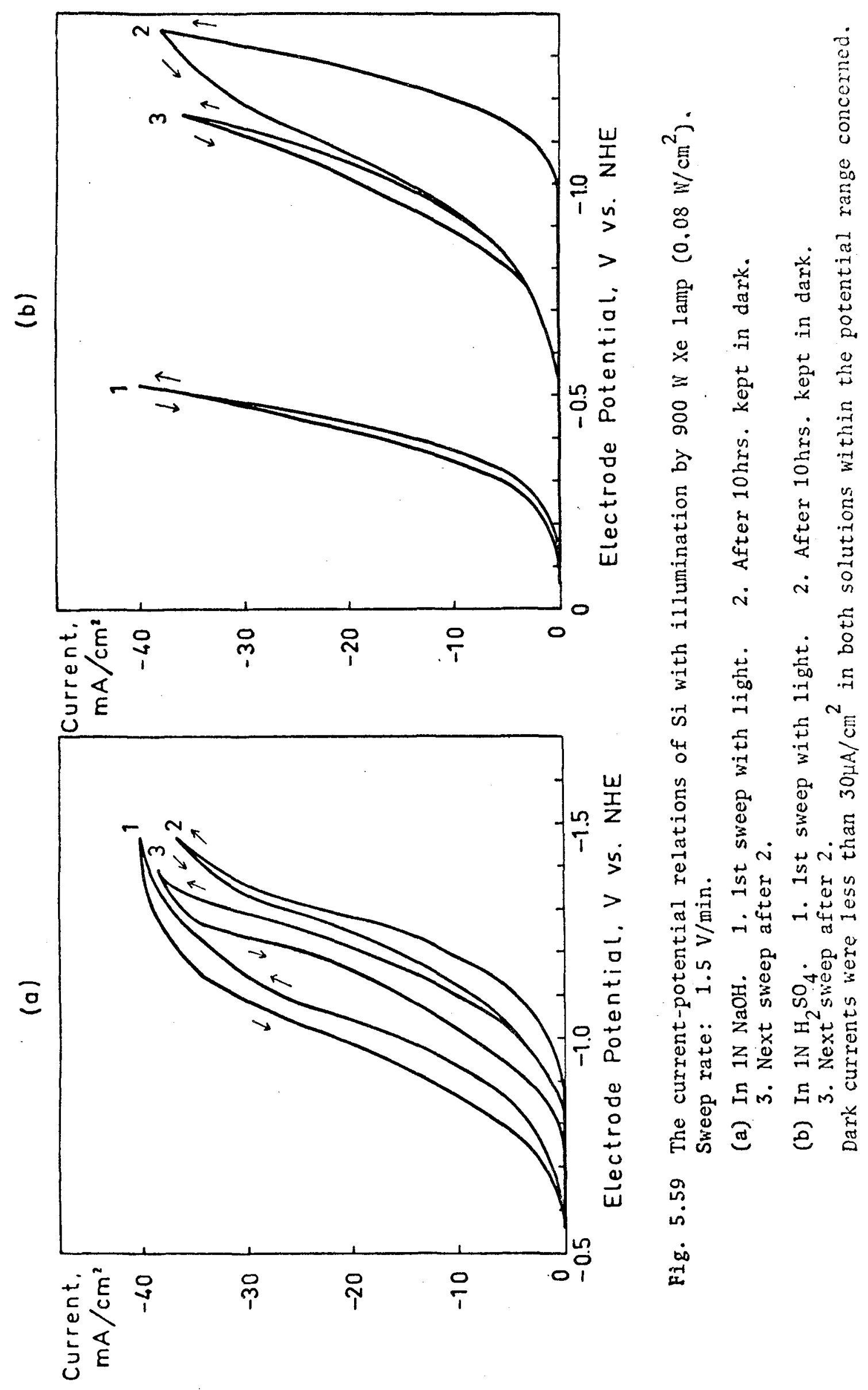


181.

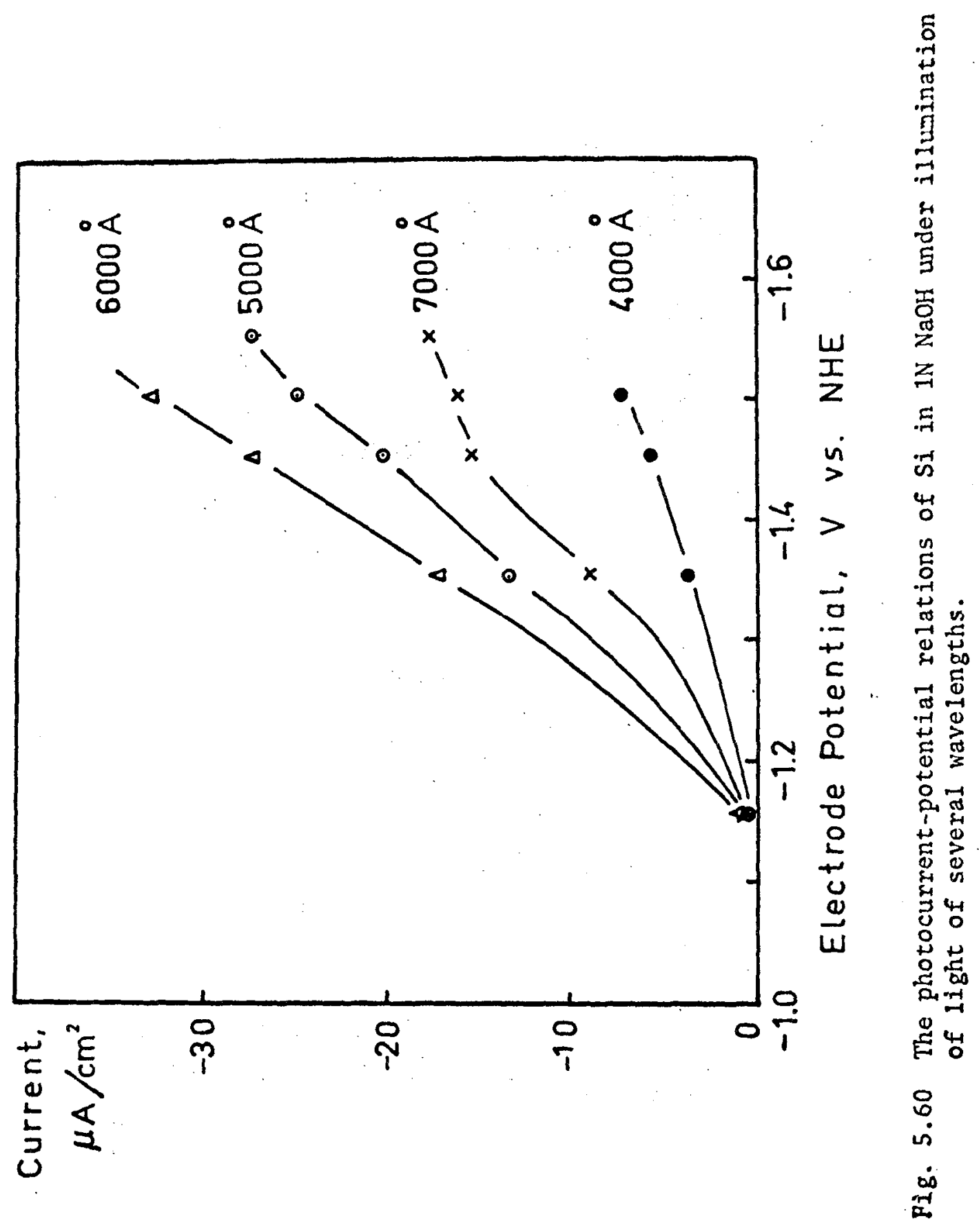


182.

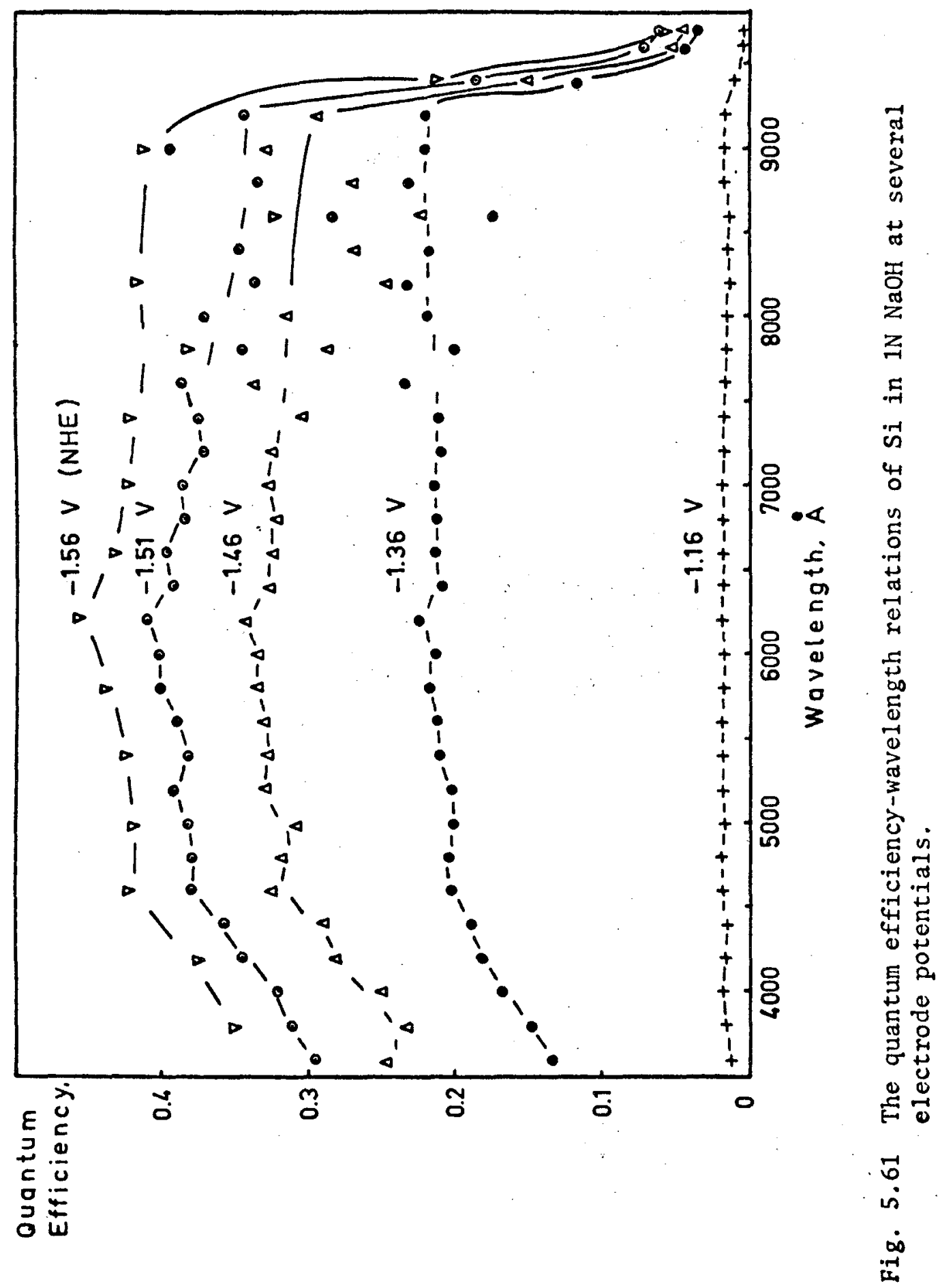


183.

\subsubsection{Transient measurement}

Transient measurements were carried out in $1 \mathrm{~N} \mathrm{NaOH}$ and the results are shown in Fig. $5.62(\mathrm{a} \sim \mathrm{e})$. The behaviour is more or less the same as those of the other semiconductors.

\subsubsection{Stability}

The photocurrents at fixed potential were measured as a function of time for over one hour in $1 \mathrm{~N} \mathrm{NaOH}$ and in $1 \mathrm{~N} \mathrm{H}_{2} \mathrm{SO}_{4}$. The results are shown in Fig. 5.63(a) and in Fig. 5.63(b) for $\mathrm{NaOH}$ and for $\mathrm{H}_{2} \mathrm{SO}_{4}$, respective1y.

The photocurrents in $1 \mathrm{~N} \mathrm{NaOH}$ was relatively stable but in both cases the photocurrents decreased very much after the electrode was kept in dark at open circuit condition for about 10 hours. The photocurrent again increased on repeating the potential sweep under illumination (see Fig. 5.59(a) and (b)). Etching in HF solution made the photocurrent very large (see Fig. 5.63(b)). 
184.

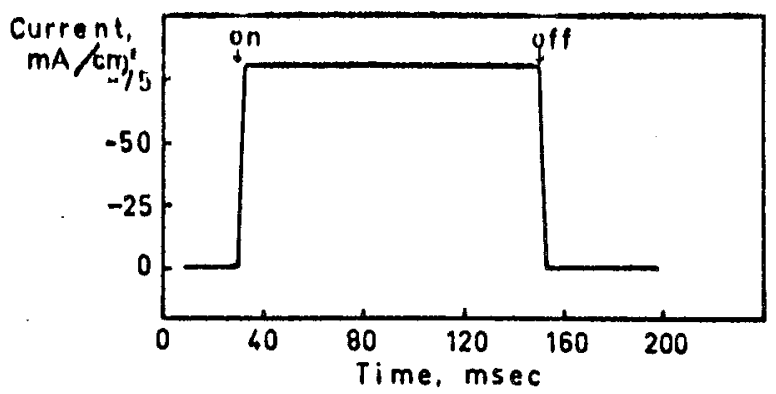

$(0)-1.56 \vee$ (NHE)

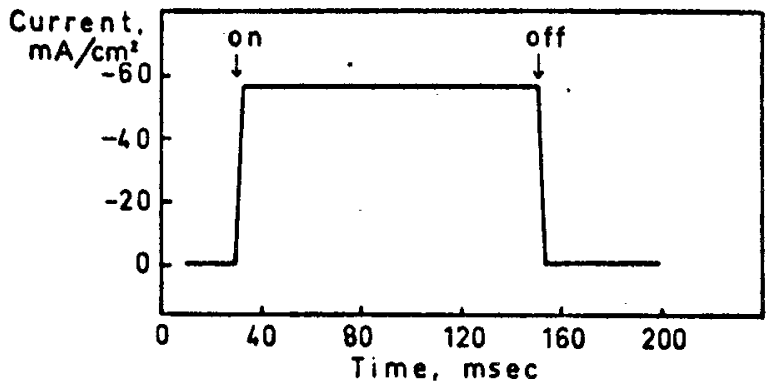

(b) $-1.16 \vee($ NHE)

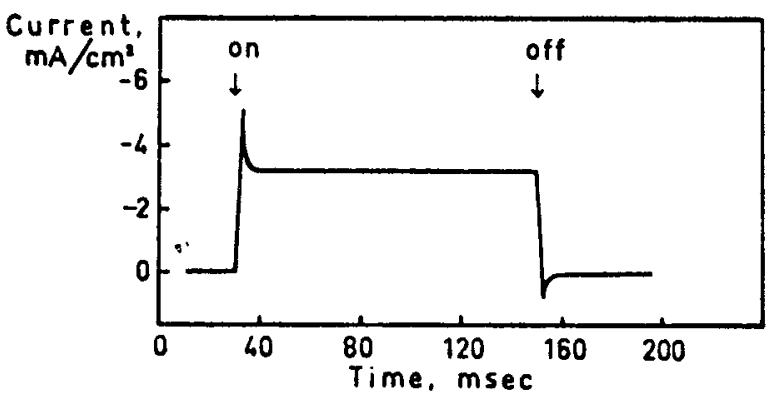

(c) $-0.76 \vee$ (NHE)

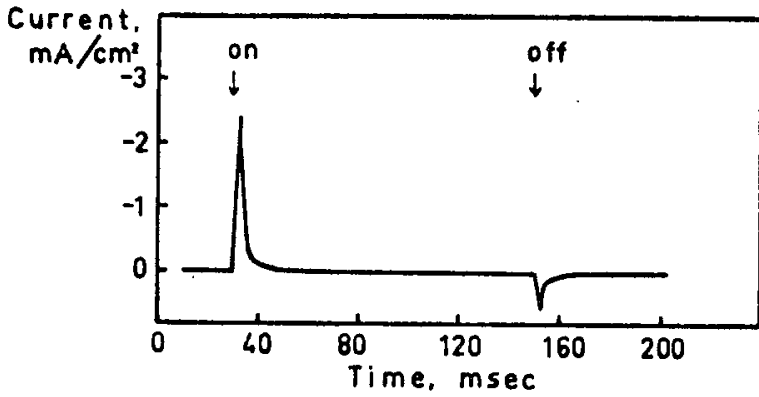

(d) $-0.56 \vee(\mathrm{NHE})$

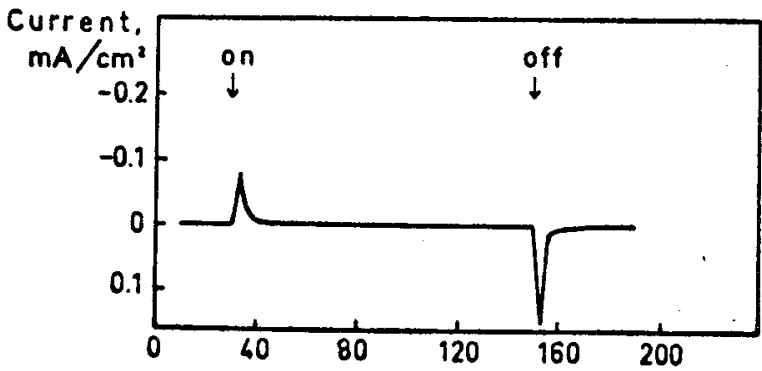

(e) $-0.36 \vee(\mathrm{NHE})$

Fig. 5.62 The transient behaviour of the current of $\mathrm{Si}$ in IN NaOH after illumination and intermuption of light $\left(0.08 \mathrm{~W} / \mathrm{cm}^{2}\right)$ at several electrode potentials. 


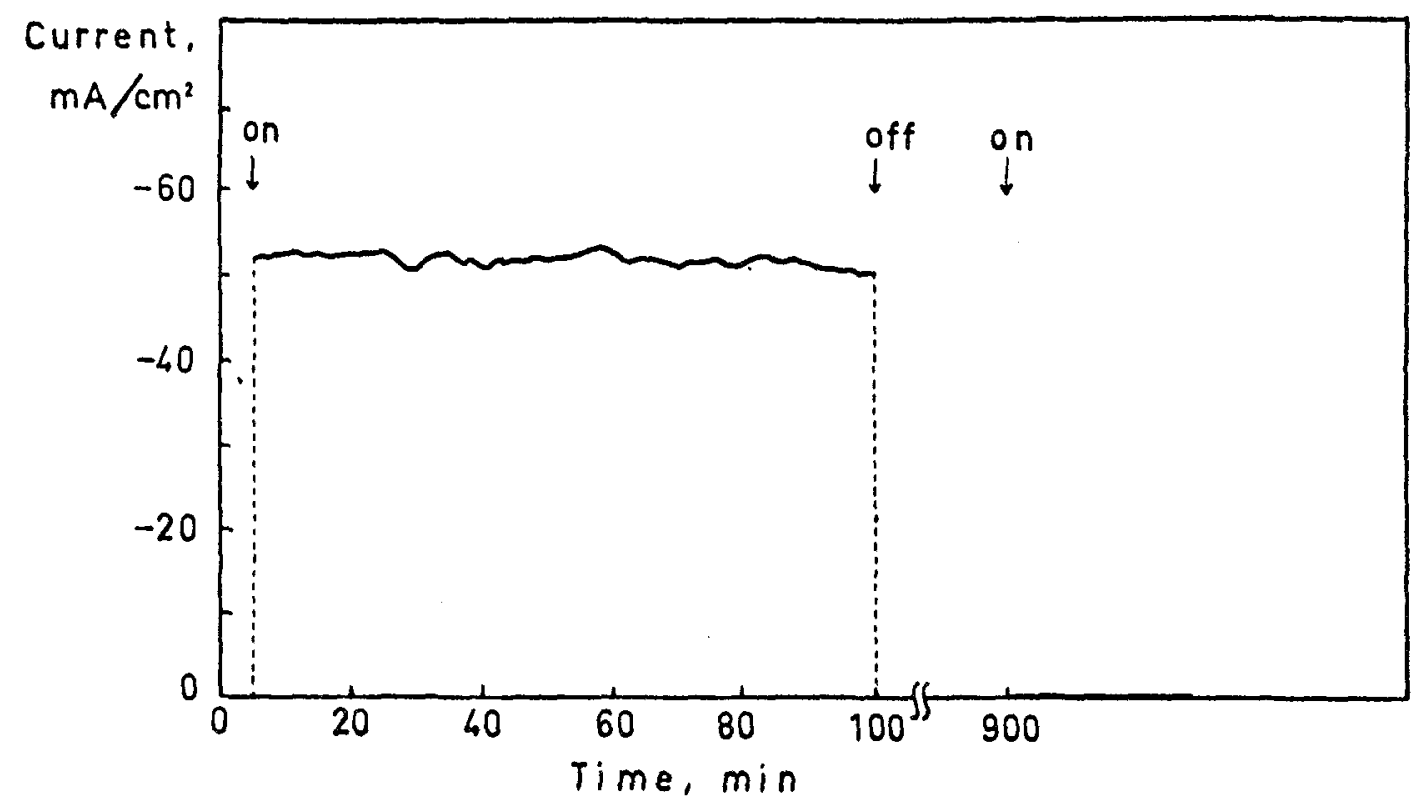

(a)

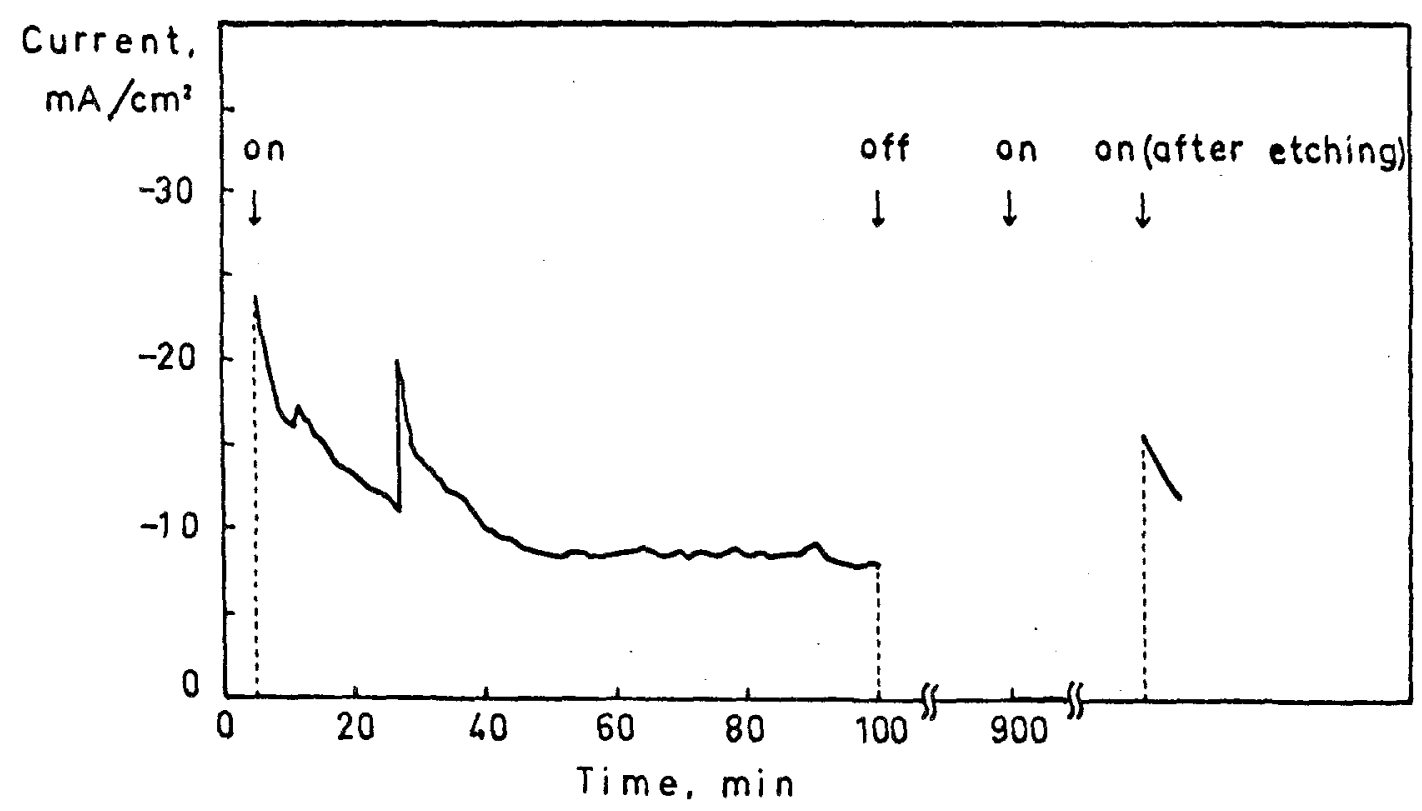

(b)

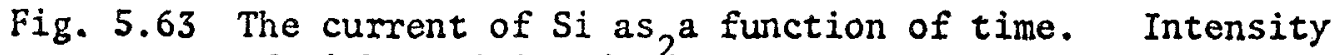
of light: $0.08 \mathrm{~W} / \mathrm{cm}^{2}$.

(a) In $1 \mathrm{~N} \mathrm{NaOH}$ at $-1.06 \mathrm{~V}$ (NHE)

(b) In $1 \mathrm{~N} \mathrm{H}_{2} \mathrm{SO}_{4}$ at $-0.41 \mathrm{~V}$ (NHE) 


\section{BIBLIOGRAPHY OF CHAPTER FIVE}

1. K.L. Hardee and A.J. Bard, J. EZectrochem. Soc., 122, 739 (1975) .

2. L.A. Harris and R.H. Wilson, J. Electrochem. Soc., 123, 1010 (1976).

3. A. Fujishima, K. Kohayakawa and K. Honda, J. EZectrochem. Soc., 122, 1487 (1975).

4. A.J. Voge1, "Macro and Semimicro Qualitative Inorganic Analysis", 4th ed., Longman (1974).

5. S. Mayumi, C. Iwakura, H. Yoneyama and H. Tamura, Denki Kagaku, 44, No. 5 (1976).

6. M. Gleria and R. Memming, J. EZectroanal. Chem., 65, 163 (1975). 
CHAPTER SIX

DISCUSSION 
187.

CHAPTER SIX

DISCUSSION

\subsection{INTRODUCTION}

First, the experimental results of this work are compared with those of previous works.

Experimental results, especially those of p-type semiconductors, are generalized and analysed by the theory given in chapter three. The experimental results are compared with the theoretical results and the discrepancies between the experimental and calculated results are discussed. The theory is modified. 


\subsection{COMPARISON OF EXPERIMENTAL RESULTS}

WITH THOSE OF PREVIOUS WORKS

\subsubsection{Titanium Dioxide Single Crystal}

The current-potential relations obtained are essentially the same as those of earlier works $[1,2]$.

The quantum efficiency-wavelength relations at several electrode potentials were measured in this work for the first time and the result at $3650 \AA$, at which wavelength Ohnishi et a1. measured the quantum efficiency at several electrode potentials, agreed with their results [3] .

$\mathrm{TiO}_{2}$ was described as a stable electrode by Fujishima et al. by chemical analysis of the solution [1] and by measurement of $\mathrm{pH}$ changes of solution [4] and by Wrighton et a1. by measurement of weight changes of the electrode [5]. However, recently, Harris et a1. [6] reported the photocurrent decreased with time in all cases they examined. The results of this work, i.e. constant photocurrent for over 20 hrs., confirmed the stability of the electrode.

The reasons of the high stability of the $\mathrm{TiO}_{2}$ single crystals of this work compared with the results of Harris et al. [6] may be:

\section{(a) Solution}

The stability was examined in $1 \mathrm{~N} \mathrm{NaOH}$ solution in this research and they used $1 \mathrm{~N} \mathrm{H}_{2} \mathrm{SO}_{4}$.

(b) Reduction Condition

$\mathrm{TiO}_{2}$ was reduced at $800^{\circ} \mathrm{C}$ in hydrogen atmosphere for five hours in this work and they reduced $\mathrm{TiO}_{2}$ at $600^{\circ} \mathrm{C}$ in hydrogen atmosphere for up to 15 minutes. They found the number of donors in $\mathrm{TiO}_{2}$ decreased 
189.

with time and claimed that this was the reason of deterioration of photocurrent. In this work, since the reduction was carried out more thoroughly than their work, the density of donor was quite high and little change with time is expected.

(c) Intensity of light

Intensity of 1 ight was $0.08 \mathrm{~W} / \mathrm{cm}^{2}$ in this work and was $1.4 \mathrm{~W} / \mathrm{cm}^{2}$ in their case. Accordingly, the current density of this work was $1.7 \mathrm{~mA} / \mathrm{cm}^{2}$ and theirs was $16 \mathrm{~mA} / \mathrm{cm}^{2}$ at maximum.

Too strong illumination may damage the crystal.

\subsubsection{Titanium Oxide Film}

The results of anodic oxide film without further treatment basically agreed with those reported before without details $[7,8]$.

The quantum efficiency-wavelength relation and cathodic polarization effect were examined here for the first time.

The results of partly reduced $\mathrm{TiO}_{2}$ film made by high temperature oxidation in electric furnace were essentially the same as those of $\mathrm{TiO}_{2}$ films made by high temperature oxidation in a gas burner [8] and of $\mathrm{TiO}_{2}$ single crystals.

The dependence of quantum efficiency-wavelength relation on oxidation time has not been reported before.

The results of CVD film on Ti are essentially the same as those of Hardee et a1. [7].

\subsubsection{Prevention of Anodic Dissolution by Coating}

The prevention of anodic dissolution of a semiconductor, which has a relatively low energy gap, by $\mathrm{TiO}_{2}$ film has not been reported before, although Nakato et a1. carried out independently a similar attempt to prevent anodic dissolution by a coating with metal film [9] . 


\subsubsection{Meta1 Titanate}

Iron titanate and cobalt titanate were examined in this work for the first time.

\subsubsection{Zinc Telluride}

The current-potential relations of $\mathrm{ZnTe}$ have been measured only in $\mathrm{ZnSO}_{4}$ solution by Sapritskii et a1. [10]. The relatively negative value of critical potential at which the photocurrent was first observed in this work agreed with the results of theirs.

The EMF of $\mathrm{ZnTe} / 0.1 \mathrm{M} \mathrm{KCl} \mathrm{/} \mathrm{SCE} \mathrm{with} \mathrm{and} \mathrm{without} \mathrm{illumination}$ were measured by Williams [11] and no photoeffect on the EMF was observed. Correspondingly, $E_{\text {rest }}$ with and without light in this work were more or less the same.

No flat band potential measurement has been carried out before.

\subsubsection{Cadmium Te1luride}

CdTe has not been examined photoelectrochemically before.

No value of the flat band potential has been reported.

\subsubsection{Gallium Arsenide}

Gerischer et al. reported the current-potential relation in $2 \mathrm{~N} \mathrm{H}_{2} \mathrm{SO}_{4}$ with and without illumination [12] . The current-potential relations of this work are essentially the same as those of their work except for the fact that they observed the saturation of photocurrent at $-1.0 \mathrm{~V}$. No such a saturation current was observed in this work within the potential range concerned. The difference of light intensity may cause this discrepancy. However, it is not possible to compare these results, because intensity of light was not reported in their work. The GaAs used by them was not characterized.

The values of the flat band potential of GaAs were reported as $-0.2 \mathrm{~V}(\mathrm{NHE})$ in $0.01 \mathrm{M} \mathrm{KOH} \mathrm{[13]} \mathrm{and} 0.6 \mathrm{~V}(\mathrm{NHE})$ in $1 \mathrm{M} \mathrm{H}_{2} \mathrm{SO}_{4}$ [14], 
191.

respectively. The results of this work were $-0.01 \mathrm{~V}(\mathrm{NHE})$ in $1 \mathrm{~N} \mathrm{NaOH}$ and $0.43 \mathrm{~V}$ (NHE) in $1 \mathrm{~N} \mathrm{H}_{2} \mathrm{SO}_{4}$.

\subsubsection{Indium Phosphide}

Mayumi et al. measured current-potential relations with and without illumination and quantum efficiency-wavelength relation in $1 \mathrm{~N} \mathrm{H}_{2} \mathrm{SO}_{4}[15]$. Also they measured the flat band potential in the same solution.

They observed a white film on the electrode surface after the illumination under cathodic polarization as observed in this work.

The results of current-potential relation of this work were different from those of theirs. This may be due to the film formation. As reported in section 5.2.4 the photocurrent of InP in $1 \mathrm{~N}_{2} \mathrm{SO}_{4}$ decreased very quickly and, therefore, the current-potential relation should be treated only as a typical result.

The quantum efficiency-wavelength relation and the flat band potential in $1 \mathrm{~N} \mathrm{H}_{2} \mathrm{SO}_{4}$ could not be measured in this work because of instability of the electrode.

The measurements in $\mathrm{NaOH}$ have not been reported before.

\subsubsection{Gallium Phosphide}

The current-potential relation of $\mathrm{GaP}$ with and without illumination was measured by Memming et al. [16,17] in $3 \mathrm{~N} \mathrm{NaOH}$ and in $1 \mathrm{~N} \mathrm{KCl}$ and by Yoneyama et al. [18] in $1 \mathrm{~N} \mathrm{H}_{2} \mathrm{SO}_{4}$ and in $1 \mathrm{~N} \mathrm{NaOH}$. The results of this work agreed with those of these workers.

Yoneyama et a1. also reported the photocurrent-wavelength relation in $\mathrm{H}_{2} \mathrm{SO}_{4}$ in which the maxima appeared at $4500 \AA$. The maxima appeared at about $3500 \AA$ in this work.

The values of flat band potential were reported by many workers and those are $1.1 \sim 1.2 \mathrm{~V}$ (NHE) in $1 \mathrm{~N} \mathrm{H}_{2} \mathrm{SO}_{4}[18,19]$ and $0.05 \sim 0.3 \mathrm{~V}$ 
192.

(NHE) in the solution of $\mathrm{pH}=14[18,19]$. The results of this work were $1.13 \mathrm{~V}$ in $1 \mathrm{~N} \mathrm{H}_{2} \mathrm{SO}_{4}$ and $0.18 \mathrm{~V}$ in $1 \mathrm{~N} \mathrm{NaOH}$ and agreed with those results mentioned above.

Yoneyama et a1. reported that the photocurrent of $\mathrm{GaP}$ at $0.19 \mathrm{~V}$

(NHE) (solution used is not mentioned, but may be $\mathrm{H}_{2} \mathrm{SO}_{4}$ ) decreased with time very quickly but the result in this work showed that the decreasing rate was much slower than that of their result.

This discrepancy may be due to the difference of illumination condition. Although they did not report the actual illumination intensity, their illumination intensity seemed stronger than this work, since they concentrated the light of 500W Hg lamp onto the electrode while parallel light of $900 \mathrm{~W}$ Xe lamp was used in this work.

\subsubsection{Silicon Carbide}

The current-potential relation and photocurrent-wavelength relation in $0.05 \mathrm{M} \mathrm{H}_{2} \mathrm{SO}_{4}$ were reported by Gleria and Memming [20] and the results of this work are essentially the same as those of theirs. They mentioned that they could not measure the flat band potential of p-type semiconductor*, although they estimated the value in $0.05 \mathrm{M}$ $\mathrm{H}_{2} \mathrm{SO}_{4}$ as $1.64 \mathrm{~V}$ from the measured value of n-type $\mathrm{SiC}$ [20]. The flat band potentials measured in this work were $1.2 \mathrm{~V}$ (NHE) in $1 \mathrm{~N}$ $\mathrm{NaOH}$ and $1.47 \mathrm{~V}(\mathrm{NHE})$ in $1 \mathrm{~N} \mathrm{H}_{2} \mathrm{SO}_{4}$.

\subsubsection{Silicon}

Most works on Si have been carried out in solutions containing HF [22], because otherwise oxide films cover the electrode surface, and this happened in this work when the electrode was left at open circuit condition without illumination.

* The Mott-Schottky plots are not linear or the slope has a completely wrong sign [21] . 
6.3 PHENOMENOLOGICAL GENERALIZATIONS ARISING FROM THE RESULTS

\subsubsection{Current-Potential Relations}

(a) Photocurrent increased, firstly, gradually with increase of potential, then, it increased sharply and, finally, reached a saturation value.

(b) The more negative the flat band potential and the larger the energy gap, the more positive the critical potential (with respect to the flat band potential) at which the photocurrent becomes significant.

(c) The current-potential relations in $\mathrm{NaOH}$ solution appeared at more negative potentials than those in $\mathrm{H}_{2} \mathrm{SO}_{4}$ solution.

\subsubsection{Quantum Efficiency-Wavelength Relations}

The nearer the electrode potential to the flat band potential, the larger the ratio of the quantum efficiency at high, compared with that at low, energies of the incident light.

\subsubsection{F1at Band Potential}

The flat band potential in $\mathrm{NaOH}$ was more negative than that in $\mathrm{H}_{2} \mathrm{SO}_{4}$ except for CdTe.

\subsubsection{Transient Behaviour}

The nearer the electrode potential to the flat band potential, the longer the time to reach a steady state at constant potential.

\subsubsection{TiO $_{2}$ Film}

The longer the oxidation time, the longer the wavelength of light at which a maxima in the quantum efficiency-wavelength relation was observed. 


\subsection{ANALYSIS OF THE PHOTOCURRENT-POTENTIAL RELATION}

\subsubsection{Typical Results}

Typical photocurrent-potential relations are seen in those found for $\mathrm{GaP}$ and $\mathrm{TiO}_{2}$. The photocurrent increases, firstly, gradually with increase of potential, then it increases sharply and, finally, reaches a saturation value.

\subsubsection{Comparison Between Experimental Results and Calculated} Results

As an example GaP in $1 \mathrm{~N} \mathrm{H}_{2} \mathrm{SO}_{4}$ is taken.

In Fig. 6.1, the quantum efficiency-potential relations for $3500 \AA, 4000 \AA$ and $4500 \AA$, of 1ight calculated by using Eq. (3.23) (3.26) and Eq. (3.39) in chapter three are shown with experimental values. The parameters used in the calculation have been taken from Table 4.1 except for life time which has been taken as $10^{-10} \mathrm{sec}$ [23] and optical properties which have been taken from ref. 24 and 25.

In respect to the shape and position of the quantum efficiencypotential curves obtained for various photon energies, discrepancies exist of the following kinds.

Although both experiment and theory agree in respect to the fact that the quantum efficiency depends upon the photon energy, the experimental results show that the originating, or critical, potential at which the quantum efficiency becomes significant is independent of the photon energy, while such dependence exists in the theoretical curves. Also, the experimental quantum efficiency increased with the potential much more quickly than expected by the theory of chapter three and reached a saturation value. No such a value was exhibited 


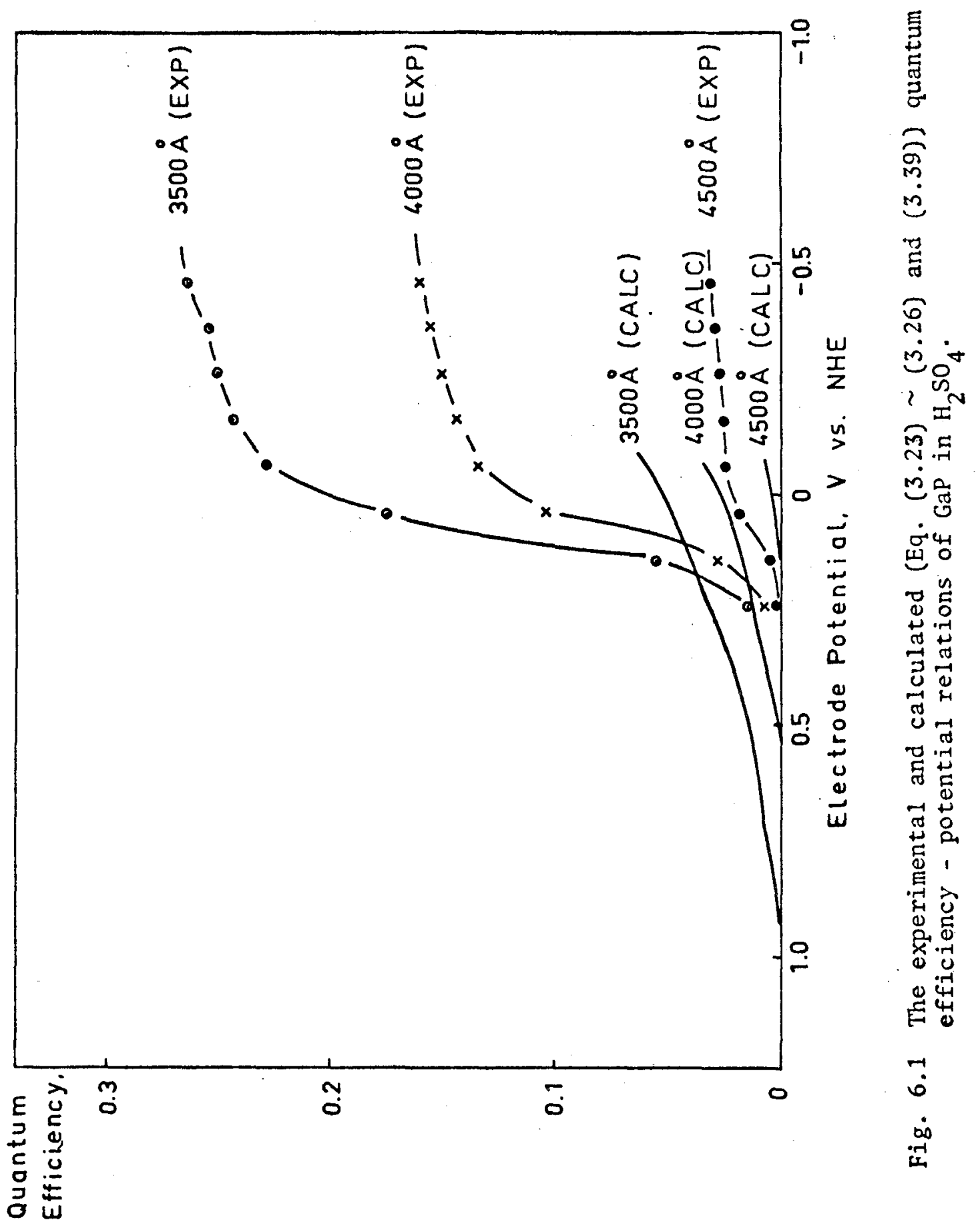


196.

by the calculation within the potential range concerned.

6.4.3 Qualitative Analysis of the Discrepancies between the Experimental Results and the Calculated Results

A schematic diagram of energy levels of $\mathrm{H}_{3} \mathrm{O}^{+}$in solution and valence band and conduction band of GaP are shown in Fig. 6.2.

According to the theory of chapter three, the photocurrent, $i_{p}$, is given by:

$$
i_{p}=e_{o} \frac{C_{A}}{C_{T}} \int_{0}^{\infty} N_{e}(E) G_{A}(E) W_{c}(E) d E
$$

Since $W_{c}(E)$ is given by

$$
\begin{aligned}
& W_{c}(E)=\exp \{-\beta(\Delta H(e)-E) / k T\} \quad(\text { when } E \leqslant \Delta H) \\
& =1 \quad \text { (when } E>\Delta H \text { ) }
\end{aligned}
$$

the contribution of the electrons, the energy of which is less than $\Delta H(e)$, to the photocurrent is very small $\left(W_{c}(E)=0.135\right.$ when $\Delta H(e)-E=0.1 \mathrm{eV}$ and $W_{c}(E)=0.05$ when $\left.\Delta H(e)-E=0.15 \mathrm{eV}\right)$. Therefore, by following the theory given in chapter three, in which the energy of the excited electron was considered to be constant along the $x$ coordinate from the locus of activation of the electron inside the semiconductor to $\mathrm{H}_{3} \mathrm{O}^{+}$ion, the existence of a dependence of the critical potential at which the photocurrent becomes significant on the energy of the photons is expected. Thus, when the maximum energy of electrons, $E_{\max }$, under illumination by the light, the energy of which is $\mathrm{h} v$ at potential $V$ (with respect to the flat band potential) exceeds the energy level of the acceptor $\left(\mathrm{H}_{3} \mathrm{O}^{+}\right.$in this case) significant increase in the photocurrent is expected. A schematic diagram is shown in Fig. 6.2.

Since $E_{\max }$ is given by (see Fig. 6.2): 

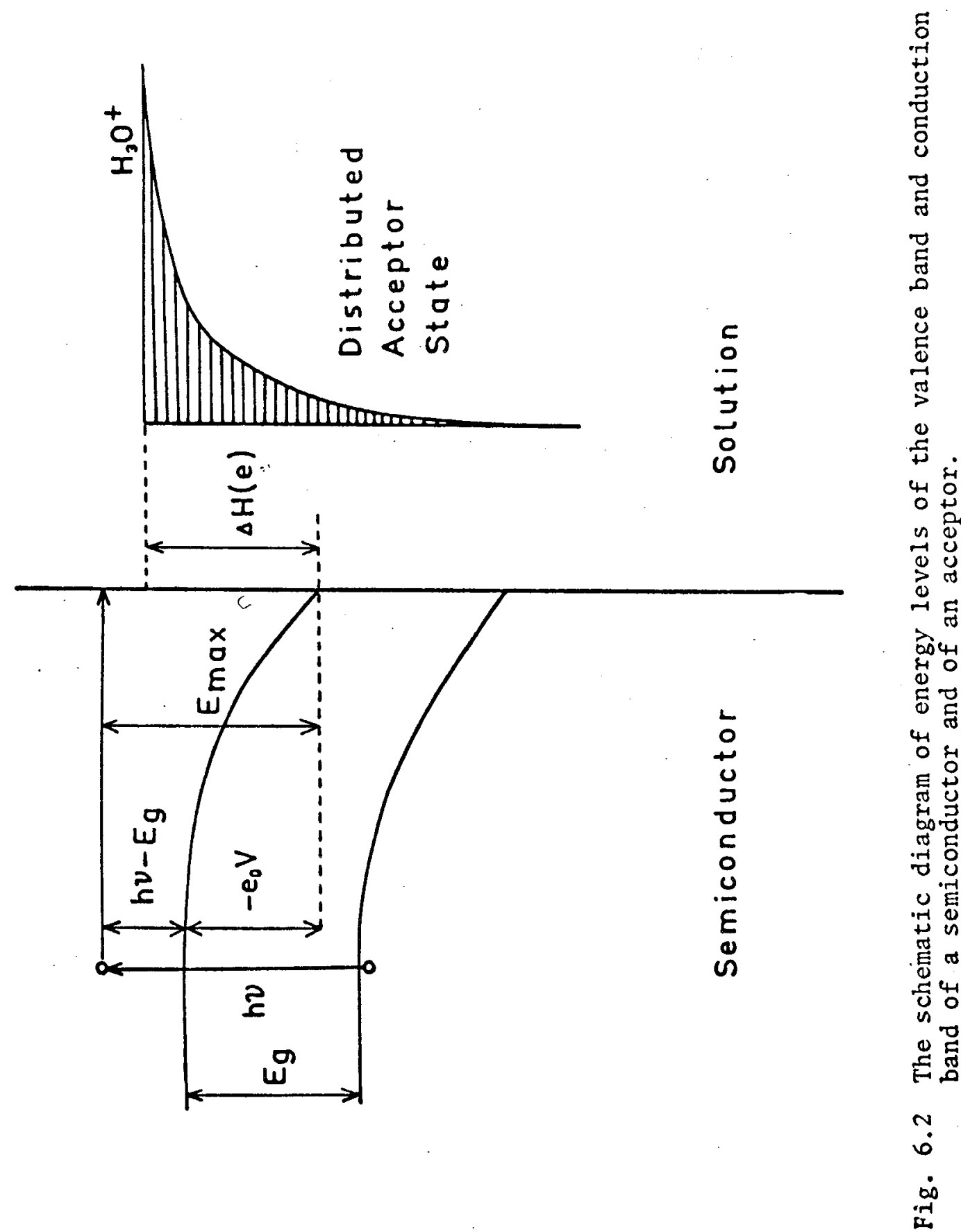


$$
E_{\max }=\left(h \nu-E_{g}\right)-e_{o} v
$$

where $E_{g}$ is the energy gap of the semiconductor, the critical potential with respect to the flat band potential, $V_{\text {crit }}$, may be related with $\Delta H(e)$, the energy level of $\mathrm{H}_{3} \mathrm{O}^{+}$in solution with respect to the bottom of the conduction band at the electrode surface, as follows:

$$
\begin{array}{r}
\left(h \nu-E_{g}\right)-e_{o} V_{c r i t}=\Delta H(e) \\
\text { i.e., } e_{o} V_{\text {crit }}=\left(h \nu-E_{g}\right)-\Delta H(e)
\end{array}
$$

The expected values of the critical potential for GaP* from Eq. (6.3) are $-0.21 \mathrm{~V}(\mathrm{NHE})$ for $3500 \AA,-0.65 \mathrm{~V}(\mathrm{NHE})$ for $4000 \AA$ and $-0.93 \mathrm{~V}(\mathrm{NHE})$ for $4500 \AA$, while the calculated value shown in Fig. 6.1 are $-0.23 \mathrm{~V}(\mathrm{NHE})$ for $3500 \AA,-0.63 \mathrm{~V}$ (NHE) for $4000 \AA$ and $-1.05 \mathrm{~V}$ (NHE) for $4500 \AA$. Although the estimated values from Eq. (6.3) agree with the values in Fig. 6.1, no photon energy dependence on the critical potential was actually observed in experimental results as mentioned before.

To explain this discrepancy, it may be suggested that the excited electrons diffusing and being electrically transported to the surface, will lose their energy as a function of passage along the $x$ coordinate towards the surface, due mainly to phonon collisions. One can see from the average depth of penetration of the photon, say $10^{-4} \mathrm{~cm}$, that the typical electron has about $10^{4} \AA$ to travel before it reaches the surface. A typical mean free path of an electron in a semiconductor is about $60 \AA$ [26], so that the number of collisions which an electron makes with phonons is of the order of magnitude $10^{4} / 60$,

* The flat band potential of $\mathrm{GaP}$ in $\mathrm{H}_{2} \mathrm{SO}_{4}$ is $1.13 \mathrm{~V}$ (NHE) and $\Delta \mathrm{H}(\mathrm{e})$ for $\mathrm{GaP}$ is calculated as $1.5 \mathrm{eV}$ from $\mathrm{Eq}$. (3.3). 
199.

or about 170. At each collision it may be assumed that the electron loses about $\mathrm{kT}$, in energy, or about $0.025 \mathrm{eV}$, so that the energy loss for the typical electron after it has been activated by a photon is of the order of $170 \times 0.025 \mathrm{eV}$. It is clear, therefore, that the electron loses all the energy which it gained from the photon before it reaches the surface. However, this does not mean the electrons which are activated by the photons are deactivated into valence band before they reach the electrode surface. Thus, - and herewith one sees the main difference between the semiconductor and the metal -, the electron does not easily make the jump over the energy gap down towards the valence band once more because the energy gap is several electron volts in order of magnitude, so that the energy change needed is too great for the electrons to make the jump. Therefore, the energy of electrons arriving at the surface is expected not to depend upon the photon energy and is almost the same energy at the bottom of the conduction band as at the surface.

\subsubsection{First Order Approximation}

For a first order approximation, let it be supposed that all excited electrons arriving at the surface have energy $E_{c, 0}$ (the energy of the bottom of the conduction band at the surface).

In this case, the photocurrent, $i_{p}$, is given by:

$$
i_{p}=e_{o} \frac{C_{A}}{C_{T}} N(h \nu, V) \exp \left(-\frac{\pi^{2} \ell}{h} \sqrt{2 m U_{\max }}\right) \exp (-\beta \Delta H(e) / k T)
$$

where $N(h \nu, V)$ is the number of electrons arriving at the surface per unit time and is given by

$$
N(h \nu, V)=\int_{0}^{\infty} N_{e}(E) d E
$$


where $N_{e}(E)$ is given by Eq. (3.17).

Or, $N(h \nu, v)$ could be calculated more simply as follows.

The number of electrons excited between $x$ and $x+d x, N_{e}(x) d x$, is equal to the number of photons absorbed between $x$ and $x+d x$, $\mathrm{N}_{\mathrm{ph}}(\mathrm{x}) \mathrm{dx}$. From Eq. (3.4), $\mathrm{N}_{\mathrm{e}}(\mathrm{x}) \mathrm{dx}$ is given by:

$$
N_{e}(x) d x=N_{p h}(x) d x=I_{0}(1-R) \alpha_{p h} e^{-\alpha} p h{ }^{x} d x
$$

The number of photo-excited electrons, originally expressed for $x=x$ in Eq. (6.6), decreases to $N_{e, x=x-d x}(x) d x$ given by Eq. (6.7), after travelling $\mathrm{dx}$.

$$
N_{e, x=x-d x}(x) d x=N_{e}(x) e^{-\frac{1}{L(x)} d x} d x
$$

where $L(x)$ is given by Eq. (3.11).

Similarly,

$$
\begin{aligned}
N_{e, x=x-2 d x}(x) d x= & N_{e, x=x-d x}(x) e^{-\frac{1}{L(x-d x)} d x} d x \\
& =N_{e}(x) e^{-\left(\frac{1}{L(x)}+\frac{1}{L(x-d x)}\right) d x} d x \\
N_{e, x=x-3 d x}(x) d x & =N_{e, x=x-2 d x}(x) e^{-\frac{1}{L(x-2 d x)} d x} d x \\
& =N_{e}(x) e^{-\left(\frac{1}{L(x)}+\frac{1}{L(x-d x)}+\frac{1}{L(x-2 d x)}\right) d x} d x
\end{aligned}
$$

and so on.

After $N$ steps $(N=x / d x)$,

$$
\begin{aligned}
N_{e, x=0}(x) d x & =N_{e, x=d x} e^{-\frac{1}{L(d x)} d x} d x \\
& =N_{e}(x) e^{-\left(\frac{1}{L(x)}+\frac{1}{L(x-d x)}+\cdots+\frac{1}{L(d x)}\right) d x} d x
\end{aligned}
$$


201.

$N_{e, x=0}(x) d x$ gives the number of electrons arriving at the surface per unit area per unit time which were excited between $\mathrm{x}$ and $\mathrm{x}+\mathrm{dx}$.

Therefore, the total number of electrons arriving at the surface per unit area per unit time, $N(h \nu, V)$ is given by:

$$
N(h v, V)=\int_{0}^{\infty} N e, x=0(x) d x
$$

Since $\Delta H(e)=1.5 \mathrm{eV}$ for $\mathrm{GaP}$ (see section 6.4.3), $\exp \{-\beta(\Delta H(e) / \mathrm{kT}\}=$ $10^{-13}$ and, therefore, almost no photocurrent is expected for the whole potential range.

The mechanism therefore needs further modification.

\subsubsection{Alternative Mechanism}

To solve this discrepancy, another alternation of the theory is required. In the theory given in chapter three, the potential drop in the electric double layer was ignored. However, when the carrier density of the semiconductor is high, or the density of the surface states (or surface charged groups), is high, which may be so in the case of most semiconductor electrodes, the potential drop in the electric double layer cannot be ignored $[27,28]$.

For an extreme example, let it be supposed that all the potential drop occurs in the electric double layer. No surface state or charged group is assumed, i.e. no potential drop in the electric double layer at the flat band potential.

In this case, Eq. (6.2) becomes,

$$
i_{p}=e \frac{C_{o}}{A_{T}} N(h \nu) \exp \left\{-\frac{\pi^{2} \ell}{h} \sqrt{2 m\left(U_{\max }+e_{o} V\right)}\right\} \exp \left\{-\beta\left(\Delta H(e)+e_{o} V\right) / k T\right\}
$$

where $V$ is the electrode potential with respect to the flat band 
potential and with the present assumption, the absolute potential*, $N(h \nu)$ is not a function of potential because there is no potential drop in the semiconductor.

Since no potential drop in the semiconductor is assumed, $L(x)$, is not a function of $x$ and always equal to $l_{D}(=\sqrt{D \tau})$, the diffusion length (see Eq. (3.12)).

Therefore, $N_{e, x=0}(x) d x$ is given by:

$$
N_{e, x=0}(x) d x=N_{e}(x) e^{-\frac{1}{2} x} d x
$$

i.e., from Eq. (6.4),

$$
=I_{0}(1-R) \alpha_{p h} e^{-\left(\alpha_{p h}+\frac{1}{l_{D}}\right) x} d x
$$

Hence, $N(h \nu)$ is given by:

$$
\begin{aligned}
N(h \nu) & =\int_{0}^{\infty} N_{e, x=0}(x) d x \\
& =I_{0}(1-R) \alpha_{p h} \int_{0}^{\infty} e^{-\left(\alpha_{p h}+\frac{1}{\ell_{D}}\right) x} d x \\
& =I_{0}(1-R) \frac{\alpha_{p h}}{\alpha_{p h}+\frac{1}{l_{D}}}
\end{aligned}
$$

* The values of the dipole potential drop, $\Delta x$, is neglected and this is justified on the basis of calculation for metals where it is low (e.g. $0.01 \mathrm{~V})$. The value of the electron contribution to $\Delta x$ has been neglected and will be considered in section 6.4.7. 


$$
=I_{0}(1-R) \frac{1}{1+1 /\left(\alpha_{p h} \sqrt{D \tau}\right)}
$$

The quantum efficiencies have been calculated by using Eq. (6.12) and Eq. (6.14). The parameters used in the calculation are the same as those in section 6.4.2. The calculated results are shown in Fig. 6.3 and compared with the experimental results.

Although the discrepancies which existed between the experimental results and the calculated results in Fig. 6.1, i.e., the photon energy dependence of the critical potential and the slow increment of the quantum efficiency with potential, do not exist in the calculated results in Fig. 6.3, the calculated quantum efficiencies are several times lower than the experimental ones and the quantum efficiency-potential relations appear at more negative potential than estimated by the calculation. The experimentally observed high quantum efficiencies (order of several tens of percent) suggest the very high tunneling probability and, therefore, the shape of barrier suggested in chapter three must be reconsidered.

The discrepancy in respect to the position of quantum efficiencypotential relations may be due to neglect of the potential drop in the electric double layer at the flat band potential.

* Because of no potential drop in the semiconductor, a refinement of $l$ with direction ought to be made similar to that applied in Eq. (2.14) in chapter two. However it is probably not worth introducing this degree of refinement here and it will be kept to remember that the values obtained by using Eq. (6.14) are maximum. 
204.

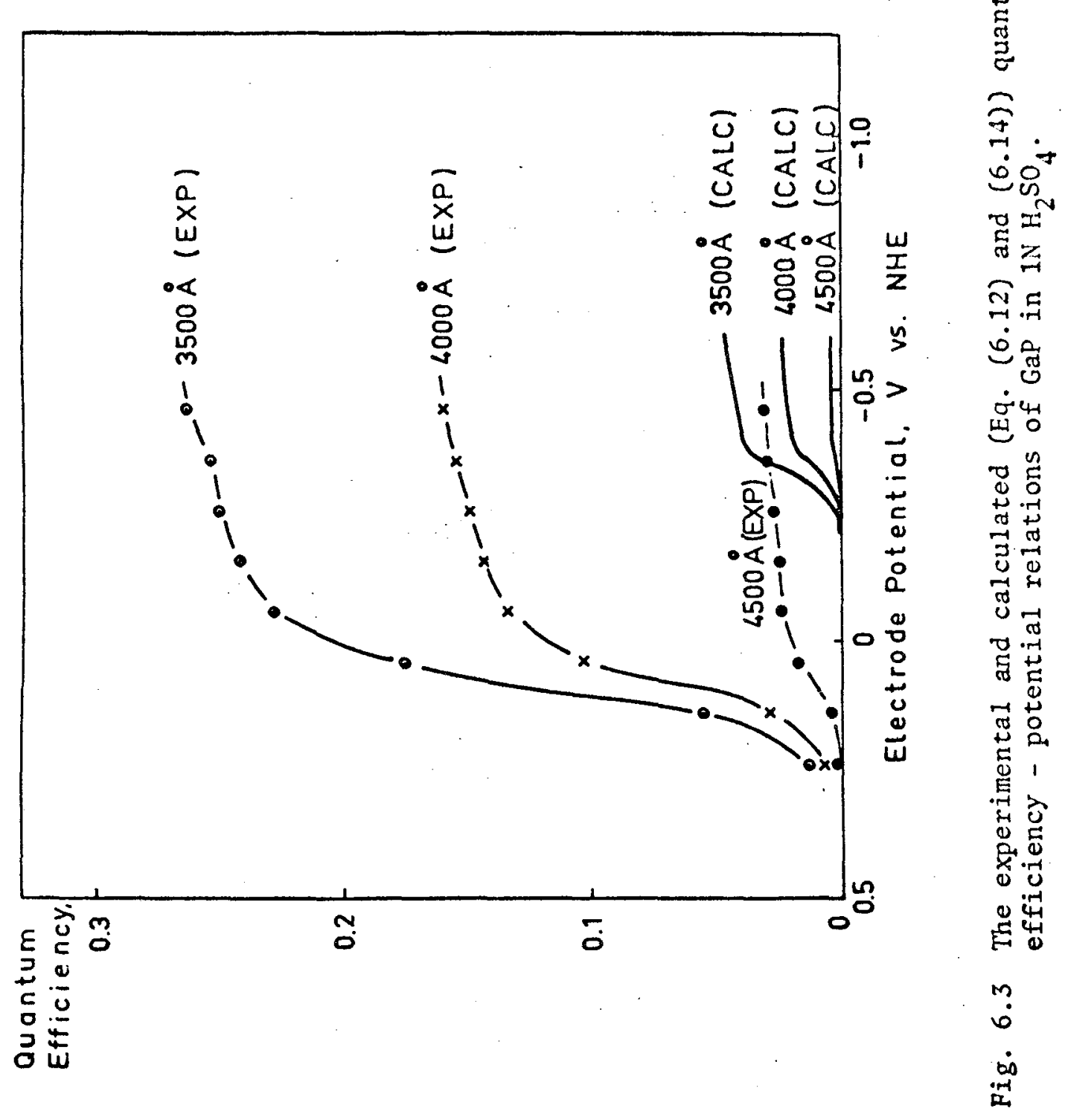


205.

\subsubsection{Modification of the Potential Barrier}

\subsubsection{Effect of proton transfer}

In chapter three, the electrons were considered to transfer from the electrode to the $\mathrm{H}_{3} \mathrm{O}^{+}$ion at the OHP. However, according to Bockris and Matthews [29], proton transfer from the $\mathrm{H}_{3} \mathrm{O}^{+}$ion at OHP (1 in Fig. 6.4) to the hydrogen-bonded water molecule ( 2 in Fig. 6.4) prior to the electron transfer brings the proton to its reaction position $\left(\delta_{r}\right.$ from the electrode surface).

Therefore, the first two terms of the Eq. (3.17) must be changed from

$$
-\frac{e_{o}^{2}}{(d-x)^{2} \varepsilon_{o p}}+\frac{e_{o}^{2}}{(d+x)^{2} \varepsilon_{o p}} \frac{\varepsilon-\varepsilon_{o p}}{\varepsilon+\varepsilon_{o p}}
$$

to

$$
-\frac{\mathrm{e}_{o}^{2}}{\left(\delta_{\mathrm{r}}-\mathrm{d}_{0-\mathrm{H}^{-x}}\right)^{2} \varepsilon_{o p}}+\frac{\mathrm{e}_{\mathrm{o}}^{2}}{\left(\delta_{\mathrm{r}}-\mathrm{d}_{0-\mathrm{H}}+\mathrm{x}\right)^{2} \varepsilon_{\mathrm{op}}} \frac{\varepsilon-\varepsilon_{\mathrm{op}}}{\varepsilon+\varepsilon_{\mathrm{op}}}
$$

where $d_{0-H}$ is the distance between hydrogen and oxygen atom in water.

\subsubsection{Effect of dielectric constant}

The image charge of the ion in the semiconductor, $q^{\prime}$, was considered in chapter three as:

$$
q^{\prime}=q \frac{\varepsilon_{o p}-\varepsilon}{\varepsilon_{o p}+\varepsilon}
$$

However, since the image formation is a static process, the static dielectric constant of water in the electric double layer must be used instead of the optical dielectric constant.

Therefore,

$$
q^{\prime}=q \frac{\varepsilon_{s t}-\varepsilon}{\varepsilon_{s t}+\varepsilon}
$$


206.

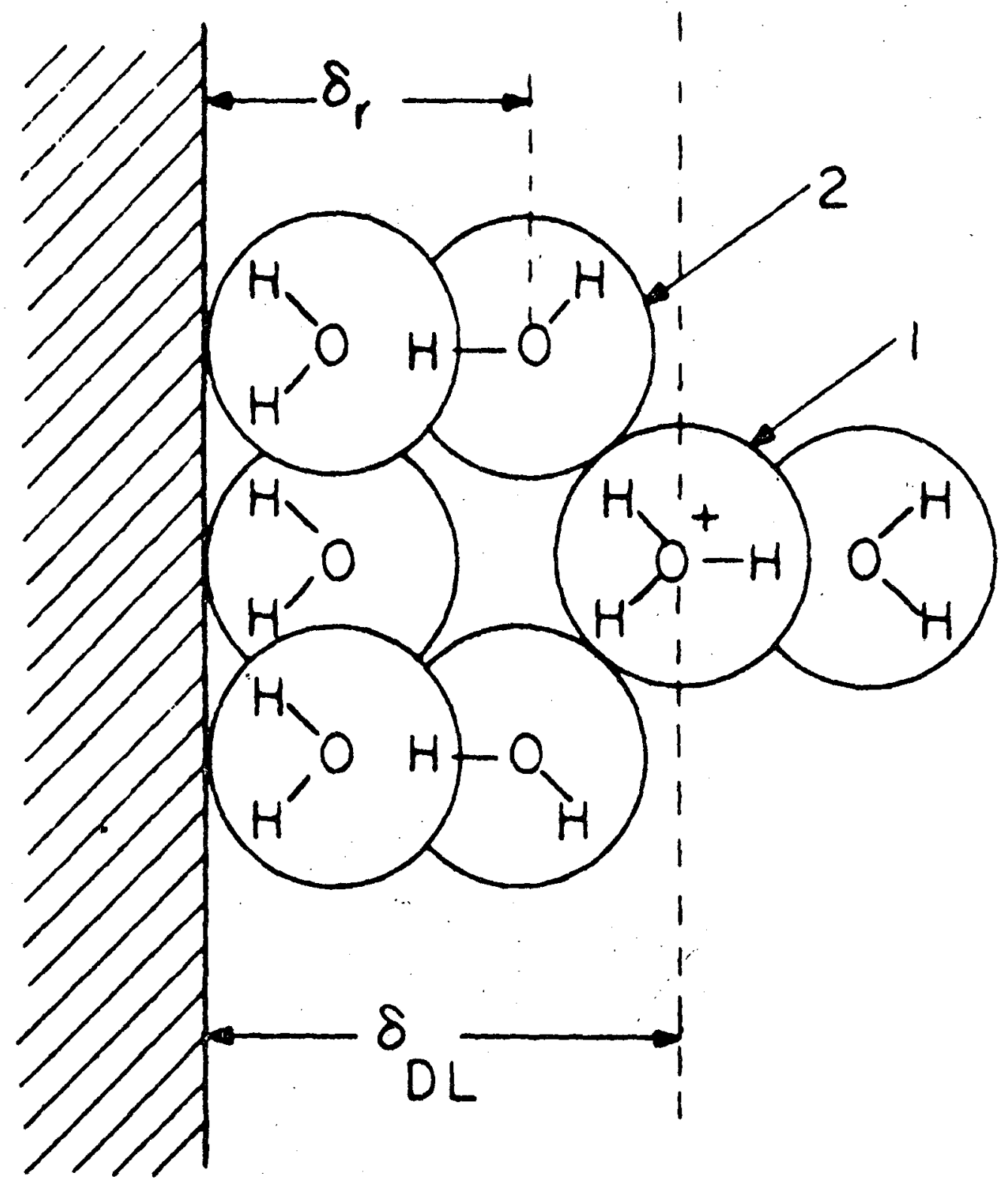

Electrode

Outer Helmholtz plone

Pig. 6.4 Model of the electrode-solution double Iayer [29] . 


\subsubsection{Direction of the Coulomb force}

In the calculation of the Coulomb force in chapter three, the direction of force was not considered. Since the electron transfering along an $x$ coordinated only is considered, only the $\mathrm{x}$ component of Coulomb force must be summed.

\subsubsection{Image interaction and dielectric constant of water}

In chapter three, the interaction energy between an emitted electron and its image in semiconductor was ignored, following the treatment of Khan [30]. Also, the optical dielectric constant was used for the dielectric constant of water. The reason of neglect of image interaction, suggested by Khan, was that the emitted electrons travel across the barrier too quickly to make an image in the semiconductor. The optical dielectric constant was used for the same reason.

However, there was some misunderstanding in these considerations. When one wants to construct a potential barrier, one should consider an ideal test charge, i.e., a ("classical") electron moving slowly enough to make its image in the semiconductor. Thus, the interaction energy between the emitted electron and its image should be taken into account with the static dielectric constant of water $(=6$ in the electric double layer [31]).

The importance of the image interaction in barrier construction was stressed by Penn et al. for field emission [32] and by A. Rothwarf for the flow of electron from the semiconductor to the metal [ 33].

The image interaction, $\mathrm{U}_{\mathrm{im}}(\mathrm{x})$, is given by:

$$
\mathrm{U}_{\mathrm{im}}(\mathrm{x})=\frac{\mathrm{e}_{\mathrm{o}}^{2}}{4 \mathrm{x} \varepsilon_{\mathrm{st}}} \frac{\varepsilon_{\mathrm{st}}{ }^{-\varepsilon}}{\varepsilon_{\mathrm{st}}{ }^{+\varepsilon}}
$$




\subsubsection{Field Effect}

Since no potential drop in the electric double layer was assumed in the theory given in chapter three, there was no need of considering the field effect on the potential barrier. However, if there is some potential drop in the electric double layer, the field effect on the potential barrier should be considered.

The field, $x$, is given by:

$$
X=S \cdot C_{\Delta} S_{\phi} / 6.5 \times 10^{-8} \quad(V / c m)
$$

where ${ }^{S . C_{\Delta} S_{\phi}}$ is the potential drop in the electric double layer. $6.5 \AA$ is taken as the double layer thickness [34] .

\subsubsection{Modified barrier construction}

By taking into account all the factors mentioned above, the potential energy for the electron transfer, $U(x)$, is given by: $U(x)=U_{i m}(x)+\int_{0}^{x} F(x) d x+F X x$ $=\frac{e_{o}^{2}}{4 x \varepsilon_{s t}} \frac{\varepsilon_{s t}-\varepsilon}{\varepsilon_{s t}+\varepsilon}$

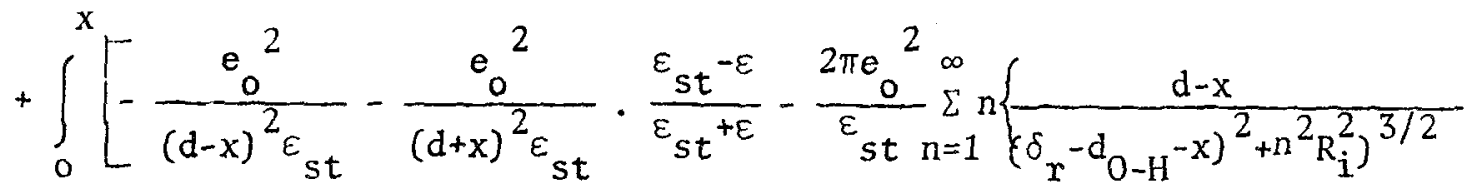
$\left.+\frac{d-x}{\left.\left(\delta_{r}-d_{0-H}+x\right)^{2}+n^{2} R_{i}{ }^{2}\right)^{3 / 2}} \frac{\varepsilon_{s t}-\varepsilon}{\varepsilon_{s t}+\varepsilon}\right\} d x+F X x$

$U(x)$ is shown in Fig. 6.5 as a function of distance from the electrode surface, $x . \quad \delta_{r}-d_{0-H}=2.7 \AA$ was used for the calculation [29] . 


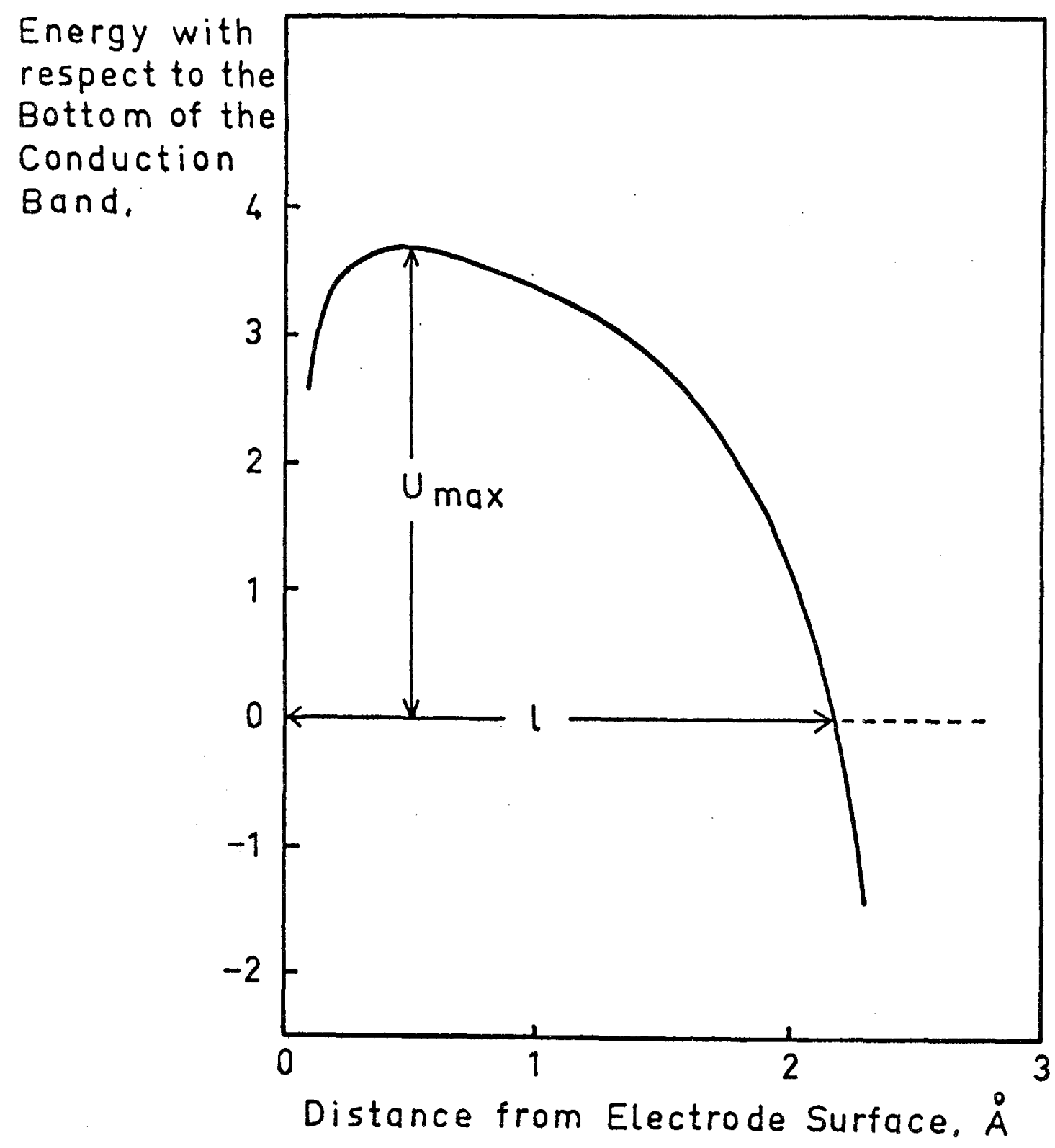

Fig. 6.5 The schematic diagram of the potential energy barrier for electron transfer from GaP electrode to an acceptor at the flat band potential. 
210.

6.4.7 Effect of a Potential Drop in the Electric Double Layer at the Flat Band Potential on the Quantum EfficiencyPotential Relation (Theory)

6.4.7.1 Estimation of the potential drop in the electric double layer at the flat band potential

The flat band potential, $V_{f b p}$, with respect to the NHE is given by:

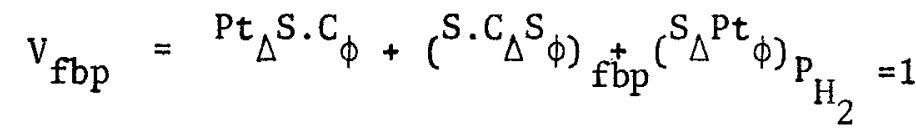

$$
\begin{aligned}
& \mathrm{C}_{\mathrm{H}^{+}}{ }^{+}=1
\end{aligned}
$$

where ${ }^{\mathrm{Pt}} \triangle \mathrm{S}_{\phi}$ is the potential difference between the semiconductor and Pt wire, $\left({ }^{S . C}{ }_{\Delta}{ }^{S}\right)_{f b p}$ is the potential drop in the electric double layer of the semiconductor at the flat band potential and $\left({ }^{\mathrm{S}} \Delta{ }^{\mathrm{Pt}} \phi\right)_{\mathrm{P}_{\mathrm{H}_{2}}}=1$ is the potential drop in the electric double layer of $\mathrm{Pt}$ electrode in the presence of 1 atmosphere of hydrogen gas and with $\mathrm{C}_{\mathrm{H}}{ }^{+}=1$.

Since,

$$
\overrightarrow{\mu_{e} t}=\overrightarrow{\mu_{e}^{S} \cdot C}
$$

where $\vec{\mu}_{e}^{P t}$ and $\vec{\mu}_{e}^{S . C}$ are the electrochemical potential of $\mathrm{Pt}$ and the semiconductor, respectively

$$
{ }^{\mathrm{Pt}}{ }_{\Delta} \mathrm{S} \cdot \mathrm{C}_{\phi}=\left(\mu_{\mathrm{e}}^{\mathrm{Pt}}-\mu_{\mathrm{e}}^{\mathrm{S} \cdot \mathrm{C}}\right) / \mathrm{F}
$$

where $\mu_{e}^{\text {Pt }}$ and $\mu_{e}^{\text {S.C }}$ are the chemical potential of Pt and the semiconductor, respectively.

Therefore,

$$
V_{f b p}=\left\{\left({ }^{S \cdot C} \Delta_{\phi)_{f b p}}-\mu_{e}^{S \cdot C} / F\right\}-\left[\left({ }^{\mathrm{Pt}} \Delta^{S} \phi\right)_{\mathrm{P}_{\mathrm{H}_{2}}}=1-\mu_{\mathrm{e}}^{\mathrm{Pt} / \mathrm{F}}\right]\right.
$$


211.

Thus, the potential drop in the electric double layer of the semiconductor at the flat band potential is given by:

$$
\begin{aligned}
& \left({ }^{S \cdot C} \Delta_{\phi b p}=v_{f b p}+\left[\left({ }^{P t} \Delta^{S}\right)_{P_{H_{2}}}=1-\mu_{e}^{P t} / F\right]+\mu_{e}^{S . C} / F\right. \\
& \mathrm{C}_{\mathrm{H}}{ }^{+=1} \\
& =V_{f b p}+\left[\left({ }^{\mathrm{Pt}} \Delta^{\mathrm{S}} \phi\right)_{\mathrm{P}_{\mathrm{H}_{2}}}=1-\mu_{\mathrm{e}}^{\mathrm{Pt}} / \mathrm{F}\right]-\left(\Phi / \mathrm{F}-\chi^{\mathrm{S} \cdot \mathrm{C}}\right) \\
& \mathrm{C}_{\mathrm{H}}{ }^{+=1}
\end{aligned}
$$

where $\Phi$ is the work function of the semiconductor and $\chi^{S . C}$ is the surface potential of the semiconductor. $\quad\left[\left({ }^{\mathrm{Pt}} \Delta^{\mathrm{S}} \phi\right)_{\mathrm{P}_{\mathrm{H}}}=1-\mu_{\mathrm{e}}^{\mathrm{Pt}} / \mathrm{F}\right]$ was calculated by Trasatti [35] using the $\quad \mathrm{C}_{\mathrm{H}}^{+=1}$ method of Bockris and Argade [36] as 4.3V.

Therefore,

$$
\left({ }^{S \cdot C} S_{\phi}\right)_{f b p}=4.3 / F+V_{f b p}-\left(\Phi / F-\chi^{S \cdot C}\right)
$$

The schematic diagram of the energy levels of a semiconductor which has surface states in a vacuum is shown in Fig. 6.6. From this figure, $x^{\text {S.C }}$ is given by:

$$
\mathrm{FX}^{\mathrm{S} \cdot \mathrm{C}}=\Phi+\delta-\mathrm{E}_{\mathrm{a}}-\mathrm{E}_{\mathrm{g}}
$$

where $\delta$ is the energy difference between the Fermi level and the top of the valence band in the bulk.

Hence, Eq. (6.24) becomes

$$
\left({ }^{S} \cdot C_{\Delta} S_{\phi}\right)_{f b p}=4 \cdot 3 / F+V_{f b p}-\left(E_{a}+E_{g}-\delta\right) / F
$$

For a first order approximation, $\delta$ is assumed to be zero for all p-type semiconductors concerned. (Since the carrier density of the semicon- 
212.

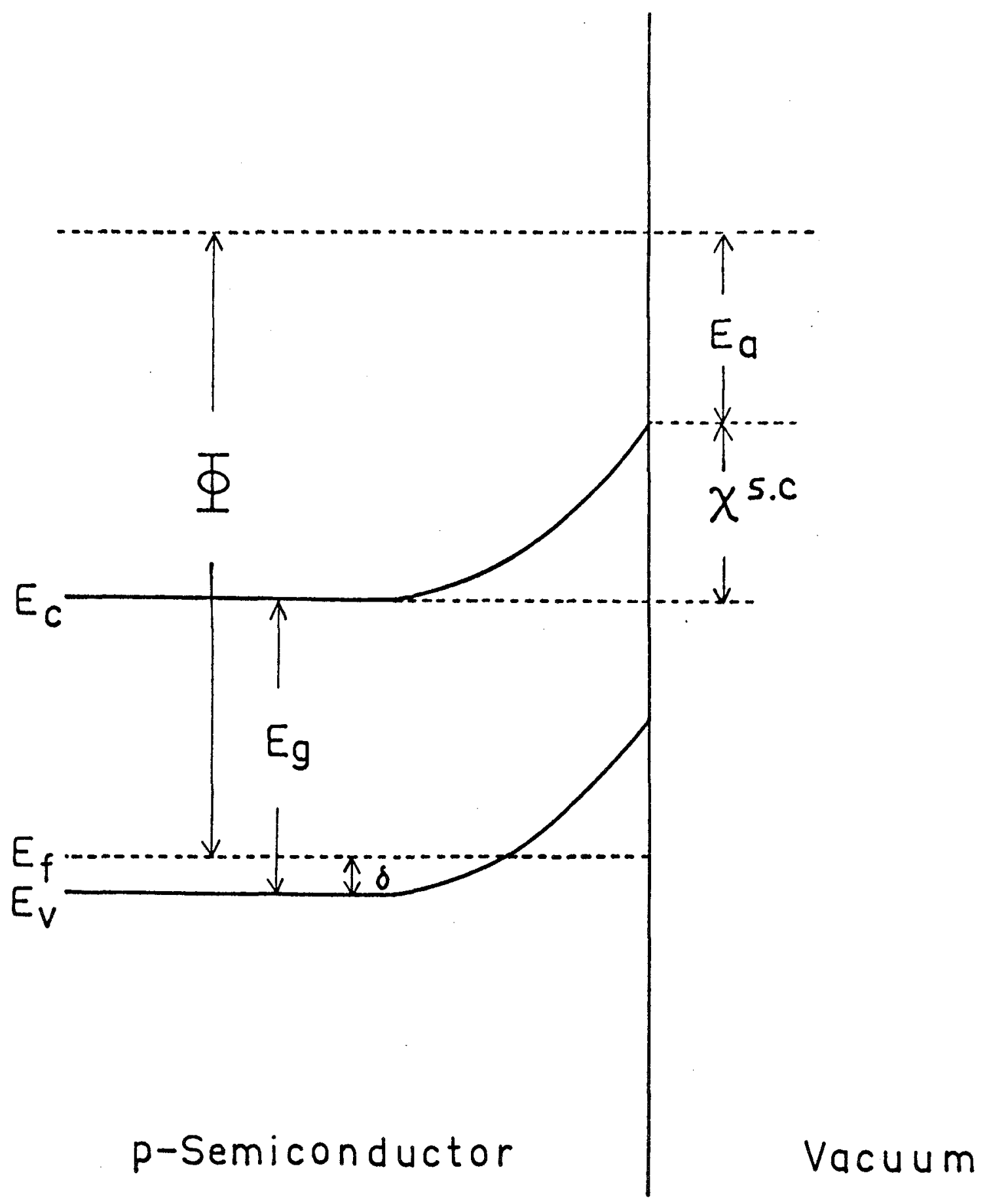

Pig, 6.6 The schematic diagram of the energy levels of a semiconductor which has surface states in vacuum. 
ductors are very high, i.e., $10^{18} \sim 10^{19} \mathrm{~cm}^{-3}$, except for CdTe, this assumption may be reasonable).

In Table 6.1, the values of $\left({ }^{S . C} \Delta_{\phi}\right)_{\text {fbp }}$ calculated from Eq. (6.26) are listed for various semiconductors. The values of $\mathrm{E}_{\mathrm{a}}$ and $E_{g}$ in Table 4.1 were used.

$\left({ }^{S . C} S_{\Delta} \mathscr{Q}_{f b p}\right.$ is negative in all cases and ${ }^{S} \cdot C_{\Delta} S_{\phi}$ in $\mathrm{NaOH}$ is more negative than that in $\mathrm{H}_{2} \mathrm{SO}_{4}$ in most cases with the exception of cdTe.

TABLE 6.1 THE VALUES OF THE FLAT BAND POTENTIAL AND THE POTENTIAL DROP IN THE ELECTRIC DOUBLE LAYER AT THE FLAT BAND POTENTIAL

\begin{tabular}{|c|c|c|c|c|}
\hline \multirow{2}{*}{ Semiconductor } & \multicolumn{2}{|c|}{ In $1 \mathrm{~N} \mathrm{NaOH}$} & \multicolumn{2}{c|}{ In $1 \mathrm{~N}_{2} \mathrm{SO}_{4}$} \\
\cline { 2 - 5 } & $\mathrm{FBP}, \mathrm{V}(\mathrm{NHE})$ & $\mathrm{S} . \mathrm{C}_{\Delta} \mathrm{S}_{\phi} \mathrm{V}$ & $\mathrm{FBP}, \mathrm{V}(\mathrm{NHE})$ & $\mathrm{S}_{\Delta} \mathrm{C}_{\phi} \mathrm{V}$ \\
\hline $\mathrm{ZnTe}$ & -0.79 & -2.25 & 0.04 & -1.42 \\
\hline $\mathrm{CdTe}$ & 0.21 & -1.27 & -0.35 & -1.83 \\
\hline $\mathrm{GaAs}$ & -0.04 & -1.20 & 0.43 & -0.77 \\
\hline $\mathrm{InP}$ & -0.07 & -1.42 & - & - \\
\hline $\mathrm{GaP}$ & 0.18 & -2.07 & 1.13 & -1.12 \\
\hline
\end{tabular}

6.4.7.2 The energy 1 evel of an electron in the ground state of The energy level of an electron in the $\mathrm{H}_{3} \mathrm{O}^{+}$, when the protonsolvent system is in its ground state, with respect to the bottom of the conduction band at the flat band potential, $\Delta H(e)$, was calculated 
in chapter three by assuming the no potential drop in the electric double layer and given by:

$$
\Delta H(e)=-L_{0}+E_{a}-J+A+R
$$

When the potential difference $\left({ }^{S \cdot C_{\Delta} S_{\phi}}\right.$ fbp , exists between these two levels, the energy difference, $\Delta H(e)$, becomes

$$
\Delta H(e)=-L_{o}+E_{a}-J+A+R+\left({ }^{S \cdot C_{\Delta} S_{\phi}} f b p\right.
$$

In the case of p-type $\mathrm{GaP}$ in $1 \mathrm{~N} \mathrm{H}_{2} \mathrm{SO}_{4}, \Delta \mathrm{H}(\mathrm{e})$ is $1.5 \mathrm{eV}$ when the potential drop in the electric double layer at the flat band potential is ignored (see section 6.4.3) and it becomes $0.38 \mathrm{eV}$ if the potential drop is taken into account.

\subsubsection{Calculation of Quantum Efficiency with New Barrier and New Energy Level}

The quantum efficiency has been calculated by using Eq. (6.12) with new values of the barrier maximum given in section 6.4.6 and of $\Delta H(e)$ given in 6.4.7. The calculated results are shown in Fig. 6.7. The shape of the calculated curves are essentially the same as those of experiments, although the calculated values of the quantum efficiencies are relatively low compared with experimental ones $(20 \sim 30 \%)$. Also the quantum efficiency dependence on the photon energies are very similar in both cases.

However, the position of the calculated curves are more positive than those of experimental ones by about $650 \mathrm{mV}$.

This discrepancy is analysed as follows.

\subsubsection{Potential Distribution}

First it was assumed in chapter three that the whole potential drop occurred in the space charge region of the semiconductor. Then, 


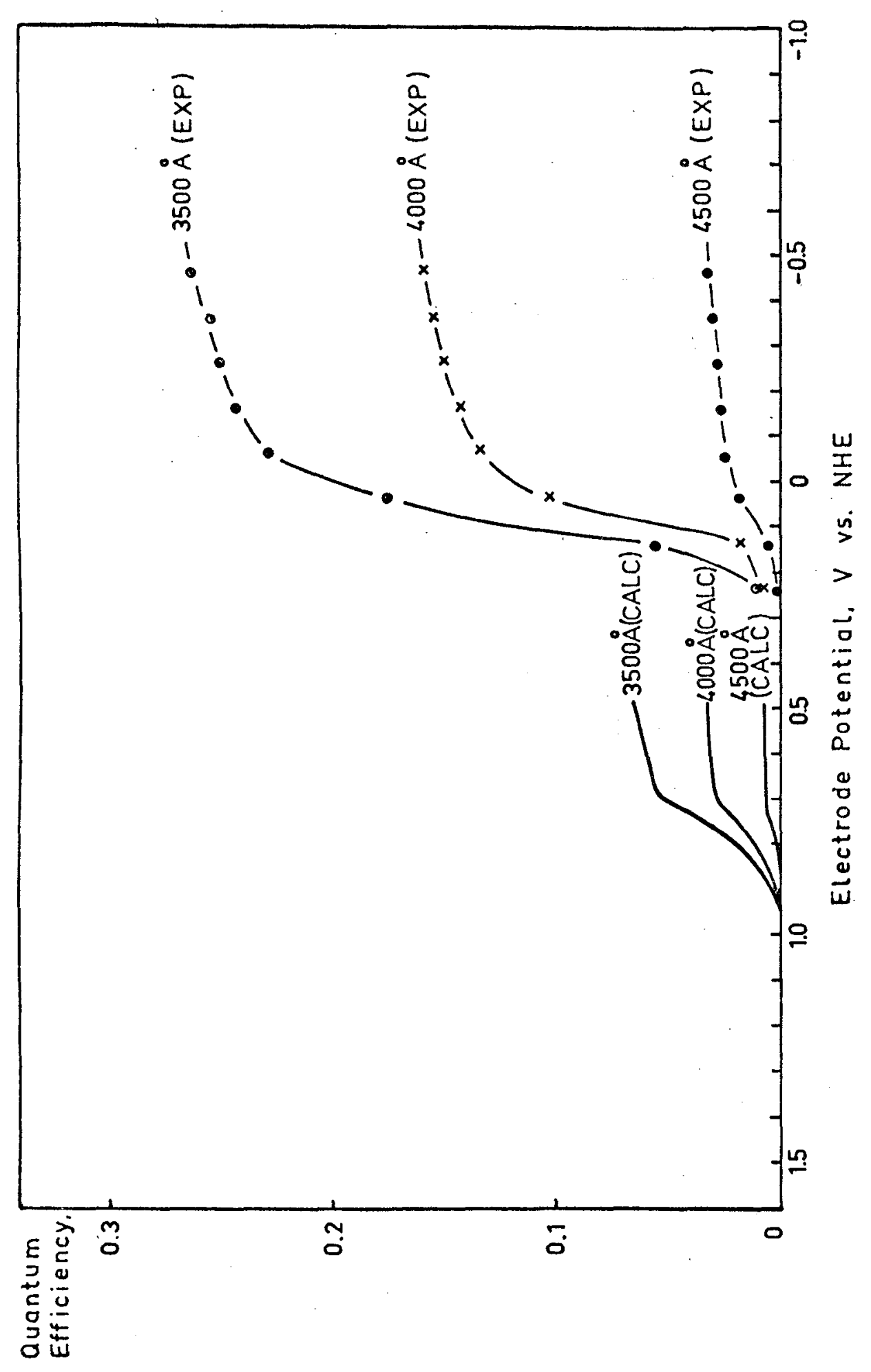

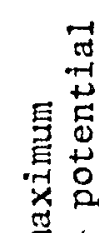

얼

$\rightarrow$

สิ

4 थ

\& 5

3

$3 \frac{\pi}{3}$

言下

㝴宁

赵

จ.

공

西

这仓

㕂

$\alpha$

㟧出

Эై ్ㅜㅇ

开

80

苟需

공 동 옹

茪4

崖告

兵电

․ㅜㄷㅏ

\&

$0 \geq$

E总总

ڤ.

in 
216.

in section 6.4.5, another assumption that all the potential drop occurred in the electric double layer was made. However, in real situation, the potential drop occurred both in the space charge layer of the semiconductor and in the electric double layer.

If one knows the carrier density of the semiconductor concerned, one can calculate the slope of the Mott-Schottky plot and estimate the potential distribution by comparing it with the slope of the plot in the solution $[37,38]$ as follows.

The Mott-Schottky relation is given by:

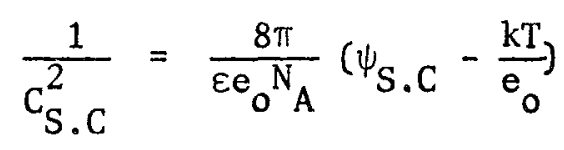

where $\mathrm{C}_{\mathrm{S} . \mathrm{C}}$ is the space charge capacity, $\mathrm{N}_{\mathrm{A}}$ is the concentration of ionized acceptors and $\psi_{S . C}$ is the potential drop in the space chargc layer.

The appropriate relation in the case of measurements in solution is given by:

$$
\frac{1}{c^{2}}=\frac{8 \pi}{\varepsilon e_{0} N_{A}}\left(V-V_{f b p}-\frac{k T}{e_{0}}\right)
$$

where $C$ is the total capacity of the electrode and $V$ and $V_{f b p}$ are the electrode potential and the flat band potential with respect to a reference electrode, respectively.

Since,

$$
\mathrm{V}-\mathrm{V}_{\mathrm{fbp}}=\psi_{\mathrm{S} . \mathrm{C}}+\Delta \Delta \phi_{\mathrm{H}}
$$

where

$$
\Delta \Delta \phi_{H}=\left({ }^{S \cdot C} \Delta_{\phi}\right)_{V}-\left({ }^{S \cdot C} \Delta^{S}\right)_{f b p}
$$

Eq. (6.29) becomes 


$$
\frac{1}{\mathrm{C}^{2}}=\frac{8 \pi}{\varepsilon \mathrm{e}_{\mathrm{O}} \mathrm{N}_{\mathrm{A}}}\left(\psi_{\mathrm{S} . \mathrm{C}}+\Delta \Delta \phi_{\mathrm{H}}-\frac{\mathrm{kT}}{\mathrm{e}_{\mathrm{o}}}\right)
$$

On1y when $\Delta \Delta \phi_{\mathrm{H}}=0$ or $\Delta \Delta \phi_{\mathrm{H}}=\mathrm{c} \psi_{\mathrm{S}} . \mathrm{C}$, where $\mathrm{c}$ is a proportional constant, the plot between $\left(1 / C^{2}\right)$ and $V$ becomes linear $[37,38]$.

If $\Delta \Delta \phi_{\mathrm{H}}=0$, Eq. (6.32) becomes Eq. (6.28) (the Mott-Schottky relation) and, therefore, the slope of the experimental plot (Eq. (6.29)) must be the same as that of the theoretical plot.

In the case of $\Delta \Delta \phi_{H}=c \psi_{S} . C, E q .(6.32)$ becomes

$$
\frac{1}{c^{2}}=\frac{8 \pi}{\varepsilon e_{0} N_{A}}\left\{\psi_{S . C}(1+c)-\frac{k T}{e_{0}}\right\}
$$

and, from this relation, $c$ can be calculated by comparing the experimental slope with theoretical one. $\left(V-V_{f b p}\right) /(1+c)$ gives the potential drop in the space charge layer in the semiconductor.

De Gryse et al. [39] criticized this approach by showing that the slope of the plot has the same value whether the potential drop occurred in the electric double layer or not. However, in their treatment they assumed an absence of surface charge and this assumption limits the applicability of the interpretation. From the fact that there is a potential drop in the electric double layer at the flat band potential which could not exist if there is no surface states (see section 6.4.7), and the experimental $\mathrm{pH}$ dependence of the flat band potential, which cannot be explained without assuming the existence of surface states (charged surface group), their treatment is not valid, at least, for the semiconductors investigated in this research.

The experimental values of the slope and the theoretical ones are listed in Table 6.2 with the values of $\mathrm{c}$. This comparison was 
possible only for $\mathrm{GaP}, \mathrm{GaAs}$, InP and $\mathrm{SiC}$, the carrier density of which were reported by the suppliers.

TABLE 6.2 THEORETICAL AND EXPERIMENTAL SLOPE OF MOTT-SCHOTTKY PLOT AND THE COEFFICIENT

\begin{tabular}{|c|c|c|c|c|}
\hline Semiconductor & $\begin{array}{c}\text { Carrier Density } \\
\mathrm{cm}^{-3}\end{array}$ & $\begin{array}{l}\text { Theoretical } \\
\text { Slope } \\
\left(\mu \mathrm{F} / \mathrm{cm}^{-2}\right)^{-2} / \mathrm{V}\end{array}$ & $\begin{array}{l}\text { Experimental } \\
\text { Slope } \\
\left(\mu \mathrm{F} / \mathrm{cm}^{-2}\right)^{-2} / \mathrm{V}\end{array}$ & $c$ \\
\hline \multirow{2}{*}{$\mathrm{GaP}$} & \multirow{2}{*}{$6.7 \times 10^{17}$} & \multirow{2}{*}{10.7} & $6.0(\mathrm{NaOH})$ & 0.78 \\
\hline & & & $4.6\left(\mathrm{H}_{2} \mathrm{SO}_{4}\right)$ & 1.32 \\
\hline \multirow{2}{*}{ GaAs } & \multirow{2}{*}{$2.0 \times 10^{19}$} & \multirow{2}{*}{0.35} & $0.115(\mathrm{NaOH})$ & 2.04 \\
\hline & & & $0.22\left(\mathrm{H}_{2} \mathrm{SO}_{4}\right)$ & 0.59 \\
\hline InP & $5.6 \times 10^{18}$ & 1.27 & $0.48(\mathrm{NaOH})$ & 2.65 \\
\hline \multirow{2}{*}{ znTe } & \multirow{2}{*}{ - } & \multirow{2}{*}{-} & $28(\mathrm{NaOH})$ & - \\
\hline & & & $150\left(\mathrm{H}_{2} \mathrm{SO}_{4}\right)$ & - \\
\hline \multirow{2}{*}{ CdTe } & \multirow{2}{*}{ - } & \multirow{2}{*}{ - } & $6000(\mathrm{NaOH})$ & - \\
\hline & & & $2200\left(\mathrm{H}_{2} \mathrm{SO}_{4}\right)$ & - \\
\hline \multirow{2}{*}{ SiC } & \multirow{2}{*}{$4 \times 10^{18}$} & \multirow{2}{*}{1.75} & $0.86(\mathrm{NaOH})$ & 2.0 \\
\hline & & & $0.7 \quad\left(\mathrm{H}_{2} \mathrm{SO}_{4}\right)$ & 2.5 \\
\hline
\end{tabular}

\subsubsection{Modified Quantum Efficiency-Potential Relation}

When the potential drop occurs both in the space charge layer in the semiconductor and in the electric double layer (Eq. (6.12) must be modified and the photocurrent is given by:

$i_{p}=e_{o} \frac{C_{A_{T}}}{C_{T}}\left(h \nu, \psi_{S . C}\right) \exp \left\{-\frac{\pi^{2} \ell}{h} \sqrt{2 m\left(U_{\max }+e_{o} \Delta \Delta \phi_{H}\right)}\right\} \exp \left\{-\beta\left(\Delta H(e)+e_{o} \Delta \Delta \phi_{H}\right) / k I^{\prime}\right\}$ 
219.

where $N\left(h \nu, \psi_{S . C}\right)$ is given by Eq. (6.11) by replacing $V$ by $\psi_{S . C}$.

For $\mathrm{GaP}, \mathrm{c}$ in Eq. $(6.33)$ is 1.32 from Table 6.2 and the quantum efficiencies were calculated by using this value and Eq. (6.34). The calculated results are shown in Fig. 6.8 with the values of the experiment.

The calculated and experimental results agree fairly in respect to the position and shape of the quantum efficiency-potential relation. However, discrepancies exist as follows:

1. Theoretically estimated quantum efficiencies are only $20 \sim 30 \%$ of the experimental quantum efficiencies.

2. The position of theoretical quantum efficiency-potential relations appear about $0.25 \mathrm{~V}$ more positive than those of experiment. These discrepancies may be due to errors involved in the estimation of energy levels of electrons in $\mathrm{H}_{3} \mathrm{O}^{+}, \Delta \mathrm{H}(\mathrm{e})$, at the flat band potential and the dimension of barrier $\left(U_{\max }\right.$ and $\left.\ell\right)$.

In respect to the determination of $\Delta H(e), \delta$ was assumed as zero (see section 6.4.7). However, $\delta$ depends on the carrier density and has the order of $0.01 \sim 0.2 \mathrm{eV}$. Correspondingly, theoretical quantum efficiency-potential relation shifts towards more negative potentials by $0.01 \sim 0.2 \mathrm{~V}$ depending on the carrier density.

In respect to the determination of the barrier dimension, the electron was assumed to transfer to second layer of water to which a proton transfers prior to the electron transfer [29]. However, it may be possible that proton transfers to water attached to the electrode surface and electron transfers to it. In this case, the barrier thickness becomes very small and, therefore, higher quantum efficiency than that calculated with the present model is expected. In this respect, a more detailed study is required. 


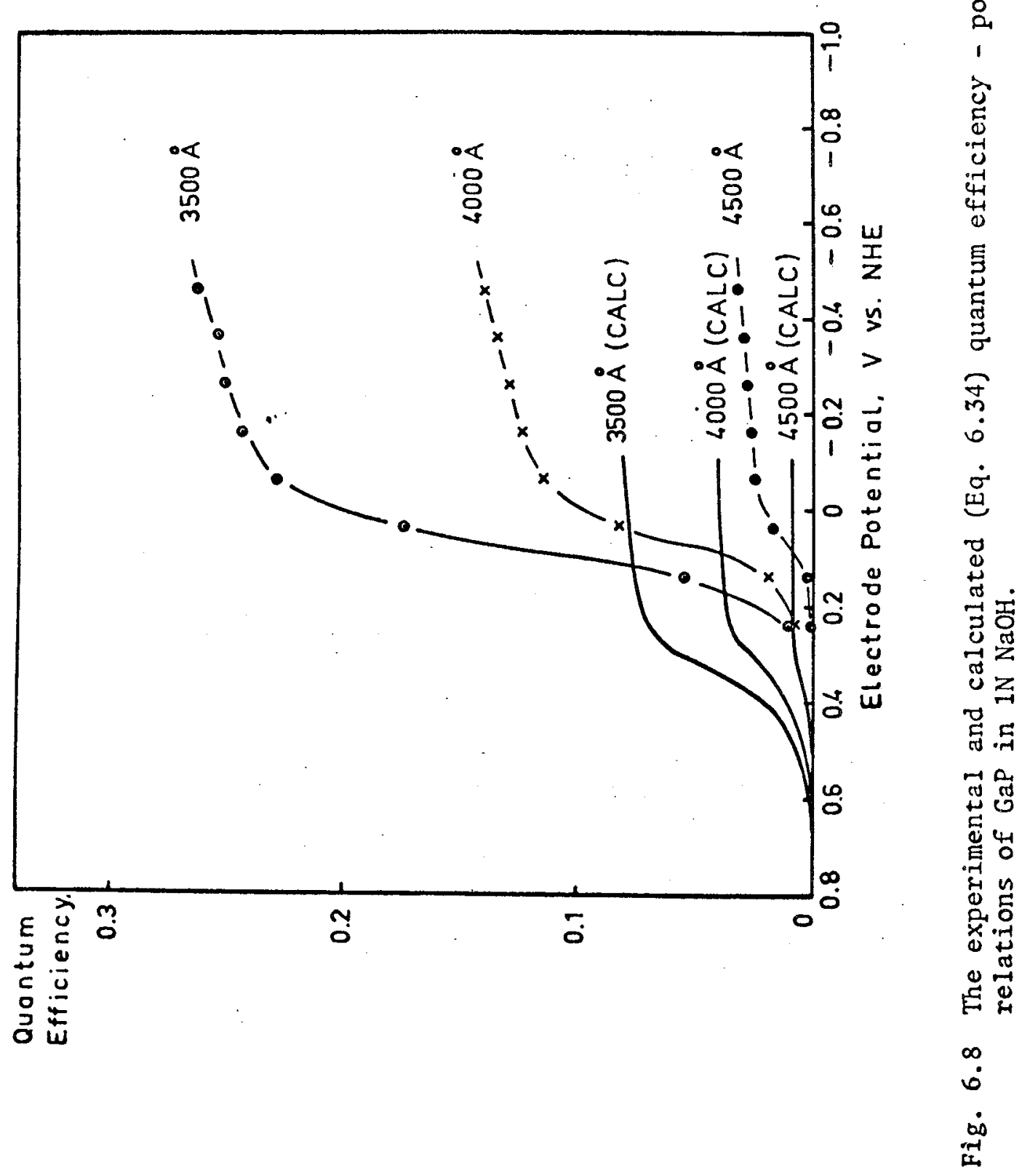


6.5 THE RELATION BETWEEN THE CRITICAL POTENTIAL IN THE PHOTOELECTROCHEMICAL GENERATION OF HYDROGEN AND THE PROPERTIES OF THE SEMICONDUCTOR

The critical potential at which the photocurrent due to hydrogen evolution is first observed has a very important meaning from the practical point of view.

There is a difficulty of definition because the critical potential depends upon the sensitivity of detection of the photocurrent.

The square root of the quantum efficiencies are plotted against electrode potential in Fig. 6.9 Fig. 6.13 for various semiconductors. Although the results for $\mathrm{CdTe}$ and $\mathrm{ZnTe}$ are not very clear, linear relations are observed from $\sqrt{\text { quantum efficiency (Q.E) }}$ $=0.1$ to $\sqrt{Q . E}=0.25$ in most cases. The critical potential was defined as extrapolated value of this linear part to $\sqrt{Q \cdot E}=0$. By this extrapolation, the same value of the critical potential was obtained for all photon energies concerned. The critical potentials determined in this way are listed in Table 6.3.

As discussed in section 6.4.3, when the energy of electrons at the semiconductor surface exceeds the energy level of electron in $\mathrm{H}_{3} \mathrm{O}^{+}$ in the ground state, the photocurrent (quantum efficiency) becomes significant. Therefore, the critical potential (with respect to the flat band potential) is expected to have strong relation with the value of $\Delta H(e)$, the energy difference between the bottom of the conduction band and the energy level of electron in $\mathrm{H}_{3} \mathrm{O}^{+}$in the ground state at the flat band potential.

$$
\Delta H(e) \text { is given by }
$$

$$
\Delta H(e)=-L_{o}+E_{a}-J+A+R+\left(C^{S \cdot C} \Delta^{S} \phi\right) f b p
$$


222.

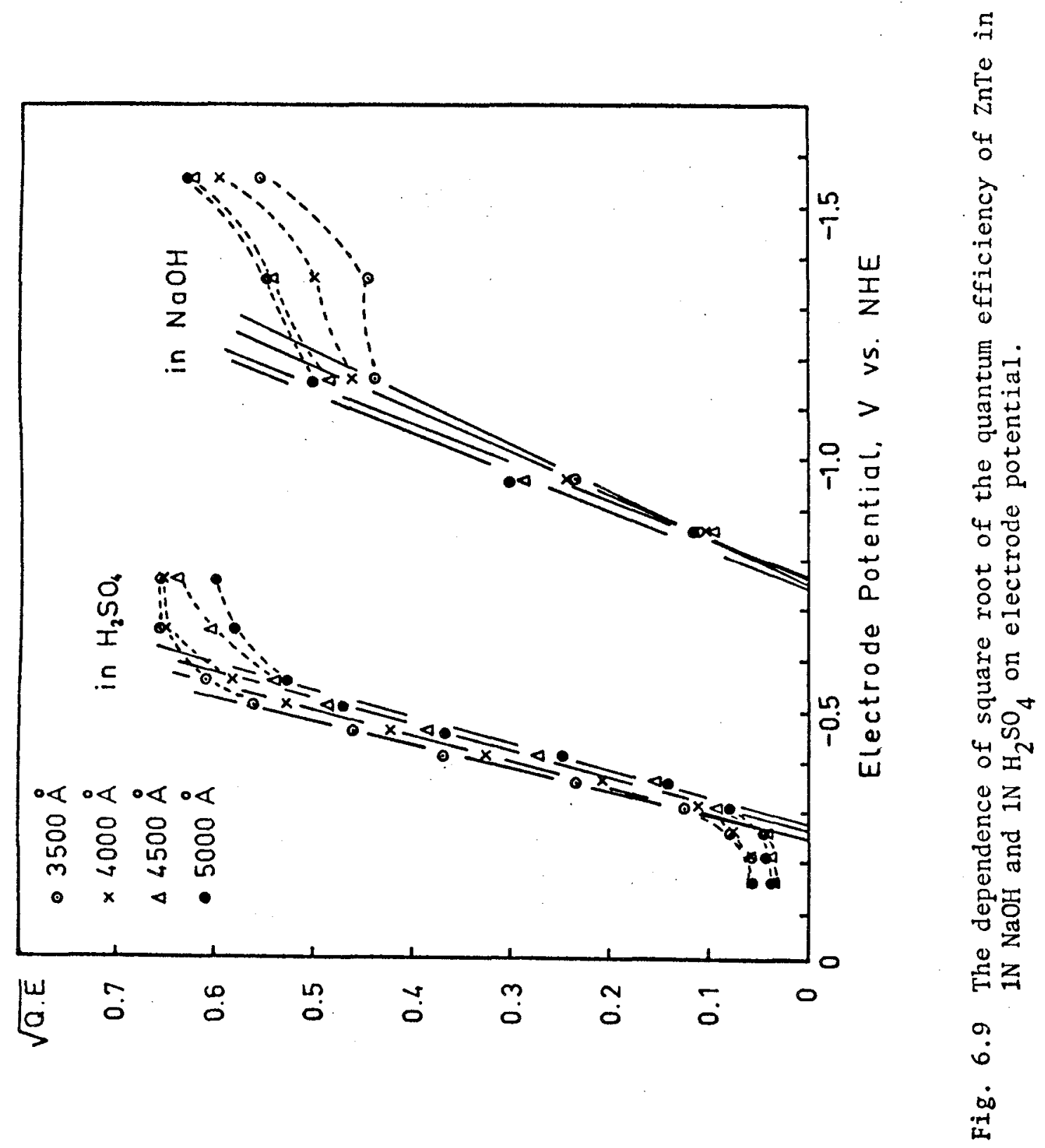


223.

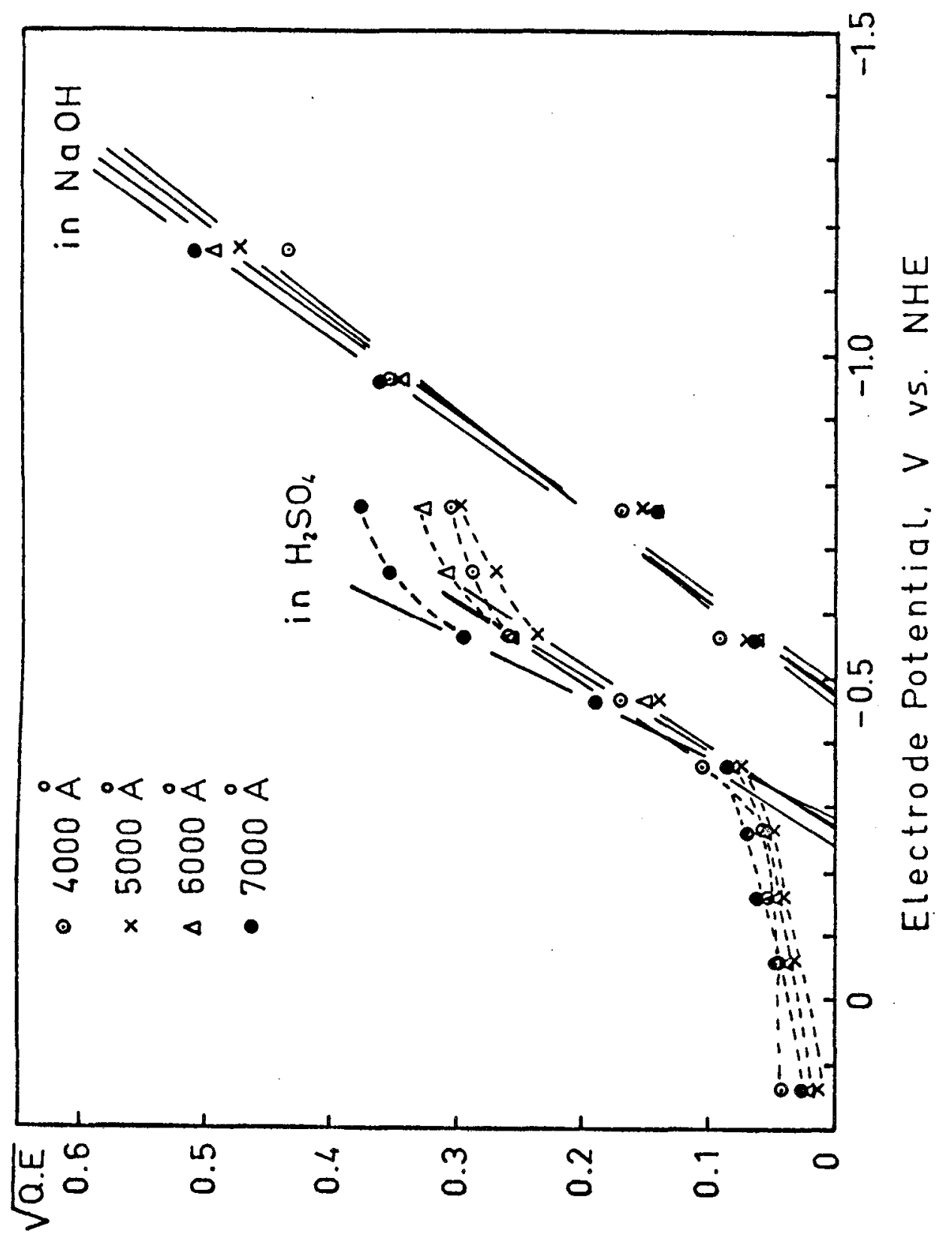

.7

它

4

宓

o

出

站

要

릉

总品

यั

芩

억

-

弯 5

己े

जि

4 थ

过

芑 究

(5)

品

总爫

움.

$\dot{0}$ 


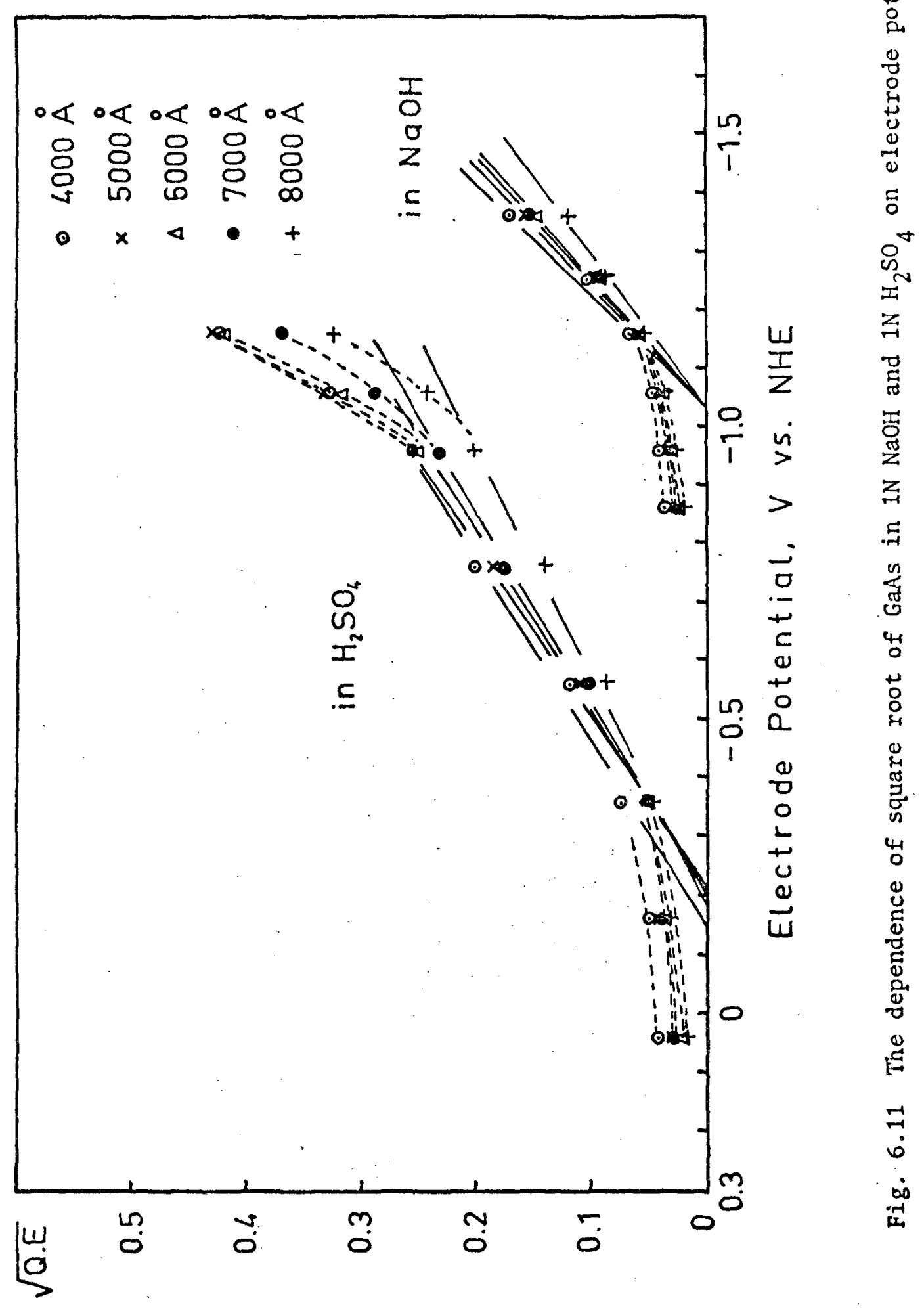


225.

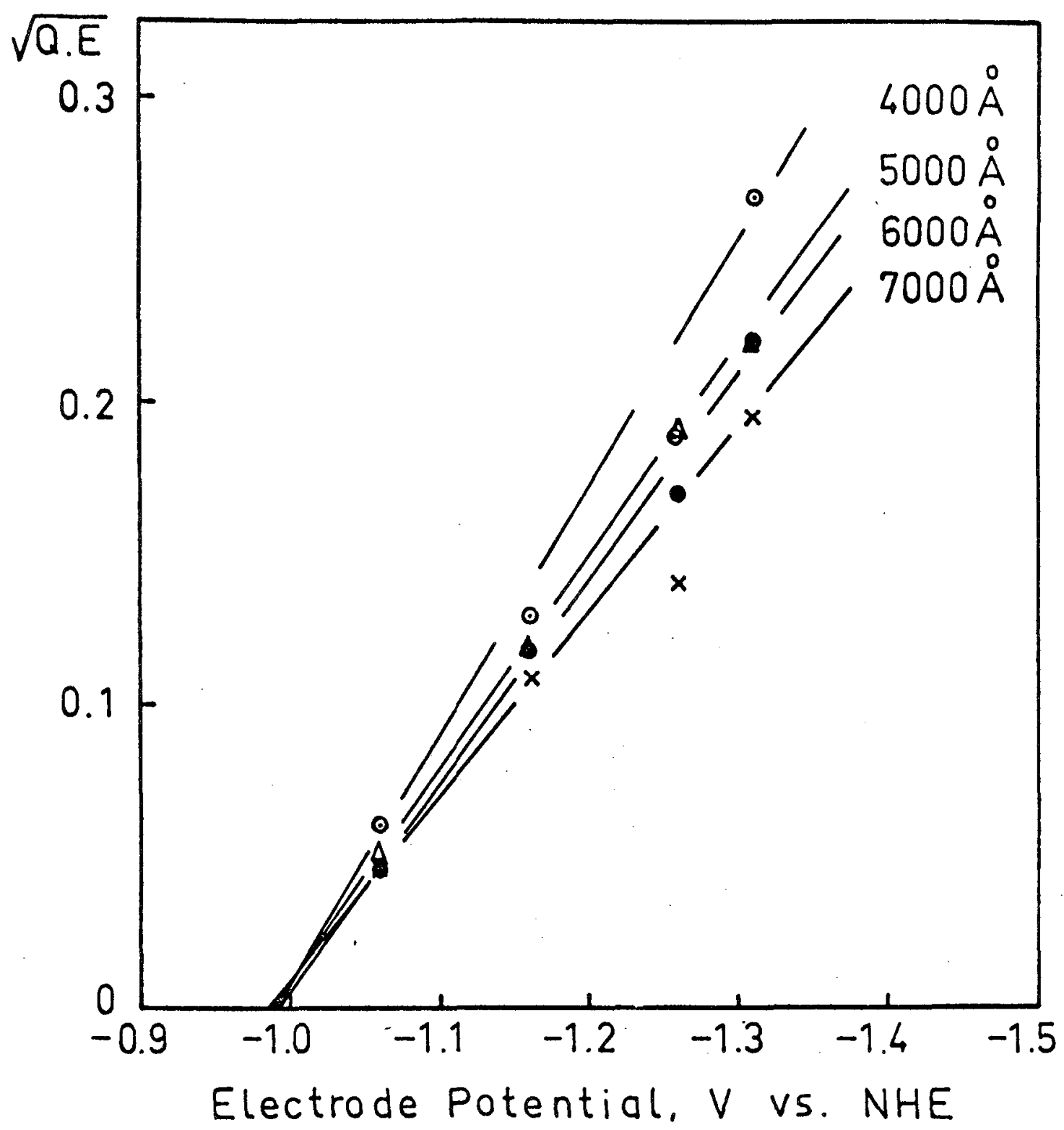

Fig. 6.12 The dependence of square root of the quantum efficiency of InP in $1 \mathrm{~N} \mathrm{NaOH}$ on electrode potential. 

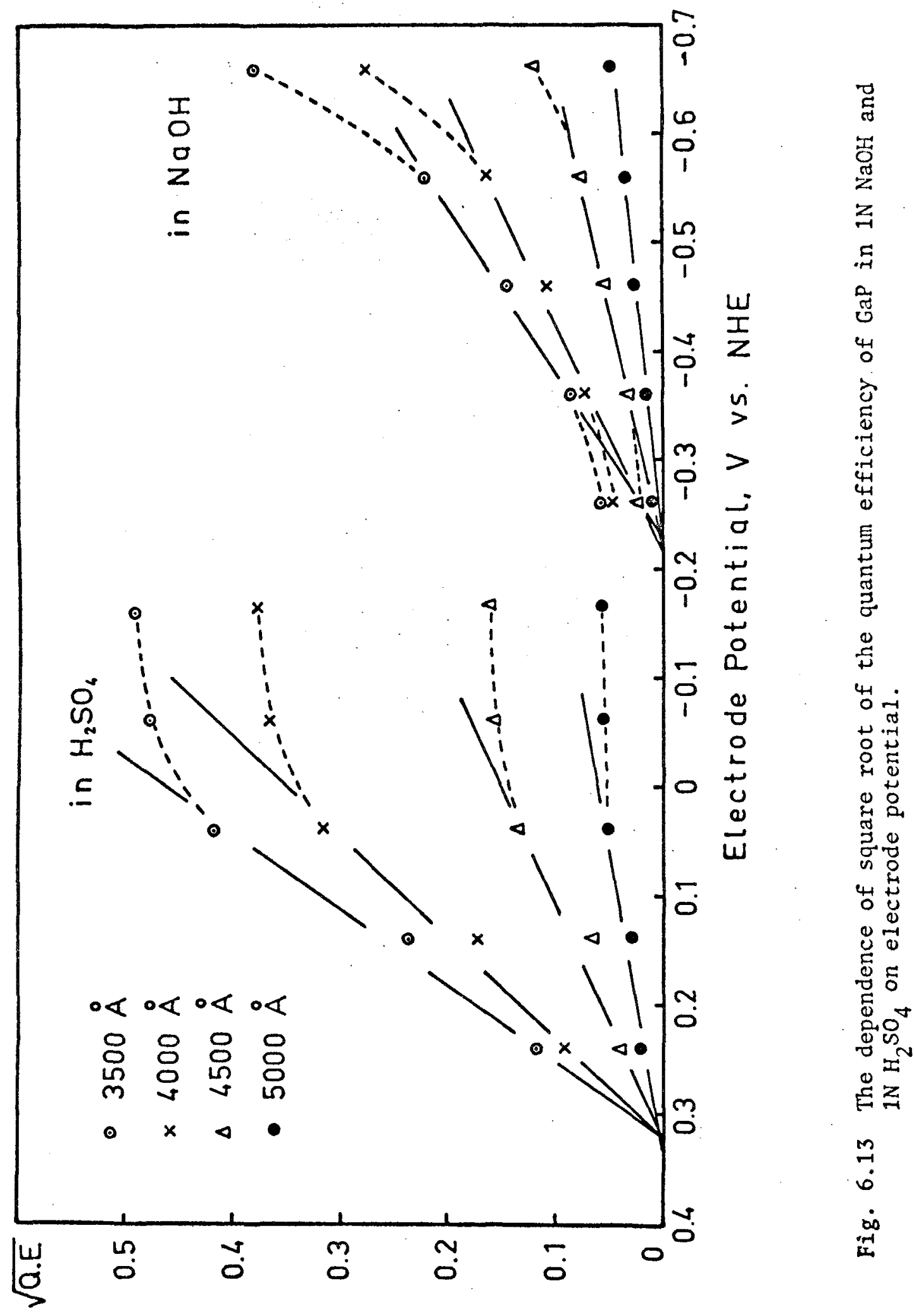
TABLE: 6.3 TIEE CRITICAL POTENTIAL OF SEVERAL SEMICONDUCTOR ELECTRODES WITH RESPECT TO NORMAL HYDROGEN ELECTROLE AND THE FLAT BAND POTENTIAL

\begin{tabular}{|c|l|l|l|l|}
\hline \multirow{2}{*}{ Semiconductor } & \multicolumn{4}{|c|}{ Critical Potential } \\
\cline { 2 - 5 } & In $1 \mathrm{~N} \mathrm{NaOH}$ & \multicolumn{2}{|c|}{ In $1 \mathrm{~N} \mathrm{H}_{2} \mathrm{SO}_{4}$} \\
\cline { 2 - 5 } & Vs. NHE & vs. FBP & vs. NHE & vs. FBP \\
\hline ZnTe & -0.76 & 0.03 & -0.26 & -0.30 \\
\hline CdTe & -0.48 & -0.69 & -0.27 & 0.48 \\
\hline GaAs & -1.03 & -0.99 & -0.20 & -0.6 \\
\hline InP & -0.99 & -0.92 & - & - \\
\hline
\end{tabular}


Since the values of $L_{o}, J$ and $R$ do not depend on nature of the semiconductor, and the dependence of A on semiconductor is expected to be smal1 (see Appendix 3.1 in chapter three),

$$
\Delta H(e) \bumpeq E_{a}+\cdot\left(S_{\Delta}^{S} \phi_{f b p}+\right.\text { const. }
$$

If $\left({ }^{S . C} \Delta^{S} \phi\right)_{\text {fbp }}$ is zero as assumed in chapter three, a strong correlation between $\mathrm{E}_{\mathrm{a}}$ and the critical potential is expected.

The critical potential is plotted against the electron affinity in Fig. 6.14(a) for $\mathrm{NaOH}$ solution and in Fig. 6.14(b) for $\mathrm{H}_{2} \mathrm{SO}_{4}$ solution. The correlation coefficients of these plots are -0.76 for $\mathrm{NaOH}$ solution and -0.20 for $\mathrm{H}_{2} \mathrm{SO}_{4}$ solution, respectively, and suggest relatively poor correlation, especially in $\mathrm{H}_{2} \mathrm{SO}_{4}$. Since, from (Eq. 6.24),

$$
\left({ }^{S \cdot C} S_{\phi}\right)_{f b p} \bumpeq V_{f b p}-'\left\{\left(E_{g}+E_{a}\right)+4.3\right\} / F
$$

$\Delta H(e)$ is given by:

$$
\Delta H(e) \bumpeq V_{f b p}-E_{g} / F+\text { const. }
$$

Therefore, a strong correlation between the critical potential and $\left(V_{f b p}-E_{g} / F\right)$ is expected. Fig. 6.15(a) and Fig. 6.15(b) show the relation between the critical potential and $\left(\mathrm{V}_{f b p}-\mathrm{E}_{\mathrm{g}} / \mathrm{F}\right)$ in $\mathrm{NaOH}$ and in $\mathrm{H}_{2} \mathrm{SO}_{4}$, respectively. The correlation coefficient of these plots are -0.94 and -0.76 for $\mathrm{NaOH}$ and for $\mathrm{H}_{2} \mathrm{SO}_{4}$ solution, respectively. These values suggest a very strong relation between the critical potential and the value $\left(\mathrm{V}_{\mathrm{fbp}}-\mathrm{E}_{\mathrm{g}} / \mathrm{F}\right)$ and confirms the importance of the potential drop in the electric double layer at the flat band potential in respect to the position of the quantum efficiency-potential relation, although the correlation in $\mathrm{H}_{2} \mathrm{SO}_{4}$ is relatively poor. 


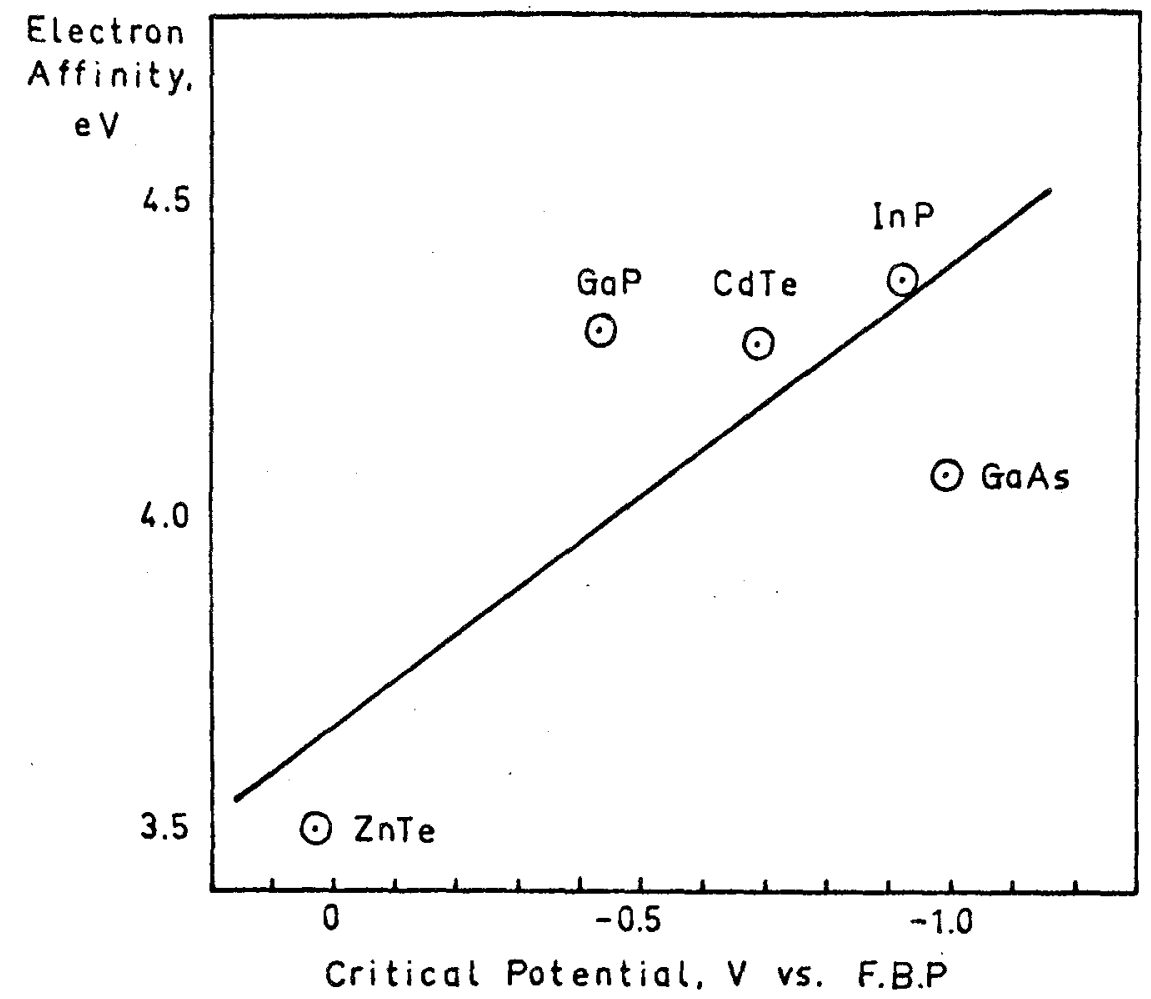

(a)

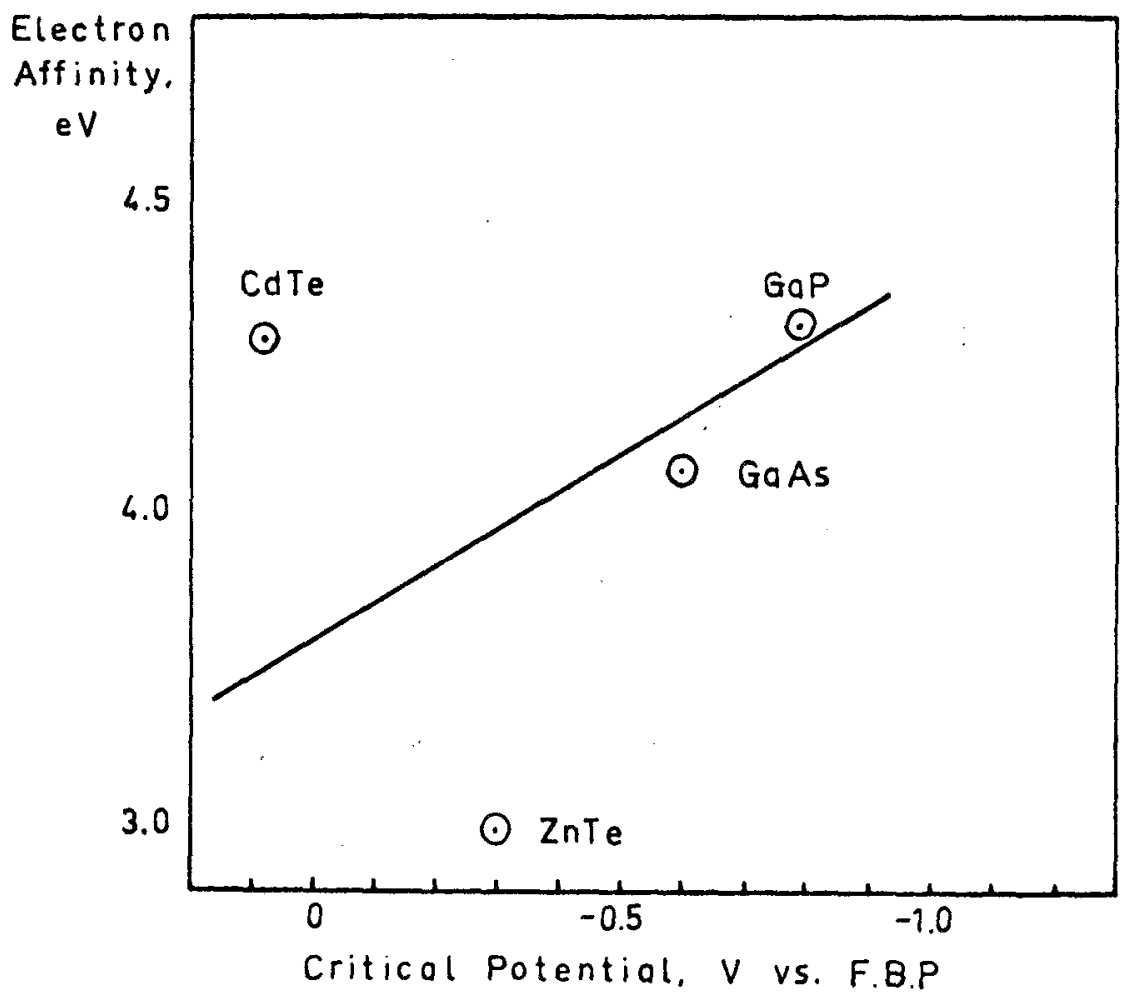

(b)

Fig. 6.14 The relations between the electron affinity and the critical potential with respect to the flat band potential in $1 \mathrm{~N} \mathrm{NaOH} \mathrm{(a)} \mathrm{and} 1 \mathrm{~N}_{2} \mathrm{SO}_{4}$ (b). 


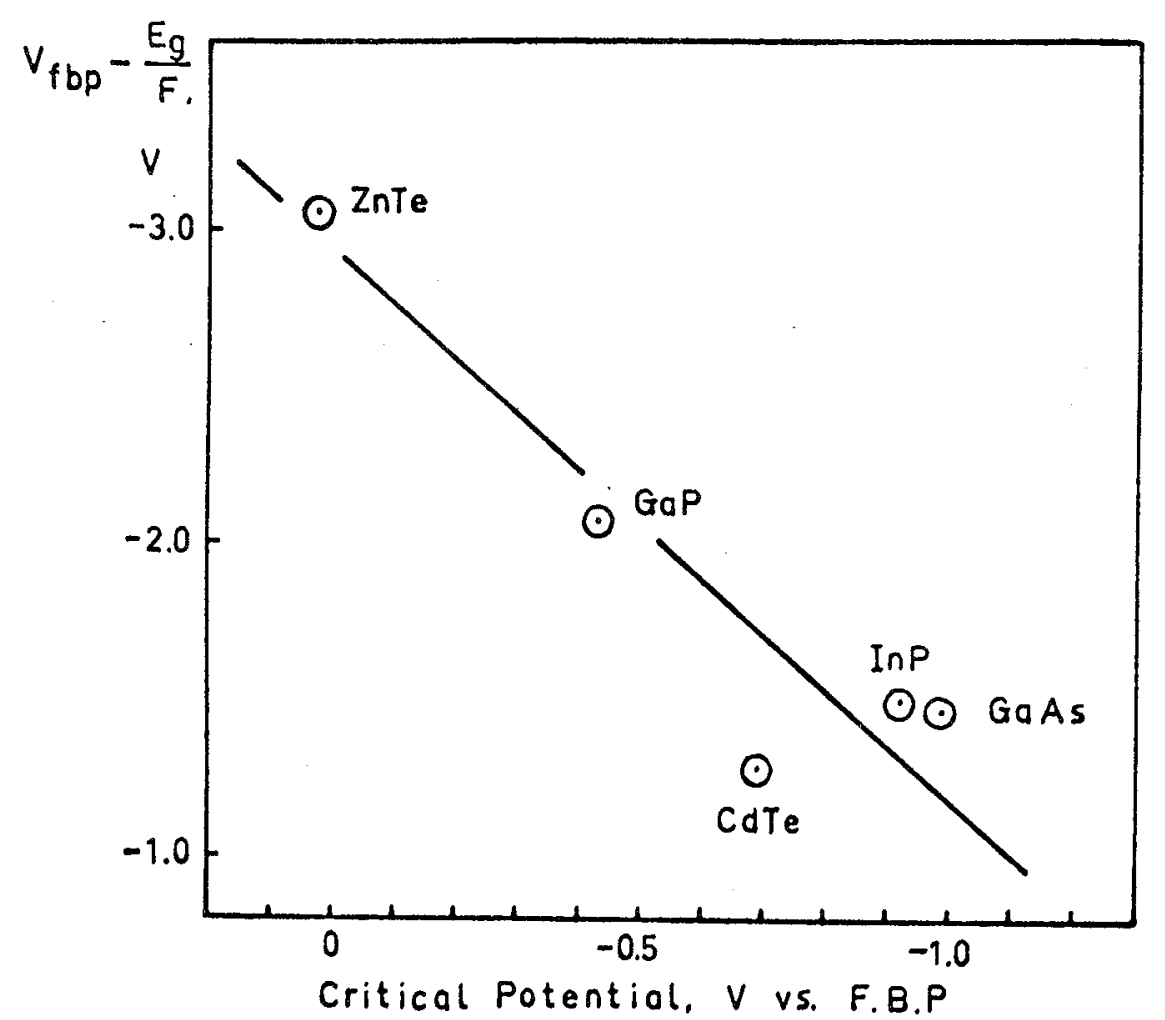

(a)

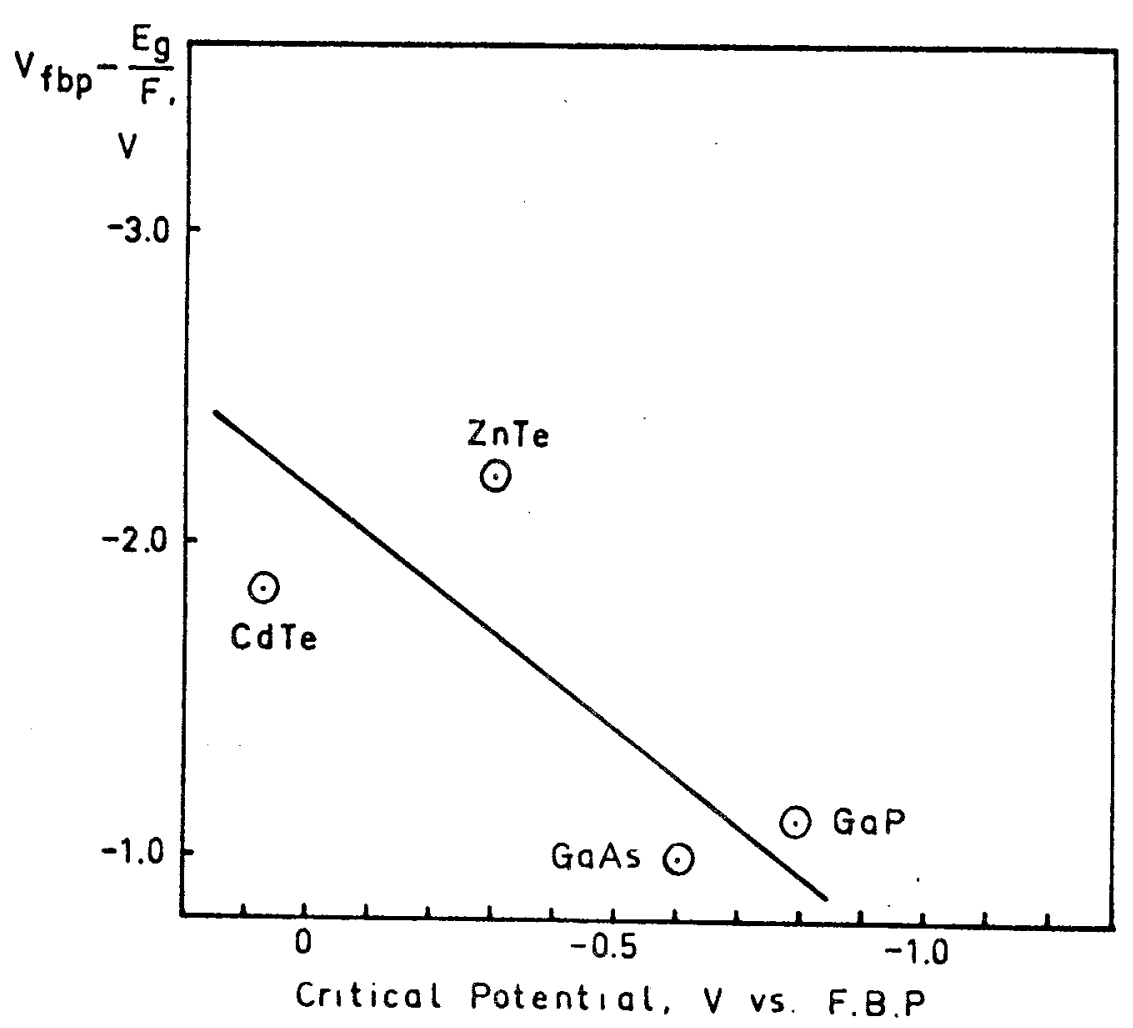

(b)

Fig. 6.15 The relations between $\left(V_{f b p}-\frac{E_{g}}{F}\right)$ and the critical potential with respect to the flat band potential in IN NaOH (a) and $1 \mathrm{~N} \mathrm{H}_{2} \mathrm{SO}_{4}$ (b). 
231.

This relation also suggests the importance of the energy gap. Although the small energy gap is required from the point of solar energy absorption, the smaller the energy gap, the more negative the critical potential (with respect to the flat band potential) and, therefore, the smaller the efficiencies as a whole cell system.

When the energy gap is small, the energy of electron at the surface is not high enough to react with $\mathrm{H}_{3} \mathrm{O}^{+}$or $\mathrm{H}_{2} \mathrm{O}$ (Boltzmann distributed states) even when the electrode potential is relatively negative with respect to the flat band potential. The good example of this situation was $\mathrm{CdTe}$ in $\mathrm{NaOH}$. The flat band potential is $0.21 \mathrm{~V}$ (NHE) and the critical potential is - $0.48 \mathrm{~V}$ (NHE). However, if oxygen existed in the solution, photocurrents were observed even at $-0.1 \mathrm{~V}$ (NHE) .

Thus, many excited electrons are arriving at the CdTe surface even at $-0.1 \mathrm{~V}$ (NHE) and if there is an acceptor, oxygen in this case, the electrons will transfer to the acceptor. However, if there is no oxygen in the solution, although many excited electrons are arriving at the surface, they could not find an acceptor, since their energy is not high enough to transfer to $\mathrm{H}_{3} \mathrm{O}^{+}$or water unless the electrode potential becomes sufficiently negative. 


\section{6 $\mathrm{pH}$ DEPENDENCE OF THE FLAT BAND POTENTIAL}

The values of the flat band potential of the semiconductors were the $\mathrm{pH}$ dependence and the values in $\mathrm{NaOH}$ were more negative than those in $\mathrm{H}_{2} \mathrm{SO}_{4}$ except for CdTe.

This behaviour was interpreted by Gerischer for Ge [40] by considering the dissociation equilibrium of hydroxide group which are chemically bonded to the atoms of the semiconductor at the surface. This interpretation was applied to other semiconductors $[28,41,42]$ and is seemed to be applicable in this work except for CdTe.

The special behaviour of CdTe may be due to the change of surface structure. As seen in the Mott-Schottky plots, the slope of the plot in $\mathrm{NaOH}$ and that in $\mathrm{H}_{2} \mathrm{SO}_{4}$ are different and that in $\mathrm{H}_{2} \mathrm{SO}_{4}$ have larger frequency dependence. Also there is a possibility that the measured values of impedance in $\mathrm{H}_{2} \mathrm{SO}_{4}$ is not the impedance of the space charge but the Faradic impedance because, although the measured current was small, there is a possibility of the corrosion

$$
\mathrm{CdTe}+2 \mathrm{H}_{3} \mathrm{O}^{+} \rightarrow \mathrm{Cd}^{\mathrm{T}}+\mathrm{Te}+2 \mathrm{H}_{2} \mathrm{O}+\mathrm{H}_{2}
$$

when the electrode potential is relatively positive. 


\subsection{HYDROGEN EVOLUTION IN ALKALINE SOLUTION}

An electron will transfer not to $\mathrm{H}_{3} \mathrm{O}^{+}$but to water or $\mathrm{Na}^{+}$ ion in alkaline solution*.

\subsubsection{The Energy Level of $\mathrm{H}_{2} \mathrm{O}$}

The standard entha1py change (no potential drop in the double layer) for the reaction

$$
\mathrm{p}-\mathrm{S} . \mathrm{C}(\mathrm{e})+\mathrm{H}_{2} \mathrm{O} \text { aq } \stackrel{\Delta \mathrm{H}(\mathrm{e})}{\longrightarrow} \mathrm{p}-\mathrm{S} \cdot \mathrm{C}-\cdots-\mathrm{H}--\left.\right|_{\mathrm{H}} ^{-\mathrm{O}}--\mathrm{H}_{2} \mathrm{O}
$$

can be estimated by considering the following thermodynamic cycle.

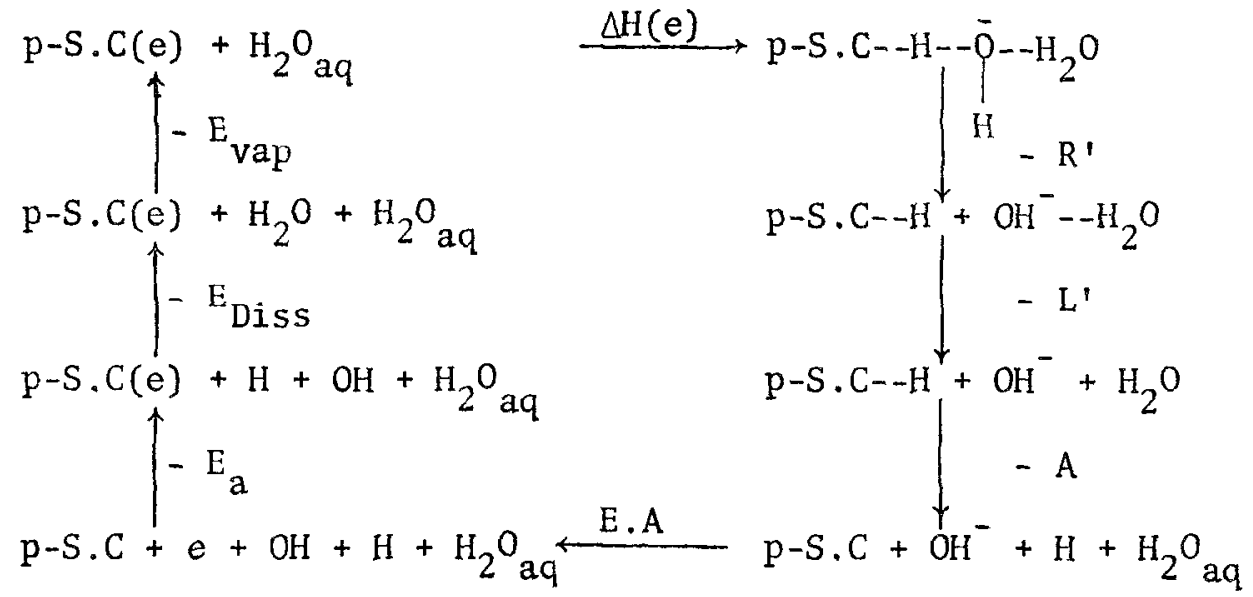

where $\mathrm{R}$ is the interaction energy between an $\mathrm{H}$ atom and the $\mathrm{OH}^{-}$and it is assumed as follows.

Interaction energy between an ion and a dipole, $u$, is given by $[45]$

$$
\mathrm{u}=\mathrm{Aa}^{-9}-\mathrm{Ba}^{-4}-\mathrm{Ca}^{-2}
$$

and where,

$$
\mathrm{A}=(4 / 9) \mathrm{Ba}_{\mathrm{O}}^{5}+(7 / 9) \mathrm{Ca}_{0}^{7}
$$

* At $\mathrm{Hg}$ electrode, electrons transfer to $\mathrm{Na}^{+}[43]$ and at $\mathrm{Ni}$ electrode, they transfer to $\mathrm{H}_{2} \mathrm{O}[44]$, both in dark. 


$$
\begin{aligned}
& B=\frac{1}{2} \alpha\left(z e_{0}\right)^{2} \\
& C=z e_{o} \mu
\end{aligned}
$$

$a$ is the distance between the ion and the dipole, $a_{0}$ is the equilibrium distance, $\alpha$ and $\mu$ are the polarizability and the dipole moment, respective1y. By assuming, $a=a_{0}=0.97 \AA(\mathrm{H}-\mathrm{OH}$ distance of water molecule [46], $\alpha=0.42$ (polarizability of hydrogen [47], $\mu=0$, $z=-1, u$, which is $R$ in this case, is calculated as $-1.88 \mathrm{eV}(43.2$ $\mathrm{kcal} / \mathrm{mole})$. Therefore, $\Delta \mathrm{H}(\mathrm{e})$ is given by:

$$
\begin{aligned}
\Delta H(e) & =E_{\text {vap }}+E_{\text {Diss }}+E_{a}-E \cdot A+A+L_{o}+R \\
& =10+119+E_{a}-42-6-87-43 \\
& =E_{a}-49(\mathrm{kcal} / \mathrm{mole})
\end{aligned}
$$

Since the energy level of $\mathrm{H}_{3} \mathrm{O}^{+}$is given by

$$
\Delta H(e)=E_{a}-62 \quad(\mathrm{kcal} / \mathrm{mole})
$$

in section 3.2.1.1, the energy level of $\mathrm{H}_{2} \mathrm{O}$ is higher than that of $\mathrm{H}_{3} \mathrm{O}^{+}$by $13 \mathrm{kcal} / \mathrm{mole}$.

\subsubsection{The Energy Leve1 of $\mathrm{N}_{a}^{+}$}

The standard enthalpy change of the reaction.

$$
\mathrm{p}-\mathrm{S} . \mathrm{C}(\mathrm{e})+\mathrm{N}_{\mathrm{a}}^{+} \stackrel{\Delta \mathrm{H}(\mathrm{e})}{\longrightarrow} \text { p-S.C }--\mathrm{N}_{\mathrm{a}}-\mathrm{H}_{2} \mathrm{O}
$$

can be estimated by considering the following thermodynamic cycle

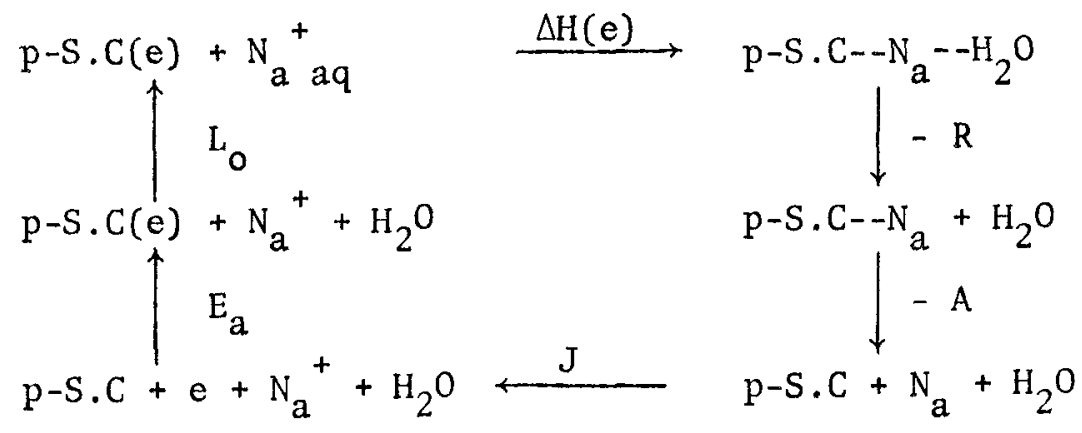




$$
\begin{aligned}
\Delta H(e) & =-L_{o}+E_{a}-J+A+R \\
& =95+E_{a}-118-A+R \\
& =E_{a}-23+A+R
\end{aligned}
$$

Assuming $A$ and $R$ have the same value as for hydrogen atom, $\Delta \mathrm{H}(\mathrm{e})$ is given by:

$$
\Delta H(e)=E_{a}-33(\mathrm{kcal} / \mathrm{mole})
$$

and this is about $16 \mathrm{kcal} / \mathrm{mole}$ higher than that for water.

\subsubsection{The Quantum Efficiency-Potential Relation in Alkaline Solution}

From above consideration, electrons seem to mainly transfer to water molecule in an alkaline solution.

The shift of the position of quantum efficiency-potential relation due to solution change is analysed as follows.

$\Delta H(e)$ in alkaline solution, $\Delta H_{a l k}$, and acid solution, $\Delta H_{\text {acid }}$, at the flat band potential, with taking into account the potential drop in the electric double layer, are given by

$$
\underset{\mathrm{alk}}{\Delta \mathrm{H}_{\mathrm{a}}}=\mathrm{E}_{\mathrm{a}}-2.13+\mathrm{F}\left(\mathrm{S}^{\mathrm{S} \cdot \mathrm{C}_{\Delta} \mathrm{S}_{\phi)} \underset{\mathrm{fbp}}{\mathrm{a} 1 \mathrm{k}}} \underset{ }{ }(\mathrm{eV})\right.
$$

and

$$
\Delta H_{\text {acid }}=E_{a}-2.70+F\left({ }^{S \cdot C} S^{S}\right)_{\substack{\text { acid } \\ \text { apd }}}(e V)
$$

respectively.

Therefore,

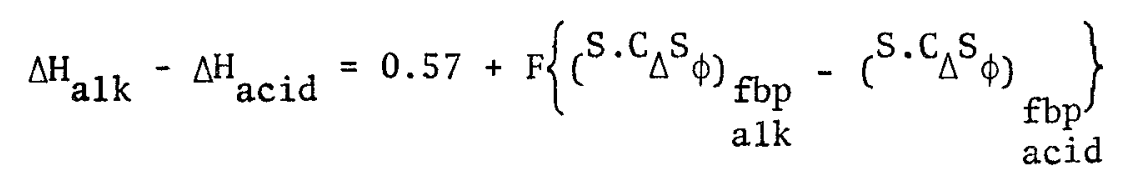


236.

As discussed before (see section 6.5), $\Delta H(e)$ has quite good correlation with the critical potential (with respect to the flat band potential). Thus, the difference between the critical potential in $\mathrm{NaOH}$ and that in $\mathrm{H}_{2} \mathrm{SO}_{4}$ and the value of right hand side of Eq. (6.51) are expected to have a good correlation. Fig. 6.16 shows this correlation and the correlation coefficient, -0.94 , supports the above consideration and also confirms the validity of the mode 1 which has been taken to interpret the experimental results. 


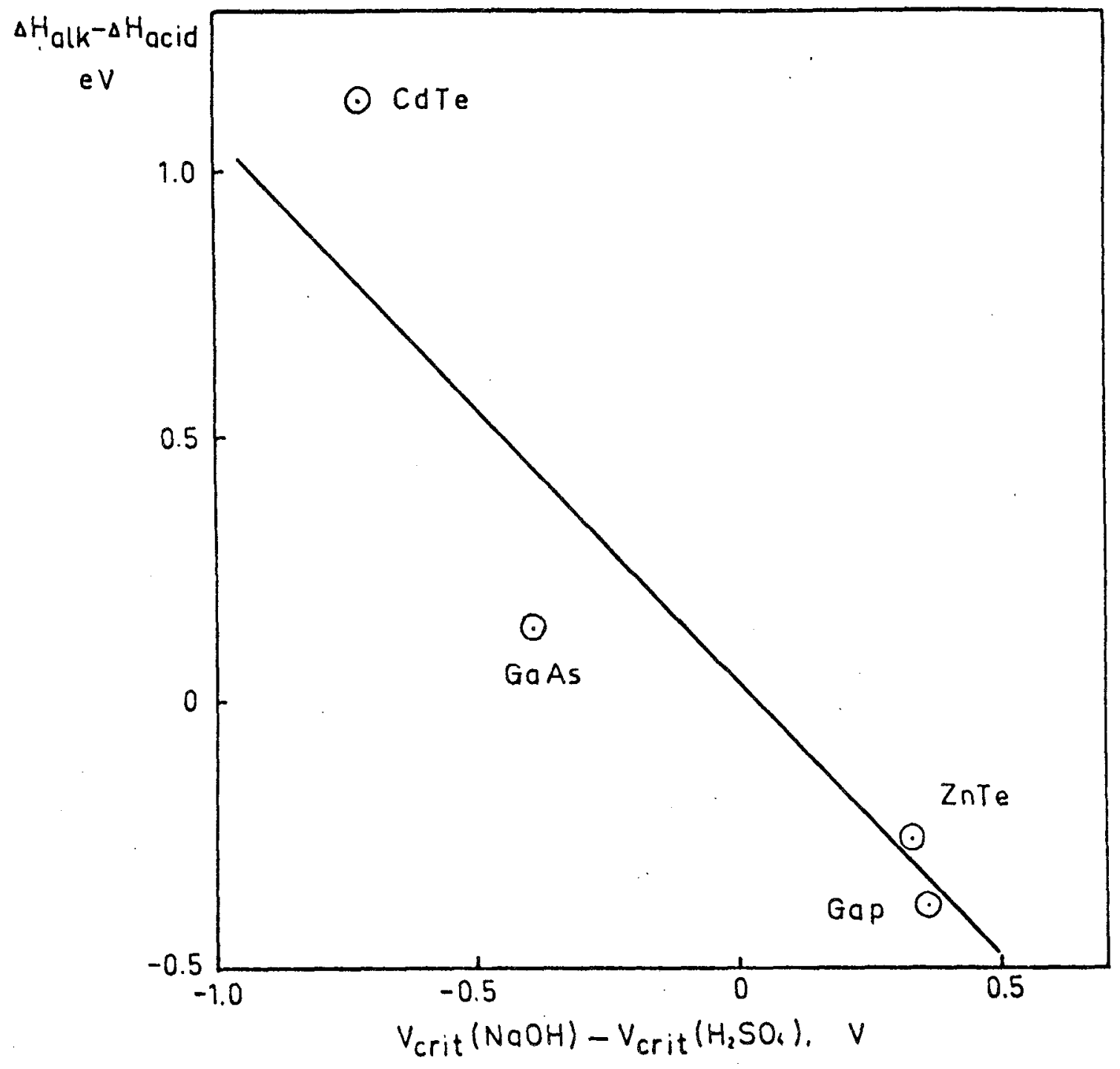

Fig. 6.16 The relation between

$\left[0.57+F\left\{\left({ }^{\left.S . C_{\Delta} S_{\phi}\right)_{f b p}}-\left({ }^{\mathrm{alk}} \cdot \mathrm{C}_{\Delta} \mathrm{S}_{\phi)} \underset{\mathrm{fbp}}{\mathrm{acid}}\right\}\right]\right.\right.$

(Eq. 6.51)

and the difference between the critical potential (with respect to the flat band potential) in $1 \mathrm{~N} \mathrm{NaOH}$ and that in $1 \mathrm{~N} \mathrm{H}_{2} \mathrm{SO}_{4}$. 


\subsection{EFFECT OF POTENTIAL ON QUANTUM EFFICIENCY- WAVELENGTH RELATTON}

As stated in section 6.3 , the nearer the electrode potential is to the flat band potential, the larger is the ratio of the quantum efficiency at high, compared with that at low, energies of the incident 1ight*, although for GaAs and for InP, the effect of potential on the form of the quantum efficiency-wavelength relations is small.

\subsubsection{Qualitative Analys is}

Analysis is given for an anodic photocurrent at an n-type semiconductor, but it can be easily modified to a cathodic photocurrent at a p-type semiconductor.

The photocurrent, $i_{p}$, can be written as:

$$
i_{p} \propto J_{h}-v_{s . r}
$$

where $J_{h}$ is the number of holes arriving at the surface per unit area per unit time and $v_{s, r}$ is the surface recombination rate.

When the energy of the photons is relatively large, the absorption coefficient is large, so that most of the photons are absorbed near the electrode surface, and therefore holes are created near the surface, and easily arrive there ( $J_{h}$ is large). Conversely, at lower photon energies, there will be a lower absorption coefficient,

* For example, the results in Fig. $5.2\left(\mathrm{TiO}_{2}\right.$ single crystal) may be taken. At $-0.45 \mathrm{~V}$, the quantum efficiencies at $3200 \AA$ and $3800 \AA$ are 0.12 and 0.046 , respectively, and, therefore, the ratio (= quantum efficiency at $3200 \AA$ /quantum efficiency at $3800 \AA$ ) is 2.6. On the other hand, at $1.25 \mathrm{~V}$, the quantum efficiencies at $3200 \AA$ and $3800 \AA$ are 0.39 and 0.28 , respectively, and the ratio is 1.4 . 
so that most photons penetrate further into the electrode before being absorbed. The holes thus produced can therefore only reach the surface when the field strength in the semiconductor is large. When the potential of the electrode becomes more negative, and moves, thus, nearer to the flat band potential, the field in the semiconductor becomes smaller, and its effect on the holes reaching the surface is less than that at more positive potentials. Thus, at such more negative potentials, only the holes created by the higher energy photons will reach the surface (Fig. 5.2). As the wavelength of the photons increases, there will therefore be observed a lesser quantum efficiency.

6.8.2 Semi-Quantitative Analysis for Maxima in the Quantum Efficiency-Potential Relation

Existence of maxima in the quantum efficiency-wavelength relation can be explained as follows.

At steady state,

$$
-J_{f}-J_{b}+N_{p h}=0
$$

where $J_{f}$ is the flux of electrons towards the surface, $J_{b}$ is the flux of electrons towards the bulk and $\mathrm{N}_{\mathrm{ph}}$ is the number of photons absorbed, i.e., number of electrons created. $J_{f}$ and $J_{b}$ are given by $[48]$ :

$$
J_{f}=-\frac{D c}{R T} F X+D\left(\frac{\partial c}{\partial x}\right)_{f}
$$

and

$$
J_{b}=\frac{D c}{R T} F X+D\left(\frac{\partial c}{\partial x}\right)_{b}
$$

where $x$ is the field, $c$ is the concentration of electrons, $(\partial c / \partial x)_{f}$ 
240.

is the concentration gradient towards surface, $(\partial c / \partial x)_{b}$ is the concentration gradient towards bulk and $D$ is the diffusion coefficient. From Eq. (6.53), (6.54) and (6.55),

$$
-D\left(\frac{\partial c}{\partial x}\right)_{f}-D\left(\frac{\partial c}{\partial x}\right)_{b}+N_{p h}=0
$$

For a first order approximation,

$$
\left(\frac{\partial c}{\partial x}\right)_{f}=\frac{c}{(1 / \alpha)}
$$

and

$$
\left(\frac{\partial c}{\partial x}\right)_{b}=\frac{c}{\ell_{D}}
$$

are assumed, where $\alpha$ is the absorption coefficient and $l_{D}$ is the diffusion length $(=\sqrt{\mathrm{D} \tau})$.

From Eq. (6.56), (6.57) and $(6.58), \mathrm{c}$ is given by

$$
c=\frac{N_{p h}}{D\left(\alpha+1 / \ell_{D}\right)}
$$

Therefore, by using Eq. (6.54), $\mathrm{J}_{\mathrm{f}}$ is given by:

$$
\begin{aligned}
J_{f} & =-\frac{D c}{R T} F X+D\left(\frac{\partial c}{\partial x}\right)_{f} \\
& =-\frac{1}{R T} N_{p h} \frac{F X}{\alpha+\left(1 / \ell_{D}\right)}+N_{p h} \frac{\alpha}{\alpha+\left(1 / \ell_{D}\right)} \\
& =N_{p h} \cdot \frac{1}{\alpha+\left(1 / \ell_{D}\right)}(-38 X+\alpha)
\end{aligned}
$$

Surface recombination rate, $v_{s . r}$, is proportional to $J_{f}{ }^{*}$ and, therefore,

* Rough estimation of the amount of $\mathrm{J}_{f}$ is given by assuming $\mathrm{N}_{\mathrm{ph}}=10^{16}$, $\mathrm{cm}^{2} \cdot \mathrm{sec}, \alpha=10^{6} \mathrm{~cm}^{-1}, l_{D}=10^{-5} \mathrm{~cm}, \mathrm{X}=1 \mathrm{~V} / 5000 \AA=2 \times 10^{4} \mathrm{~V} / \mathrm{cm}$ as about $2 \times 10^{15} / \mathrm{cm}^{2}$. sec which is equivalent to $0.3 \mathrm{~mA} / \mathrm{cm}^{2}$. 
Eq. (6.52) becomes

$$
i_{p} \propto J_{h}-k J_{f}
$$

where $\mathrm{k}$ is a proportional constant.

When the energy of photon increases to sufficient degree (absorption coefficient relatively large), from Eq. $(6.60), \mathrm{J}_{f}$ increases and, correspondingly, surface recombination increases. Thus, lower quantum efficiency for too energetic light is expected. 


\subsection{ANALYSIS OF TRANSIENT BEHAVIOUR}

\subsubsection{The Origin of the Transient Behaviour}

The transient behaviour may be due to either a process in the semiconductor or a process on the surface of the electrode.

In the former case, the origin of the transient behaviour is due to the time dependence of the number of electrons arriving at the surface. Since the transient behaviour measured in this work is about $10^{-3} \mathrm{sec}$, the only process which has such a long time constant in the semiconductor could be recombination process. By considering a recombination process, the number of excess electrons at time $t$ after illumination is started, $N(t)$, is given by [49] :

$$
N(t)=N\left(1-e^{-t / \tau}\right)
$$

where $N$ is the number of excess electrons at the steady state and $\tau$ is the life time of the excited electron. Also, the number of electrons at time $t$ after illumination is turned off, $N^{\prime}(t)$, is given by

$$
N^{\prime}(t)=N e^{-t / \tau}
$$

Since the time constant of diffusion is far less than that of recombination process, the number of excess electrons at the surface, $N_{0}(t)$, is given by

$$
N_{0}(t)=N_{0}\left(1-e^{t / \tau}\right)
$$

when light is on

and

$$
N_{0}^{\prime}(t)=N_{0} e^{-t / \tau}
$$

when light is off,

where $N_{0}$ is the steady state concentration of excess electrons at 
the surface.

Since the photocurrent, $i_{p}(t)$, is given by

$$
i_{p}(t) \propto N_{0}(t)
$$

the time dependence of the photocurrent is given by

$$
\begin{aligned}
i_{p}(t) & =k N_{0}(t) \\
& =k N_{0}\left(1-e^{-t / \tau}\right) \\
& =i_{s t .}\left(1-e^{-t / \tau}\right)
\end{aligned}
$$

when the light is turned on,

where $i_{\text {st }}$ is the steady state photocurrent.

Similarly,

$$
i_{p}(t)=i_{s t} e^{-t / \tau}
$$

when the light is turned off.

The time dependence of the photocurrent following these equations is shown in Fig. 6.17. However, the result of the transient behaviour of the semiconductors investigated in this work were quite different, especially when the electrode potential was near to the flat band potential. Typical behaviour is shown also in Fig. 6.17, schematically.

From the above consideration it may be concluded that since the life time of the excited electrons is less than $10^{-3} \mathrm{sec}$, the transient behaviour observed are due to surface electrochemical process.

6.9.2 Cathodic Current Other than Hydrogen Evolution

In steady state measurements, the measured current is considered due to hydrogen evolution. However, there is a possibility of a 
244.

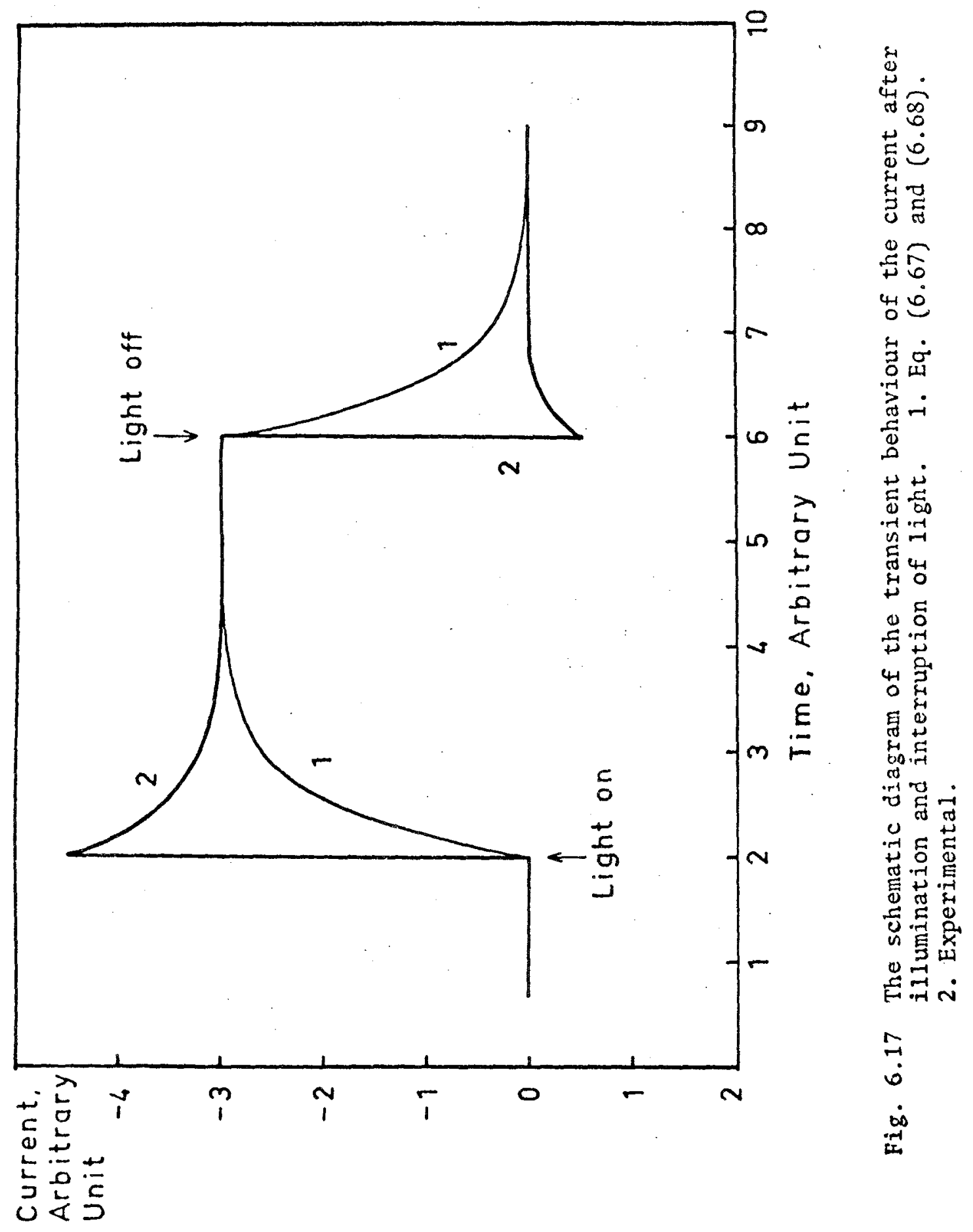


245.

cathodic photocurrent due to the reduction of a species which is adsorbed on the electrode surface when the electrode is in the dark. The species may be oxygen and metal cation of the semiconductors, e.g., $\mathrm{Cd}^{++}$for CdTe, $\mathrm{Zn}^{++}$for $\mathrm{ZnTe}$, etc.

\subsubsection{Time Dependence of the Cathodic Current}

The measured current, $i_{p}$, may be given by

$$
\begin{aligned}
i_{p} & =i_{p, H_{2}}{ }^{i} p, \text { red } \\
& =k_{\mathrm{H}_{2}} \mathrm{C}_{\mathrm{H}_{3} \mathrm{O}^{+}+k_{\text {red }} \mathrm{C}_{\text {red }}}
\end{aligned}
$$

where $\mathrm{k}_{\mathrm{H}_{2}}$ and $\mathrm{k}_{\text {red }}$ are the rate constant for hydrogen evolution reaction and other reduction reaction, respectively, and $\mathrm{C}_{\mathrm{H}_{3}} \mathrm{O}^{+}$and $\mathrm{C}_{\text {red }}$ are the concentration of $\mathrm{H}_{3} \mathrm{O}^{+}$and the species to be reduced, respectively.

As far as hydrogen evolution reaction is not diffusion controlled, $\mathrm{C}_{\mathrm{H}_{3}} \mathrm{O}^{+}$can be considered as time independent. On the other hand, one can assume that under illumination there will be almost no oxidation process which creates the species to be reduced and, therefore, $C_{\text {red }}$ decreases with time.

Thus, Eq. (6.69) becomes:

$$
\begin{aligned}
i_{p}(t) & =i_{p, H_{2}}+i_{p, \text { red }}(t) \\
& =k_{\mathrm{H}_{2}} \mathrm{C}_{\mathrm{H}_{3} \mathrm{O}^{+}+k_{\text {red }} \mathrm{C}_{\text {red }}(t)}
\end{aligned}
$$

Also, from Faraday's law,

$$
C_{\text {red }}(t+\Delta t)=C_{\text {red }}(t)-\frac{M}{F} \int_{t}^{t+\Delta t} i_{p, r e d}(t) d t
$$

where $M$ is the gram equivalent of the species to be reduced and $F$ 
is the Faraday's constant. $C$ is given by $\mathrm{g} / \mathrm{cm}^{2}$.

From these two equations, the current at time $t$ is given by

$$
i_{p}(t)=i_{p, H_{2}} C_{H_{3}}++k_{\text {red }} C_{o, r e d} \exp \left(-\frac{M}{F} k_{\text {red }} t\right)
$$

where $\mathrm{C}_{0, \text { red }}$ is the concentration of the species to be reduced at time zero.

\subsubsection{Comparison with the Experimental Results}

Some experimental results are plotted in Fig. 6.18 as $\log \left(i(t)-i_{s t}\right)$ vs. $t$. These plots show a good linear relation. Also the fact the closer electrode potential to the FBP, the larger the effect and also the longer the time constant can be explained as follows.

The integration of the excess cathodic current, i.e. $\int_{0}^{\infty}\{i(t)-i(\infty)\} d t$, gives the $\frac{F_{M}}{\mathrm{C}_{0}}$ and, since $\frac{F}{M}$ is constant for a system
concerned, the integrated value is proportional to $C_{0}$, the concentration of species to be reduced. One can easily think that the more anodic the electrode potential the larger the amount of the species.

The time constant of the behaviour is given by $\frac{F}{M k}$ and since $\frac{F}{M}$ is constant it is proportional to $\frac{1}{k}$. This $k$ is a function of potential and it is easily understood that the more positive the potential the smaller the $k$ (rate constant for cathodic reaction) and, therefore, the longer time constant.

The $\mathrm{C}_{0}$ is for order of $1 \sim 1000 \mu \mathrm{c} / \mathrm{cm}^{2}$ which is about $0.01 \sim 1$ monolayer of adsorption.

This amount may a1so depend how long the electrode is kept in dark before illumination. In this work, this effect was not examined. 


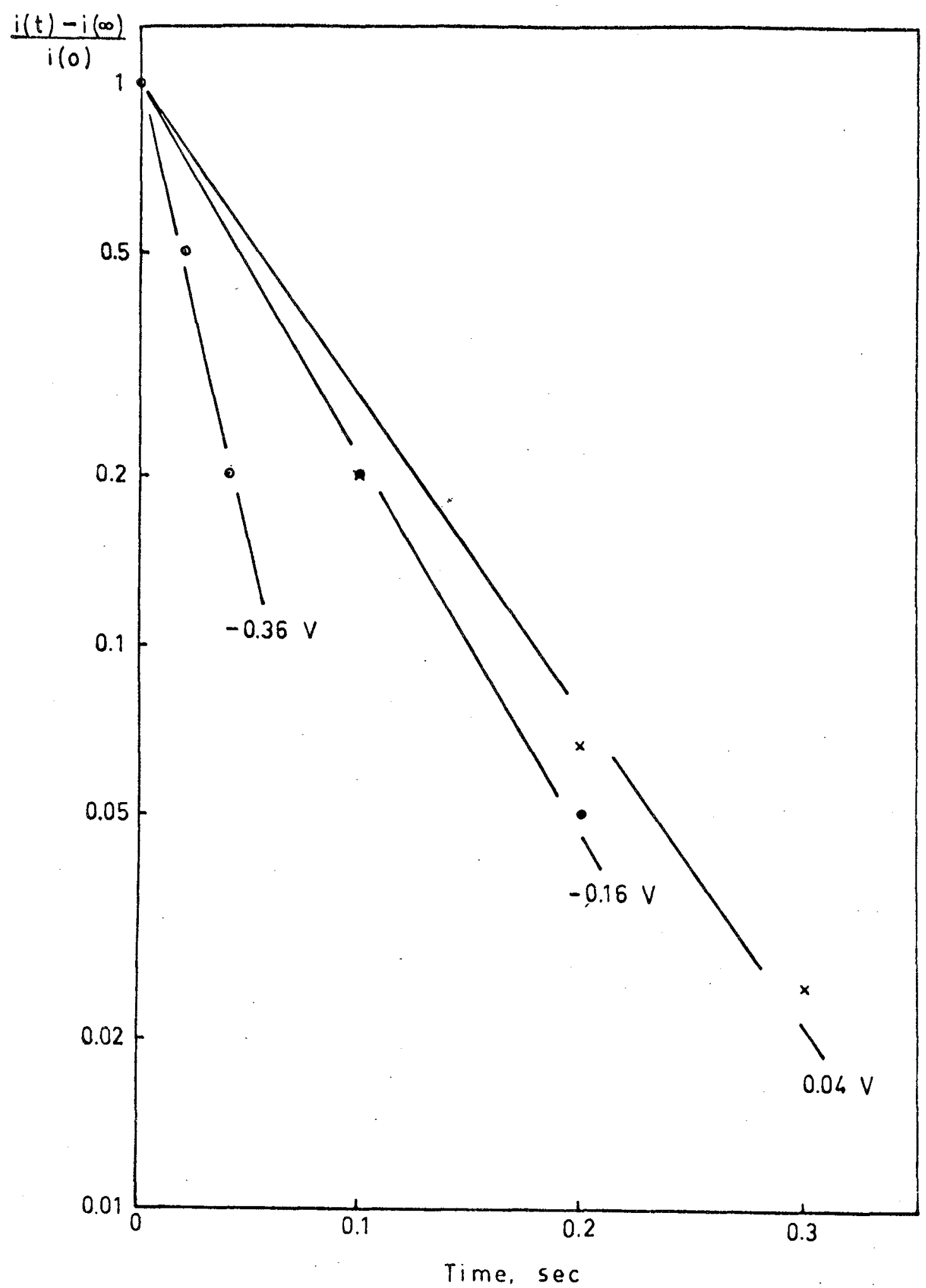
Fig. 6.18 The relation between $\frac{i(t)-i(\infty)}{i(0)}$ and time of GaP in
$\underset{1 \mathrm{~N} \mathrm{H}_{2} \mathrm{SO}_{4}}{ }$. 


\subsection{THE EFFECT OF THE FILM THICKNESS (TiO 2 ) \\ ON QUANTUM EFFICIENCY -WAVELENGTH RELATION}

If the film is too thin, then most of illuminated photon are not absorbed in oxide film layer but in the substrate layer and wasted. Therefore the film thickness has a very important meaning.

In Fig. 6.19, the fraction of photon absorbed in the oxide film layer is shown as a function of film thickness for several wavelength of light.

By multiplying this fraction by the quantum efficiency of single crystal of $\mathrm{TiO}_{2}$ at several wavelength (Fig. 5.2), quantum efficiencywavelength relation of the film, the properties of which are the same as those of single crystal except for the film thickness is calculated and is shown in Fig. 6.20 for several film thicknesses.

The thicker the film, the larger the quantum efficiency and the longer the wavelength of light for maximum quantum efficiency is expected from this consideration.

In the experiments at $\mathrm{Ti}$ anodic oxide films was observed that a maximum in quantum efficiency-wavelength relation appeared at shorter wavelength than that of $\mathrm{TiO}_{2}$ single crystal. Also in the case of high temperature oxidized $\mathrm{Ti}$ film, the longer the oxidation time, the longer the wavelength at which a maximum of quantum efficiency was observed. These results are easily understood from the above considerations. In the case of an anodic oxide film, the thickness of the film may be very thin and, therefore, a maximum in the quantum efficiency-wavelength relation appeared at shorter wavelength than that of $\mathrm{TiO}_{2}$ single crystal.

Also, the longer the oxidation time is, the thicker the filn is and, therefore, the longer the wavelength at which a maximum is observed. 


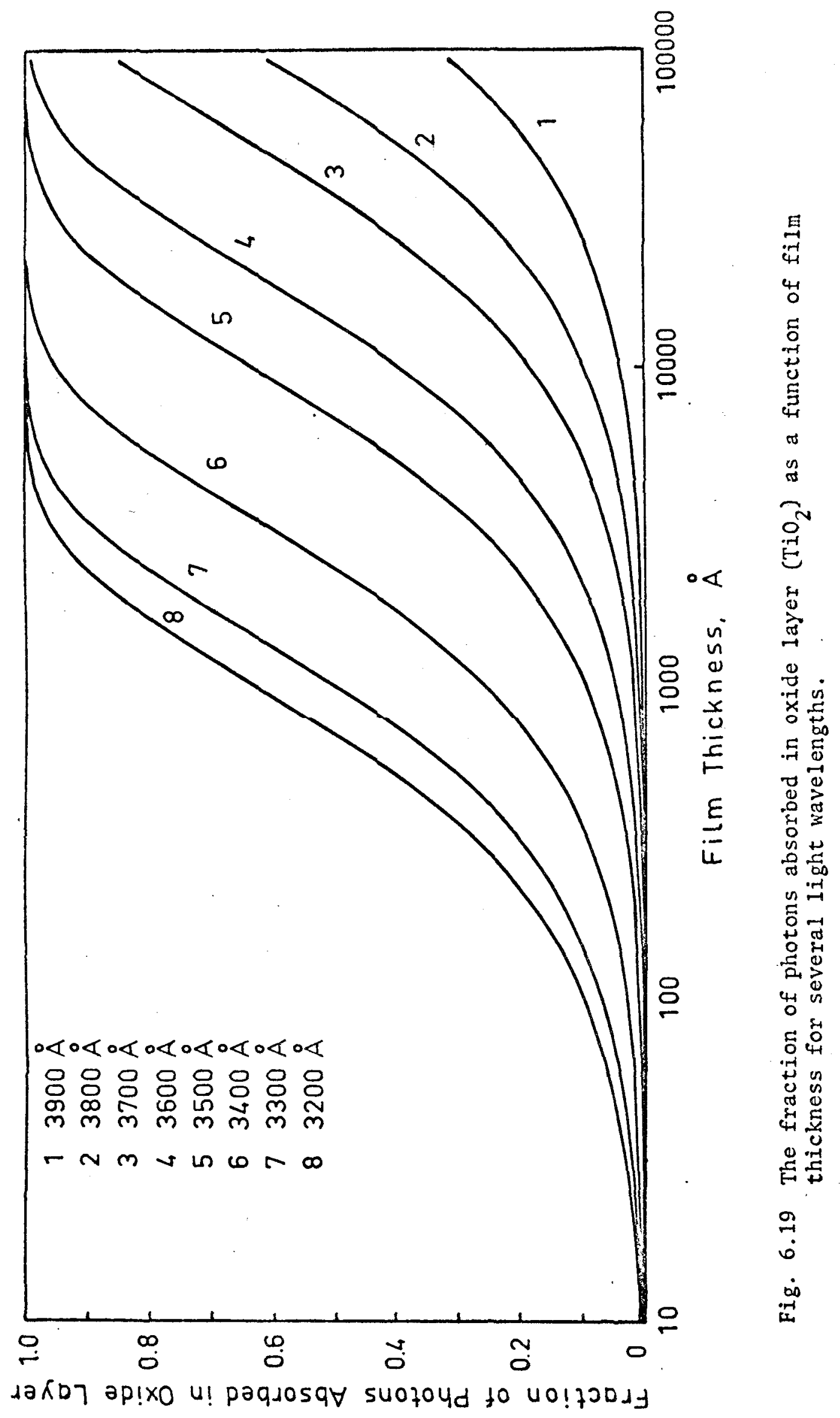


250.

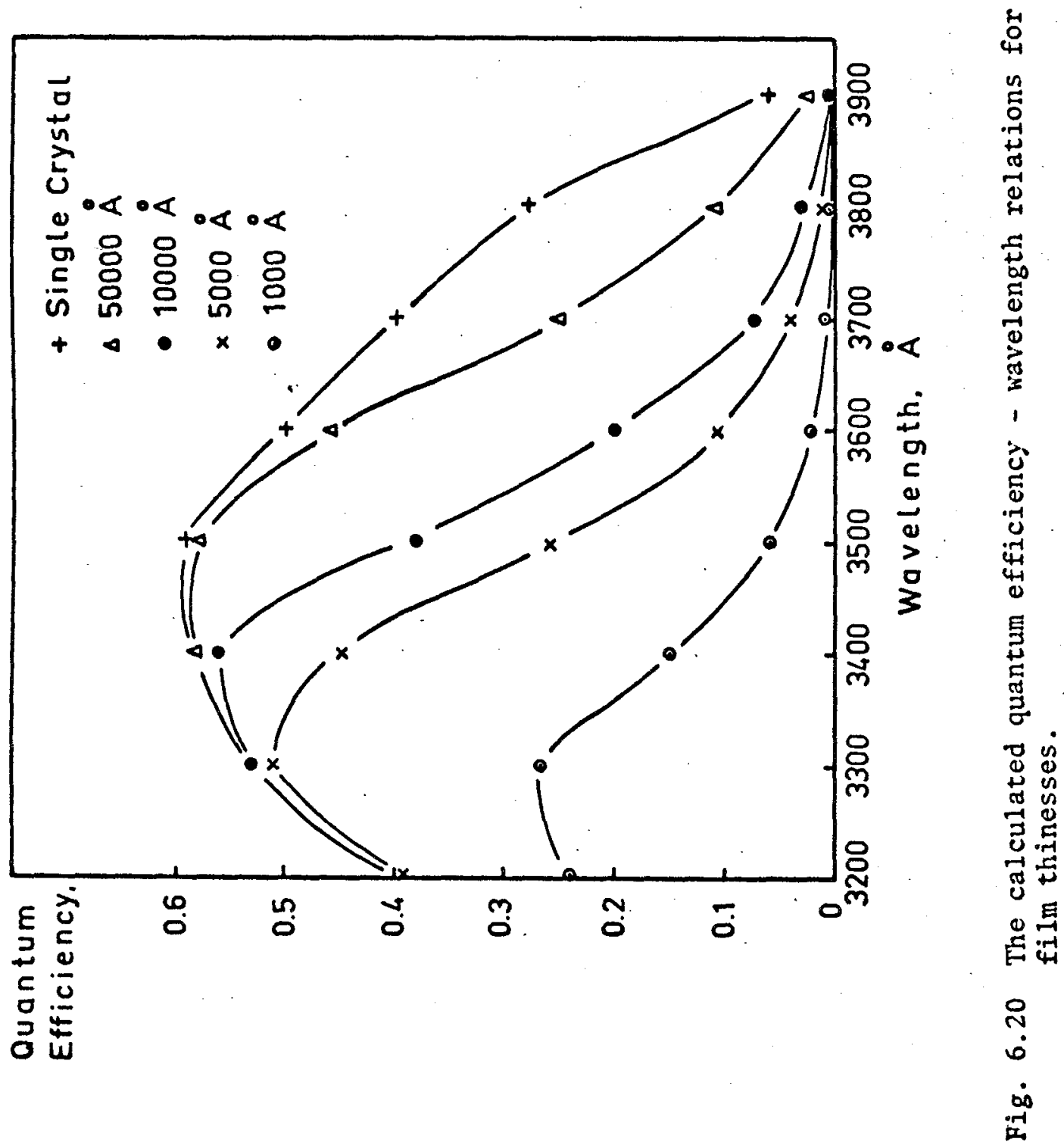




\subsection{THE PREVENTION OF ANODIC DISSOLUTION OF CdS BY COATING WITH TiO 2 FILM}

$\mathrm{TiO}_{2}$ is the best photoanode which has up till the present been shown to combine a sufficient photon absorption in the range of the solar spectrum with limitingly small anodic dissolution. If a semiconductor, which has a relatively low energy gap, is protected from anodic dissolution, there may be a wider choice of possibilities. In this respect, CdS single crystal was coated with a $\mathrm{TiO}_{2}$ film and it was examined photoelectrochemically. As reported in section 5.1.2, the photocurrents were observed at CdS single crystal coated with $\mathrm{TiO}_{2}$ film even when the energy of the light was smaller than the energy gap of $\mathrm{TiO}_{2}(3.0 \mathrm{eV} \simeq 4100 \AA)$, al though the quantum efficiency of this electrode was low compared with that of CdS single crystals (although much of this is due to CdS dissolution). Also, the decreasing rate of the photocurrent at this electrode was about $20 \%$ of that of CdS single crystal used alone. Fig. 6.21 shows the spectral response of this electrode and $\mathrm{TiO}_{2}$ single crystal under solar energy calculated by using the results of this work and the data of solar energy. It is apparent that the CdS coated with $\mathrm{TiO}_{2}$ film converts about four times more solar energy to electricity than a $\mathrm{TiO}_{2}$ single crystal.

One may question whether the photocurrent observed at CdS coated with $\mathrm{TiO}_{2}$ film is perhaps not oxygen evolution reaction but CdS decomposition because of imperfection of the electrode surface. However, if the photocurrent is due to CdS decomposition, then, the deterioration of the photocurrent should be similar to that of CdS single crystal used alone. Actually a very considerable improvement of stability was observed for the CdS coated with $\mathrm{TiO}_{2}$ film. 


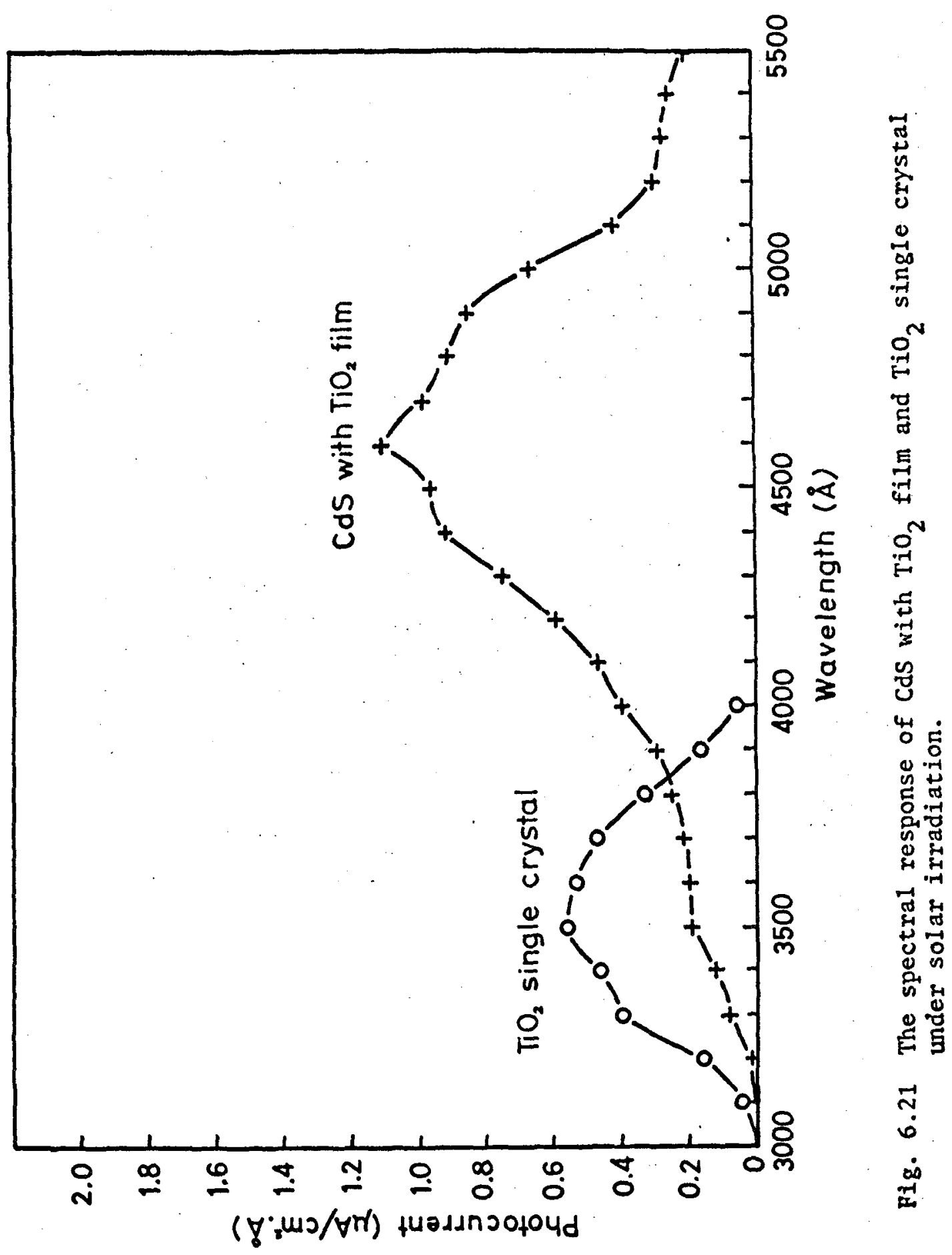


253.

Therefore, one deduces that a hole created in the CdS crystal does indeed travel through the $\mathrm{TiO}_{2}$ layer, arriving at the surface of the electrode, and reacting with $\mathrm{OH}^{-}$.

Since the experiment was carried out as a preliminary basis, a detailed discussion is not practical. However, some qualitative analysis is given as follows.

The energy diagram for $\mathrm{CdS} / \mathrm{TiO}_{2} /$ solution system in equilibrium and under anodic bias are shown in Fig. 6.22 (a) and (b), respectively. The situation is considered to be similar to that of an $\mathrm{n} / \mathrm{p} / \mathrm{n}$ junction.

The photon, the energy of which is less than the energy gap of $\mathrm{TiO}_{2}$, pass through a $\mathrm{TiO}_{2}$ layer without absorption by $\mathrm{TiO}_{2}$ and is absorbed by CdS. A photon adsorbed by CdS creates an electron in the conduction band and a hole in the valenue band. A field exists in the CdS which separates the electron-hole pair in such a way that the electron moves to the bulk and the hole moves towards the $\mathrm{CdS} / \mathrm{TiO}_{2}$ interface. The holes accumulate in that region (similar to a p region of an $\mathrm{n} / \mathrm{p} / \mathrm{n}$ junction). Correspondingly, the electrons in the conduction band of $\mathrm{TiO}_{2}$ pass easily over the barrier and move to the bulk of CdS under the internal CdS field. Since the region of that interface is narrow and the density of electrons is 1ow, recombination is unlikely and the holes diffuse into the $\mathrm{TiO}_{2}$ region, whereafter they are carried to the surface by the field present, as suggested by McKay [50] and Schokley et a1. [51] in the case of $n / p / n$ junction.

To treat this system more quantitatively, further more detailed experiments should be carried out. Some suggestions are given in section 6.12 .

Similar attempts were made by Nakato et al. [9]. They prevented anodic dissolution of semiconductors by coating with metal films. 


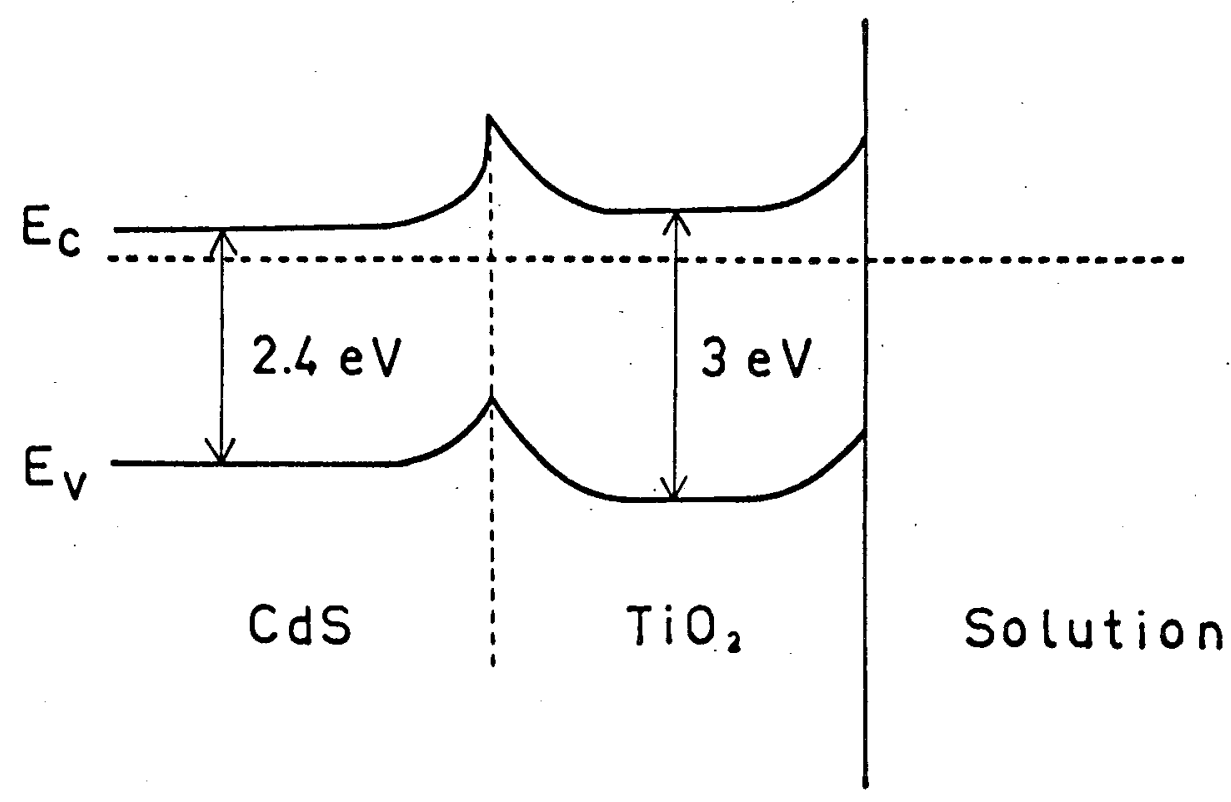

(a)

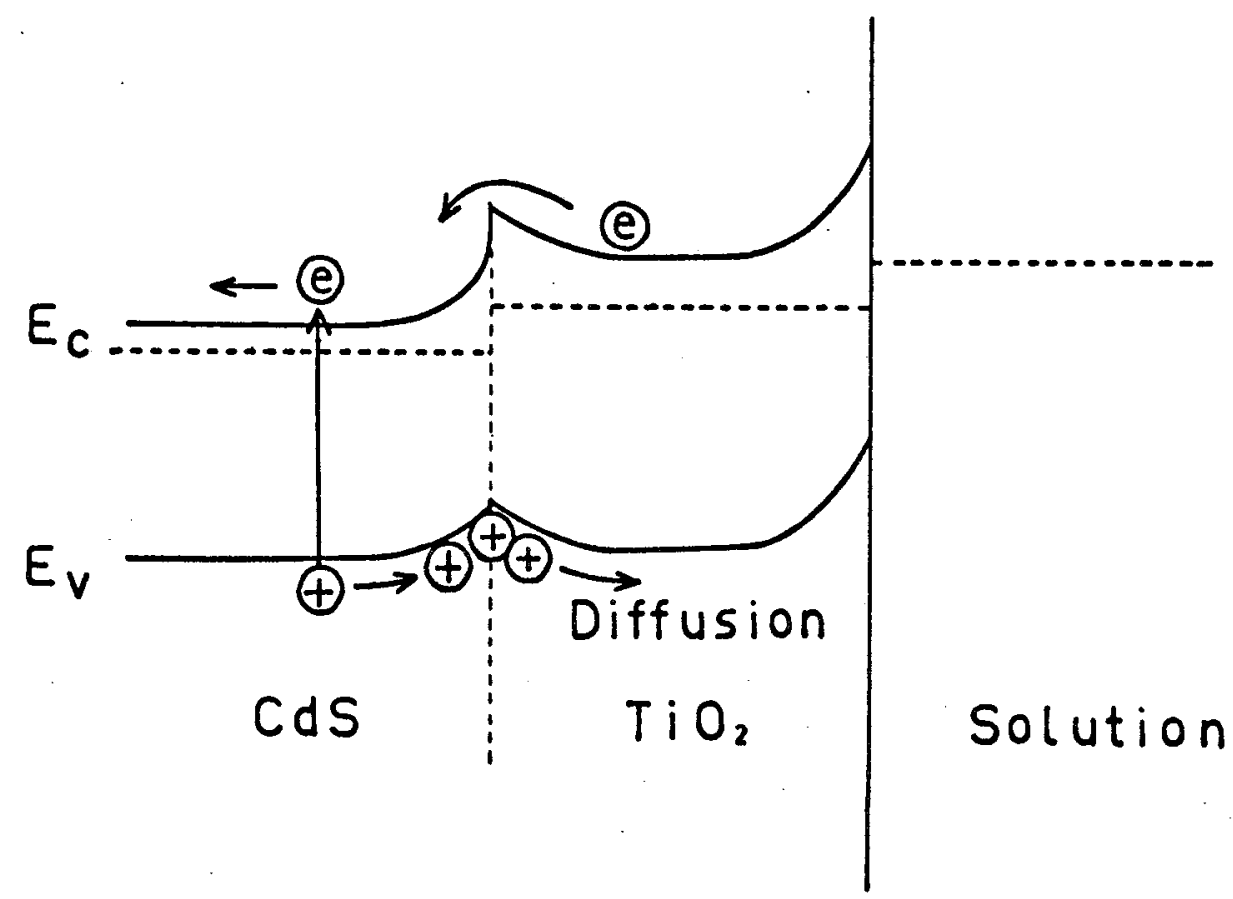

(b)

Fig. 6.22 The energy band profile of $\mathrm{CdS} / \mathrm{TiO}_{2} /$ solution system. (a) At thermal equilibrium.

(b) With an applied anodic bias. 
255.

Also, quite recently, Morisaki et al. coated $\mathrm{p}^{+} / \mathrm{n}$ Si solar cell with $\mathrm{TiO}_{2}$ film [52] and found the system worked we11. They claimed that there is no undesirable potential barrier at the interface between Si solar cell and $\mathrm{TiO}_{2}$ film. 


\subsection{FUTURE RESEARCH}

\subsubsection{Estimation of the Potential Drop in the Double Layer}

As strongly stressed in this work, the potential drop in the electric double layer has very important meaning in the photoelectrochemical kinetics at semiconductor electrodes, and has been usually neglected, in favour of the known potential drop in the semiconductor. In this work, the potential distribution in the semiconductor and the electric double layer was estimated from the value of the Mott-Schottky plot (see section 6.3 .9 ). This can be estimated more accurately by measuring the surface conductivity at steady state and under rapid potential change [28]. Also the comparison of the slope of MottShottky plot at steady state and under rapid potential change may be interesting. A1so, in this respect, the carrier density of the semiconductor should be measured by a solid state measurement, e.g. Ha11 measurement, capacitance measurement outside solution, etc.

\subsubsection{Surface Recombination}

In this work, the contribution of surface recombination was not considered quantitatively. For more accurate treatment, this must be taken into account.

Accordingly, the surface recombination velocity [28] should be measured for each crystal in several solutions at several potential ranges.

\subsubsection{Surface States}

Surface states influence greatly the potential drop at the flat band potential and, therefore, they should be estimated quantitatively. Green et a1. have estimated surface state concentration for $\mathrm{Ge}$ electrode [ 53]. 


\subsubsection{Carrier Density}

The photoelectrochemical efficiency may largely depend on the carrier density of the semiconductor which determines the width of space charge layer and, a1so, has strong effect on the potential drop in the electric double layer. Therefore the photoelectrochemical measurements should be carried out for the semiconductor with different carrier densities. Tamura et al. studied the effect of carrier density on quantum efficiency for $\mathrm{TiO}_{2}$ and $\mathrm{p}-\mathrm{GaP}$ briefly [54]

\subsubsection{Transient Measurement}

Transient measurements in this work could measure the phenomena, the time constant of which was larger than $10^{-3} \mathrm{sec}$. However, to see the transient behaviour in the semiconductor, measurements which can measure the phenomena, the time constant of which is less than $10^{-6} \mathrm{sec}$, should be carried out. Thus, it is necessary to determine directly the life time of carriers in the electrochemical situation and not to use the values measured in vacuo.

\subsubsection{Coating}

The structure of energy junction between the base material and coating material should be understood quantitatively. 'In this respect, a number of combination of base materials and coating materials must be made and not only photoelectrochemical measurement but also the $I-V$ relation (dark and under illumination) and Mott-Schottky plot must be measured outside solution. Also film perfection must be studied (EM, AE, etc.) 


\subsection{FUTURE PROSPECT OF THIS FIELD}

The most important prospective advantage of this process is that water (an abundant source) can be decomposed into oxygen and hydrogen (a clean fuel) directly by solar energy (abundant source), with byproduct electricity.

There are the following difficulties in the practical use of this process at the present time.

(1) Limited absorption in the solar spectrum by the semiconductor electrode.

(2) Instability of the electrode material in solution.

(3) Additional external energy requirement, if only one semiconductor is used.

Fig. 6.23 shows this situation schematically. As explained in section 3.4.1, when I-V curve of photoanode appears more negative potential than that of photo (or dark) cathode, the combination of the two electrodes works as a se1f-driven cell. In Fig. $6.23 \mathrm{I}-\mathrm{V}$ relation (under solar irradiation) of oxygen evolution (anodic) reaction at $\mathrm{TiO}_{2}$, the best photoanode at present in this field, and $\mathrm{SrTiO}_{3}$, an alternative stable photoanode, and that of hydrogen evolution (cathodic) reaction at GaP, photocathode proposed by Yoneyama et al. [18], and CdTe, an alternative photocathode found in this work, are shown. I-V relation of hydrogen evolution (cathodic) reaction at $\mathrm{Pt}$ in dark is also shown in Fig. 6.23. If one takes $\mathrm{TiO}_{2}$ as a photoanode, one should have a photocathode or Pt cathode with an auxiliary external potential because $\mathrm{I}-\mathrm{V}$ relation of $\mathrm{Pt}$ appears at more negative potentials than that of $\mathrm{TiO}_{2}$ (difficulty (3)). $\mathrm{TiO}_{2} /$ solution/CdTe and $\mathrm{TiO}_{2} /$ solution/ Gap give maximum current $\mathrm{I}_{3}$ and $\mathrm{I}_{5}$, respectively (see Fig. 6.23). 


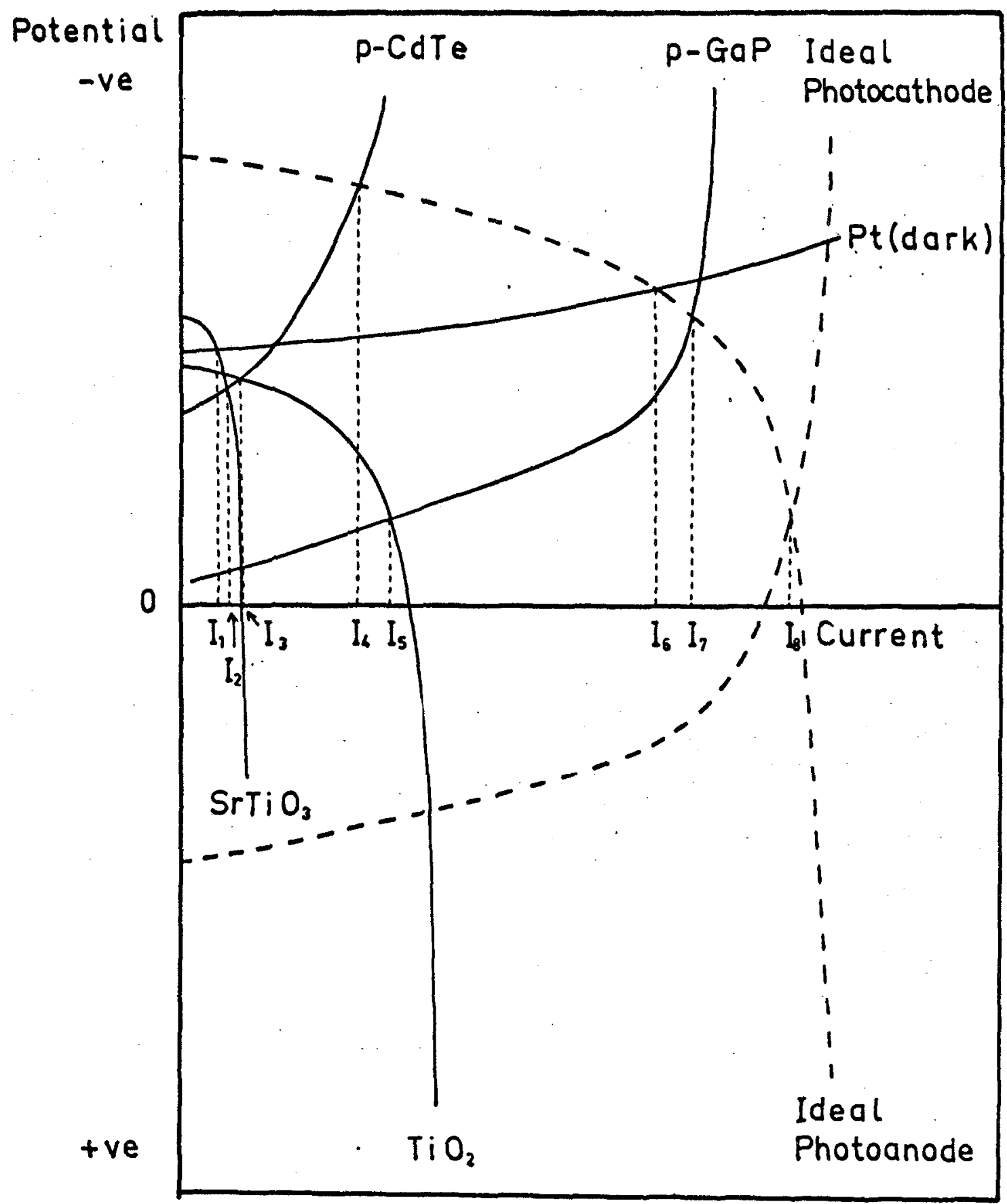

Pig. 6.23 The current-potential relations for hydrogen evolution reaction at $\mathrm{Pt}$ (dark), p-CdTe, p-GaP and an ideal photocathode and oxygen evolution reaction at $\mathrm{TiO}_{2}, \mathrm{SrTiO}_{3}$ and an ideal photoanode. 
260.

In this respect $\mathrm{GaP}$ is a good photocathode but it is not a stable electrode (difficulty (2)). In the cell, $\mathrm{TiO}_{2} /$ solution/CdTe, the critical point is not a high energy gap of $\mathrm{TiO}_{2}$, i.e., low absorption which is stressed by many research workers but a relative position of I-V relation of both electrodes. In the case of $\mathrm{SrTiO}_{3}$ photoanode, I-V the photocurrent appears at very negative potentials and $\mathrm{SrTiO}_{3}$ /solution/Pt works as a photo-driven cell without an external potential (see Fig. 6.23). However, in this case, high energy gap of $\mathrm{SrTiO}_{3}$, low solar energy absorption, limit the cell current, i.e., $\max . \mathrm{I}_{1}$ (difficulty (1)). I-V relations of ideal photoanode and cathode are shown in Fig. 6.23, i.e., the photocurrent at very negative potential for photoanode and that at very positive potential for photocathode with high absorption of solar energy. In the ideal photoanode/solution/Pt cell, maximum current is $I_{6}$ and in the ideal photoanode/solution/photocathode cell, it is $I_{8}$ (Fig. 6.23). However, the results reported so far suggest an improvement in efficiency is often coupled with a decrease in stability, and also an improvement in the position of $I-V$ relation is often coupled with a higher energy gap (lower absorption of solar energy).

Recently, several workers are trying to overcome these difficulties, especially (1) and (2), i.e., to find a low energy gap semiconductor with sufficient stability, by adding a redox couple so that a redox reaction takes place instead of decomposition of the material itself. Some stable photoelectrochemical cells have been reported in this way $[55,56]$.

However, the most important advantage of this process, the direct production of hydrogen, is no longer applicable to this redox type photoelectrochemical cell. As an electricity generator from solar 
261.

energy, one must compare the wet redox cell with a photovoltaic cell and, in this respect, the latter is more convenient because of the absence of an involvement of the solution. Therefore, there is no advantage in the wet redox cell, in the present author's opinion, and one should concentrate on the photoelectrochemical decomposition of water, as far as this process is concerned.

Now, are there any possible solutions to the problems stated above except the use of a wet redox cell?

One solution may be coating the electrodes, and this method should be examined more closely. If one can prevent decomposition of the material without much loss of quantum efficiency at a given wavelength by the coating, the choice of material becomes significant.

What about the requirement of an auxiliary external potential?

This difficulty may be solved by using a photocathode and photoanode together and by illuminating both electrodes as mentioned above. However, in this way, solar energy must illuminate both electrode effectively and that would involve the use of further optical construction. As far as illumination of the electrode is concerned, a photovoltaic electrode is easier than this electrode, because the former case no solution is involved and the electrode itself can face the sun directly. In the latter case, since the cathode and anode in solution should be illuminated, beam splitting and mirror are needed to illurinate the electrodes.

Considering the advantage of the direct production of hydroger., compared with electrolysis using electricity from photovoltaic cells, and involvement of solution in the photoelectrochemical cell, the present author opines that unless a big breakthrough, e.g., the finding of a 
262.

very cheap, stable and highly absorbing material, is achieved or a similar result can be achieved by cladding, this process is unlikely to become as economic as the combination of photovoltaic and improved, modern water electrolysis*.

* But note that the efficiency of the photoelectrochemical plant can be acceptably less than that of the combination of the photovoltaics with water electrolysis. This is because of the reduced capital cost (one plant, not two) offered by the photoelectrochemical method. 


\subsection{SUMMARY OF CHAPTER SIX}

(1) The theory given in chapter three was applied to analyse the quantum efficiency-potential relations.

The energy of electrons arriving at the surface and the barrier height were modified. The potential drop in the electric double layer at the flat band potential was estimated and its important role was shown.

The calculated results of the quantum efficiency-potential relation with this model was in fair agreement with experimental results.

(2) The critical potential at which the quantum efficiency becomes significant was defined and it was related to the values of the flat band potential and the energy gap.

(3) The shift of the quantum efficiency-potential relation with a change of solution was explained by the difference of the energy level of the acceptor in $\mathrm{NaOH}$ and in $\mathrm{H}_{2} \mathrm{SO}_{4}$.

(4) The potential effect on the quantum efficiency-wavelength relation was analysed in terms of the absorption coefficient, field in the semiconductor, and surface recombination.

(5) The transient behaviour was analysed by considering the reduction of adsorbed species.

(6) The mechanism of prevention of anodic dissolution of CdS by coating with $\mathrm{TiO}_{2}$ film was briefly interpreted.

(7) The effect of film thickness on the quantum efficiency-wavelength relation at $\mathrm{TiO}_{2}$ electrodes was theoretically interpreted. 


\section{BIBLIOGRAPHY OF CHAPTER SIX}

1. A. Fujishima, K. Honda and S. Kikuchi, Kogyo Kagaku Zasshi, 72, 108 (1969) .

2. A.J. Nozik, Nature, 257, 383 (1975).

3. T. Ohnishi, Y. Nakato and H. Tsubomura, Ber. Bunsenges. Phys. Chem., 79, 523 (1975).

4. A. Fujishima and K. Honda, Kogyo Kagaku Zasshi, 74, 355 (1971).

5. M.S. Wrighton, D.S. Ginley, P.T. Wolczanski, A.B. E11is, D.L. Morse and A. Linz, Proc. Nat. Acad. Sci. U.S.A., 72, 1518 (1975).

6. L.A. Harris and R.H. Wilson, J. EZectrochem. Soc., 123, 1010 (1976) .

7. K.L. Hardee and A.J. Bard, J. EZectrochem. Soc., 122, 739 (1975).

8. A. Fujishima, K. Kohayakawa and K. Honda, J. EZectrochem. Soc., 122,1487 (1975) .

9. Y. Nakato, T. Ohnishi and H. Tsubomura, Chem. Lett., 883 (1975).

10. V.I. Sapritskii and N.G. Bardina, Elektrokhimiya, 8, 655 (1972).

11. R. Williams, J. Chem. Phys., 32, 1505 (1960).

12. H. Gerischer and I. Mattes, Z. Phys. Chem. (N.F.), 49, 112 (1966).

13. W.P. Gomes and F. Cardon, 2. Phys. Chem. (N.F.), 86, 330 (1973).

14. D.J. Benard and P. Handler, Surface Sci., 40, 141 (1973).

15. S. Mayumi, C. Iwakura, H. Yoneyama and H. Tamura, Denki Kagaku, 44, No. 5, (1976).

16. R. Memming and G. Schwandt, Electrochim. Acta, 13, 1299 (1968).

17. R. Memming and H. Tributsch, J. Phys. Chem., 75, 562 (1971).

18. H. Yoneyama, H. Sakamoto and H. Tamura, Electrochim. Acta, 20, $341(1975)$.

19. R. Memming, J. EZectrochem. Soc., 116, 785 (1969). 
265.

20. M. Gleria and R. Memming, J. EZectroanal. Chem., 65, 163 (1975).

21. R. Memming, private communication (1976).

22. F.F. Red'ko and S.O. Idizinov, EZektrokhimiya, 2, 1128 (1966).

23. R.A. Logan and A.G. Chynoweth, J. Appl. Phys., 33, 1649 (1968).

24. M.A. Kettani, "Direct Energy Conversion", Chap. 8, AddisonWesley Pub. Co., Reading, Mass. (1970).

25. B.0. Seraphin and H.E. Bennett, "Semiconductors and Semimetals", Vol. 3, Chap. 12, Eds. R.K. Willardson and A.C. Beer, Academic Press, New York (1967).

26. J.I. Pankove, "Optical Processes in Semiconductors", Chap. 13, Prentice-Ha11, Inc., New Jersey (1971).

27. M. Green, "Modern Aspects of Electrochemistry", Vo1. 2, Chap. 5, Ed. J.0'M. Bockris, Butterworths, London (1959) .

28. V.A. Myamlin and Yu. V. Pleskov, "Electrochemistry of Semiconductors" (English Edition), Chap. I, Plenum Press, New York (1967) .

29. D.B. Matthews and J.O'M. Bockris, "Modern Aspects of Electrochemistry", Vo1. 6, Chap. 4, Eds. J.0'M. Bockris and B.E. Conway, P1enum Press, New York (1971).

30. S.U.M. Khan, Ph.D. Thesis, The Flinders University of South Australia (1976).

31. J.0'M. Bockris, M.A.V. Devanathan and K. Müller, Proc. Roy. Soc., A274, 55 (1963).

32. D. Penn, R. Gomer and M.H. Cohen, Phys. Rev., B5, 768 (1972).

33. A. Rothwarf and K.W. Böer, Prog. in Solid-State Chem., 10, 71 (1975) •

34. J.0'M. Bockris and A.K.N. Reddy, "Modern Electrochemistry", Vol. 2, Chap. 7, Plenum Press, New York (1970). 
266.

35. S. Trasatti, J. EZectroanal. Chem., 52, 313 (1974).

36. J.0'M. Bockris and S.D. Argade, J. Chem. Phys., 49, 5133 (1968).

37. T.0. Rouse and J.L. Weininger, J. EZectrochem. Soc., 113, 184 (1966)

38. T.P. Birintseva and Yu. V. Pleskov, Izv. Akad. Nauk SSSR, Ser. Khim., 251 (1965) .

39. R. De Gryse, W.P. Gomes, F. Cardon and J. Vennik, J. Electrochem. Soc., 122, 711 (1975).

40. H. Gerischer, "Physical Chemistry: An Advanced Treatise", Vo1. IX A, Chap. 5, Ed. H. Eyring, Academic Press, New York (1970).

41. T. Watanabe, A. Fujishima and K. Honda, Chem. Lett., 897 (1974).

42. T. Watanabe, A. Fujishima and K. Honda, BuZZ. Chem. Soc. Japan, 49, $355(1976)$.

43. J.O'M. Bockris and R.G.H. Watson, J. de Chimie Phys., 49,1 (1952)

44. J.0'M. Bockris and E.C. Potter, J. Chem. Phys., 20, 614 (1952).

45. E.A. Moelwyn-Hughes, "Physica1 Chemistry", 2nd edition, Chap. XVIII, Pergamon Press, London (1961).

46. R.A. Robins on and R.H. Sokes, "Electrolyte Solutions", 2nd edition, Chap. 1, Butterworths, London (1968).

47. K. Shinoda, "Yo-eki to Yokaido", Chap. 14, Maruzen, Tokyo (1966).

48. J.O'M. Bockris and A.K.N. Reddy, "Modern Electrochemistry", Vo1. 1, Chap. 4, Plenum Press, New York (1970).

49. S.M. Ryvkin, "Photoelectric Effects in Semiconductors", (English Edition), Chap. I, Consultants Bureau, New York (1964).

50. K.G. McKay, Phys. Rev., 84, 833 (1951). 
267.

51. W. Shockley, M. Sparks and G.K. Tea1, Phys. Rev., 83, 151 (1951).

52. H. Morisaki, T. Watanabe, M. Iwase and K. Yazawa, Appl. Phys. Lett., 28 , No. 18 (1976).

53. M. Green, V. Jendrasic and J. McBreen, J. Phys. Chem. Solid., 24, 701 (1963).

54. H. Tamura, H. Yoneyama, C. Iwakura and H. Sakamoto, Japan Chem. Soc., 34th Spring Meeting (1976).

55. A.B. Ellis, S.W. Kaiser and M.S. Wrighton, J. Amer. Chem. Soc., $98,1635(1976)$.

56. B. Miller and A. Heller, Nature, 262, 680 (1976). 